ESTUDIO COMPARATIVO DE LOS PROCESOS DE PLANEACIÓN EN MUNICIPIOS DE TERCERA A SEXTA CATEGORÍA EN CUNDINAMARCA:

\title{
ESTUDIO DE CASO
}

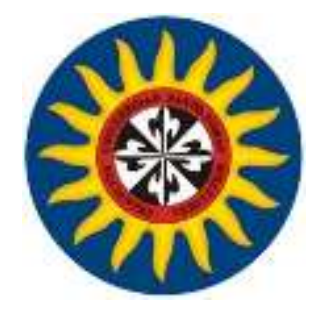

Elaborado por:

MARÍA CONSTANZA GUTIÉRREZ ALDANA ANA MARÍA RESTREPO MARTÍNEZ

DIRECTOR TRABAJO DE GRADO JOSÉ SALOMÓN MENESES

UNIVERSIDAD SANTO TOMÁS

Facultad de Sociología

Maestría en Planeación para el Desarrollo

Bogotá, Colombia, abril 20 de 2015 


\title{
AGRADECIMIENTOS Y DEDICATORIA
}

\begin{abstract}
A la Madre Berta Revollo (q.e.p.d.), Pepita, Elvia y Clemencia, quienes me acogieron y dieron la oportunidad de formarme como persona y profesional, en la que fuera mi universidad y espacio laboral por 25 años, la Fundación Universitaria Monserrate.
\end{abstract}

Ana María

A Dios, por permitir acercarme al conocimiento, para el aporte en la formación de mis estudiantes de la Fundación Universitaria Monserrate; a mi familia, especialmente a mi hijo Diego Fernando, el motor, quien todos los días me motivó a seguir estudiando; y a mi esposo Miguel Ángel por su paciencia y comprensión durante estos dos años de estudio en la maestría.

María Constanza

En los pequeños municipios de Colombia, y en su gente, está el potencial de desarrollo humano y territorial de este país.

Gracias por sus aportes y colaboración para la realización de esta investigación.

Ana María y María Constanza 


\section{RESUMEN}

La investigación denominada, "Estudio comparativo de los procesos de planeación en municipios de tercera a sexta categoría en Cundinamarca", cuyo propósito fue identificar aspectos significativos que tuvieron en cuenta para orientar el desarrollo local, adelantar el proceso de elaboración del Plan de Desarrollo Municipal y el seguimiento a su implementación. Para este fin, desde la perspectiva metodológica, se utilizó un Enfoque Mixto, con el cual se "recolecta, analiza y vinculan datos cuantitativos y cualitativos en un mismo estudio o una serie de investigaciones para responder a un planteamiento", según Creswell, citado por (Gutiérrez, 2010).

En esta investigación se asumió el análisis comparativo, con apoyo en el estudio de caso, por considerarlo el más pertinente para identificar las particularidades de los procesos de elaboración de los planes de desarrollo municipal, teniendo en cuenta que los municpios seleccionados, del Departamanto de Cundinamarca, se encuentren clasificados en las categorias 3 a 6, lo que marca diferencias en cuanto a autonomía, manejo de recursos y calidad y cantidad de funcionarios que apoyan estos procesos. La recolección de la información se realizó por medio de entrevistas a profundidad con los jefes de planeación o funcionarios participantes en la elaboración e implementación del plan de desarrollo municipal.

Con el análisis de los resultados de la investigación, se determinaron factores que favorecen los procesos de planeación municipal, así como aquellos que dificultan su desarrollo, como es el caso de la falta de coherencia entre planear y actuar, en unos municipios; la falta de pertinencia de algunos aspectos contemplados en los planes de desarrollo; en ocasiones, la descontextualización de las acciones y la implementación de politicas publicas nacionales no precisamente acordes con las necesidades de los contextos. 
También se identificaron aspectos que muestran los avances frente a la identidad y la exigencia del cumplimiento, a través de programas y proyectos de los derechos politicos, económicos, sociales, culturales y ambientales de la población y el territorio, lo que ha marcado el derrotero y transformado la vocación e intereses particulares de los municipios y sus gentes, en asuntos de prioridad nacional.

El analisis de los procesos de planeación en los seis mucipios seleccionados, permitió identificar que sí existen diferencias en los procesos, especialmente en la consulta que se le hace a la comunidad; los métodos varian según los recursos economomicos disponibles y la experticia de los funcionarios de la alcaldía, así como de la posibilidad de contar con asesores externos y de acceder a capacitación técnica y a tecnologías de punta para la consulta, sistematización de datos y el posterior seguimiento a la implementación del plan de desarrollo Municipal.

Palabras clave: Planeación, desarrollo, territorio, participación.

\section{ABSTRACT}

The research work entitled "Comparative study of the planning processes in third to sixth category municipalities in Cundinamarca" aimed at identifying significant aspects that the towns of Facatativá, Sopó, Gachancipá, Sibaté, La Calera and Subachoque took into account to steer their local development, perform the creation of their Municipal Development Plan, and follow up their implementation. With this purpose in mind and from the research perspective, a mixed view was utilized, from which, according to Creswell (quoted by Gutierrez, 2010), quantitative and qualitative data is collected, analyzed and linked in one study or a series of studies to respond to one statement.

In this research the case study method was chosen, as it was considered the most pertinent to identify the municipal development plans writing processes 
singularities, taking into account that the chosen towns from the Cundinamanarca Department, were to be classified between the categories 3 to 6 , which have them differentiate themselves in their autonomy, resources management and the number of public service officials that support this process. The collection of information was made through extensive interviews with the planning directors or other public servants that were involved in the creation and implementation of the municipal development plan.

By analyzing the results of the research, it was determined which factors have a positive and negative impact the municipal planning processes, such as the lack of coherence between the planning and the actions of some towns, the irrelevance of some aspects included in the development plans and the fact that some actions were taken out of context, at times, due to the pressure of the centralized orientation of the country's planning, or the implementation of national public policies not aligned with the contexts needs.

Some aspects identified show the advances in terms of the identity and demand of compliance through projects and programs related to the population and territorial political, economical, social, cultural and environmental rights, which defined the direction and transformed the vocation and particular interest of some towns and their people, in affairs of national priority.

The analysis of the planning processes of the six selected towns, allowed to identify if there are differences in their processes, especially in the way they gather information from the community; the methods vary depending on the financial resources available and the level of expertise of the town government officials, as well as the possibility to hire external consultants and have access to technical training and leading technologies to gather the information, data management and its later follow up to the implementacion of the municipal development plan.

Key words: Planning, development, territory, participation. 


\section{TABLA DE CONTENIDO}

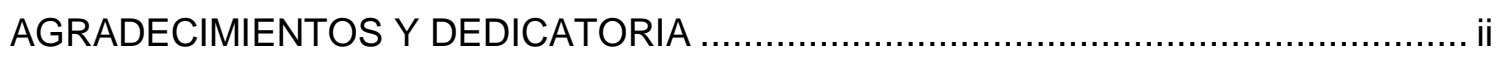

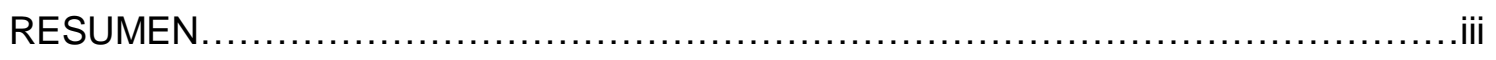

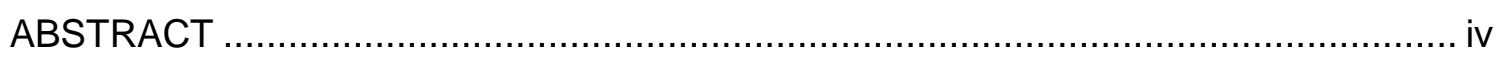

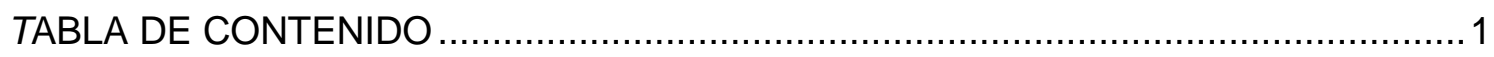

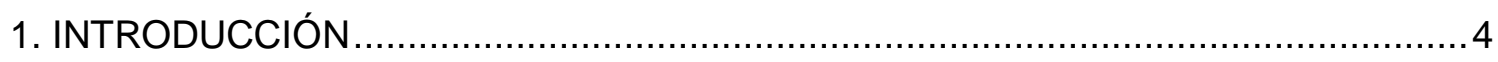

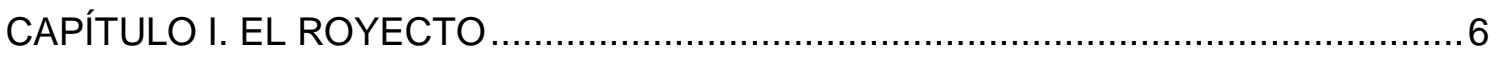

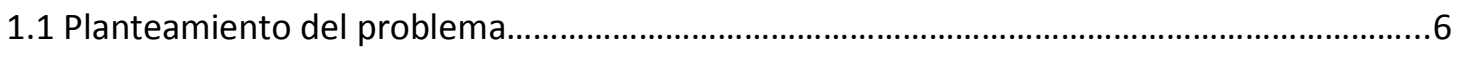

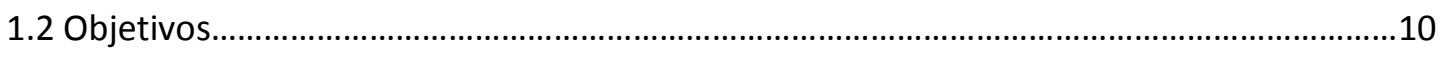

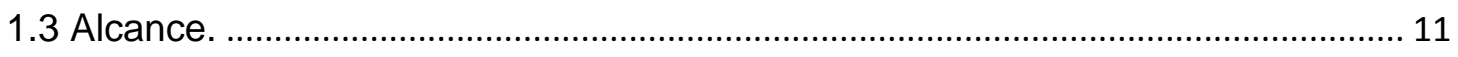

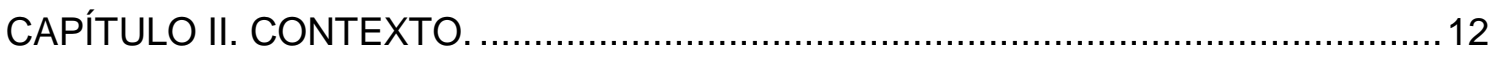

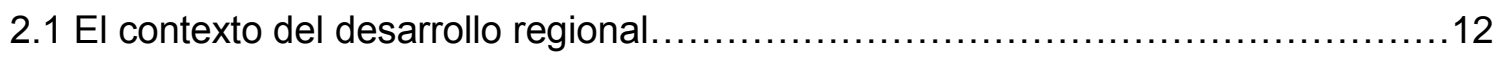

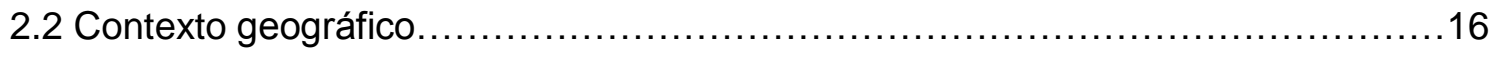

CAPÍTULO III. ESTADO DEL ARTE Y MARCO CONCEPTUAL .............................27

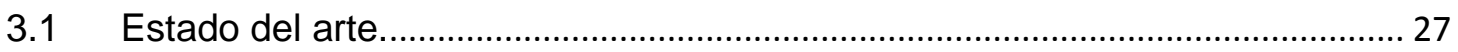

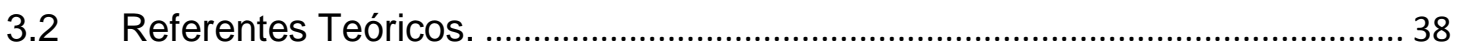

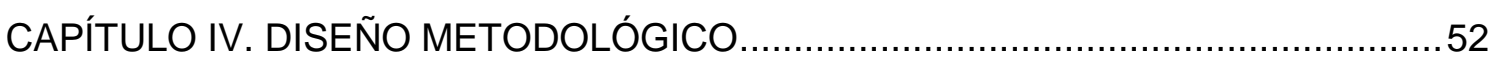

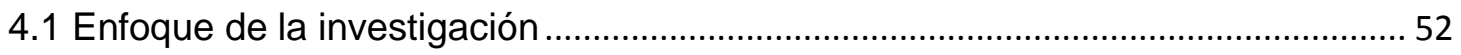

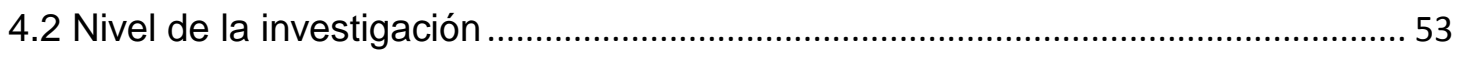

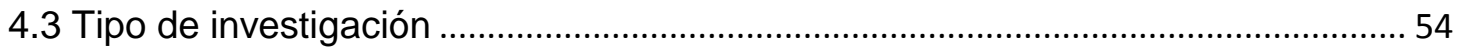

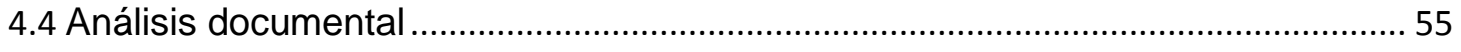

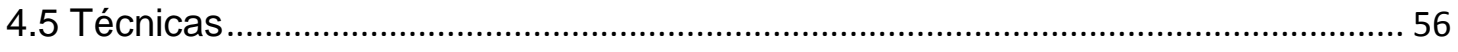

4.6 Muestra desde la perspectiva teórica del estudio de caso. ..................................... 56

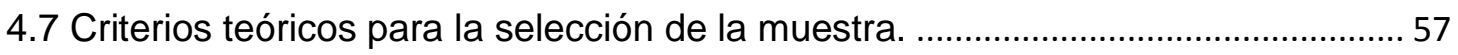




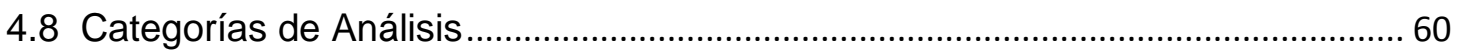

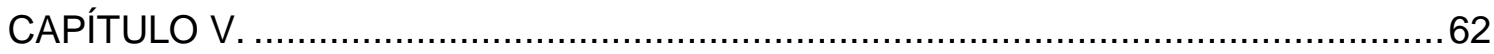

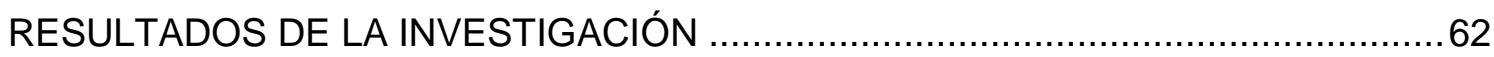

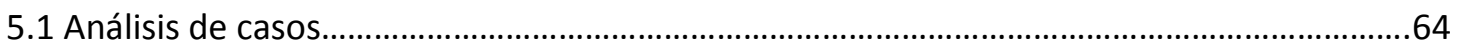

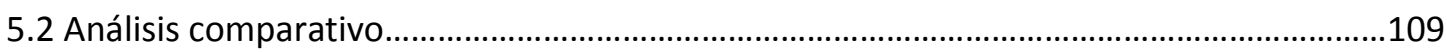

5.3 Fortalezas y debilidades, similitudes y diferencias......................................................112

5.4 Gestión para el direccionamiento de la planeación.........................................................120

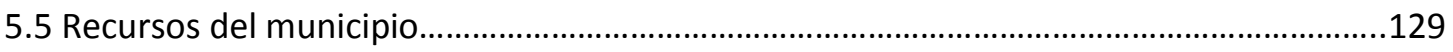

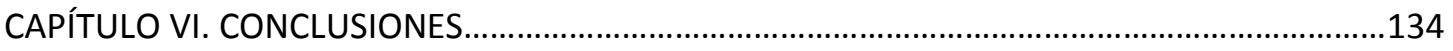

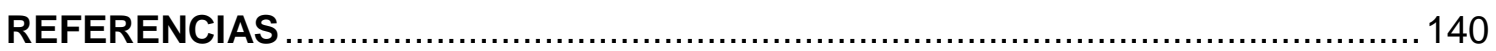

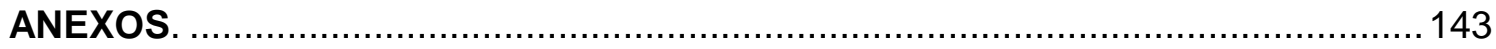

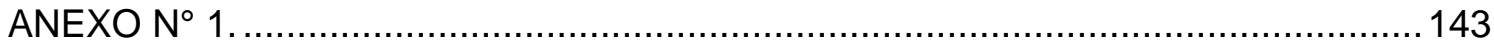

MATRIZ DE EVALUACIÓN PLANES DE DESARROLLO.....................................143

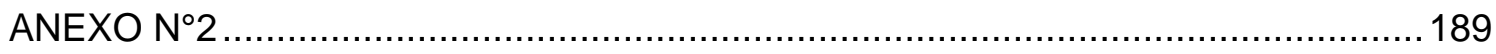

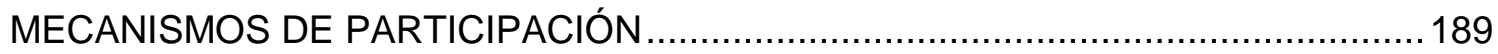

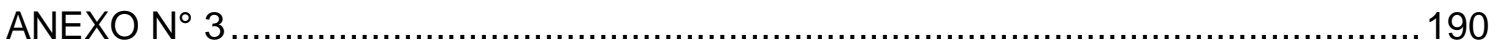

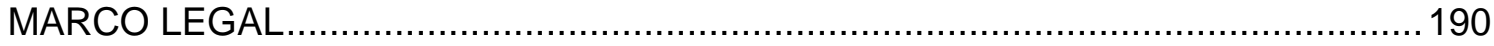

ANEXO No4

Municipios seleccionados según categorización 2013- 2014 …................................ 196

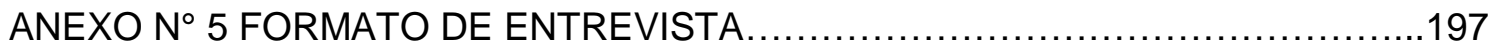

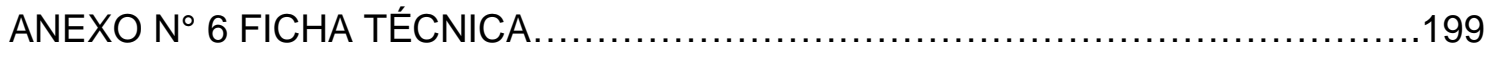


LISTADO DE GRÁFICOS

GRÁFICO N 1.PARTICIPACIÓN Y CRECIMIENTO DEL PIB, POR DEPARTAMENTO 2010 13

GRÁFICO N². PARTICIPACIÓN. 60

LISTADO DE CUADROS

CUADRO 1. CATEGORIZACIÓN DE LOS MUNICIPIOS................................58

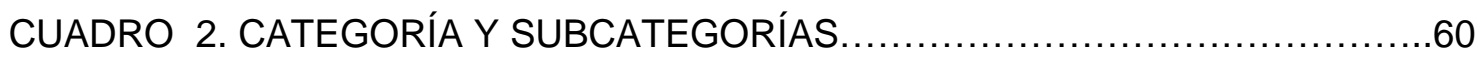

CUADRO 3. CARACTERÍSTICAS Y RECURSOS (1)................................70

CUADRO 4. CARACTERÍSTICAS Y RECURSOS (2) ..................................77

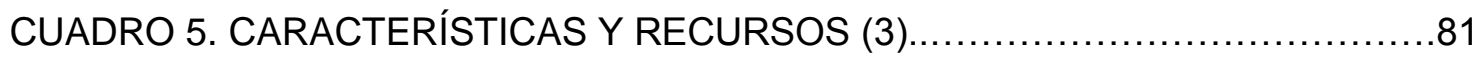

CUADRO 6. CARACTERÍSTICAS Y RECURSOS (4).................................92

CUADRO 7. CARACTERÍSTICAS Y RECURSOS (5).................................98

CUADRO 8. CARACTERÍSTICAS Y RECURSOS (6)...............................108

CUADRO 9. PARTICIPACIÓN........................................................................................115

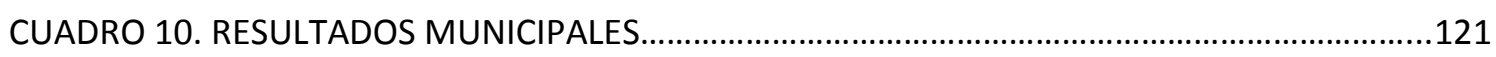

CUADRO 11. COMPARATIVO DE LAS ESTRUCTURAS Y PARTICULARIDADES DE LOS PMD...........122 


\section{INTRODUCCIÓN}

En Colombia, la planeación municipal es un tema relevante, que convoca a la reflexión y al estudio, debido a su desigual desarrollo local y regional. Colombia es un país multicultural, con multiplicidad de factores geográficos, sociales y económicos, muchos de ellos afines; sin embargo, la división geopolítica y administrativa del país en departamentos ha hecho que se generen rupturas en la identidad como nación, discriminación y un desarrollo desigual en los municipios.

Su extenso territorio, de $2.129 .748 \mathrm{~km}^{2}$, de los cuales $1.141 .748 \mathrm{~km}^{2}$ son territorio continental y los restantes $988.000 \mathrm{~km}^{2}$ extensión marítima, la abrupta topografía, la densidad poblacional, el clima, la disponibilidad y calidad de tierras cultivables y recursos naturales explotables, hacen que el país sea muy variado y diverso. Por su parte, las prácticas políticas con pocos principios éticos y morales, las dificultades de acceso a algunas zonas y la violencia, han marcado el modo de ser y actuar de las poblaciones y caracterizado el nivel de desarrollo humano y socio-económico de los 1.123 municipios del país (Dane, 2014), cantidad que incluye 5 distritos especiales, que se cuentan también como municipios.

En este sentido, dadas esas condiciones y las notorias diferencias entre los distintos lugares de Colombia, se hace prioritario iniciar procesos que conlleven a la superación de la inequidad existente, en cuanto al desarrollo humano integral y territorial, que es visible en los municipios clasificados, especialmente en las categorías 5 y 6 ; este es un reto que el Estado, la universidad y la sociedad deben enfrentar, y que atañe, entre otros, a quienes se forman como Magísteres en Planeación para el Desarrollo, en la Universidad Santo Tomás, como es el caso de las investigadoras. 
Además, es pertinente tener en cuenta el papel que juega el Departamento Nacional de Planeación (DNP) en el diseño de instrumentos y estrategias para la elaboración de los planes de Desarrollo de los entes territoriales y el acompañamiento, la capacitación y asesoría que les ofrece el Departamento de Cundinamarca, por medio de la Oficina de Planeación. Estas variables inciden en la calidad, pertinencia y efectividad del proceso adelantado en el municipio, el cual se constata con las evaluaciones que realiza periódicamente el DNP, la rendición de cuentas que hace el alcalde a la comunidad y la eficiencia en la implementación de lo propuesto en los planes de desarrollo de la municipios (PDM).

En concordancia con lo anterior, la línea de investigación Descentralización y Ordenamiento Territorial, de la Maestría en Planeación para el desarrollo, ha brindado los elementos conceptuales y ha despertado el interés de las investigadoras por conocer Cómo realizan los municipios de Cundinamarca de tercera a sexta categoría, los procesos de planeación para el desarrollo cuatrienal y con qué recursos cuentan para este fin.

Para ello, se parte de identificar que Cundinamarca tiene 116 municipios (Gobernación de Cundinamarca, 2014), en su mayoría en categorías 5 y 6 . Esta situación hizo que, en la búsqueda de soluciones al problema planteado, las investigadoras optaran por realizar una investigación descriptiva, sustentada en el método de análisis comparativo, a partir del estudio de caso, con el fin de identificar los procesos adelantados en seis de ellos, para el periodo 2012-2015; las similitudes y diferencias que hay entre municipios y si la categoría a la que cada uno de ellos pertenece, influye en su proceso de planeación y gestión del plan de desarrollo. 


\section{CAPÍTULO I. EL PROYECTO}

\subsection{Planteamiento del problema}

En Colombia hay la necesidad de lograr, en un mediano plazo, el desarrollo integral y armónico de todas las personas y todo el territorio nacional, como fundamento para la consecución y consolidación de la paz; el aumento de la competitividad, para responder a las exigencias que conllevan los tratados de libre comercio; el fortalecimiento del sector productivo y de la economía en general, con el fin de aumentar los niveles de ingreso personal y general; yla búsqueda del mejoramiento de la calidad de vida en las grandes ciudades y en los municipios, que permitan el disfrute de una vida digna; estos aspectos exigen al gobierno nacional y a los gobiernos regionales, municipales y distritales enfrentar el reto de asumir procesos de planeación contextualizados, que respondan a las diversas necesidades, a la especificidad de las regiones y culturas, manteniendo el sentido de unidad territorial en la diversidad geopolítica que caracteriza a cada región.

Dado que en Colombia existe una gran diversidad geopolítica, social, étnica y económica, entre otras, junto con ello hay desigualdad en el desarrollo humano, socioeconómico y político, que se aumenta por la corrupción, la violencia, la discriminación étnica y de género, además de la inequidad en la distribución de la riqueza y los recursos en el país, situaciones que hacen de Colombia el tercer país más inequitativo del mundo (Foro Urbano Nacional, 2013). Así mismo, la pobreza, la ignorancia, el desplazamiento, el uso indiscriminado e inapropiado del territorio para cultivos ilícitos, la explotación minera ilegal, la construcción de vivienda sin tener en cuenta el hábitat y las necesidades de las familias, y la expansión de áreas urbanas, el desarrollo empresarial y el conflicto armado, entre otros, tienen marginados social y 
económicamente a la mayor parte de la población y de los municipios del país, especialmente a los clasificados en las categorías $5^{\circ}$ y $6^{\circ}$, según la clasificación contenida en la ley 136 de 1994.

Según la Cepal (2014), el 61,9\% de las personas de estos municipios vive en condiciones de pobreza, lo cual exige que el Estado, los gobiernos regionales y locales, el sector privado y las universidades, entre otras entidades, ofrezcan alternativas y soluciones políticas, estructurales, académicas, técnicas, económicas y de infraestructura, que contribuyan con el progreso de los pueblos, con la distribución justa y equitativa de recursos, para el mejoramiento significativo de la calidad de vida de las personas, las familias y las comunidades, en un marco de restitución de derechos y ejercicio pleno de la ciudadanía. (Cepal, 2014).

En el caso que ocupa a esta investigación, los municipios de Cundinamarca, en su mayoría, se encuentran categoría 6, lo cual indica que son pequeños en cuanto a número de pobladores y cuentan con mínimos recursos económicos para su autofinanciación; por lo tanto, dependen, en gran medida, de lo que el Departamento y la Nación les asigne como presupuesto, además de buscar créditos que les permita ejecutar proyectos formulados dentro del plan de desarrollo. La cualificación en procesos de planeación, las competencias personales, técnicas y profesionales de sus dirigentes, la participación activa de la comunidad en la decisión de su proyecto de vida y, por ende, en el proyecto de desarrollo de su territorio, cobran especial relevancia en estos municipios.

Otros fenómenos que afectan a estos municipios de Cundinamarca tiene que ver con la migración de las personas más calificadas profesionalmente a los centros urbanos más desarrollados, especialmente a Bogotá, la politiquería partidista, la falta de formación política de los ciudadanos, la incredulidad de la comunidad frente a las promesas fallidas del Estado, las dificultades de 
comunicación y para desplazarse entre la zona urbana y rural, así como la carencia de soportes tecnológicos, redes públicas de internet y el desconocimiento de los derechos promulgados y protegidos por la Constitución Política de 1991 y la creación de valiosos mecanismos para la participación que por su desconocimiento y, en ocasiones, desinterés por su municipio y región. Todos estos elementos que pueden favorecer el desarrollo de las comunidades, han sido desaprovechados para incidir sobre el direccionamiento de los planes de desarrollo municipal y la inversión de los recursos que el municipio dispone para propiciar mejor calidad de vida para sus habitantes.

Teniendo en cuanta lo expuesto anteriormente, se considera pertinente plantear la siguiente pregunta de investigación ¿Cómo realizan los municipios de Cundinamarca, de tercera (3) a sexta (6) categoría, los procesos de planeación para el desarrollo cuatrienal?

Al analizar el procedimiento y la aplicación de la normatividad contenida en la Ley 152 de 1994 y las actividades realizadas en cada municipio para la construcción del Plan de Desarrollo, se espera poder identificar algunos de los aspectos más relevantes de los procesos particulares de los seis municipios seleccionados. Se detectan las fortalezas y debilidades que se evidencian en cada uno y se establecen la posibles correlaciones existentes entre la categoría a la que cada uno pertenece y aquellos aspectos que son susceptibles ser mejorados a través del acompañamiento técnico del Departamento Nacional de Planeación (DNP), la Secretaria de Planeación Departamental y/o asesorías prestadas por entidades públicas, privadas y universitarias, comprometidas con el fortalecimiento del desarrollo local y regional, la consolidación de la planeación como proceso técnico y normativo, que direcciona la modernización, gestión, funcionamiento y la vinculación, y participación activa de la comunidad en el desarrollo integral de los municipios 
Para ello, es indispensable partir del reconocimiento de la situación colombiana, donde el asunto del desarrollo territorial y lo relacionado con los procesos de la planeación nacional y de los entes territoriales está debidamente explicitado en la Constitución Política de 1991, en la cual se reconoce como instrumento técnico los planes de desarrollo y su perspectiva estratégica y se designa como el ente responsable, para su direccionamiento y gestión, al Departamento Nacional de Planeación (DNP), departamento administrativo de carácter técnico que depende directamente de la Presidencia de la República, cuya finalidad es impulsar "la implantación de una visión estratégica del país en los campos social, económico y ambiental, a través del diseño, la orientación y evaluación de las políticas públicas colombianas, el manejo y asignación de la inversión pública y la concreción de las mismas en planes, programas y proyectos" (DNP, 2014).

Con la promulgación de la Constitución Política de 1991, sin importar el tamaño del municipio, se ordena que todos ellos deben formular planes de desarrollo, en cuyas orientaciones se definan las estrategias que propicien la implementación de acciones concordantes con las políticas económicas, de infraestructura física, capital humano, desarrollo territorial y de políticas sociales contenidas en el documento Visión Colombia II Centenario: 2019, elaborado por el DNP en el 2005, mandato que se regula por medio de la ley 152 de 1994.

En la Ley 152 de 1994, en el Capítulo II, Artículos 5, $6^{\circ}$ y $7^{\circ}$ y Capítulo VIII, artículos 31 y 39, se establecen los procedimientos y mecanismos requeridos para la elaboración, aprobación, ejecución, seguimiento, evaluación y control de los planes de desarrollo, los cuales deben estar concatenados con las prioridades de los grupos sociales que conforman la Entidad Territorial y el programa de gobierno, los mecanismos para su armonización e interrelación con los procesos presupuestales y las funciones de cada dependencia e instancia que participa en el proceso, enfatizando en la participación de la sociedad civil. (Municipio de Gachancipá, 2012, p.5). 
Además del referente legal, también se tiene en cuenta la bibliografía revisada, el conocimiento cercano de algunos municipios de Cundinamarca y de sus posibilidades de modernización de la gestión y la asunción desde la perspectiva profesional que por medio de la planeación es posible visualizar y estructurar las formas, estrategias, acciones y recursos para conseguir que en Colombia, las regiones y los municipios se conviertan en territorios con mejores condiciones de vida, salud, educación y empleo, como se plantea en el documento Visión Colombia Il Centenario: 2019 (2005).

También se pretende aportar elementos que permitan iniciar procesos conducentes a que Colombia sea un país con mejor infraestructura, con ciudades más amables, un país respetuoso con el medio ambiente y con las libertades básicas fundamentales de sus ciudadanos. Un país que logra resultados gracias a la consecución de metas comunes y a una visión compartida, donde el fin último es el bienestar general, un país en paz, incluyente, respetuoso de los derechos humanos y de la autodeterminación de los pueblos, animó la realización de esta investigación y permitió profundizar en el tema de la planeación municipal y su incidencia en el desarrollo de los casos estudiados.

\subsection{Objetivos}

\subsubsection{Objetivo General}

Analizar los procesos de planeación que desarrollan los Municipios de Sopó, Facatativá, Sibaté, La Calera, Gachancipá y Subachoque, del Departamento Cundinamarca, Colombia, con el fin de identificar aspectos significativos que se tuvieron en cuenta para orientar el desarrollo local.

\subsubsection{Objetivos específicos}

a) Identificar las fortalezas y debilidades del proceso de elaboración del Plan de Desarrollo Municipal (P.D.M), de seis municipios de Cundinamarca. 
b) Evidenciar los logros y dificultades presentadas durante el proceso de elaboración del Plan de Desarrollo Municipal, teniendo en cuenta el talento humano que intervino y la metodología desarrollada.

c) Determinar los recursos económicos, materiales y tecnológicos con que cuentan los municipios para adelantar los procesos requeridos para el diseño e implementación del Plan de Desarrollo Municipal.

\subsection{Alcance}

Desde la perspectiva del estudio de caso, esta investigación pretende lograr una aproximación perceptual, a través de entrevistas a profundidad con las personas encargadas de las oficinas de planeación, en seis (6) municipios de Cundinamarca $y / 0$ con otros funcionarios que hubieren participado activamente en la elaboración del Plan de desarrollo Municipal para el periodo de gobierno 2012-2015, con la finalidad de conocer de viva voz la experiencia tenida en el municipio, la metodología utilizada y los recursos con que contaron para el diseño del plan y su posterior implementación. 


\section{CAPÍTULO II. CONTEXTO}

Con el fin de ubicar el entorno geográfico, político y social donde se circunscribe el desarrollo municipal en Colombia y, en general, en América Latina, se elabora este capítulo, buscando recrear las condiciones e influencias externas e internas que, desde una mirada sistémica, es importante contemplar en los estudios de caso que se adelantan en esta investigación.

\subsection{El contexto del desarrollo regional}

Los entes territoriales en Colombia, así como en los demás países de Latinoamérica, han estado influenciados por una apertura comercial externa, estimulada por la globalización que se inició en los años noventa y expuso a las regiones y sus territorios a los flujos del comercio internacional, sus correspondientes presiones competitivas y consabidos shocks externos. (Hawkins, 2008, p. 7).

El modelo de desarrollo económico neoliberal se insertó en América Latina; la mayoría de sus países, de economías agrícolas desprotegidas, con baja tecnología y altos índices de desempleo y mínima capacitación laboral, se vieron empobrecidos, inundados de productos industriales extranjeros y se inició un fuerte movimientos de transculturación y globalización de la información que trasformó las vocaciones territoriales y el modo de ser y actuar de los pueblos.

En Colombia, el fortalecimiento de los cultivos ilícitos y el narcotráfico, influenciaron el desarrollo territorial; se arreció la violencia social y se 
transformaron los valores del consumo y las necesidades de las personas y los municipios y el proceso de descentralización, ordenado por la Constitución Política de 1991, empezó a implementarse, acarreando nuevas dinámicas y desequilibrios regionales.

"A su vez, los procesos de descentralización territorial surgidos en el país, a partir de los años ochenta, en sus componentes administrativo y fiscal, han consolidado un proceso de apertura interna, donde los territorios se han convertido en actores y gestores de su propio desarrollo, al serles trasladadas ciertas competencias y recursos para su cabal cumplimiento, como agentes conscientes y sensibles de sus necesidades y problemáticas, capaces de identificar, cuantificar, valorar y jerarquizar las inversiones que requieren para proveer los bienes y servicios públicos que demandan sus correspondientes sociedades territoriales".(Hawkins, et al., 2008, p. 7).

Desde la década del 90, del siglo XX, y con el apoyo en estudios de Naciones Unidas, del Departamento Nacional de Planeación (DNP) y de Centros de investigación como la CEPAL y ANIF, se ha podido apreciar que la desigualdad en el desarrollo humano, socioeconómico y político, la corrupción, la violencia, la discriminación étnica, de género, además de la inequidad con que se distribuye la riqueza y los recursos en el país, han hecho de Colombia el tercer país más inequitativo del mundo. (Valencia, 2011).

La pobreza, la ignorancia, el desplazamiento, el uso abusivo del territorio y la guerra, ha llevado a la marginación del desarrollo social y económico a la mayor parte de la población y municipios, especialmente a los clasificados en la $5^{\circ}$ y 6ํㅡㄹ categoría (ver anexo $N^{\circ} 3$, ley 136 de 1994); también se evidencia que el $60 \%$ de las personas de estos municipios, viven en condiciones de pobreza.

En 2002, los cuatro territorios con mayor tamaño económico, representados por el "Triángulo de Oro" (Bogotá, Antioquia y Valle) y Santander, generaron cerca del $54.7 \%$ del PIB nacional, así como los mayores ingresos per cápita, los cuales fueron superiores a los dos millones de pesos en 1994. A su vez, los catorce departamentos más pequeños generaron apenas el $21.6 \%$ del PIB nacional (Dane, 2012). 


\section{Gráfico $N^{\circ} 1$}

\section{Participación y crecimiento del PIB, por departamento 2010}

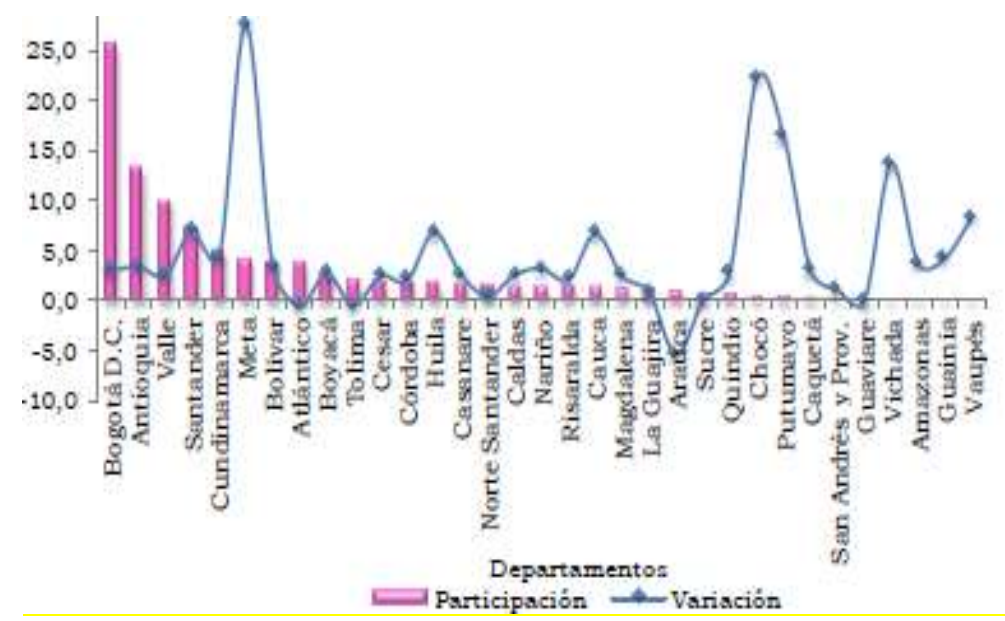

Fuente: ICER. Informe de Coyuntura Económica Regional. 2011. - Banco de la República, Noviembre 2012.

En la gráfica se puede observar que en un período de 8 años, los departamentos con mayor tamaño siguen siendo los mismos, incluido en el último período Cundinamarca, lo que demuestra que los municipios no cuentan con recursos para generar desarrollo económico y social, lo que mantiene condiciones de desigualdad evidente, debido a que se concentra el desarrollo económico solo en unos pocos municipios; por lo tanto, como plantea Hawkins et al. (2008) "es necesario que las regiones se consoliden para poder responder a los procesos de transformación productivas que puedan aportar los ingresos y mejorar las finanzas públicas territoriales para enfrentar las nuevas dinámicas de los mercados internacionales, como la globalización y poder competir con calidad y que esto repercuta en mejores condiciones de vida para las poblaciones" (Hawkins et al., 2008, p.14). 
En los municipios, la superación de las desigualdades y el impulso al desarrollo integral están directamente ligados al Plan de desarrollo cuatrienal que propongan los alcaldes y a la articulación con los planes de desarrollo departamental y nacional que desde una perspectiva sistémica generen sinergias.

Por lo tanto, el desarrollo del territorio se torna político por el hecho de que responde a un ideal colectivo, en el cual coexisten diferenciados esfuerzos y acciones provenientes de actores sociales, gubernamentales, gremiales y académicos; no puede obviarse que tales esfuerzos se encuentran implicados directamente por las políticas públicas que tienen como principal reto concretar oportunidades que cobijen a amplios sectores de la sociedad. (Gutierrez et al., 2008, p. 24).

Para el análisis del proceso de elaboración de los planes de Desarrollo de los municipios de Factativá, Sopó, Sibaté, La Calera, Subachoque y Gachancipá se consideró importante contar con un conocimiento previo y sucinto del contexto territorial y económico en que están inmersos, ya que de ello depende, en parte, la categoría en la que están clasificados y la especificidad de su vocación, así como la pertinencia del plan de desarrollo formulado para el periodo 2012-2015.

En el artículo 1, de la Constitución Política de 1991, se define a Colombia como un Estado Social de Derecho, organizado en forma de República Unitaria, cuya división política y administrativa se rige por los principios de descentralización y autonomía de sus entes territoriales. En el Artículo 287, define al municipio como entidad territorial con el derecho de ser gobernado por autoridades propias, a ejercer las competencias que le correspondan, a administrar sus recursos y a establecer los tributos necesarios para el cumplimiento de sus funciones. 
En el artículo 311 de la Constitución Política de 1991 y la ley 136 de 1994 (ver anexo $N^{\circ} 3$ ) se define el municipio como "la entidad territorial fundamental de la división político administrativa del Estado, con autonomía política, fiscal y administrativa, dentro de los límites que le señalen la Constitución y las leyes de la República." República de Colombia, 1991). La finalidad de los municipios es generar las condiciones territoriales para lograr el bienestar general y el mejoramiento de la calidad de vida de la población en su respectivo territorio. Partiendo del principio de autonomía que tiene lo municipios según la Constitución y la normatividad expedida para regular tal fin, estos deben elaborar sus planes de desarrollo de acuerdo con su necesidades, contexto y deseos de la población que en ellos habita, derecho que no excluye la obligatoriedad de armonizarlos con el Plan Nacional de Desarrollo, la articulación con el plan departamental y el cumplimiento de lo exigido por la Ley 152 de 1994.

\subsection{Contexto geográfico}

La investigación se realizó en 6 municipios de Cundinamarca, departamento colombiano en el que está Bogotá, capital del país; es un departamento ubicado en la Cordillera Central, con una topografía de sabana y de montaña, que limita por el norte con el departamento de Boyacá, por el sur con los departamentos de Huila, Tolima y Meta, por el occidente con Tolima y Caldas y por el oriente con el departamento de Casanare. Concentra el $21.6 \%$ de la población del país (Dane, 2010).

Cundinamarca está dividida en 116 municipios, distribuidos en 15 provincias (Departamento de Cundinamarca, 2001): Almeidas, Alto Magdalena, Bajo Magdalena, Gualivá, Guavio, Magdalena Centro, Medina, Oriente, Rionegro, Sabana Centro, Sabana de Occidente, Soacha, Tequendama, Ubaté y Sumapaz (Alcaldía Mayor de Bogotá. 2010, p. 9), que contienen diversos climas, calidad de suelos, tipos de explotación y diferentes niveles de desarrollo 
agro industrial, ambiental y de desarrollo humano, que marcan diferencias profundas en su calidad de vida y grados de desarrollo social y económico.

En los últimos años, los municipios más cercanos a Bogotá han alcanzado una tasa de crecimiento del $25.2 \%$, superior al nacional, esto es debido a que han logrado absorber, de diferentes maneras, la dinámica de crecimiento de la capital, aspectos que, bien favorecen la generación de riqueza y un aparente progreso para los municipios aledaños, también se ha dado un mayor detrimento ambiental, problemas de movilidad vial y de la calidad de vida para la población residente en las poblaciones periféricas a Bogotá, lo cual ha requerido que las administraciones municipales suplan las necesidades de equipamiento y servicios básicos, salud, educación, vivienda para la población que ha migrado hacia estos municipios, considerados dormitorios, como ocurre con Gachancipá, La Calera, Sopo y Sibaté, entre otros, afectando de manera significativa los presupuestos locales, el sentido de pertenencia y la vocación agrícola de la mayoría de ellos, sin que para esto se haya contado con el apoyo de la nación y el acompañamiento en los procesos de planeación para el desarrollo integral.

A continuación se hace una breve caracterización de los municipios seleccionados como muestra para hacer el estudio de casos en esta investigación.

\section{a) Municipio de Facatativá}

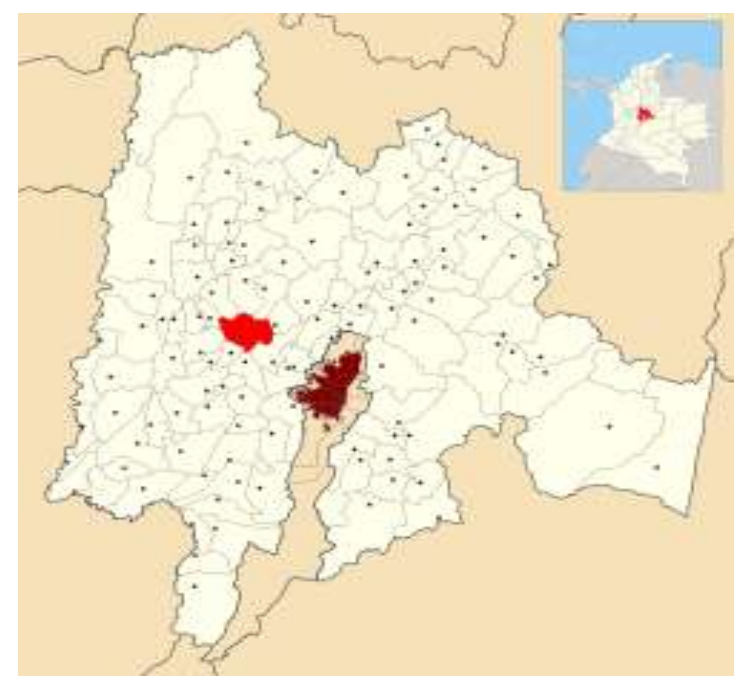


Facatativá en el Departamento1

Tomado de http://www.facatativa-cundinamarca.gov.co/mapas_municipio.shtml

El Municipio de Facatativá, fue fundado el 3 de julio de 1600 por Diego Gómez de Mena. Se encuentra ubicado geográficamente en el extremo occidental de la Sabana de Bogotá, a 36 km de la ciudad capital, cerrándose en dos ramificaciones de la Cordillera Oriental.

Tiene una extensión de $158 \mathrm{Km}$ cuadrados, de los cuales $6 \mathrm{~km}$ cuadrados abarcan el área urbana y los restantes $152 \mathrm{Km}$ cuadrados lo ocupa el área rural. Es la capital de la provincia de Sabana Occidente, la cuarta ciudad de Cundinamarca en población y hace parte del área metropolitana de Bogotá, según el censo del Dane de 2005. Su vocación económica, debido en parte a su localización, es industrial, un centro de servicio regional, sitio de producción y suministro de alimentos; su economía está conformada por los sectores primario, secundario y terciario y está clasificado como municipio de categoría tres (3).

El Plan de Desarrollo de Facatativá fue denominado "Todos somos Facatativá 2012 - 2015" y aprobado por medio del Acuerdo Municipal No. 009 del 8 de Junio de 2012.

Como visión de desarrollo se establece que en el año 2025 Facatativá será una "Ciudad Contemporánea, segura y amable, posicionada como referente de alto significado histórico y cultural; con una sociedad del conocimiento que avanza en armonía ambiental, para asegurar la sostenibilidad de las generaciones venideras. Se consolidará como POLO DE DESARROLLO REGIONAL en proceso de internacionalización, conforme a la importancia geoestratégica que representa para Bogotá D.C. y el centro del país". (Municipio de Facatativá, 2012). 
"El gobierno municipal como objetivo se propone mejorar la calidad de vida de los habitantes de Facatativá, transformando positivamente sus condiciones actuales, mediante la puesta en marcha de alternativas de solución y de acuerdo a las potencialidades de la persona y del territorio, la competitividad local y los factores diferenciales". (Municipio de Facatativá, 2012, p. 16).

\section{b) Municipio de Sopó}

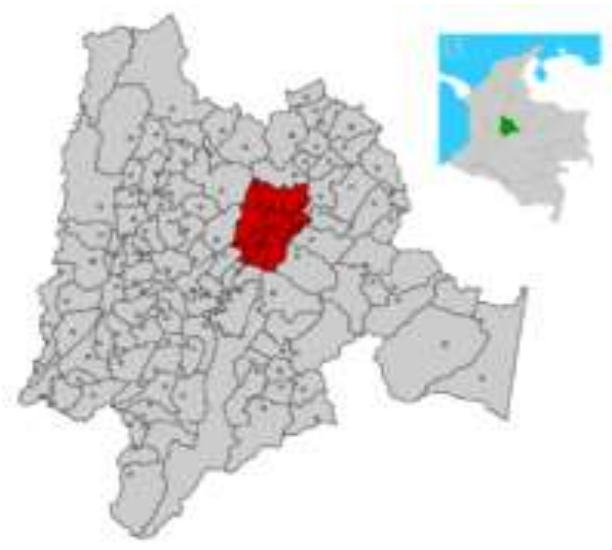

Sopó en el Departamento

Tomado de http://www.sopo-cundinamarca.gov.co/mapas_municipio.shtml

Sopó fue fundado el 25 de Mayo de 1653 por Fray Francisco Chacón y su nombre en lengua chibcha significa "Piedra o Cerro Fuerte". Se encuentra ubicado a $39 \mathrm{Km}$ al norte de la Capital de la República; tiene un área de $111.5 \mathrm{Km} 2$, de los cuales $1.06 \mathrm{Km} 2$ son el área urbana y $110.44 \mathrm{Km} 2$ al área rural; cuenta con 17 veredas y limita al oriente con Guasca, al occidente con Cajicá y Chía, al norte con Tocancipá y al sur con el municipio de La Calera. Su población es de 23.251 habitantes, de los cuales 16.727 están ubicados en la cabecera municipal. 
La principal actividad económica del municipio es la agroindustria, especialmente la de derivados lácteos y algunos sectores industriales dedicados a la producción de bienes para el sector de la construcción y la fabricación de fósforo. Así mismo, cuenta con actividades comerciales, de servicio y financieras. Este municipio, por su topografía y ubicación cerca a Bogotá, ha tenido un gran desarrollo industrial e importante migración de personas desde Bogotá y los departamentos y municipios vecinos. Sopó hace parte de la Provincia de la Sabana Centro y está catalogado como municipio categoría tres (3).

Por el acuerdo Municipal No. 011 del 31 de mayo de 2012 se adopta el Plan de Desarrollo del Municipio “iSopó lo construimos todos!”, con el objetivo de:

Fortalecer la política social dentro del municipio bajo las premisas de calidad y oportunidad en la prestación de los servicios sociales, y propender por el aprovechamiento de ventajas competitivas derivadas del uso racional de los recursos naturales y la implementación de estrategias de desarrollo sostenible que garanticen la preservación del medio ambiente y el equilibrio entre la oferta ambiental y las dinámicas de poblamiento dentro del municipio con el propósito de incrementar el nivel de desarrollo humano integral (Municipio de Sopó, 2012).

Como Visión de desarrollo Sopó se propone:

Ser en el año 2016 un municipio más equitativo, reconocido a nivel regional, nacional e internacional por su nivel de Desarrollo Humano Integral satisfactorio, concebido a través de la participación comunitaria activa, la creación de un modelo socioeconómico que permita la generación de oportunidades para todos y garantice el equilibrio entre la oferta y demanda de bienes y servicios ambientales, y un profundo sentido de corresponsabilidad que incluya a todos los sectores económicos, 
urbanos y rurales en la consolidación de pactos colectivos, que direccionen el desarrollo comunitario hacia un proceso de construcción y transformación positivo, sostenible en el largo plazo. (Municipio de Sopó, 2012, p.6).

\section{c) Municipio de Sibaté}

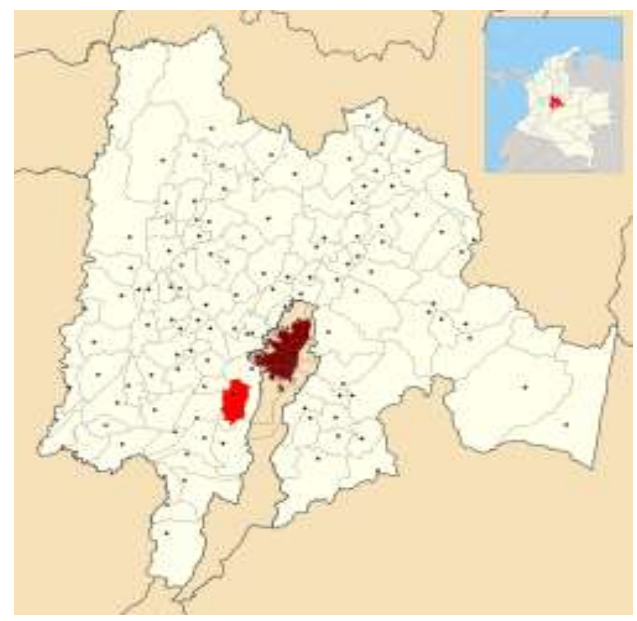

Sibaté en el Departamento

Tomado de http://www.sibaté-cundinamarca.gov.co/mapas_municipio.shtml

En lengua chibcha, Sibaté significa "derrame de la laguna". "El municipio fue fundado el 24 de Noviembre de 1967 en el lugar que ocupaba una hacienda llamada Sibaté, tierras que aparecen escrituradas bajo documento No. 1639 del 27 de diciembre de 1883, situadas en los Municipios de Soacha y Fusagasugá y en los de la Hacienda Aguas Clara, considerada punto de partida de lo que hoy es el área urbana del municipio de Sibaté." (Municipio de Sibaté (Municipio de Sibaté, s.f.). 
Sibaté limita al norte con el municipio de Soacha, al sur con Pasca y Fusagasugá, al oriente con Soacha y al occidente con Silvania y Granada. Tiene una extensión total de $125.6 \mathrm{Km} 2$, de los cuales $16.9 \mathrm{Km} 2$ están ocupados por el área urbana; su principal actividad económica es la producción agrícola, con cultivos de papa, fresa y arveja, y grandes extensiones de tierra dedicadas a la producción de ganado de leche, ganado de carne y otras especies pecuarias. Por su ubicación geográfica, también se ha facilitado el crecimiento industrial en la zona. Sibaté hace parte de la Provincia del Sumapaz y está clasificado como categoría cuatro (4).

Por el acuerdo No. 004 del 26 de Mayo del 2012 se adopta El Plan de Desarrollo Municipal para los años 2012 y 2016, "Todos de la mano transformamos a Sibaté" y tiene como objetivo "Promover el desarrollo integral de la población, el crecimiento económico y social para mejorar sus condiciones de vida, ampliar las oportunidades y garantizar la equidad social." (Municipio de Sibaté, 2012).

Como visión de desarrollo Sibaté se propone que "en el 2023 será un Municipio seguro, competitivo, ambientalmente sostenible y generador de escenarios propicios para el desarrollo humano integral". (Municipio de Sibaté, 2012).

\section{d) Municipio de La Calera}

El municipio de La Calera fue fundado el 16 de diciembre de 1772. Tiene una extensión de 31.686,06 Km2, de los cuales $144.34 \mathrm{~km} 2$ corresponden al área urbana. Hace parte de la Provincia del Guavio y está considerado como municipio categoría cinco (5). 
La calera en el Departamento

Tomado de http://www.La Calera- cundinamarca.gov.co/mapas_municipio.shtml

La formulación del Plan de Desarrollo Municipal parte de los lineamientos que el Departamento Nacional de Planeación ha establecido como metodología para que las entidades territoriales formulen, planteen y desarrollen sus planes locales. Dentro del Plan de Desarrollo se establecieron cuatro ejes a trabajar: eje social, eje económico, eje ambiental e infraestructura pública, eje gestión administrativa y el programa democratización y buen gobierno.

Por el acuerdo Municipal No. 005 de Junio 02 de 2012 se adopta el plan de desarrollo "Unidos somos más, hacia el Futuro", cuyo objetivo es:

Integrar las fuerzas vivas del municipio representadas en los diferentes grupos políticos existentes actualmente, a las organizaciones gremiales, juntas de acción comunal, asociaciones de usuarios, comités de padres de familia y de jóvenes, así como las demás autoridades civiles, militares y eclesiásticas. Será una administración de puertas abiertas sin distingos de ninguna índole, con calidad y eficiencia en la atención y servicio al ciudadano; con el fin de fortalecer el aspecto social y poder concretar las alternativas que mejor conlleven al desarrollo y bienestar de la comunidad caleruna. (Municipio de La Calera, 2012, p. 16). 
El desarrollo del municipio de plasma en la visión que plantea que "La Calera será un Municipio seguro, con una comunidad educada y fortalecida en el núcleo familiar, sano y trabajando, con una infraestructura que nos permita ser competitivos, productivos, en paz, en armonía con la naturaleza y con oportunidades para todos". (Municipio de La Calera, 2012).

\section{e) Municipio de Gachancipá}

Gachancipá fue fundada el 1 de Enero de 1612; está ubicado a $42 \mathrm{~km}$ al norte de Bogotá, tiene una extensión de $44 \mathrm{Km} 2$ y $42.50 \mathrm{Km} 2$ corresponde al área urbana. Limita por el norte Suesca, por el oriente Sesquilé, por el nororiente con Guatavita, por el occidente con Nemocón y por el sur con el municipio de Tocancipá. Hace parte de los municipios de la Provincia de Sabana Centro y es municipio categoría seis (6).

Este municipio ha sido tradicionalmente agrícola y ganadero; sin embargo, y debido a la creación de la Zona Industrial, aprobada por los ajustes realizados al Plan de Ordenamiento Territorial, la vocación económica del municipio se ha transformado a industrial. Hay varias empresas que dedican su actividad al cultivo de flores, lo que generan una gran cantidad de empleos.

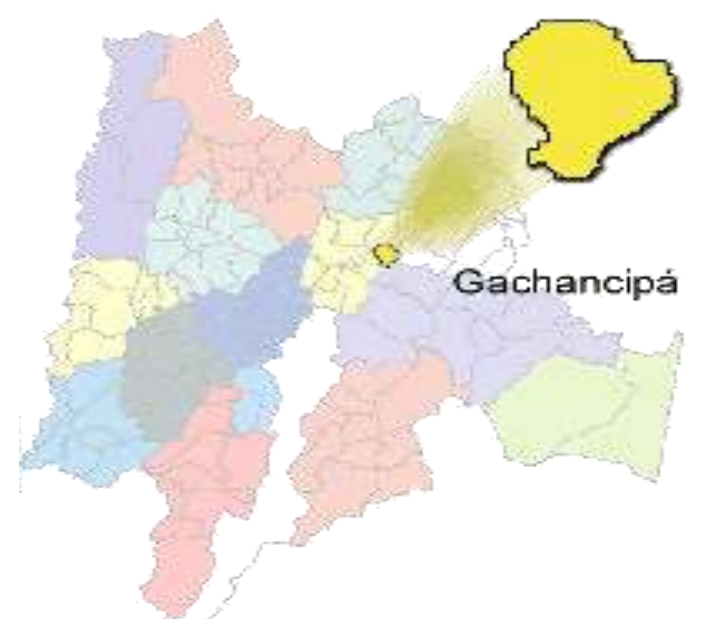


Por el acuerdo Municipal No. 011 de Mayo 31 de 2012, se adopta el plan de desarrollo "Unidos somos más, hacia el Futuro", cuyo objetivo es:

Afianzar la participación y la democratización de las políticas públicas del municipio, como estrategia para mejorar la calidad de vida y el progreso de todos los habitantes, a través de la integración de elementos que busquen disminuir la pobreza extrema y el uso adecuado de los recursos, de esta manera garantizar los derechos ambientales y del desarrollo humano de todos, especialmente el de las personas en estado de vulnerabilidad en un escenario de justicia y equidad, como lo establece el Estado Social de Derecho, con un denominador común: el principio de la dignidad humana. (Municipio de Gachancipá, 2012, p. 16).

El plan de desarrollo formula como visón de desarrollo que:

En 16 años, el municipio de Gachancipá brindará calidad de vida a sus habitantes desde los principios constitucionales de la dignidad humana y el respeto al medio ambiente como garantía de progreso, a través de un crecimiento económico y territorial ordenado, responsable y sostenible. En ese mismo periodo, el ciudadano gachancipeño, basado en un proceso educativo fortalecido, afrontará las necesidades y políticas públicas con alto grado de participación democrática. (Municipio de Gachancipá, 2012, p. 15).

\section{e) Municipio de Subachoque}

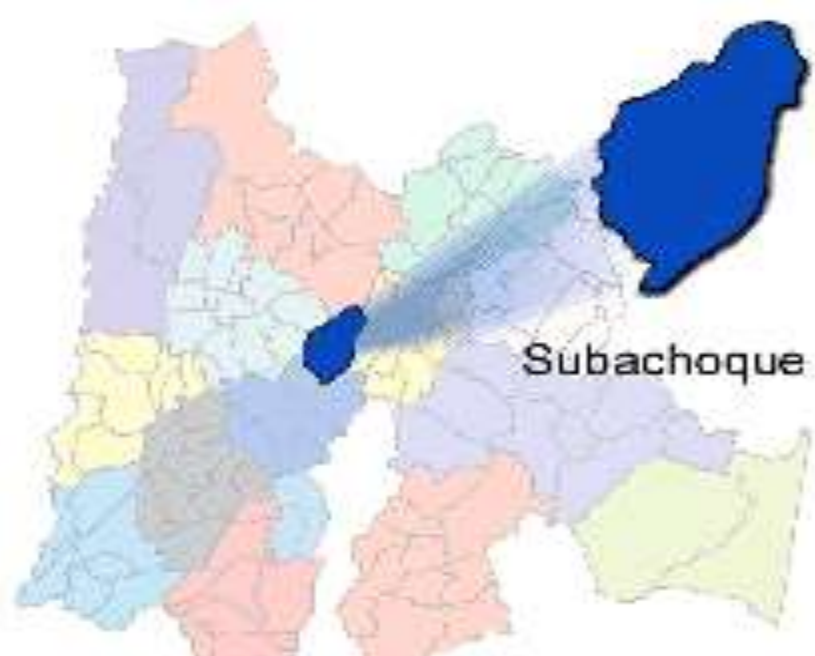


Fue fundado el 16 de marzo de 1774, está ubicado al noroccidente de Bogotá, a $45 \mathrm{~km}$ de la capital y tiene una temperatura media entre los 7 y los $13^{\circ} \mathrm{c}$.

El Programa de Gobierno del municipio de Subachoque tiene como lema "Unidos logramos el cambio" y constituye la base para la realización del ejercicio de planificación del Plan de Desarrollo, que se enriquece con los aportes de los diferentes actores de la dinámica local y la articulación con las políticas nacionales, departamentales y regionales.

Por el acuerdo Municipal No. 05 de Junio 5 de 2012, se adoptó el plan de desarrollo "Unidos logramos el Cambio", como visión en el Plan de Desarrollo 2012- se propone que "será un municipio verde, agropecuario, ecológico y productor de bienes y servicios agropecuarios y ambientales especialmente de recurso hídrico que será fuente económica de ingresos para el Municipio. (Municipio de Subachoque, 2012, p. 6 y 9).

El desarrollo municipal está afectado y condicionado por múltiples variables y factores, tanto de orden geográfico como político, económico y social. La capacidad técnica, ética y visión de futuro de sus alcaldes, Concejo Municipal, directores de entidades públicas y privadas y, sobre todo, por la visión que tenga la población de su territorio y cultura y de la voluntad política 
del gobierno nacional, se jalonan o frenan los procesos de desarrollo local integral.

\section{CAPÍTULO III. ESTADO DEL ARTE Y MARCO CONCEPTUAL}

Con el fin de comprender el sentido que tienen los términos y teorías que sustentan este trabajo de grado y los referentes existentes en torno a los trabajos elaborados sobre los procesos de planeación municipal que se han realizado en los municipios del Departamento de Cundinamarca, Colombia, se realizó un rastreo (estado del arte) sobre los documentos y Centros de Consultorías identificados en las diferentes universidades, Organizaciones no Gubernamentales y entidades que acompañan procesos de elaboración de Planes de Desarrollo y/o evaluación y seguimiento a la implementación en municipios ubicados en las categoría 3 a 6 (Ver anexo № 3, Ley 136 de 1994).

En este capítulo también se incluyen los aportes teóricos y metodológicos que han realizado algunos estudiosos del desarrollo local, la planeación y gestión municipal, la descentralización, el desarrollo humano integral y la participación, referentes conceptuales que han sido tomados para este estudio como categorías de análisis y referentes conceptuales para la comprensión de los casos estudiados. 


\subsection{Estado del arte}

La elaboración del estado del arte tuvo como fuente la indagación realizada sobre las experiencias tenidas por organizaciones internacionales y nacionales, $\mathrm{y}$ en las universidades colombianas sobre experiencias, investigaciones y publicaciones relacionadas con procesos de diseño, gestión y evaluación de planes de desarrollo a nivel local en América Latina y Colombia

\subsubsection{Desarrollo Regional en Colombia: Un análisis desde las estructuras productivas y las disparidades económicas departamentales 1990-2005}

La investigación tuvo como propósito analizar el desarrollo regional en Colombia, desde las estructuras productivas y disparidades económicas departamentales, en el periodo 1990-2005; para el logro del objetivo se realizó un estudio de caso, donde se aborda el desarrollo regional en Colombia desde una perspectiva económica, caracterizando su estructura económica regional y sectorial, el crecimiento económico y las transformaciones productivas que han determinado la concentración (especialización) o diversificación de las estructuras productivas inter-temporales de los departamentos, así como las disparidades económicas derivadas de estas dinámicas. (Hawkins, 2008).

\subsubsection{La Planeación Participativa, el sistema nacional de planeación y los presupuestos participativos en Colombia}

El libro escrito por Fabio Velásquez y Esperanza González (2003), muestra las deficiencias de la planeación participativa en Colombia, los déficits normativos de la Ley Orgánica de Planeación, la cual no sólo pasó por alto la reglamentación del Sistema Nacional de Planeación sino que limitó el alcance de los Consejos de Planeación, pues los restringió a la elaboración de un concepto sobre la propuesta de plan presentada por el 
respectivo gobernante. De otra, la escasa influencia de los Consejos de Planeación en los contenidos de los planes y las políticas públicas y, finalmente, la debilidad de los actores sociales para convertir la planeación participativa en un escenario para el ejercicio de la ciudadanía activa y la creación de contrapesos sociales a las decisiones de las autoridades públicas. (Fundación Foro por Colombia, 2003).

\subsubsection{De la descentralización a la regionalización: Nuevo escenario de la guerra y oportunidad para la paz}

El artículo de investigación, escrito por Darío Restrepo (2004), plantea que la combinación entre políticas de ajuste neoliberal, apertura económica y transformaciones a los regímenes políticos, modifican tanto la geografía económica como la conformación espacial de las instituciones, los sistemas políticos, los actores empresariales y sociales, en muchos países de América Latina y que por lo tanto Colombia no es ajena a tal modificación, que compromete el funcionamiento de sus políticas externas e internas. 
Los efectos espaciales de la apertura económica se combinan con los del proceso de descentralización política, fiscal y administrativa, generando una tensión sobre la unidad geográfica del Estado. La consideración de estas tendencias que desde hace veinte años han marcado los senderos de las transformaciones sociales, políticas, institucionales y económicas, indican un camino probable hacia la regionalización del país. ¿Será ésta conveniente para un desarrollo interno más equilibrado y un escenario propicio para un acuerdo de paz con base en una distribución territorial del poder, o por el contrario, el camino más expedito para abandonar cada territorio a su suerte en la competencia mundial y romper la unidad territorial del Estado colombiano? Tal es la inquietud que se deja aquí planteada. (Restrepo, 2004, p. 81 - 96).

\subsubsection{Desarrollo económico local y descentralización en América Latina}

El artículo de investigación escrito por Francisco Alburquerque (2004), muestra que la emergencia de iniciativas de desarrollo económico local no se explica únicamente como consecuencia del avance de los procesos de descentralización en marcha en los diferentes países de la región, sino como resultado de un conjunto más complejo de factores surgidos desde los propios territorios, con la movilización y actuación de agentes locales, públicos y privados. El proyecto realizó casi treinta estudios de casos en siete países de la región y constituye una de las investigaciones más amplias llevadas a cabo sobre el despliegue de iniciativas de desarrollo económico local en América Latina.

El autor define que es necesario plantear que el desarrollo económico local se convierte en un enfoque alternativo al de las políticas asistenciales de superación de la pobreza, y que busca incidir en la generación de empleo e ingresos mediante la mejora de la productividad y competitividad de los diferentes sistemas productivos locales. Esto supone avanzar desde 
un diseño asistencial a un planteamiento de desarrollo económico, y desde una perspectiva sectorial a una de carácter horizontal e integrado, según las características, actores y capital social de cada territorio. Es en el ámbito local donde se define la demanda de modernización del tejido de empresas existente, y a partir de esa demanda debe construirse la oferta apropiada de servicios de innovación y capacitación técnica y empresarial para el fomento productivo local. (Alburquerque, 2004).

\subsubsection{Estado del arte de la investigación universitaria en desarrollo económico local en Colombia}

El artículo escrito por Álvaro Albán Moreno y Jorge Alberto Rendón Vélez (2008) presenta el estado del arte de la investigación universitaria en desarrollo económico local en Colombia. El diseño metodológico se centró en un proceso hermenéutico y crítico de tres fases: fase descriptiva, fase interpretativa y fase de valoración crítica. Por lo tanto fue necesario desarrollar diferentes instrumentos para obtener la información de los productos de investigación de los grupos reconocidos por Colciencias. Los resultados permiten categorizar los problemas de investigación, las tendencias teóricas sobre el desarrollo, los enfoques metodológicos, los resultados y conclusiones; y finalmente, reconstruir críticamente dichos resultados y aportar algunas recomendaciones. Se destacan, explícita o implícitamente, los enfoques teóricos integrales sobre el desarrollo, tanto en general, como cuando se utiliza la acepción local; y el avance de perspectivas cualitativas en los diseños investigativos. La multidimensionalidad, transdisciplinariedad, holismo, integralidad y el carácter de estructura del Desarrollo Económico Local son significados que ganan espacio en la investigación reciente sobre el tema. (Albán y Rendón, 2008).

\subsubsection{Fragmentación social y Planeación Territorial}


El artículo de investigación escrito por Liliana María Sánchez Mazo (2007), muestra que aproximarse al fenómeno contemporáneo de la fragmentación social en el marco de las transformaciones legales precisa hacer explícito su significado y sus manifestaciones en los ámbitos económico, político y sociocultural, enfatizando, en el ámbito económico, las lógicas individuales, en el ámbito político la incidencia de prácticas sociales fragmentadas en la planeación territorial y en el ámbito sociocultural, las dinámicas de la desterritorializadas que dichas lógicas señalan en el territorio. Desde esta perspectiva, se hace necesario plantear la planeación territorial como un proceso sociopolítico que posibilita el análisis de las prácticas participativas. Así, los tres ámbitos sirven de fundamento analítico para develar las implicaciones más significativas que vinculan la fragmentación social con la planeación territorial. (Sánchez, 2007).

Las investigaciones y artículos resultado de investigación, muestran temas relacionados con esta investigación, como son la planeación participativa, el desarrollo regional, la descentralización, el desarrollo local , así como también los análisis que se realizan a través de estos estudios sobre lo que ha significado la descentralización, los efectos a nivel municipal, la disparidad en el desarrollo regional, la influencia del modelo neoliberal, la apertura económica y los cambios en el panorama a nivel del América Latina y, por ende, de Colombia, lo que significa que se pueda transitar de la descentralización a la regionalización; igualmente, se plantea cómo el desarrollo local es una opción de poder superar la pobreza a nivel municipal y hacerle frente a las políticas asistenciales de los gobiernos.

Estas investigaciones plantean un panorama amplio sobre el interés que ha despertado el tema de la planeación municipal, cómo se realiza el proceso de elaboración de planes de desarrollo de los municipios y cómo la descentralización ha desfavorecido el desarrollo y el mejoramiento de la calidad de vida de los pobladores. 


\subsubsection{Metodología para la elaboración de estrategias de desarrollo local}

En América Latina el Instituto Latinoamericano y del Caribe de Planificación Económica y Social (Ilpes) y la Cepal, han estudiado a profundidad el tema del desarrollo local y elaborado documentos de gran valía académica y metodológica con la finalidad de contribuir con la reflexión, tecnificación e instrumentalización de un tema tan sensible para este continente como es el desarrollo local. Su aportes han contribuido con la capacitación y desarrollo de habilidades para la gestión pública de alcaldes, funcionarios y en general de los equipos de gobierno y la consolidación de grupos e instituciones interesadas en el desarrollo desde una perspectiva espacial, territorial, regional y local.

Iván Silva Lira, director de Gestión del Desarrollo Local y Regional del Ilpes, publicó en el 2003 en la Serie Gestión Pública, \# 42, el documento Metodología para la elaboración de estrategias de desarrollo local, en el cual presenta las etapas pertinentes del proceso que se deben seguir para construir el perfil de plan estratégico de desarrollo local.

Su propuesta parte de la elaboración del diagnóstico; a continuación se identifican las vocaciones del territorio; posteriormente definen los objetivos estratégica y se elabora el plan de desarrollo local, en el que se incluye la elaboración de las acciones específicas, redactadas en forma de proyectos y/o políticas, las ayudas metodológicas requeridas con el fin de poder ir desarrollando en forma coherente y articulada cada una de las fases del proceso de planificación alcanzar los objetivos en función de las vocaciones detectadas. (Silva, 2013).

\subsubsection{Introducción a la Planificación Estratégica del Desarrollo Local}


En 2009, la Federación Dominicana de Municipios elaboró la cartilla Introducción a la Planificación Estratégica del Desarrollo Local, documento con el que busca "hacer un aporte significativo a la construcción de una nueva gobernabilidad, fundamentada en una gestión municipal planificada, con participación de todos los actores sociales "en república Dominicana. Esta propuesta teórica y metodológica, base principal de una serie de cursos de capacitación dirigidos a funcionarios de los gobiernos municipales aborda temas como: Nuevos Retos del Territorio y la necesidad de Planificar el Desarrollo; la planificación estratégica: Herramienta para el desarrollo local, la puesta en práctica de la Planificación Estratégica, entre otros. (Federación Dominicana de Municipios, 2009).

Igualmente, en la indagación realizada sobre el tema, se encontraron varios programas e iniciativas públicas y privadas, del orden nacional e internacional, como el Banco Mundial, el Bid, la Fundación Konrad Adenauer, EL Centro Iberoamericano de Desarrollo Estratégico Urbano (Cideu), el Instituto Latinoamericano y del Caribe de Planificación Económica y Social (llpes), La Cepal, la Federación Colombiana de Municipios, y centros de investigación y corporaciones como el Cinep, el Programa de Desarrollo y Paz del Magdalena, la Fundación Social entre otras, que se interesan y fomentan el desarrollo regional y municipal a través de empréstitos, financiación de proyectos, investigaciones, acompañamiento a la gestión y en la formulación y seguimiento a la implementación de políticas públicas y procesos de descentralización de las entidades estatales .

En el rastreo, se identificaron organizaciones sociales, académicas y programas, cuya apuesta política toca directa o indirectamente los municipios y las regiones, ya que en sus misiones, objetivos o programas se aprecia de manera explícita su apuesta por el desarrollo humano, la defensa de los derechos humanos, la formación de ciudadanos, o la defensa del territorio y del hábitat como es el caso de: 
a) En América latina hay experiencias además de las ya citadas, otras como la del Centro Iberoamericano De Desarrollo Estratégico Urbano (Cidceu), organismo fundado en Argentina en 1994, que ha venido incursionando en procesos de desarrollo territorial desde la perspectiva de la Planificación Estratégica Urbana, cuya trayectoria y experiencia ha iluminado la reflexión sobre el desarrollo de los territorios, en diferentes países del continente, cuanta con 141 miembros de 21 países Iberoamericanos. (Cideu, s.f.)

b) La Federación Colombiana de Municipios (FCM) es una entidad gremial de naturaleza asociativa, de derecho privado y sin ánimo de lucro, creada en 1989, por iniciativa de un grupo de alcaldes de diferentes regiones del país, que busca promover el desarrollo de los municipios a través de estrategias, alianzas, proyectos y servicios orientados a fortalecer la capacidad de gestión y autonomía local, prestando asesorías, consultorías para el fortalecimiento de la gestión de las administraciones municipales, diseño y gestión de programas y proyectos.

c) La Corporación para el Desarrollo Regional (CDR) organización no gubernamental que dirige su accionar alrededor de iniciativas de desarrollo alternativo, desde una apuesta política de participación abierta e incluyente, que en el marco de los derechos humanos incentive la convivencia pacífica y ciudadana, como camino para el desarrollo de las comunidades "excluidas" por el modelo de desarrollo vigente.

La CDR utiliza metodologías como la educación popular y el empoderamiento de la comunidad, como medio para la fortalecer la autogestión del desarrollo local, la consolidación de principios como la solidaridad, la cooperación y el trabajo en red, en interacción con los gobiernos locales responsables de la implementación de las políticas públicas. 
Ofrece servicios orientados al fortalecimiento de la Participación y la Democracia, por medio de procesos de organización social, formación y brindando herramientas que permitan identificar problemáticas, elaborar propuesta o alternativas de carácter colectivo, mejorando la capacidad de convocatoria y movilización social e incidencia política a nivel local y regional.

Educación, cultura y comunicación, empoderamiento de las comunidades frente a su realidad inmediata, legitimando su historia y cultura, valorando y confiando en la riqueza de lo local, como poder que dialoga con el poder macro con el que coexiste, para lograr un desarrollo efectivo, en lo ambiental, lo humano, lo social, lo económico y lo político. Reafirmando la relación entre derechos humanos, democracia y desarrollo.

El programa de fortalecimiento institucional. Busca aumentar la capacidad de las organizaciones para dar respuesta a las necesidades o para reivindicar los cambios políticos necesarios para responder a las problemáticas estructurales que generan inequidad y exclusión. Se considera diferentes esferas como la capacitación técnica, metodológica y gerencial, espacios para el intercambio de experiencias institucional, espacios de formación y reflexión sobre temas de interés compartido que pueden hacer aportes valiosos al desarrollo de capacidades locales. (Corporación para el Desarrollo Regional, 2003).

d) El CINEP. El Centro de Investigación y Educación Popular/ Programa por la Paz (CINEP/PPP) es una fundación que anima el cambio social desde las orientaciones de la Compañía de Jesús en Colombia. Trabaja por la edificación de una sociedad más justa, democrática y en paz desde una opción preferencial por hombres y mujeres que han sido excluidos y las víctimas. Para ello, genera alternativas para la construcción de la paz, el desarrollo humano integral, la realización de los derechos y la ampliación de la democracia, desde la investigación y producción de información, la educación, 
el acompañamiento a procesos sociales, el ejercicio de la incidencia y la comunicación. (Cinep, s.f.).

El conocimiento de la realidad social del país, vista desde lo local y lo regional, han sido algunos de los principales aportes de la investigación desarrollada por el Cinep/PPP. Sus experiencias pedagógicas y su presencia en diferentes regiones le han permitido generar alternativas de inclusión política, económica y social; de tal manera que su acción, así como su pensamiento crítico y propositivo, siempre nacen de una postura ética fundamentada en lo humano.

El Cinep/PPP ha logrado consolidar propuestas de paz y convivencia como Programa por la Paz cuyo objetivo ha sido construir alternativas de paz $y$ desarrollo para la realización de los derechos y la ampliación de la democracia. Para lograrlo, desarrolla programas y proyectos y presta servicios de asistencia técnica para la elaboración de planes de ordenamiento territorial y planes de desarrollo por corregimiento/comuna y municipal a través de:

1. Corporación Desarrollo y Paz del Bajo Magdalena.

2. Programa Construcción de paz y desarrollo.

3. Programa Realización de derechos para la ampliación de la democracia.

4. Sistema de información general.

5. Proyecto institucional de Incidencia y comunicación.

Además, participa en acciones interinstitucionales con el fin de potencializar su quehacer acompañado de otras instituciones. (Cinep, s.f.).

Promover la realización de actividades tendientes a fortalecer los procesos de planificación y gestión pública territorial, que contribuyan a la articulación entre los diferentes niveles de gobierno y el desarrollo local y regional. 
e) Departamento Nacional de Planeación DNP. El Departamento Nacional de Planeación (DNP) es una entidad de carácter técnico, que tienen la misma categoría de los Ministerios; es el encargado de dirigir, coordinar servicios y otorgar al Gobierno la información adecuada para la toma de decisiones. El DNP pertenece a la Rama Ejecutiva del poder público y depende directamente de la Presidencia de la República fue creada en 1958, y estaba encaminada a constituirse en un grupo macroeconómico integrado por expertos de talla nacional, cuyo objetivo era asesorar al Presidente con la finalidad que éste adoptara las políticas macroeconómicas apropiadas para alcanzar las metas propuestas en su plan de desarrollo. (Departamento Nacional de Planeación, s.f.).

Por medio del DNP se impulsa la implantación de una visión estratégica del país en los campos social, económico y ambiental, a través del diseño, la orientación y evaluación de las políticas públicas colombianas, el manejo y asignación de la inversión pública y la concreción de las mismas en planes, programas y proyectos del Gobierno.

Dentro de sus funciones está “(24) promover la realización de actividades tendientes a fortalecer los procesos de planificación y gestión pública territorial que contribuyan a la articulación entre los diferentes niveles de gobierno y el desarrollo local y regional." (Departamento Nacional de Planeación, s.f.), función a través de la cual hace ocasionalmente acompañamiento a los municipios y monitorea los Planes de Desarrollo Municipal.

Por ser un país que infunde confianza a la banca multilateral y a las agencias de cooperación internacionales, han surgido en el país numerosas organizaciones privadas y centros de estudio político, social y económico, que observan y, en ocasiones, acompañan procesos políticos y programas dirigidos a fortalecer el desarrollo social y económico del país, lo cual ha permitido que 
ONG y programas del gobierno nacional brinden asesorías para la planeación regional o sectorial y desarrollen programas de capacitación a funcionarios públicos y líderes de las organizaciones sociales, la cobertura departamental de estos servicios es mínima y menos aún llega a los pequeños municipios.

Por medio de la exploración realizada, se pudo observar que en el departamento de Cundinamarca, se requiere contar con centros de investigación y consultoría, programas y proyectos dirigidos a fortalecer los procesos de planeación local especialmente.

\subsection{Referentes teóricos}

Este aparte contiene los desarrollos conceptuales que dan soporte teórico a las categorías que se contemplan para el análisis de los resultados de la investigación, como son la descentralización, la planeación, el desarrollo regional, el desarrollo local, la gestión municipal y la participación.

\subsubsection{Planeación municipal}

Con la Constitución Política de Colombia, de 1991, se incorporó el tema de la planeación en su Capítulo 2, artículo 339 del Título XII, en el que se explicita que "Las entidades territoriales elaborarán y adoptarán de manera concertada entre ellas y el gobierno nacional, planes de desarrollo, con el objeto de asegurar el uso eficiente de sus recursos y el desempeño adecuado de las funciones que les hayan sido asignadas por la Constitución y la ley. Los planes de las entidades territoriales estarán conformados por una parte estratégica y un plan de inversiones de mediano y corto plazo. (República de Colombia, 1991).

Igualmente, la constitución de 1991 avanzó en el sentido de abrir paso a la participación de los ciudadanos en la planeación de sus regiones y 
municipios; en su artículo 340 se conformó el Sistema Nacional de Planeación compuesto por el Consejo Nacional y los Consejos Territoriales de Planeación; luego, la Ley 152 o Ley Orgánica Nacional de Planeación reglamentó lo estipulado en la Constitución.

En la reglamentación, establecida por el Estado para darle un marco jurídico a la planeación, se contempló el decreto 1333 de 1986, así como la Ley Novena de 1989, en las cuales se plantea que es necesario la integración entre el plan de desarrollo municipal y la región circundante. A juicio de algunos analistas (Forero, Cardona y Córdoba, 1999; Velásquez y González, 2003), en esas normas, la planeación local debe articularse con la planeación regional y también con la nacional. La consolidación definitiva de la articulación de la planeación local, tanto con la regional como con la nacional, se establece con la Constitución de 1991; en ella, lo novedoso de la planeación es que debe entenderse como un sistema, es decir, debe darse una articulación entre los niveles nacional y territorial de la planeación.

Por lo tanto, el plan de desarrollo municipal es el resultado inicial y principal de la asignación de un esquema de planificación. En el proceso de elaboración se articulan la acción coordinada de la planeación del orden nacional, departamental y municipal, así como de los sectores social y privado del municipio. De esta manera, el Plan se convierte en un instrumento político que responde a la dirección general del municipio a partir de unas realidades y necesidades concretas y que se proyecta al logro de un futuro deseable. (Trujillo, 2001, p. 252).

De acuerdo con los parámetros establecidos por la Ley, en la elaboración de los planes de desarrollo municipal, los municipios deben partir de un proceso de diagnóstico, donde se determinan las necesidades de la población y el desarrollo deseado para los municipios y/o las regiones. La elaboración está enmarcada dentro de los métodos de planeación estratégica y de planeación 
prospectiva, cuyas metodologías son eminentemente participativas, han sido utilizados en las dos últimas décadas tanto en el sector privado como en el público.

En Colombia, a partir de la Constitución de 1991, se han venido formalizando los procesos y métodos de planeación municipal. Stoner (1984, p. 39-40) plantea que tanto los individuos como las organizaciones tiene que planear...; la planeación es el proceso básico del que nos servimos para escoger nuestras metas y determinar cómo las vamos a alcanzar. Para este autor la Planeación Estratégica es el proceso formalizado de planeación a largo plazo, que se usa para definir y alcanzar las metas organizacionales; en el caso del desarrollo local, el proceso se encamina a lograr las metas del desarrollo del municipio.

La Planeación estratégica, para el caso de los municipios, implica definir las estrategias, seleccionar las metas, determinar los medios y recursos que se requieren para lograr los objetivos propuestos y establecer los métodos para asegurarse que lo planeado sea ejecutado y pueda ser verificado a través de los indicadores formulados.

Dentro de las diferentes teorías elaboradas sobre la planeación o la planificación (uso indiscriminado del término en algunos autores) está la denominada Teoría del desarrollo o del cambio planificado, que define, según Quintero (2013), la planeación como el proceso de promoción del desarrollo y cómo un instrumento necesario para el desarrollo de un país, sector o municipio.

Este concepto parte de la premisa de que necesario que exista la participación del pueblo, frente al tipo de desarrollo que requiere el país; en el caso de la investigación, son los municipios que, al elaborar los planes de desarrollo, convocan a la comunidad, a las organizaciones sociales y a los 
diferentes sectores para que planteen sus necesidades y conjuntamente visualizan en el futuro. "Para que esta estrategia resulte viable, se requiere una estrecha vinculación y articulación entre las políticas económica, política educativa y social, dentro de un contexto participativo y democrático". (Quintero, 2013, p.11).

En Colombia se establece la participación de los ciudadanos en el proceso de formulación de los planes de desarrollo durante los años ochenta, en la cual se reglamentó la planeación, en primera instancia a través del código de régimen municipal; y, en segunda instancia, por medio de la Ley 9 de 1989, llamada Ley de Reforma Urbana, la cual planteó la obligatoriedad de la planeación urbana para todos los municipios del país. Esta reglamentación permitió el desarrollo del proceso de planeación en el país, generando nuevas estrategias para la integración territorial y regional, incluyendo al proceso la participación activa de la comunidad. (Vallejo y Fuentes, 2006).

Para los procesos de planeación, establecida por la ley y desarrollados por los municipios, algunos autores han definido el significado de la planificación, los cuales se presentan a continuación.

Ahumada, citado por Quintero (2013), plantea que "La planificación es una metodología para escoger alternativas, que se caracteriza porque permite verificar la prioridad, factibilidad y compatibilidad de los objetivos y seleccionar los instrumentos más eficientes. La planificación no es solo el proceso de elaborar un documento que se denomina plan o programa; esto es sólo una parte del proceso". Para el desarrollo de la metodología, Ahumada, formuló unas etapas que se han hecho clásicas en América Latina, el cual comprende las siguientes "etapas": diagnóstico, programación, discusión -decisión, selección de alternativas, ejecución y evaluación. (Quintero, 2013, p.11). 
En la investigación se ha encontrado que en el proceso de planeación para la elaboración del plan de desarrollo comprende las mismas etapas, se inicia con un diagnóstico, que permite la selección de unas alternativas sobre las cuales se formula el plan de desarrollo para, posteriormente, ejecutar los programas planteados a través de acciones, lo que conlleva a una evaluación constante del desarrollo del plan.

A diferencia de Ahumada, Friedman, citado por Quintero (2013), considera que la planeación se convierte en un subproceso crítico del proceso de orientación social. La planeación se puede realizar de dos formas, la de asignación o racionalización y la de innovación. La primera se refiere a las acciones que se plantean en el proceso de planeación y que implica "la distribución de recursos limitados entre usuarios que compiten entre sí por el uso de esos mismos recursos". La segunda, se relaciona con "aquellas acciones que producen cambios estructurales en la orientación de la sociedad. La planeación innovadora es esencial para el crecimiento estructural y sostenido del sistema social y, consiguientemente, para el desarrollo. Este planteamiento implica la participación activa de la población, en un diálogo entre la comunidad y los planeadores del municipio. (Quintero et al., 2013, p. 12)

Igualmente, se plantea otro concepto de planeación, formulado por Parra, citado por Vallejo y Fuentes (2007), que consiste esencialmente en un proceso de naturaleza sistémica, con mecanismos incorporados de revisión y retroalimentación continua, en el que se define la visión del futuro en el largo plazo, se formulan las estrategias para llegar a ella, se estructuran programas y proyectos que concretizan esas estrategias, se pone en ejecución lo planeado, se hace seguimiento y se evalúa en cumplimiento de programas y proyectos y su impacto en términos del avance hacia el logro de la visión, se replantean los proyectos y programas y eventualmente las estrategias adoptadas, en respuesta a los resultados de la evaluación y finalmente se vuelve a revisar la definición de la visión para reiniciar el proceso. (Vallejo y Fuentes, 2007, p. 64). 
Por lo tanto, la planeación se concibe como una práctica de la sociedad, la cual tiene como función básica proporcionarle un norte, un punto hacia dónde mirar. Es una práctica que permite armonizar las acciones del Gobierno con las necesidades que demanda la sociedad, con la participación de los diferentes actores que conforman el territorio y poder concebir un futuro deseable que permita generar un desarrollo a nivel municipal $y$, por ende, mejorar las condiciones de vida de sus habitantes.

\subsubsection{Desarrollo regional en Colombia}

La transformación de los territorios urbanos y rurales, ocurrida en Colombia desde mediados del siglo $\mathrm{XX}$, debido a múltiples factores de orden político, social, económicos y culturales, internacionales y nacionales, surgidos a raíz de los modelos de desarrollo implementados después de la Segunda Guerra Mundial y sus consecuentes procesos de modernización y globalización, que se dinamizaron con la industrialización, la apertura económica, las nuevas tecnologías y, en el caso colombiano, además, con la migración del campo a la ciudad, el empobrecimiento y abandono del sector rural, la ausencia de políticas agrarias y de distribución de tierras y el gamonalismo político, son hechos que han impactado negativamente las regiones $y$, especialmente, aquellas afectadas por desastres naturales, la violencia y los cultivos ilícitos, alterando la dinámica y los valores sociales y culturales que cohesionaban las regiones, cambiando su sentido y estructura económica y su vocación como región y territorio.

Al retomar el pasado y mirar el presente, permite vislumbrar la situación de los territorios y comunidades, que se perciben atrapadas entre el atraso y la modernidad, entre la tradición y el cambio. Territorios y comunidades invisibles que el país ignora intencionalmente y que son base fundamental para que se dé un desarrollo integral en los municipios y en las regiones más olvidadas de Colombia. 
La inminente industrialización de la zona central del país, le impregnó a las zonas urbanas valores y dinámicas modernas, que se caracterizaron por generar mayores costos de la tierra, la densificación del uso del espacio, niveles de bienestar, la introducción de nuevas tecnologías, permitiendo a algunas minorías el acceso a redes informáticas, incorporar capital internacional a la economía nacional y desarrollar la industria con alta tecnificación, elementos de la modernidad que modificaron de manera importante la forma de vivir, pensar y actuar de los pobladores de las ciudades $y$, en especial, a las nuevas generaciones, mientras la vida en los municipios rurales transcurría en medio del atraso del campo y la modernización, que les llegaba como un eco por su vecindad con las ciudades.

Según datos consignados en los informes de la CEPAL de los últimos cinco años, Colombia es un país de contradicciones, permeado estructuralmente de condiciones sociales inequitativas y desequilibradas; el país se adhiere políticamente desde la década de los noventa a los modelos desarrollistas, neoliberales, globalizados, sin una adecuada preparación social y económica para el cambio y la participación activa de la sociedad civil, en la planeación del desarrollo del territorio y de la nación, agudizando las discordancias e inequidades en la distribución de la riqueza, obstaculizando aún más la subsistencia digna de las familias pobres y, en especial, de aquellas estancadas en el tiempo y espacio rural.

El territorio, además de ser la base física de las actividades humanas, comprende un conjunto organizado y complejo que involucra sistemas naturales, instituciones, organizaciones y redes que los interrelacionan. Como instancia de articulación, el territorio es un medio transformador que genera sinergias y entornos favorables para la producción y el mejoramiento social, constituyéndose en un espacio que brinda pautas para la definición de políticas de desarrollo. 
Pensar el desarrollo sin asociarlo al territorio, sería un una propuesta descontextualizada, ya que el desarrollo, cualquiera que este sea, y el territorio están directamente asociados. El Desarrollo, según Tamayo (2000), puede ser entendido como un proceso dinámico de realización de un sistema de necesidades en una sociedad dada.

El Desarrollo territorial es aquel proceso que conduce a la transformación de una sociedad localizada en un territorio específico, en virtud de la generación de conocimiento y de la creatividad de los actores para emprender los cambios requeridos.

Sergio Boisier (1999), citado por el DNP. (s/f), relaciona el desarrollo territorial con los "procesos de cambio socioeconómico, de carácter estructural, delimitados geográficamente e insertos en un marco configurado por: sistemas económicos de mercado, amplia apertura externa y descentralización de los sistemas decisionales". (Boisier, 1999, p. 9).

El desarrollo territorial, según el autor antes citado, persigue tres objetivos fundamentales, a saber:

a. "El perfeccionamiento del territorio (contenedor físico de elementos naturales, sistema físico y social estructuralmente complejo, dinámico y delimitado).

b. "El perfeccionamiento de la sociedad o comunidad que habita el territorio (referente de identidad y cultura.

c. "El perfeccionamiento de cada persona..... (Boisier, 1999).

Por lo tanto, el desarrollo territorial debe vincular activamente a los diversos actores y sectores de actividad y ser el gran objetivo de las acciones de los gobernantes territoriales durante sus períodos de gobierno. 
Las propuestas teóricas anteriormente expuestas confirman que para que se dé un auténtico desarrollo territorial, este debe ser emprendido y apropiado por los actores que lo habitan; dichos actores, como artífices de su desarrollo, deben diseñar e implementar estrategias claras, consistentes y compartidas, soportadas en un juicioso análisis territorial que identifique los potenciales y las restricciones en cada una de las dimensiones del desarrollo, con el fin de constituir entornos territoriales que contribuyan al mejoramiento de la calidad de vida de la población. (DNP, s.f.).

Para lograr la participación de los diferentes actores en el desarrollo de los municipios, es necesario plantear lo que significa el desarrollo local, el cual se concibe, según Vásquez, citado por Carvajal (2009), como un conjunto de procesos económicos, sociales, culturales, políticos y territoriales a través de los cuales las comunidades, a partir de determinar sus potencialidades y las oportunidades que les ofrece, pueden acceder al bienestar, sin exclusiones que garanticen la participación de futuras generaciones. El acceso a lograr el bienestar depende de la concertación de las organizaciones sociales, gremiales y comunitarias con los entes municipales. (Carvajal, 2009, p. $60-$ $61)$.

Lo anterior se evidenció en la investigación, en las metodologías participativas utilizadas por la oficina de planeación para lograr la participación de toda la comunidad, al elaborar los diagnósticos para la formulación de los planes de desarrollo municipal. "Entendido entonces el desarrollo local como un proceso localizado de cambio social y de crecimiento económico sostenible, que tiene como finalidad el progreso permanente de la comunidad". (Carvajal, 2002, p.61).

\subsubsection{Participación}

Dentro de la investigación, se evidencia la importancia de la participación de la población en la elaboración de los planes de desarrollo; por lo tanto, es 
importante analizar los procesos participativos que se han dado en Colombia y que surgen a partir de la Constitución Política de 1991, donde se pasa de una democracia representativa a una democracia participativa; en la Constitución se formulan diferentes artículos referidos a la participación: el artículo $1^{\circ}$ afirma que Colombia es un Estado Social de Derecho, con autonomía de sus entidades territoriales, democrática, participativa y pluralista; en el artículo $2^{\circ}$ indica que uno de los fines esenciales del Estado es "facilitar la participación de todos en las decisiones que los afectan y en la vida económica, política, administrativa y cultural de la Nación"; el artículo 40 plantea que "Todo ciudadano tiene derecho a participar en la conformación, ejercicio y control del poder político"; el artículo 103 habla de los mecanismos de participación, los cuales posteriormente fueron reglamentados a través de la ley 134 de 1994 (ver anexo $\mathrm{N}^{\circ}$ 3) y otra serie de artículos correspondientes a la participación política y ciudadana.

Igualmente, es importante contemplar la participación de las comunidades y las diferentes organizaciones sociales y gremiales en la formulación de los planes de desarrollo, especialmente en la etapa de diagnóstico, donde se plantean las necesidades y problemas, a partir de los ejes contemplados en los planes de gobierno; dicha participación se da a partir de lo exigido por la ley 152 de 1994 (ver anexo $N^{\circ} 3$ ), que contempla en su artículo $3^{\circ}$, literal g, que habla de la participación. "Durante el proceso de discusión de los planes de desarrollo, las autoridades de planeación velarán porque se hagan efectivos los procedimientos de participación ciudadana".

Para Velásquez (2003), la participación es entendida como un proceso social que resulta de la acción intencionada de individuos y grupos en busca de metas específicas, en función de intereses diversos y en el contexto de tramas concretas de relaciones sociales y de poder. Es, en suma, un proceso en el que distintas fuerzas sociales, en función de sus respectivos intereses (de clase, de género, de generación), intervienen, directamente o por medio de sus 
representantes, en la marcha de la vida colectiva, con el fin de mantener, reformar o transformar los sistemas vigentes de organización social y política.

En este sentido, la participación es entendida como la intervención directa o indirecta de los distintos actores para definir las metas de acción de una colectividad y los medios para lograrlos. Es un proceso social que genera la interacción entre los diferentes actores, que involucra relaciones de poder, con una incidencia menor o mayor según las percepciones y los intereses de las colectividades. Es necesario tener en cuenta que las relaciones de poder conciben tensiones y conflictos que puede tener un efecto positivo o negativo en los procesos participativos. (González et al., 1995, p. 17).

Dos características marcan al sistema político colombiano desde la segunda mitad del siglo XX: el clientelismo y el autoritarismo del Estado para desestimular la protesta ciudadana, que se erigieron como ejes articuladores del sistema y, además el clientelismo se percibió como legítimos frente a las conductas políticas de gobernantes y gobernados. Sin embargo, las lógicas subyacentes a ambas prácticas se encargaron de crear las condiciones para su deslegitimación. (Velásquez et al., 2003, p. 4).

La respuesta de la ciudadanía fue diversa: de un lado, el abstencionismo de un porcentaje creciente de la población que no veía en las elecciones un instrumento favorable a sus intereses; de otro, el incremento de la protesta ciudadana ante la incapacidad del Estado de satisfacer las necesidades de la población y, finalmente, la intensificación del conflicto armado. El cierre institucional llevó al sistema a entrar en crisis y creó las condiciones propicias para su reforma. (Velásquez et al., 2003).

Como respuesta, se plantea la institucionalización de espacios de participación ciudadana, ligada a las políticas descentralizadoras de la década del 80 (Ley 11 de 1986), implicó un cambio radical en la arquitectura del 
sistema político: la gente podría intervenir directamente en la discusión de las políticas y programas gubernamentales en el nivel local, rompiendo el monopolio que las élites políticas (alcaldes y concejales) tenían sobre las decisiones públicas. (Velásquez et al., 2003, p. 4).

Los espacios de la participación se concretaron en la Carta Política de 1991, donde se consideró la participación como un componente esencial de la construcción de la democracia en Colombia; los desarrollo legislativos de la Constitución dan cuenta de los canales y mecanismos de la participación en los diferentes ámbitos de la vida nacional (González, 1995).

Según González (1995), "Es una forma de intervención social que le permite a los individuos reconocerse como actores que, al compartir una situación determinada, tiene la oportunidad de identificarse a partir de intereses, expectativas comunes y que están en capacidad de traducirlas en formas de actuación colectiva con cierta autonomía frente a otros actores sociales y políticos". (González, 1995, p. 17).

En el artículo 103 de la Constitución se establecen los mecanismos de participación del pueblo, en ejercicio de su soberanía: el voto, el plebiscito, el referendo, la consulta popular, el cabildo abierto, la iniciativa legislativa y la revocatoria del mandato, herramientas a través de los cuales los ciudadanos pueden proteger sus derechos de acuerdo con parámetros legales.

Posteriormente son reglamentados por medio de la ley 134 de 1994 y de los cuales los ciudadanos pueden hacer uso cuando consideren que están vulnerando sus derechos; pero igual, algunos pueden ser utilizados por los gobernantes a nivel municipal, regional o nacional para consultar asuntos de interés común para los ciudadanos y que se requiere la consulta de las personas para que se convierta en mandato popular, como en el caso de la consulta popular o del referendo. 


\section{a) Niveles de participación}

No todos los procesos participativos de los grupos, comunidades 0 poblaciones tienen el mismo alcance; cada uno va subiendo en una escala, comenzando por la información, hasta llegar al nivel más alto que es la gestión; por lo tanto, a medida que cada grupo muestra un progreso, el proceso de participación se hace más complejo y exigente, pues requiere que cada participante cumpla con unos requisitos y unas condiciones de diferente orden como conocimiento, experiencia, autonomía, liderazgo, capacidad de gestión y demostrar capacidad de convocatoria, identificación de estrategias y administración de recursos. (González, 1995, p. 19).

Para poder trabajar sobre los niveles de participación en los cuales se encuentra una población, se requiere crear una cultura democrática de la participación, que implica valores como la solidaridad, el respeto por la diferencia, la tolerancia y la participación. (González et al., 1995, p. 20).

A continuación presentamos la escala de la participación y a qué se refiere cada nivel.

1. Información: La comunidad se informa a través de hechos, datos y mensajes.

2. Consulta: La comunidad opina sobre todos o algunos aspectos de un problema o situación, sirve para tomar decisiones.

3. Iniciativa: La comunidad sugiere ideas para transformar o resolver un problema.

4. Fiscalización: La vigilancia que ejerce la comunidad sobre el cumplimiento de las acciones propuestas y las decisiones tomadas.

5. Concertación: Toda la comunidad acuerda trabajar sobre determinado problema y propone soluciones conjuntas y los medios para ejecutarlas.

6. Decisión: Adopción de la idea principal sobre un problema a partir de las alternativas de solución. 
7. Gestión: Manejo de un conjunto de recursos de diversa índole, destinados a ejecutar las acciones necesarias para obtener un resultado final, satisfacción de necesidades o solución de los problemas.

\section{b) Tipos de participación}

Hay diferentes tipos de participación, tanto en el ámbito de lo privado como en la esfera de lo público; los primeros corresponden a la participación social y comunitaria, y los segundo a la participación ciudadana y política.

Los tipos de participación permiten que los ciudadanos puedan organizarse para resolver sus necesidades y problemáticas o expresar sus opiniones frente a decisiones a nivel de asociación, comunitario y la elección de las personas que dirigirán los destinos del país.

Los tipos de participación comprenden:

- Participación Social: Proceso de agrupamiento de individuos en distintas organizaciones de la sociedad civil para la defensa y representación de sus respectivos intereses.

- Participación Comunitaria: Alude a las acciones ejecutadas colectivamente por los ciudadanos en la búsqueda de soluciones a las necesidades de su vida cotidiana.

- Participación Ciudadana: Intervención de los ciudadanos en la esfera pública en función de intereses sociales de carácter particular.

- Participación Política: Intervención de los ciudadanos para lograr materializar los intereses de una comunidad política: referendo, revocatoria del mandato, cabildo abierto, consulta popular, iniciativa popular. 


\section{CAPÍTULO IV. DISEÑO METODOLÓGICO}

El diseño metodológico se entiende como un "procedimiento ordenado que sigue para establecer lo significativo de los hechos y fenómenos hacia los cuales está encaminado el interés de la investigación; se refiere a la descripción de las unidades y las técnicas de análisis y de observación, recolección de datos, instrumentos y los procedimientos para el análisis" (Tamayo y Tamayo, 2002, p. 173).

También brinda los elementos necesarios para la sistematización y el análisis de los datos que se obtengan, a través de la utilización de diferentes técnicas empleadas para recopilar información de los municipios, que permiten identificar los procesos de planificación del desarrollo y que recursos utilizan para su diseño e implementación.

\subsection{Enfoque de la investigación}

La investigación se abordara desde un enfoque mixto entendido como un proceso que recolecta, analiza y vincula datos cuantitativos y cualitativos en un mismo estudio o una serie de investigaciones para responder a un planteamiento" (Creswell, citado por Gutiérrez, 2010); este enfoque permite obtener una mejor perspectiva del fenómeno, incrementando la confianza de los resultados, ayudando a clarificar el planteamiento del problema, así como las 
formas más apropiadas para ordenar y sistematizar las situaciones encontradas durante el proceso de la investigación.

La combinación de los dos enfoques aporta a la investigación datos desde diferentes perspectivas: el cualitativo contribuye a la investigación para identificar los procesos de planificación del desarrollo y evaluar los recursos con los que cuentan los municipios, en su diseño e implementación, ya que este enfoque busca ,conceptualizar sobre la realidad, con base en el comportamiento, los conocimientos, las actitudes y los valores que comparten los individuos en un determinado contexto espacial y temporal; esto implica que de manera inductiva pasa del dato observado a identificar los comportamientos de los otros y de la percepción que tiene el sujeto de su propio contexto (Bonilla, 1995, p. 47).

En cuanto al enfoque cuantitativo, se define como una "forma de aproximación sistemática al estudio de la realidad, se apoya en categorías numéricas y permite realizar el análisis de los fenómenos a través de diferentes formas de inter-relacionarse estadísticamente esas categorías", además, "usa los datos para probar hipótesis, con base en la medición numérica y el análisis estadístico para establecer patrones de comportamientos" (Hernández, 2008, p. 5). En este sentido, el enfoque cuantitativo permite realizar evaluación sobre los recursos utilizados por los municipios en el diseño y ejecución de los planes de desarrollo y hacer comparaciones entre los municipios de acuerdo con su clasificación. ( Carvajal, 1999, p. 37).

\subsection{Nivel de la investigación}

El alcance de esta investigación es descriptivo, ya que busca, a través de los seis estudios de caso, conocer, describir y caracterizar los procesos y recursos con que cuentan los municipios para elaborar sus planes de desarrollo cuatrienales, identificando y destacando sus aspectos diferenciadores y particulares. 
Según Deobold B. Van Dalen y William J. Meyer (2006), el objetivo de la investigación descriptiva consiste en llegar a conocer las situaciones, costumbres y actitudes predominantes a través de la descripción exacta de las actividades, objetos, procesos y personas.

Su meta no se limita a la recolección de datos, sino a la predicción e identificación de las relaciones que existen entre dos o más variables. (Van Dalen y Meyer, 2006).

\subsection{Tipo de investigación}

El tipo de investigación es estudio de caso, el cual se define como un determinado fenómeno ubicado en tiempo y espacio, abarcando cualquier problemática de la realidad social (Ragin, citado por Gialdino, 2006); en este sentido, el estudio de caso busca maximizar las posibilidades y las capacidades que las condiciones y característica del caso presentan para desarrollar conocimiento a partir de su estudio. La muestra es intencionada, en función de los intereses temáticos y conceptuales. Por lo tanto, el caso se define como un sistema, delimitado en el tiempo y, así mismo, de actores relaciones e instituciones sociales, donde se busca dar cuenta de las particularidades del fenómeno investigado. (Gialdino de Vasilachis, 2006, p. 219-220).

"El caso puede estar constituido por un hecho, un grupo, una relación, una organización, un proceso social, construido a partir de un determinado, y siempre subjetivo y parcial, recorte empírico y conceptual de la realidad social, que conforma un problema de investigación. Los estudios de caso tienden a focalizar, dadas sus características, en un número limitado de hechos y situaciones para abordarlos con la profundidad requerida para su comprensión holística y conceptual". (Dooley, citado por Gialdino, 2006). 
El estudio de caso se aplica en esta investigación, ya que el interés de la misma es realizar un estudio de los municipios, seleccionados de acuerdo con las diferentes categorías, establecidas en la ley 136 de 1994, de cinco municipios de Cundinamarca, donde se pretende conocer la forma como realizan los procesos de planificación del desarrollo.

Chetty (1996), citado por Páramo (2011), plantea que el estudio de caso puede ser de carácter descriptivo, si pretende identificar y caracterizar los distintos factores que ejercen influencia en el fenómeno estudiado; o explicativo si pretende conseguir un acarcamiento entre las teorías revisadas en el marco teórico y la realidad del fenómeno bajo estudio, con el fin de constrastarlas.

Para el caso de esta investigación, se utilizó el método de estudio de caso descriptivo, ya que pretendió conocer los procesos de adelantados en los municipios para la construcción de los planes de desarrollo, sus fortalezas, debilidades y aspectos significativos.

\subsection{Análisis documental}

La investigación fue de tipo documental, la cual "depende fundamentalmente de la información que se recoge o consulta en documentos, entendiéndose este término, en sentido amplio, como todo material de índole permanente, es decir, al que se puede acudir como fuente o referencia en cualquier momento o lugar, sin que se altere su naturaleza o sentido, para que aporte información o rinda cuentas de una realidad o acontecimiento". (Cazares, 1992, p.18, Citado por Baena y Gutiérrez, 2012).

Las fuentes documentales que se utilizaran en la investigación son los planes de desarrollo de los municipios, los presupuestos y los informes de gestión de los alcaldes. 
También se utilizó el método comparativo, con el fin de identificar similitudes y diferencias entre los procesos, planes de desarrollo y recursos de los municipios, teniendo en cuenta que este método generalmente "se aplica sobre todo allí donde los métodos estandarizados de las ciencias sociales no funcionan debido a lo específico del objeto a analizar, ya sea porque éste no puede ser examinado de manera experimental o porque el número de casos es tan escaso que no pueden utilizarse procedimientos estadísticos" (Nohlen, s.f., p. 8). Tal es el caso de los procesos adelantados en los municipios para la elaboración de los planes de desarrollo, en los que las particularidades de los municipios, definidas por la categoría a la que pertenecen, el contexto y la cultura social y política que lo caracteriza y el nivel de participación de la sociedad civil, así como los métodos utilizados para la consulta, hacen que cada uno sea particular y no fácilmente estandarizable.

\subsection{Técnicas}

Las técnicas seleccionadas para la recolección de la información fueron: registro de documentos y entrevista a profundidad.

\section{- Registro de la información}

Para el registro de la información se tuvo en cuenta los Centros de consulta como: Federación de Municipios, bibliotecas de instituciones de educación superior, centros de investigación de universidades y páginas web. Los tipos de documentos que se revisaron fueron: Planes de desarrolla, presupuestos e informes de Gestión del último cuatrienio 2008- 2011.

\section{- Entrevista a profundidad}

En el caso de esta la investigación, las entrevistas se realizaron a los jefes, asesores o directores de la Oficina de Planeación Municipal y a miembros de los Consejos Territoriales de Planeación, con el fin de conocer los procesos que realizan en los municipios para la elaboración de los planes de desarrollo, 
así como los recursos asignados y los que se utilizan para la implementación del plan.

\subsection{Muestra, desde la perspectiva teórica del estudio de caso}

El estudio de caso se presenta como una estrategia metodológica de investigación, orientada a la comprensión de un fenomeno social, de interés por su particularidad, con lo cual se busca posibilitar el fortalecemiento, crecimiento y desarrollo de teorías existentes o proponer nuevas para entender o explicar un fenómeno. (Páramo, 2011, p. 307).

En esta investigación se opto por el método de estudio de caso, por considerarlo el más pertinente para identificar las particularidades de los procesos de elaboración de los planes de desarrollo municipal, en municipios de Cundinamarca que se encuentren clasificados entre las categorias 3 a 6 , con el fin de identificar y analizar aquellos aspectos tenidos en cuenta para la formulación del plan de desarrollo y su posterior implementacion.

El estudio de caso se centra en el material e información suministrada por los entrevistados, en este caso, Secretarios de Planeación Municipal y miembros del Consejo Territrorial de Planeación, quienes se han considerado los actores más relevantes para dar cuenta del proceso vivido y los acontecimientos y estrategias que rodearon la construccion del plan de desarrollo municipal.

\subsection{Criterios teóricos para la selección de la muestra}

La muestra se seleccionó de acuerdo con la categoría de muestreo por conveniencia (Páramo, 2011, p. 39). Este tipo de muestreo es de tipo no probabilístico. Es una finalidada práctica; el investigador selecciona directamente a los individuos (en este caso, municipios) que más le conviene tomar, en busca de rápidez, facilidad y/o economía. Los resultados y 
conclusiones solo serán validos para los individuos seleccionados y no se podrán generalizar a la población.

Muestreo por cuotas (Páramo 2011, p. 39). Muestreo de tipo no probabilistico. Presupone un buen conocimiento de la forma como los individuos se encuentran naturalemente agrupados; es decir, asume que hay estratos en la población y que el investigador los conoce a la perfección. Asume que el investigador no se equivoca al asumir los estratos.

Con base en ese supuesto, el investigador toma individuos de la población de forma que los distintos segmentos estén representados en la muestra en las mismas proporciones que en la población. Dado que no hay ningun criterio de aleatoriedad, se toman los primeros encontrados que cumplan con las caracteristicas del estrato; es decir, se hace un muestreo por conveniencia en cada estrato.

Para este caso, lo referido a estratos se asimila a la clasificación de los municipios por catagorías, rigiéndose a los criterios contenidos en la Ley 1551 de 2012. El municipio se entiende como la entidad territorial fundamental de la división político administrativa del Estado, con autonomía política, fiscal y administrativa. Los municipios de Colombia se clasifican, atendiendo número de población, ingresos corrientes de libre destinación, importancia económica y situación geográfica y recursos fiscales como indicadores de condiciones socioeconómicas, dictan normas tendientes a modernizar la organización y el funcionamiento de los municipios.

El municipio es, dentro de los límites que le señalen la Constitución y la Ley y cuya finalidad es el bienestar general y el mejoramiento de la calidad de vida de la población en su respectivo territorio.

Cundinamarca cuenta con 116 municipios, de los cuales el $84,5 \%$ se 
encuentra clasificado en categoría 6; en categoría 5, el 2,6 \%; en categoria 4, el 1,7\%; en categoría 3, el 6,9\%; en catagoría 2, el 3,5\%; y en catagoria 1, el 0,8 $\%$. Bogotá representa la catagoria especial, único municipio con esta clasificación en el departamanto. Teniendo en cuenta la agrupación y aglutinamiento de los municipios en la diferentes catagorías, "se selecciona una muestra teórica, eligiendo los casos que probablemente puedan replicar o extender la teoría emergente, según lo que plantea Eisenhardt (1989), citado por Páramo (2011, p. 312).

El Departamento de Cundinamarca, localizado en la región central de Colombia, está conformado por 116 municipios y la ciudad de Bogotá, Distrito Capital. Los municipios están distribuidos en 15 provincias a saber: Almeidas, Alto Magdalena, Bajo Magdalena, Gualivá, Guavio, Magdalena Centro, Medina, Oriente, Rionegro, Sabana Centro, Sabana Occidente, Soacha, Sumapaz, Tequendama y Ubaté. Tiene una extensión territorial de 24.210 km2.

De acuerdo con los resultados del Censo general de 2005, Cundinamarca, sin incluir a la ciudad de Bogotá, D.C, es el cuarto departamento en población de Colombia con 2'340.894 habitantes. Las provincias con mayor población en Cundinamarca son: Soacha (398.298 habitantes), Sabana Centro (381.209 habitantes), Sabana Occidente (327.062 habitantes) y Sumapaz (181.204 habitantes).

Los municipios del Departamento de Cundinamarca se clasifican en 6 categorías de la siguiente manera.

CUADRO 1

CATEGORIZACIÓN DE LOS MUNICIPIOS

\begin{tabular}{|c|c|c|}
\hline Categoría & Cantidad municipios por categoría & Porcentaje \\
\hline 1 & 1 & 0,8 \\
\hline 2 & 4 & 3,5 \\
\hline 3 & 8 & 6,9 \\
\hline
\end{tabular}




\begin{tabular}{|c|c|c|}
\hline 4 & 2 & 1,7 \\
\hline 5 & 3 & 2,6 \\
\hline 6 & 98 & 84,5 \\
\hline total & 116 & 100 \\
\hline
\end{tabular}

Fuente: Contaduría General de la Nación (2014),

Los municipios se seleccionaron de acuerdo con los siguientes criterios:

1. Se tomaron cuatro municipios de Cundinamarca, de las categorías 6 y 5 , debido a que representan el $87.1 \%$, de los municipios del departamento con menor población y por lo tanto bajo presupuesto, lo que hace suponer que tienen menos recursos para invertir en el desarrollo territorial y focalizan sus recursos en la satisfacción de necesidades básicas y la implementación de Políticas Públicas del orden nacional.

2. De las categorías 3 y 4 , aunque son una minoría significativa ( $8.6 \%$ ), se seleccionaron dos municipios, uno de cada una, con el fin de valor si las diferencias en recursos, población y necesidades, inciden en el diseño y procesos de elaboración del plan de desarrollo municipal y en la capacidad de gestión y la inclusión de líneas de acción (ejes y programas) que sean propias para las necesidades particulares del territorio.

3. Se seleccionaron los municipios de Facatativá, Subachoque, Gachancipá, Sibaté, La Calera y Sopó, en el Departamento de Cundinamarca, por ser representativos de las categorías escogidas; además, por su ubicación geográfica, facilidad de acceso y posibilidades de entrevistar a los jefes de planeación o funcionarios participantes en la elaboración e implementación del plan de desarrollo municipal.

\subsection{Categorías de análisis}

Para la definición de la categoría de análisis, las subcategorías y los indicadores, se tuvo en cuenta los componentes macro que transversa la 
planeación local, como los procesos y aspectos que están asociados a la descentralización, la participación, la gestión y los recursos. El Plan de desarrollo municipal es un instrumento por medio del cual los municipios definen la ruta y los medios para realizar el grana anhelo que es el Desarrollo Humano integral y territorial de su municipio.

\section{CUADRO 2}

\section{CATEGORÍA Y SUBCATEGORÍAS}

\begin{tabular}{|c|c|c|c|}
\hline C & SUBCATEGORÍA & & INDICADOR \\
\hline \multirow{5}{*}{$\begin{array}{l}z \\
\frac{2}{0} \\
\frac{1}{4} \\
\frac{\mathbf{u}}{\mathbf{\alpha}}\end{array}$} & \multirow[t]{2}{*}{ Participación } & Tipos y formas & $\begin{array}{c}\text { Social, comunitaria, ciudadana, política. } \\
\text { Directa o indirecta, formal e informal, real o } \\
\text { aparente }\end{array}$ \\
\hline & & Niveles & $\begin{array}{c}\text { Información, consulta, iniciativa fiscalización, } \\
\text { concertación, decisión y gestión }\end{array}$ \\
\hline & \multirow[b]{2}{*}{ Gestión } & Agendas políticas & Prioridades, alianzas y sinergias \\
\hline & & $\begin{array}{l}\text { Planificación y } \\
\text { manejo del proceso e } \\
\text { implementación }\end{array}$ & $\begin{array}{l}\text { - Estructura administrativa } \\
\text { Metodología y procesos de la planificación } \\
\text { para el desarrollo }\end{array}$ \\
\hline & Recursos & $\begin{array}{l}\text { Talento humano } \\
\text { Humanos } \\
\text { Técnicos } \\
\text { Infraestructura para } \\
\text { seguimiento del plan }\end{array}$ & $\begin{array}{l}\text { Estrategias administrativas, recursos humanos, } \\
\text { materiales, económicos, técnicos y tecnológicos }\end{array}$ \\
\hline
\end{tabular}


Con base en la categoría definida, las subcategorías con las cuales se caracteriza y las variables establecidas para el análisis de los resultados, se elaboraron los cuadros y gráficos que reflejan la información sistematizada, a partir de lo recogido en las entrevistas, por medio de la observación y consulta de fuentes secundarías, que se presenta en el capítulo V.

\section{CAPÍTULO V. RESULTADOS DE LA INVESTIGACIÓN}

En este capítulo se presenta el análisis de la información obtenida por medio de entrevistas a profundidad, realizadas a jefes de planeación municipal y/o funcionarios vinculados a las alcaldías de Subachoque, Facatativá, Sibaté, Gachancipá, La Calera, Sopó; la observación de la dinámica de los municipios, la revisión de los planes de desarrollo local, aplicación de instrumentos elaborados para tal fin por el Departamento Nacional de Planeación de Colombia (DNP), la caracterización de los municipios, registrada en las páginas WEB, y datos elaborados por el DANE y otras instituciones del orden nacional..

Con este estudio se buscó conocer y describir los procesos de planeación municipal e identificar los aspectos relevantes que se evidencian en los planes de desarrollo de seis municipios representativos del ordenamiento territorial del departamento de Cundinamarca e identificar las fortalezas, debilidades, logros, dificultades y los recursos con los que cuentan los municipios para el diseño e implementación de los Planes de Desarrollo para el periodo 2012-2015. 
Los estudios de caso realizados, permitieron adentrase en las dinámicas institucionales y conocer cómo se aplicó lo ordenado a los entes territoriales (municipios) por la Ley 152 de 1.994, cual define el Plan de Desarrollo Municipal (PDM), como la "carta de navegación para el desarrollo integral de las Entidades Territoriales" y considera que a través de este se materializa el programa del gobierno propuesto como estrategia para el desarrollo local.

Para el análisis de los resultados se retoman elementos del Plan de Gobierno, el PDM, La ley 152 de 1994 y los lineamientos e instrumentos elaborados por el Departamento Nacional de Planeación ${ }^{1}$ para orientar, acompañar y evaluar el proceso de construcción de los Planes de desarrollo de las entidades territoriales, las guías y matrices de evaluación, y se retomaron algunos aspectos incluidos en el Capítulo II, con el fin de contextualizar la descripción de los procesos en el marco de las características básicas de los municipios.

Con la Constitución Política de Colombia de 1991 se incorporó el tema de la planeación en su Capítulo 2, artículo 339 del Título XII, Las entidades territoriales elaborarán y adoptarán de manera concertada entre ellas y el gobierno nacional, planes de desarrollo, con el objeto de asegurar el uso eficiente de sus recursos y el desempeño adecuado de las funciones que les hayan sido asignadas por la Constitución y la ley. Los planes de las entidades territoriales

${ }^{1}$ Según el documento elaborado por la Dirección de Desarrollo Territorial Sostenible, el Grupo de Estudios Territoriales denominado Evaluación del desempeño Integral de los municipios y Distritos, vigencia 2, en los instrumentos del DNP utilizados para evaluar los planes de desarrollo y el desempeño integral de los municipios, las calificaciones mayores de 80 hasta 100 , consideradas sobresalientes, corresponden a los municipios de mejor desempeño, que cumplen lo establecido en sus planes de desarrollo, consiguen la mayor cantidad de bienes y servicios en relación con los insumos que utilizan, cumplen a cabalidad lo estipulado en la Ley 715 de 2001 en cuanto a la ejecución de los recursos del Sistema General de Participación y tienen una alta capacidad de gestión administrativa y fiscal. Evaluación del desempeño integral

de los municipios y distritos, vigencia 2013. DNP (2014). 
estarán conformados por una parte estratégica y un plan de inversiones de mediano y corto plazo. (República de Colombia, 1991).

Teniendo como derrotero lo contemplado en la Constitución de 1991 y las directivas del Departamento Nacional de Planeación (DNP) en cuanto a la planeación territorial, se presenta a continuación lo observado, en términos generales, sobre los procesos de planeación realizados en los seis municipios estudiados, los resultados de la evaluación de cada uno de los planes elaborada a través de los instrumentos diseñados por el DNP para tal fin (se anexan las matrices de los evaluación de los municipios) y la descripción de los procesos y las fortalezas y debilidades encontradas en cada municipio. En el numeral 5.2 se realiza el análisis comparativo y se evidencian los factores diferenciadores entre ellos y su relación con la categoría en la que se encuentran clasificados.

\subsection{Análisis de casos}

En este aparte se hace una descripción de los procesos adelantados en cada uno de los municipios para la elaboración de los Planes de Desarrollo Municipales (PDM) y se identifican los aspectos relevantes, las fortalezas y debilidades que se hacen evidentes en las entrevistas y los datos obtenidos con el diligenciamiento de los formatos, en los que se recogió información relacionada con recursos, actividades y condiciones de infraestructura de los municipios.

\subsubsection{Facatativá}

El municipio de Facatativá (categoría 3), se ha convertido en polo de desarrollo del departamento de Cundinamarca, en un centro de servicios regional y sitio de producción y suministro de alimentos, con una economía conformada por los sectores primario, secundario y terciario por su cercanía a Bogotá.

En mayo de 2012, Concejo Municipal de Facatativá aprobó la adopción del Plan de Desarrollo Económico, Social, Ambiental y de Obras Públicas 
“Todos Somos Facatativá 2012-2015", como carta de navegación e instrumento de gestión que organiza, regula y orienta el cumplimiento del Programa de Gobierno "La gerencia del cambio," proceso de construcción que se realizó de manera concertada entre la comunidad y la Administración Municipal, en concordancia con los lineamientos Departamentales y Nacionales, en el cual se concibe al ser humano como el verdadero motor de desarrollo.

El documento resultante es producto del trabajo comunitario; se estructuró desde la gente y con la gente, objetivo central y propósito principal del señor alcalde Orlando Buitrago y su equipo de gobierno. Para la Administración Municipal, el insumo fundamental para la formulación de esta guía orientadora fue el sentimiento de la población, la cual suministró información primaria, mediante su opinión libre y espontánea entorno a su realidad, a su cultura, a sus necesidades, a sus sueños y expectativas de acción política.

Una fortaleza evidente en este proceso es la efectiva participación pública en veinticinco (25) mesas de diálogo y concertación, y los 16 encuentros temáticos en los que se convocó a expertos e interesados en temas como: Institucional, adulto mayor, salud, movilidad y transporte, cultura, deporte y jóvenes, vivienda, infraestructura y equipamiento, niños, niñas, mujer y género, población en condición de discapacidad y espacio público, educación, servicios públicos, población vulnerable, desplazamiento y etnia, banca, empresarios, comerciantes, turismo, seguridad, convivencia y participación ciudadana, tecnología e innovación con cuyos aportes maduraron las tesis de desarrollo y líneas de acción contenidas en el documento.

De la misma manera, se realizaron 9 jornadas generales para determinar necesidades y propuestas ciudadanas en el sector urbano y rural, producto de lo cual se determina la agenda estratégica de mencionado Plan. 
De otro lado, la Visión del Plan de Desarrollo proyecta que, en el año 2025, Facatativá será una ciudad contemporánea, segura y amable; posicionada como referente de alto significado histórico y cultural; con una sociedad del conocimiento que avanza en armonía ambiental, para asegurar la sostenibilidad de las generaciones venideras. Se consolidará como polo de desarrollo regional, en proceso de internacionalización, conforme a la importancia geoestratégica que representa para Bogotá D.C. y el centro del país. (Municipio de Facatativá, 2012).

Entre tanto, la misión institucional busca el compromiso de liderar un proceso de administración colectivo, incluyente y gerencial, poniendo en marcha políticas públicas eficientes que aseguren la democracia participativa y propicien las condiciones adecuadas para el desarrollo integral de la población.

A su turno el objetivo general del PDM tiene como propósito mejorar la calidad de vida de los habitantes de Facatativá, transformando positivamente sus condiciones actuales, mediante la puesta en marcha de alternativas de solución y de acuerdo a las potencialidades de la persona y del territorio, la competitividad local y los factores diferenciales. (Municipio de Facatativá, 2012).

La estructura de este plan de desarrollo es coherente con el plan de gobierno y se articula en torno a cinco (5) ejes básicos como son:
I. Nuestro Desarrollo Social
II. Facatativá Destino de Inversión
III. Territorio Sostenible
IV. Gobernabilidad Democrática
V. Tecnología e Innovación

\section{- El Proceso}

El proceso de elaboración del PDM se inicia según lo establece la ley 152 de 1994, con la conformación del equipo compuesto por el Alcalde y los Secretarios del Despacho, orientados por el Secretario de Planeación, quién 
recibió capacitación por parte de la Gobernación de Cundinamarca, ya que, según él, "Planeación Nacional asesora más a los municipios pequeños que no cuentan con presupuesto para pagar asesores." (Entrevista, febrero 2014).

Como estrategia para la formulación del diagnóstico, se convocó a la comunidad a través de perifoneo, volantes, cuñas radiales, se utilizaron pasacalles, para tratar de convocar a la mayor cantidad de gente, y lograr la participación de las diferentes organizaciones, sectores y grupos poblacionales.

En la entrevista realizada con el jefe de planeación, detalló el proceso adelantado:

Ese Plan de Desarrollo, pues como lo establece la Ley, se basa en el plan de gobierno que el Alcalde inscribe en la Registraduría; la primera etapa consistió en una labores, o mejor en unas mesas de concertación que se hicieron que eran de dos tipos, unas mesas de concertación ciudadanas que era de acuerdo... digamos el Municipio está dividido en unas áreas funcionales que agrupan varios barrios que serían unas mesas en esas áreas funcionales, pues una por día obviamente, en la que... de acuerdo con la mesa, pues se congregaban una cantidad determinada de barrios y otras mesas que eran, digamos, especializadas que eran por ejemplo del sector educativo, entonces se convocaban a todos los rectores, a los representantes de los estudiantes, padres de familia; otra era salud, entonces se convocaba a las EPS, IPS, exacto; una mesa de infraestructura, entonces a los arquitectos, ingenieros del Municipio; otra mesa de transporte, entonces una serie de mesas especializadas que esas sí se hacían, inclusive, dos por día dependiendo del trabajo.

La metodología utilizada en cada mesa las personas planteaba un problema y a este planteaban las diferentes soluciones, cada uno se ubicaba de acuerdo con los 5 ejes formulados, luego las mesas se 
subdividían en las diferentes problemáticas e intereses de la comunidad, al final se establecía unas relatorías por cada mesa y las conclusiones.

Para desarrollar el diagnóstico se contrató una empresa asesora de Bogotá, con la cual el Alcalde y su equipo concertaron sobre el trabajo a realizar, pero la empresa fue quién implementó la metodología y dirigieron los talleres con la comunidad. Toda esa información se tabuló, se organizó, se determinó como era las prioridades... Y ellos entregaban tabulaban y sistematizaban y entregaban el resultado... Los primeros borradores del documento. (Entrevista, 2014).

Finalizada la etapa de diagnóstico, la empresa asesora realizó la priorización de las problemáticas y determinó, junto con el equipo de gobierno, en cabeza del Alcalde, las estrategias requeridas para responder a las peticiones surgidas de la consulta y definir cuáles son financiera, técnica y legalmente viables. Una vez se realizó el filtro, se inició la construcción del PDM, definiendo ejes, programas, metas e indicadores, armonizándolos con los recursos de los cuales se dispone para los cuatro años.

Después de elaborado el documento del PDM, se presentó ante el Consejo Territorial de planeación para sus observaciones, según lo establecido en la ley 152 de 1994 en su artículo 39 y 40, para su posterior presentación al Consejo Municipal para su discusión y aprobación.

Con base en el PDM aprobado, cada una de las Secretarías del Despacho se hizo responsable de los componentes a su cargo, de acuerdo con el eje y sector que les compete. Como se puede apreciar, el proceso se cumplió con la sistematicidad que exige la Ley 152 de 1994, destacándose el componente participativo y la consulta a la comunidad. 
Para la implementación, la alcaldía de Facatativá estableció cronograma, con los plazos para entregar los planes indicativos, los planes de acción y las estrategias según los ejes. Por lo expresado en la entrevista, se percibe que la mayor dificultad está en la articulación entre secretarías, ya que cada una tiene autonomía para definir su modelo de gestión y la alcaldía no cuenta con un sistema de información municipal que le permita visualizar, en tiempo presente, las acciones y la dinámica de la implementación del PDM.

Para el seguimiento y el monitoreo, en el documento se plantean algunas estrategias como: El plan indicativo, El Plan de acción y El Plan Operativo Anual de Inversiones, lo cual se espera permita hacer un efectivo control y seguimiento a la gestión realizada por la administración municipal durante los próximos cuatro años. (Municipio de Facatativá, 2012, p. 201).

Desde la perspectiva de control y monitoreo comunitario, la administración municipal se compromete en el PDM a establecer los mecanismos para la divulgación e información a la ciudadanía, a través de los diferentes medios de comunicación y con jornadas informativas sectoriales. Según el Secretario de Planeación, la alcaldía utiliza "la matriz de seguimiento del SICEP (Aplicativo para reportar la información requerida en la evaluación de la gestión y resultados de los municipios), que es como el documento o la metodología que establece el DNP, en la cual están todas las metas y los recursos asignados, programados, ejecutados, la fuentes de financiación y el cumplimiento físico de la meta, brindando un panorama general que permite hacer seguimiento a la inversión" (Entrevista, febrero 2014).

Con el fin de tener un referente técnico de la calidad del Plan de Desarrollo de Facatativá, se diligenció una versión ejecutiva de la matriz del DNP para evaluar el cumplimiento de los requisitos, principios y características que, según la Ley 152 de 1994, deben tener los planes de desarrollo; está versión fue utilizada en ejercicios del curso Instrumentos de planeación en 
Colombia de la Maestría en planeación para el desarrollo de la Universidad Santo Tomás. - Como resultado del diligenciamiento de este instrumento, se observa que el Plan de Desarrollo de Facatativá obtiene una alta calificación, de $92 \%$ en su conjunto, discriminada de la siguiente manera, según la ponderación otorgada a cada componente: $17 \%$ de la calificación corresponde a la conformación del plan de desarrollo, un $38 \%$ a los principios y un $37 \%$ a características del Plan.

Una vez analizado y evaluado el proceso adelantado en Facatativá para la formulación y ejecución del plan de desarrollo, se pudo identificar como aspectos significativos del PDM la estructura del plan, ya que cumple los parámetros establecidos por Planeación Nacional; además, contextualiza al inicio del documento la situación del municipio en cada uno de los sectores, plantea la metodología utilizada para la elaboración del diagnóstico, la situación deseada y la visión del desarrollo. Cumple con aspectos fundamentales de la planeación estratégica, como son la misión, la visión, los objetivos, los principios, los valores, lineamientos de la política, estrategias para el desarrollo, los fundamentos del plan, su estructura y acciones para cada eje y sector.

Se visualiza una prospectiva a largo plazo y la proyección que pretende alcanzar el municipio por su ubicación estratégica.

Otro aspecto relevante es el referente al plan plurianual de inversión, en el que se especifica que Secretaria le corresponde cada eje y sector y los programas a ejecutar; sin embargo, no especifica en cada eje y sector cómo se distribuyen los recursos propios libres, los del sistema general de regalías y otros a los que tengan acceso.

Como debilidades se observaron: la no explicitación de la armonización del PDM con el Plan departamental y nacional; no se evidencia la articulación con las políticas públicas del nivel nacional 
Aparentemente la contratación de la empresa que asesoró la elaboración del PDM, disminuyó el nivel de participación activa del equipo de gobierno y la motivación para participar en las capacitaciones ofrecidas a los municipios por el departamento de Cundinamarca sobre la formulación del plan de desarrollo.

En la evaluación del desempeño integral de los municipios y distritos, vigencia 2013, realizada por el DNP (2014), que mide los componentes de eficacia y gestión administrativa y fiscal, entre otros aspectos, Facatativá se destacó por sus resultados sobresalientes obteniendo un $91,2 \%$ en el indicador de desempeño integral, lo que demuestra el compromiso de su alcalde y equipo de gobierno y que la visión y estrategias de desarrollo que se han planteado se están realizando a cabalidad. Las oportunidades y amenazas que se encuentran en el entorno, por su cercanía a Bogotá, la industrialización del campo y el crecimiento demográfico, son retos que el gobierno municipal está enfrentando, apoyado en su efectivo PDM. Los recursos con que cuenta este municipio para la gestión e implementación del plan se presentan de manera sintética en el siguiente cuadro.

\section{CUADRO 3}

\section{CARACTARÍSTICAS Y RECURSOS}

\begin{tabular}{|c|c|c|c|c|}
\hline ÍTEM & MUNICIPIOS & \multicolumn{3}{|c|}{ FACATATIVÁ } \\
\hline 1 & Categoría & & & 3 \\
\hline 2 & Tamaño en Km2 & & & 158 \\
\hline \multirow[t]{2}{*}{3} & Número de habitantes & Zona & Urbana & 112,269 \\
\hline & & & Rural & 12,51 \\
\hline 4 & $\begin{array}{l}\text { Presupuesto anual en } \\
\text { millones de pesos }\end{array}$ & & & 76.000 \\
\hline \multirow[t]{10}{*}{5} & \multirow{10}{*}{ Infraestructura } & \multirow{2}{*}{ Servicios públicos } & Domiciliarios & 1 \\
\hline & & & Veredales & 0,6 \\
\hline & & \multirow{3}{*}{ Servicios de salud } & Hospitales & 1 \\
\hline & & & Clínicas & 1 \\
\hline & & & Puestos salud & 1 \\
\hline & & \multirow{3}{*}{ Servicios educativos } & Colegios & 1 \\
\hline & & & Escuelas & 1 \\
\hline & & & Universidades (sedes) & 1 \\
\hline & & \multirow{2}{*}{ Servicios Transporte } & Municipal & 1 \\
\hline & & & Intermunicipal & 1 \\
\hline
\end{tabular}




\begin{tabular}{|c|c|c|c|}
\hline \multirow{11}{*}{1} & Servicios bancarios & & 1 \\
\hline & \multirow{5}{*}{$\begin{array}{l}\text { Espacios culturales y } \\
\text { recreativos }\end{array}$} & Casa cultura & 1 \\
\hline & & Teatros & 1 \\
\hline & & Parques públicos & 1 \\
\hline & & Cines & 1 \\
\hline & & Polideportivos & 1 \\
\hline & \multirow{5}{*}{ Entidades varias } & Bombero & 1 \\
\hline & & Estación policía & 1 \\
\hline & & Registraduría & 1 \\
\hline & & Hoteles & 1 \\
\hline & & Iglesias & 1 \\
\hline & Recursos & humanos & 0.8 \\
\hline & & $\begin{array}{l}\text { Tecnológicos y } \\
\text { conectividad }\end{array}$ & 0.5 \\
\hline $\begin{array}{l}\text { TOTALES POR } \\
\text { MUNICIPIO: }\end{array}$ & & & $(95 \%)^{2}$ \\
\hline
\end{tabular}

El municipio de Facatativá cuenta con recursos de infraestructura y humanos importantes que dan soporte a su gestión administrativa y social; sin embargo, su cercanía a Bogotá, el crecimiento demográfico y las problemáticas sociales que aquejan a la población impactan negativamente sobre la disponibilidad de recursos y sobre todo en el uso eficiente de estos; la mayor debilidad se encuentra en la escases de recursos tecnológicos para el apoyo a la gestión, seguimiento y evaluación del PDM.

\subsubsection{Sopó}

La dinámica territorial que se percibe en Sopó está básicamente impulsada por la agroindustria, especialmente la de derivados de lácteos, su principal actividad económica, y la de algunos sectores industriales dedicados a la producción de bienes para la construcción y la fabricación de fósforo. Así mismo, cuenta con actividades comerciales, de servicio y financieras.

${ }^{2}$ El promedio se obtiene de la división de la calificación sobre 23 aspectos calificados, datos que permiten constatar la disponibilidad de recursos con que cuenta el municipio para la implementación y gestión del PDM, factor que permite identificar fortalezas y debilidades en cuanto a recursos se refiere. 
Por su topografía y ubicación cerca a Bogotá, Sopó ha tenido una gran transformación de su territorio debido a la industrialización y urbanización del campo, a través del fraccionamiento de la tierra en condominios para estratos socioeconómicos 5 y 6 procedentes de Bogotá y la migración desde los departamentos y municipios vecinos hacia el centro urbano.

Este municipio hace parte de la Provincia de la Sabana Centro y está catalogado como municipio categoría tres (3), logrando consolidar su gestión administrativa, social y su proyección como polo de desarrollo del norte del departamento de Cundinamarca, volcando su proyecto político para el periodo 2012-2015 con un enfoque poblacional basado en el fortalecimiento de la participación, propiciando la equidad, el bienestar y el Desarrollo Humano integral.

Por medio del acuerdo Municipal No. 011 del 31 de mayo de 2012, se adoptó el Plan de Desarrollo del Municipio "Sopó lo construimos todos", el cual se orienta a la construcción de la visión de corto plazo que se proponen y en dar respuesta a las necesidades de la comunidad y los mandatos del gobierno departamental y nacional.

En la visión del municipio se platea "Ser en el año 2016 un municipio más equitativo, reconocido a nivel regional, nacional e internacional por su nivel de Desarrollo Humano Integral satisfactorio, concebido a través de la participación comunitaria activa, la creación de un modelo socioeconómico que permita la generación de oportunidades para todos y garantice el equilibrio entre la oferta y demanda de bienes y servicios ambientales, y un profundo sentido de corresponsabilidad que incluya a todos los sectores económicos, urbanos y rurales en la consolidación de pactos colectivos, que direccionen el desarrollo comunitario hacia un proceso de construcción y transformación positivo, sostenible en el largo plazo. (Municipio de Sopó, 2012, p. 6).

La visión muestra el modelo de desarrollo que pretende el plan, como es el desarrollo humano integral y poder ser reconocido a nivel regional, nacional e 
internacional; su vocación está orientada hacia los bienes y servicios ambientales.

Para la realización del plan, se presenta la estructura propuesta por el Alcalde, el cual es coherente con el plan de gobierno y está centrada en los ejes, líneas, pilares y objetivos. Los ejes son: Mejoramiento Institucional, Progreso y ejercicio de los derechos, Hábitat, Convivencia y Seguridad.

Para la elaboración del plan se inició, según lo establece la ley 152 de 1994, con la conformación del equipo compuesto por el Alcalde y los secretarios del despacho, se formuló el diagnóstico, con la participación de los diferentes grupos poblacionales y los diversos sectores del municipio.

La secretaría en el municipio se denomina Secretaria de Gestión Integral, quien lidero el diagnóstico, utilizando diferentes metodologías, de acuerdo con lo expuesto por el Secretario. Para el con población adulta, se utilizó cartografía social. Se llevó los mapas en blanco a las comunidades, se acompañó a cada una de las comunidades y se les dijo, sobre en el papel, planteen sus problemas y dificultades.

Entonces la población se ubica mucho más fácil sobre un mapa...

Entonces, ah aquí es la quebrada, aquí hay un problema de contaminación, en el paradero del bus, hay unos niños se sientan a fumar mariguana, el jardín infantil se quedó pequeño, aquí no hay alumbrado público, sobre el mismo mapa. Posterior a eso, hicimos un ejercicio de agruparlo por grandes temas y se hizo un ejercicio de priorización con la comunidad. Entonces llevamos unas carteleras donde esta lo que identificaron, en cada una de sus comunidades de acuerdo a los ejes que íbamos a manejar en el plan de desarrollo. Un eje de mejoramiento institucional, un segundo eje de progreso social y ejercicio de derecho, un tercer eje de hábitat y un cuarto eje de convivencia y seguridad. Así está ubicado en nuestro plan de desarrollo. Entonces llevamos eso, y a cada persona le dimos un papelito rojo, un papelito amarillo y un papelito verde. El rojo es lo más urgente, el amarillo es urgente, pero puede esperar; y el verde, si no se hace, no hay problema. (Entrevista, febrero de 2014).

Con la población de los niños y jóvenes la metodología que se utilizo fue Entonces, sobre... con ese mismo ejercicio priorizaron y con esa priorización nosotros priorizamos en nuestro plan de desarrollo, así tal 
cual se hizo el plan de desarrollo. $Y$ con los niños se hizo un ejercicio más bonito. Nosotros participamos en un premio que se llama construyendo sueños, que lo hacía el PNUD lo hacía el ICBF y quedamos de segundos en nuestra categoría. Nosotros hicimos un ejercicio muy bonito con los niños que era... o con los más pequeñitos hicimos un mapa de Sopó de grande como esta oficina tal vez, con lo más representativo. El Hospital, el colegio, el coliseo, las vías y les dábamos a los niños unas monedas y les decíamos: ustedes cómo invertirían esa plata si ustedes fuesen el Alcalde, ustedes fuesen quienes decidieran, donde lo invertirían. Entonces los niños se subían descalzos, entonces... a mí me gustaría poner tres monedas en la casa de la cultura porque a mí me gustan los programas que hacen y me gustaría que se fortalecieran; yo podría una moneda en el coliseo porque entiendo que los deportes son fundamentales para nosotros, y uno en el Hospital, y así se hizo el ejercicio. (Entrevista, febrero 2014).

Con la entrevista se pudo dilucidar que el municipio utilizo metodologías y estrategias innovadoras, propició la participación de la población y comprometió a su equipo de gobierno con el trabajo comunitario y social, que se reflejó en el diagnóstico y los aportes de la ciudadanía para la elaboración de los contenidos del PDM.

La sistematización de la información la realizó el mismo equipo, con el apoyo de un geógrafo, quien utilizó la iconografía, con el fin de asociar varias dificultades; con esta información, se elaboró el plan de desarrollo, incluido el plan de acción y el presupuesto. Algo que se planteó por parte del Secretario de Gestión Integral, fue la dificultad para la construcción de indicadores; en este tema tuvieron asesoría de un asesor externo, denominado Sinergia.

Una vez recogido el diagnóstico y elaborado el plan de desarrollo, se procedió a presentar ante el Consejo de Territorial de Planeación, el 28 de febrero de 2012, para el respectivo análisis y discusión, y la formulación de recomendaciones; al realizar los ajustes, se presentó ante el Consejo Municipal, para su aprobación. 
En cuanto a la ejecución del plan de desarrollo, el Secretario de Gestión Integral, plantea cómo se inicia la puesta en marcha del plan.

Nuestro plan de desarrollo fue aprobado el 31 de mayo, mientras surten todos los efectos de sanción, va la gobernación, resuelven la sanción jurídica, vuelve, se armoniza el presupuesto, porque tocaba organizar el presupuesto que nos habían dejado con el que nosotros queríamos. Entonces muchas metas que estaban para el primer año, no se cumplieron. De eso que las metas para el primer año fue del sesenta y tres por ciento, eso nos castigó en el índice de desempeño integral con el que nos mide el Departamento Nacional de Planeación. Pero pues de eso aprendimos. Nosotros hemos sido muy metódicos en todo el proceso de la planeación, en sacar unos estudios y diseños ya muy ajustados con presupuestos para después no incurrir en sobrecostos. Entonces, eso toma tiempo. (Entrevista, febrero 2014).

Para la evaluación del plan se utilizó una estrategia por parte del municipio, denominada Consejos Sectoriales, donde se visitaron las veredas y se les presentó la cartografía que se realizó con la participación de ellos cuando se formuló el diagnóstico; frente a esto, se les presentaron los avances en la ejecución. Entonces, el acercamiento a la comunidad fue a través de los concejos, en un espacio técnico, de discusión, de diálogo. Para el seguimiento al plan se utilizó una estrategia denominada tablero de control, donde se realizó un seguimiento al cumplimiento de las metas e indicadores.

Realizada la evaluación del plan de desarrollo a través del instrumento "Una aproximación a su estructura y contenidos", trabajado en la clase de Planeación, sugerido por el docente, la estructura y contenido del Plan de Desarrollo de Sopó obtuvo una calificación del $87 \%$, representada en un $16 \%$ en la conformación del plan de desarrollo, un $35 \%$ en los principios del plan, en un $36 \%$ en las características del Plan.

De acuerdo con la evaluación realizada al proceso de formulación y ejecución del plan de desarrollo, se destacan, como aspectos significativos, la estructura del plan, la articulación con el nivel departamental y nacional, así como la integración de los ejes y los objetivos del milenio, y las metodologías 
utilizadas con cada población, para la elaboración del diagnóstico, aun cuando en el documento no se plantea como tal. En el plan plurianual se establece para cada año la asignación de recursos para cada línea estratégica

Con respecto a las debilidades, está relacionado con la presentación del diagnóstico en el documento, solo en el plan de acción se mención a algo de la línea base. Se considera que la visión del municipio es a corto plazo, lo que hace que no se dimensione un mayor desarrollo del municipio. Cuando se hizo la evaluación por parte de Planeación Nacional, se hizo necesario realizar ajustes en el artículo 9, relacionado con la estructura programática del plan de desarrollo.

En la Evaluación del desempeño integral de los municipios y distritos, vigencia 2013 realizada por el DNP (2014), Sopó ocupo el puesto 9 con un puntaje del $88.4 \%$, dato muy significativo, pues su desempeño en la gestión administrativa denota el trabajo organizado y transparente, y los avances obtenidos en la gestión del PDM. Lo anterior se corresponde con la información sistematizada, obtenida sobre las características, infraestructura y recursos con que cuenta el municipio para la implementación del PDM.

CUADRO 4. CARACTERÍSTICAS Y RECURSOS

\begin{tabular}{|c|c|c|c|c|}
\hline ÍTEM & MUNICIPIOS & \multicolumn{3}{|c|}{ SOPÓ } \\
\hline 1 & Categoría & & & 3 \\
\hline 2 & Tamaño en Km2 & & & 115.5 \\
\hline \multirow[t]{2}{*}{3} & Número de habitantes & Zona & Urbana & 16,727 \\
\hline & & & Rural & 9,46 \\
\hline 4 & $\begin{array}{l}\text { Presupuesto anual en } \\
\text { millones de pesos }\end{array}$ & & & 25.000 \\
\hline \multirow{7}{*}{5} & \multirow{7}{*}{ Infraestructura } & \multirow{2}{*}{ Servicios públicos } & Domiciliarios & 1 \\
\hline & & & Veredales & 0,9 \\
\hline & & \multirow{3}{*}{ Servicios de salud } & Hospitales & 1 \\
\hline & & & Clínicas & 0 \\
\hline & & & Puestos salud & 0,5 \\
\hline & & Servicios educativos & Colegios & 1 \\
\hline & & & Escuelas & 1 \\
\hline
\end{tabular}




\begin{tabular}{|c|c|c|c|}
\hline & & Universidades (sedes) & 1 \\
\hline & \begin{tabular}{|l} 
Servicios Transporte \\
\end{tabular} & Municipal & 1 \\
\hline & & Intermunicipal & 0,6 \\
\hline & Servicios bancarios & & 1 \\
\hline & \begin{tabular}{|l|}
$\begin{array}{l}\text { Espacios culturales y } \\
\text { recreativos }\end{array}$ \\
\end{tabular} & Casa cultura & 1 \\
\hline & & Teatros & 0,6 \\
\hline & & Parques públicos & 0,7 \\
\hline & & Cines & 0,5 \\
\hline & & Polideportivos & 1 \\
\hline & & Bombero & 1 \\
\hline & Entidades varias & Estación policía & 1 \\
\hline & & Registraduría & 1 \\
\hline & & Hoteles & 1 \\
\hline & & Iglesias & 1 \\
\hline & & Humanos & 0,6 \\
\hline & Recursos & $\begin{array}{l}\text { tecnológicos y de } \\
\text { conectividad }\end{array}$ & 0,6 \\
\hline $\begin{array}{l}\text { TOTALES POR } \\
\text { MUNICIPIO: }\end{array}$ & & & 19. (82.6\%) \\
\hline
\end{tabular}

Como se aprecia en el Cuadro 4, en cuanto a recursos humanos y tecnológicos, en Sopó se observa que no tiene suficiente personal calificado para liderar procesos y no cuenta con los recursos de tecnología de punta, y en especial redes de internet y software, para adelantar la gestión y optimizar las comunicaciones entre y con la comunidad, lo que dificulta la gestión y limita las posibilidades del municipio para generar sinergias regionales y nacionales, así como abrir posibilidades de comunicación con el mundo vía internet al alcance de todos sus pobladores.

\subsubsection{Sibaté}

Sibaté es un municipio categoría 4, ubicado en la Provincia de Soacha, Cundinamarca; dista $29 \mathrm{Km}$ al sur de Bogotá y $14 \mathrm{Km}$ al sur del municipio de Soacha; tiene una población de 417.325 habitantes (Dane, 2011). 
La referenciación del municipio de Sibaté está estrechamente ligada a Soacha y a Bogotá, municipios vecinos que han influenciado la dinámica social y el desarrollo territorial de manera significativa, debido a que, por su cercanía, ha aumentado la población residente (dormitorio), los hurtos, presencia de población flotante, aumento de riñas y lesiones personales, micro tráfico y violencia intrafamiliar, entre otros, exacerbándose los problemas sociales y la demanda de bienes y servicios, según lo comentado por el asesor del planeación entrevistado y lo consignado en el PDM 2012-2016. (Municipio de Sibaté, 2012, p. 52); sin embargo, y a pesar de lo anterior, el municipio ha avanzado en su desarrollo integral y en el fortalecimiento de la institucionalidad según la evaluación integral de desempeño municipal elaborada por el DNP en 2013.

El Municipio de Sibaté fue catalogado en el noveno (9) puesto a nivel territorial, teniendo como base las altas calificaciones alcanzadas en las variables de Eficacia (porcentaje de avance en la implementación PDM), eficiencia (utilización de los recursos y los logros alcanzado); requisitos legales (aplicación de la normatividad) y en la gestión (capacidad administrativa y el desempeño fiscal del municipio), información que permite inferir que el desarrollo de este municipio y los contenidos de su PDM, han sido pertinentes a las necesidades y la administración municipal está respondiendo con lo propuesto.

Con el fin de corroborar los óptimos resultados obtenidos en la evaluación realizada por el DNP (89/100), las investigadoras diligenciaron la Guía básica para la revisión y comprensión de los planes de desarrollo de las entidades territoriales, elaborada por el DNP, obteniendo también en esta el mismo un puntaje, lo que indica que el plan de desarrollo de Sibaté se elaboró de acuerdo con lo estipulado en la Ley 152 de 1994 y se adelantó un proceso de construcción pertinente y efectivo, fortalezas que se reflejan en su desempeño integral que, como consta en el documento Evaluación del desempeño integral 
de los municipios y distritos, vigencia 2013 realizada por el DNP (2014), ocupó el noveno (9) puesto a nivel nacional, obteniendo una calificación sobresaliente de 89 puntos en los indicadores establecido por el DNP para la mencionada evaluación.

La creación de Sibaté como municipio data de 1967 (48 años), lo que indica que es un municipio muy joven en lo que respecta a experiencia administrativa y gestión pública; esto hace que sea aún más significativo el avance logrado en el nivel institucional y en gobernabilidad, lo que se refleja también en el proceso realizado y los resultados obtenidos en la construcción de su PDM para el periodo 2012-2015.

En cuanto al proceso de elaboración del Plan de Desarrollo, Todos de la Mano... Transformamos Sibaté, 2012-2016, como punto de partida se identificó el propósito de vincular activamente a la comunidad con sus iniciativas y prioridades, y utilizar la información como insumo para la construcción del PDM 2012. Como estrategia para la consulta y fortalecimiento del componente participativo, se realizaron 54 mesas temáticas y sectoriales, 40 en el sector rural y 14 en el urbano, con la finalidad de fortalecer la representatividad de la comunidad, realizar el diagnóstico y análisis de necesidades, a través del abordaje de temas sensibles como familia, niñez, infancia y adolescencia, adulto mayor, salud, educación cultura y sector agrícola, entre otros.

La reflexión, el diagnóstico y la priorización de necesidades se realizaron con los miembros y representantes de las Juntas de acción comunal, gremios, organizaciones sociales y población de diferentes ciclos vitales y con variados intereses.

Si bien el proceso que adelantó el Alcalde electo y el equipo de gobierno que lo acompañó en la formulación del Plan no está descrito de manera detallada en el Acuerdo 004 expedido por el Concejo Municipal, en mayo 29 de 
2012, en la entrevista tenida con el asesor de la Oficina de Planeación, se pudo conocer a profundidad el proceso metodológico:

Fase 1. Alistamiento y Participación Ciudadana. En esta fase se definieron los recursos, el cronograma, la metodología, marco orientador, definición de aulas temáticas, responsables, estrategias de divulgación y convocatoria, y los procedimientos para recopilar y sistematizar la información. Las actividades realizadas fueron:

a) Presentación ruta y objeto del plan al Gabinete municipal.

b) Primer encuentro con presidentes de JAC.

c) Mesa institucional interna con concejales y funcionarios.

d) Mesas de planificación intersectorial del Municipio-

e) Mesas de planificación con industriales.

f) Mesas de planificación con gremios y organizaciones.

g) Mesas de planificación con ciudadanía municipal.

En lo referido a la participación de la comunidad, "se tuvo en cuenta incluir todos los sectores de la comunidad Sibateña, todo ello con un enfoque para garantizar el goce efectivo de los derechos, teniendo en cuanta el ciclo vital del ser humano; se contó con la participación activa y directa de 2177 personas" (Municipio de Sibaté, 2012, p. 3).

Fase 2. Socialización proyecto del PDM

a) Talleres municipales para el PDM.

b) Presentación al Consejo Territorial de Planeación Municipal - CTPM.

c) Estudio en CTPM.

d) Observaciones y consideraciones del CTPM y aprobación por el CTPM.

e) Presentación del PDM 2012 - 2015 al H. Concejo Municipal.

Fase 3. Legalización y comunicación

a) Aprobación del PDM 2012 - 2015 por el H. Concejo Municipal (Acuerdo).

b) Sanción del PDM 2012 - 2015. 
c) Divulgación ante la comunidad del decreto 004 de 2012.

Las tres fases se desarrollaron según lo previsto y definido en la ruta por la cual se está encaminando el desarrollo de Sibaté, y los 5 ejes temáticos que concretizan el enfoque de desarrollo: 1)Desarrollo humano integral, 2) Desarrollo institucional, 3) Crecimiento económico, 4) Desarrollo territorial y ambiente sostenible, 4) Seguridad y convivencia, y 5) Desarrollo institucional; los ejes se desagregan en 43 programas y 84 subprogramas, con enfoque de derechos y basados en el ciclo vital de los habitantes del municipio, respondiendo con ellos a las necesidades de la población, a la búsqueda de una mejor calidad de vida para todos y visionando al municipio como territorio generador de oportunidades, de sana convivencia y desarrollado integral de manera sostenible.

El Plan está estructurado en tres (3) partes. En la parte I, se plantea el componente estratégico, definiendo la misión, la visión, el marco normativo y la participación comunitaria. En la parte II, se plantean los ejes estratégicos, pilares, programas y subprogramas. Y en la parte III, el marco fiscal, estrategias financieras, financiamiento y plan plurianual de inversiones.

En el componente estratégico en que se explicitan la misión y la visión, se aprecia que estas son concretas, sustentadas en el enfoque de desarrollo humano integral, el territorio y valores relacionados con la gestión pública y la participación ciudadana. En la visión, se declara que "Sibaté en el 2023 será un Municipio seguro, competitivo, ambientalmente sostenible y generador de escenarios propicios para el desarrollo humano integral" (Municipio de Sibaté, 2012, p. 2); y como Misión se establece que "Nuestro compromiso es brindar servicios con calidad, sustentados en principios de buen gobierno con la participación de todos los actores sociales, garantizando el desarrollo integral del ser humano con su territorio" (Municipio de Sibaté, 2012, p. 2). 
La experiencia del equipo de gobierno y asesor del alcalde, la estrategia metodológica utilizada y la participación activa y directa de 2.177 personas (Municipio de Sibaté, 2012), se evidencia en el texto impreso y publicado que contiene el PDM de Sibaté; sin embargo, la observación directa del casco urbano y la valoración realizada sobre las características y recursos disponibles en el municipio para la implementación del PDM 2012-2016, cuestionan la coherencia entre el ser (lo que se observa y se dice) y el deber ser, que se plantea en el plan de desarrollo.

A continuación se presenta el Cuadro 5, elaborado con la información obtenida en la entrevista con el asesor de la Oficina de Planeación, sobre los recursos disponibles y los resultados porcentuales en términos cuantitativos.

CUADRO 5.

CARACTERÍSTICAS Y RECURSOS (3)

\begin{tabular}{|c|c|c|c|c|}
\hline ÍTEM & \multicolumn{4}{|c|}{ MUNICIPIO SIBATÉ } \\
\hline 1 & Categoría & & & 4 \\
\hline 2 & Tamaño en Km2 & & & 126.5 \\
\hline \multirow[t]{2}{*}{3} & \multirow[t]{2}{*}{ Número de habitantes } & \multirow[t]{2}{*}{ Zona } & Urbana & 28.000 \\
\hline & & & Rural & 3.000 \\
\hline 4 & Presupuesto anual en millones de pesos & & & 19.000 \\
\hline \multirow[t]{3}{*}{5} & \multirow[t]{3}{*}{ Infraestructura } & $\begin{array}{l}\text { Servicios } \\
\text { públicos }\end{array}$ & Domiciliarios & 1 \\
\hline & & & Veredales & 0,6 \\
\hline & & Servicios de & Hospitales & 0 \\
\hline
\end{tabular}




\begin{tabular}{|c|c|c|c|}
\hline & \multirow[t]{2}{*}{ salud } & Clínicas & 0 \\
\hline & & Puestos salud & 1 \\
\hline & \multirow{3}{*}{$\begin{array}{l}\text { Servicios } \\
\text { educativos }\end{array}$} & Colegios & 1 \\
\hline & & Escuelas & 1 \\
\hline & & $\begin{array}{l}\text { Universidades } \\
\text { (sedes) }\end{array}$ & 0 \\
\hline & $\begin{array}{l}\text { Servicios } \\
\text { Transporte }\end{array}$ & Municipal & 1 \\
\hline & & Intermunicipal & 08 \\
\hline & $\begin{array}{l}\text { Servicios } \\
\text { bancarios }\end{array}$ & & 1 \\
\hline & Espacios & Casa cultura & 1 \\
\hline & culturales y & Teatros & 1 \\
\hline & & Parques & 0 \\
\hline & & Cines & 0 \\
\hline & & Polideportivos & 1 \\
\hline & Entidades & Bombero & 0,5 \\
\hline & & Estación policía & 1 \\
\hline & & Registraduría & 1 \\
\hline & & Hoteles & 1 \\
\hline & & Iglesias & 1 \\
\hline & Recursos & $\mathrm{R}$ humanos & 0,6 \\
\hline & & $\begin{array}{l}R \text { técnicos y } \\
\text { conectividad }\end{array}$ & 0,4 \\
\hline TOTALES POR MUNICIPIO: & & & 14.9 \\
\hline
\end{tabular}

En lo que respecta a infraestructura, servicios y recursos, la sumatoria de la valoración dada y la información obtenida a través del diligenciamiento de la encuesta, la revisión del plan de desarrollo y la observación in situ, nos permitió identificar que Sibaté cuenta medianamente (65\%) con la infraestructura básica para atender a su cerca de 30.000 habitantes, teniendo un déficit importante en tecnología, conectividad, zonas de recreación pública, centros de salud y de educación superior, lo cual repercute en la calidad de vida de las personas, disminuyendo las posibilidades de dar cumplimiento a lo propuesto en la misión y lograr consolidar aquellos aspectos del desarrollo humano integral, que permita alcanzar en el 2013 lo declarado en la visión.

Del proceso de elaboración e implementación del PDM de Sibaté, se destacan como aspectos significativos la rigurosidad del proceso, la solidez de la 
estrategia metodológica utilizada, el compromiso del equipo de gobierno y la respuesta de la comunidad a la convocatoria. La inclusión en el PDM del propósito y las estrategias para implementar un sistema general de calidad, el Modelo Estándar de Control Interno $(\mathrm{MECl}$,) hace pensar que hay una real intensión en el alcalde de cualificar, medir la gestión y propiciar el mejoramiento continuo de la administración municipal que, de hacerse así, el municipio se verá altamente beneficiado por la eficacia de sus procesos y la transparencia de su acción administrativa y política.

Como debilidades, se considera que no está explícito en ninguno de los ejes y programas la articulación regional; en la visión, la mirada es muy interna, no se contempla la posibilidad de alianzas estratégicas y la conectividad regional. Si bien hay una propuesta interesante de fortalecer el desarrollo rural, apoyar la producción campesina, tecnificar el campo, no hay propuestas para recuperar la dinámica industrial que tuvo el municipio en el siglo pasado, ni se vislumbra la relevancia incursionar o fortalece la relación municipio-empresa, si es que existe; en los programas sociales se percibe el mantenimiento de la línea asistencial del gobierno nacional, no se aprecian estrategias innovadoras que promuevan el desarrollo de competencias y habilidades personales, que contribuyan al logro desarrollo humano integral perdurable y a favorecer un desarrollo sistémico del territorio y sus pobladores.

\subsubsection{La Calera}

Teniendo en cuenta las características y contexto del municipio como un marco de referencia, se realizó el análisis del proceso desarrollado por el alcalde electo y su equipo de gobierno para la elaboración del Plan de Desarrollo Municipal (PDM) Unidos Somos Más, Hacia el Futuro.2012-2015 (Municipio de La Calera, 2012). 
Este Plan está estructurado en dos partes, como ordena la Ley 152/94. En la primera parte se desarrolla lo referente al marco estratégico, axiología, ejes estructurales (social, económico, ambiental e infraestructura pública, gestión administrativa); y en la segunda parte se consigan los lineamientos referidos a plan de inversiones, estrategia financiera y plan plurianual, que se explicitan en anexos (no están disponibles en internet para ser consultados).

El municipio de La Calera colinda con la Localidad de Chapinero, ubicada en el nororiente de Bogotá, cuya influencia sobre el desarrollo territorial de la zona urbana, semiurbana y rural aledaña a la cabecera municipal es notoria, sobre todo en la transformación del uso del territorio, que ha evolucionado paulatinamente $\mathrm{y}$ ha transformado su vocación agrícola y minera hacia la urbanización de las tierras para la construcción de conglomerados y parcelaciones para vivienda campestre, colegios privados, clubes sociales y para el albergue de las dos grandes represas que surten al Acueducto de Bogotá, San Rafael y Chingaza, así como el desarrollo de sitios turísticos y de servicios recreativos.

... La Calera, presenta varios aspectos desde el punto de vista geográfico, histórico, ubicación, tamaño poblacional, ubicación frente a el área metropolitana de Bogotá, bueno, un sinfín de situaciones que se deben tener en cuenta para la formulación del Plan de Desarrollo (Entrevista, 2014).

Con el fin de conocer, por fuente directa, se entrevistó al Secretario de la Oficina de Planeación de La Calera, persona experta en el tema y con amplia experiencia en esos procesos, quien participó activamente en su formulación y es miembro del equipo responsable de la implementación y seguimiento al PDM.

En la revisión de los contenidos de la primera parte del PDM, se realizó una mira detenida a la misión, visión, y objetivos estratégicos y demás elementos conceptuales que permitieran identificar en ellos el enfoque de desarrollo y los aspectos significativos del PDM de La Calera. 
Al adentrarse en los aspectos teleológicos, y específicamente en la Misión y Visión, llama la atención que en la formulación de la Misión simplemente se consigna lo que establece la Constitución Política de 1991, quedando redactada sin incluir aspectos específicos que visibilicen la especificidad del desarrollo municipal que va a adelantar esta administración.

La Misión dice:

"Al municipio como entidad fundamental de la división político - administrativa del Estado le corresponde prestar los servicios públicos que determine la ley, construir las obras que demande el progreso local, ordenar el desarrollo de su territorio, promover la participación comunitaria, el mejoramiento social y cultural de sus habitantes y cumplir las demás funciones que le asignen la constitución y las leyes". (Municipio de La Calera, 2012).

En cuanto a la Visión, construida través de estrategias participativas con la comunidad y validada por el Consejo Territorial de Planeación, se apuesta a que en el periodo 2012-2015:

"Los habitantes del Municipio de La Calera confiarán en sus instituciones y gobernantes, producto de una administración con alto sentido social; conocimiento, respeto y cumplimiento de la ley como fortalezas para una excelente gestión, donde prevalezca el liderazgo, la honestidad, la capacidad, transparencia y el respeto por los valores, así como el trabajo en equipo y la participación comunitaria, donde sobresalga el compromiso y la vocación por el servicio público. La parte humana y social prevalecerá sobre el crecimiento material, el cual reorientaremos mediante una planeación concertada con las distintas organizaciones.

La Calera será un Municipio seguro, con una comunidad educada y fortalecida en el núcleo familiar, sano y trabajando, con una infraestructura que nos permita ser competitivos, productivos, en paz, en armonía con la naturaleza y con oportunidades para todos". (Municipio de La Calera, 2012, p. 16).

Como se puede apreciar en la redacción de la misión y la visión, se explicitan funciones, valores y principios que permiten inferir el enfoque de desarrollo humano y social que sustenta el PMD, que por su estructura y 
funcionalidad cumple con los parámetros mínimos requeridos para su elaboración; sin embargo, en el texto del plan de desarrollo "Unidos Somos Más, Hacia el Futuro" no se percibe la visión prospectiva, ni los ejes estratégicos que les permitirán, como se consigna en la visión, "ser competitivos, productivos, en paz, en armonía con la naturaleza y con oportunidades para todos" (Municipio de La Calera, 2012, p. 16), debilidad que, en la medida que se vaya implementando el PDM, se hará más evidente, si no se hacen los correctivos pertinentes para encauzar estrategias y recursos que les permita alcanzar tales objetivos.

En la entrevista realizada con el Secretario de la Oficina de Planeación (SOP), se pudieron identificar algunas de las fortalezas y debilidades, así como el proceso y los recursos disponibles para el diseño e implementación del Plan de Desarrollo, así como la experticia que se requiere en los equipos de gobierno y más específicamente en los profesionales encargados de coordinar y redactar la elaboración del PDM, debido a que:

Hoy en día, este es un país de mucha normatividad, todos los días salen una nueva norma, una nueva Ley, un nuevo decreto reglamentario, etc. En este orden de ideas, los insumos para elaborar el Plan de Desarrollo, yo diría que supera más de cien normas, elementos, condiciones que tiene que tenerse en cuenta para elaborar el Plan de Desarrollo (Entrevista, 2013).

A través de la entrevista se pudo identificar como una fortaleza en este municipio, la experticia de algunos de los miembros del equipo responsable de liderar la elaboración del Plan de Desarrollo, su conocimiento de la normatividad y de los instrumentos elaborados para tal fin por el DNP y la capacidad de asimilar y llevar a la práctica las orientaciones recibidas de la Oficina de Planeación de la Gobernación de Cundinamarca, lo que permitió que el proceso se realizara con calidad y eficacia, siguiendo las pautas dadas en la Ley 152 de 1994, lo consignado en el plan de gobierno del alcalde electo, sustentando la estructura y contenido del PDM en la información recopilada y validada en los 
procesos participativos previos (300 reuniones con la comunidad ${ }^{3}$ ) y posteriores, así como las recomendaciones realizadas por el Consejo Territorial de Planeación, la CAR y el Honorable Concejo Municipal.

Al respecto, el Secretario de Planeación de La Calera comentó:

En el proceso, se estableció obviamente un cronograma, donde la primera instancia es el Consejo de Gobierno, con el cual se establecen las pautas en la formulación de las diferentes políticas para la elaboración del mismo. A su vez, el proceso se llevó a las diferentes veredas con el fin de tomar nuevamente notas de las inquietudes de la comunidad, con el fin de poderlas articular al Plan de Desarrollo.

Realmente el proceso inicia con la elaboración de su Programa de Gobierno, cuando uno estructura bajo el esquema del famoso voto programático, también contemplado por la Ley 131 y 134 del 94 . En este orden de ideas el mandatario que toma posesión de la entidad territorial, en este caso llamado Alcalde, pues debe de formular el Plan de Desarrollo basado en su programa de gobierno. Es uno de los elementos y documentos que deben formar parte del Plan del Desarrollo...

Adicionalmente lo que se hizo fue hacer una postulación, la preformulación del Plan de Desarrollo para socializarlo con la comunidad... También establecido por mandato de la Ley 152 y este proceso se lleva a cabo obviamente definiendo los diferentes sectores que identifican o con los cuales tienen participación de la sociedad en el municipio. Aquí está definido el sector educativo, el sector de los profesionales, el sector de la juventud, el sector de los comerciantes, el de las entidades financieras y el productor el cual se establece... y el comercial, en tres categorías, primario, secundario y terciario, con el fin de que la misma comunidad delegue la representación de ese sector a la conformación del Consejo Territorial de Planeación.

Le comentaba que se estableció obviamente un cronograma, donde la primera instancia es el Concejo de Gobierno, con el cual se establecen las pautas en la formulación de las diferentes políticas para la elaboración del mismo. A su vez, el proceso se llevó a las diferentes veredas con el fin de tomar nuevamente notas de las

\footnotetext{
${ }^{3}$ Consulta "300 reuniones que sirvieron de soporte, de las cuales se tabularon 125 reuniones, junto a 11 reuniones sectoriales en el mes de marzo y abril del 2012, para la formulación del Plan de desarrollo desde la visión de la comunidad, en donde se realizaron inicialmente procesos de concertación de temas prioritarios que contribuyeron efectivamente a la construcción del diagnóstico y posteriormente se socializó el marco estratégico del Plan de Desarrollo Municipal" (Municipio de La Calera, 2012, p. 13).
} 
inquietudes de la comunidad, con el fin de poderlas articular al Plan de Desarrollo.

Se tuvo la participación de las diferentes Juntas de Acción Comunal con los diferentes líderes y por supuesto que en esas reuniones donde se socializó el Plan de Desarrollo, se acotaron las preocupaciones de los diferentes sectores de la comunidad, refiriéndome al sector agrícola, al sector de educación, al sector de salud, al sector de agua potable y saneamiento básico, al sector de transporte, al sector de movilidad, al sector de institucionalidad, al sector de medio ambiente, al sector de programas sociales, etc."

Como se aprecia en los comentarios anteriores, la participación de la comunidad, así como la programación de actividades y cumplimento del cronograma, les permitieron lograr con calidad y eficacia lo previsto a conseguir durante el proceso de construcción del PDM en el primer semestre de 2012.

Una vez socializado el Plan de Desarrollo, pues obviamente se presenta al Consejo Territorial de Planeación para que este órgano representativo de los diferentes sectores económicos de la comunidad caleruna le hiciera las respectivas observaciones. Es de aclarar que hubo acompañamiento por parte, tanto de las entidades departamentales en cabeza de la Gobernación, y del mismo Departamento Nacional de Planeación en la elaboración y formulación del mismo. A su vez, la Gobernación de Cundinamarca, pues también elaboró reuniones sectoriales por provincia, en donde se elaboraron más mesas de trabajo con el fin de que el Departamento pudiese elaborar su plan de desarrollo articulado a las necesidades de los diferentes municipios agrupados por provincias (Entrevista, 2013).

Los resultados alcanzados en el procesos de elaboración del PDM de La Calera demuestran que seguir los parámetros establecidos en la normatividad, el aprovechamiento de los recursos técnicos e instrumentos elaborados por el DNP y la asesoría de la Gobernación de Cundinamarca son factores garantes para en este caso haber logrado estructurar el PDM, según lo exigido por la Ley $152 / 94$.

Otra de las fortalezas, encontradas en el proceso de elaboración del plan de desarrollo de La Calera, es la claridad en ellos en cuanto a la ruta metodológica a seguir, la identificación de actores relevantes, sectores, 
grupos poblacionales y ejes programáticos, lo que determinó los contenidos prioritarios y la definición de las metas a alcanzar el periodo 2012-2016. El trámite para su validación y aprobación se en el periodo establecido por la Ley, a pesar de lo que, según el Secretario de Planeación (2014), sucede en el país.

Hoy en día, este es un país de mucha normatividad, todos los días salen una nueva norma, una nueva Ley, un nuevo decreto reglamentario, etc., etc. En este orden de ideas, los insumos para elaborar el Plan de Desarrollo, yo diría que supera más de cien normas, elementos, condiciones que tiene que tenerse en cuenta para elaborar el Plan de Desarrollo. (Entrevista, 2014).

Con el fin de validar y/ o contrastar lo dicho por el Secretario de Planeación, y lo consignado en el Acuerdo 005 de 2012, las investigadoras diligenciaron la Guía básica para la revisión y comprensión de los planes de desarrollo de las entidades territoriales (DNP 2012), la cual, según los valores asignados a cada ítem por la investigación, alcanzó una puntuación de 70,78; la debilidad de este PDM, es que este no tiene una mirada sistémica del desarrollo territorial; su misión no expresa el enfoque e intencionalidad que guía el desarrollo y la visión del progreso y desarrollo territorial que se espera alcanzar en lo territorial y regional.

Otros de los aspectos explorados para poder contextualizar la gestión del PDM, fueron los recursos con que cuenta el municipio para la implementación del Plan, el formato diligenciado, la información obtenida a través de la observación de territorio y consulta de documentos, permitió concluir que La Calera cuenta con infraestructura de servicios públicos, salud, educación, transporte intra e inter municipal, espacios recreativos y culturales y entidades de servicio social como bomberos, policía, registraduría, bancos, hoteles, iglesias y centros comerciales, entre otros, básicamente ubicados en la cabecera municipal y sobre vías principales, que prestan servicios a la población residente, vecinos y turistas. 
En la zona rural hay dificultades con los acueductos veredales, la iluminación pública, la calidad de los caminos de acceso a algunas veredas, las dotaciones escolares, espacios recreativos públicos y el transporte a las veredas alejadas de la zona urbana. La extensión de municipio y la poca disponibilidad de fuerza pública y de sistemas de vigilancia, no permiten contar con medios de seguridad ciudadana que garantice a los habitantes de las zonas rurales total tranquilidad, según apreciaciones de habitantes de la región. En el Cuadro 6 se aprecian las características y recursos con que cuenta este municipio.

CUADRO 6.

CARACTERÍSTICAS Y RECURSOS (4)

\begin{tabular}{|l|l|l}
\hline ÍTEM & MUNICIPIOS & LA CALERA
\end{tabular}




\begin{tabular}{|c|c|c|c|c|}
\hline 1 & Categoría & & & 5 \\
\hline 2 & Tamaño en Km2 & & & 316 \\
\hline 3 & \multirow[t]{2}{*}{ Número de habitantes } & \multirow[t]{2}{*}{ Zona } & Urbana & 13.000 \\
\hline & & & Rural & 13.813 \\
\hline 4 & $\begin{array}{l}\text { Presupuesto anual en } \\
\text { millones de pesos }\end{array}$ & & & 21.900 \\
\hline \multirow{24}{*}{5} & \multirow{21}{*}{ Infraestructura } & \multirow[t]{2}{*}{ Servicios públicos } & Domiciliarios & 1 \\
\hline & & & Veredales & 0,6 \\
\hline & & \multirow{3}{*}{ Servicios de salud } & Hospitales & 0 \\
\hline & & & Clínicas & 1 \\
\hline & & & Puestos salud & 1 \\
\hline & & \multirow{3}{*}{ Servicios educativos } & Colegios & 1 \\
\hline & & & Escuelas & 1 \\
\hline & & & $\begin{array}{l}\text { Instituciones de } \\
\text { educación Superior } \\
\text { (sedes) }\end{array}$ & 1 \\
\hline & & Servicios Transporte & Municipal & 0,6 \\
\hline & & & Intermunicipal & 1 \\
\hline & & Servicios bancarios & & 1 \\
\hline & & \multirow{5}{*}{$\begin{array}{l}\text { Espacios culturales y } \\
\text { recreativos }\end{array}$} & Casa cultura & 1 \\
\hline & & & Teatros & 0 \\
\hline & & & Parques & 1 \\
\hline & & & Cines & 0 \\
\hline & & & Polideportivos & 1 \\
\hline & & \multirow[t]{2}{*}{ Entidades varias } & Bombero & 1 \\
\hline & & & Estación policía & 1 \\
\hline & & & Registraduría & 1 \\
\hline & & & Hoteles & 1 \\
\hline & & & Iglesias & 1 \\
\hline & \multirow{2}{*}{ Recursos } & Recursos humanos & Personal del despacho & 0.5 \\
\hline & & Recursos tecnológicos & $\begin{array}{l}\text { Software y hardware, } \\
\text { internet, conectividad }\end{array}$ & $0-5$ \\
\hline & TOTALES MUNICIPIO & & & 17.2 \\
\hline
\end{tabular}

$\%$ se obtiene sobre la base de 23 aspectos calificados del ítem 5

Como se puede observar en el Cuadro 6, La Calera dispone de infraestructura al servicio de la comunidad, sus recursos en lo que se refiere a capital humano y a medios tecnológicos, especialmente son limitados; estos, 
según lo dicho por el Secretario de Planeación, no son suficientes para asumir los compromisos adquiridos en el Plan ni hacer eficiente la gestión.

Según el informe de rendición de cuentas de 2013 presentado por el alcalde y publicado, (Municipio de La Calera, s.f., p. 25), se han hecho avances en la implementación de las actividades propuestas para el Eje de Programas Sociales y la inversión realizada en estos. Hay avances medianos en lo referente al eje ambiental y reportan muy baja inversión en los aspectos contemplados para el Eje de Crecimiento Económico y el Eje de Modernización de la Gestión.

Otro aspecto significativo a destacar en La Calera, es el reconocimiento hecho en el 2014 por la Asamblea Departamental de Cundinamarca al Alcalde por el resultado obtenido en la evaluación de desempeño integral realizada por el DNP, en el que obtuvo el noveno (9) lugar a nivel departamental y el decimoséptimo (17) a nivel nacional, (Municipio de La Calera, s.f. p. 4), lo cual demuestra que el proceso de elaboración del PDM y su gestión para la implementación ha sido exitoso en lo que se refiere a la medición de las variables que valora el DNP; lo que aún no se puede apreciar son los resultados cualitativos, que den cuenta de los avances en el desarrollo de la visión, ya que estos indicadores no están explícitos en el PDM, ni en los documentos consultados.

En el estudio, también se identificó un aspecto a destacar y que se vislumbra como un factor diferenciador de los procesos adelantados en los otros 5 municipios; se trata del intenso trabajo que hizo el alcalde electo cuando era aspirante al cargo en la campaña del 2011, a través del cual logró contactar la comunidad, conocer sus necesidades y el territorio, identificar las fortalezas, debilidades y oportunidades que en este existen en el territorio, lo que le permitió diseñar un plan de gobierno coherente y 
pertinente, ganar las elecciones para el periodo 2015-2015 y elaborar el PDM, de acuerdo con estos parámetros.

También es importante destacar la disposición del alcalde y del equipo de gobierno para acatar y aprovechar el acompañamiento de la oficina de Planeación de la Gobernación de Cundinamarca, el DNP, y la utilización rigurosa de los instrumentos elaborados por este para orientar a los municipios en la construcción del PDM y tener siempre presente y enunciado en el documento, la articulación con el nivel nacional y departamental, tal como costa en la página 10 del Acuerdo 005 de 2012, en el cual se explicita que "El Plan de Desarrollo esta articulado con el Plan Nacional de Desarrollo Prosperidad para todos 2010-2014, con el Plan de Desarrollo Departamental -Calidad de Vida 2012-2016, con el Pan Visión Colombia II Centenario y con los Objetivos de Desarrollo del Milenio, las políticas de niñez, infancia y adolescencia, población víctima, equidad y género, pobreza extrema, adulto mayor entre otros"

\subsubsection{Gachancipá}

El contexto de municipio de Gachancipá, en el conjunto de municipios estudiados por ubicación geográfica y tipo de territorio, se asemeja a Sopó, pero su desarrollo y dinámica ha sido totalmente diferente. Sólo recientemente ha emprendido la modernización y un proceso de industrialización incipiente denota que hay una intencionalidad de cambio de su vocación agrícola y ganadera, buscando darle mayor competitividad al municipio, incorporándose en la agenda estratégica de desarrollo del nororiente de Cundinamarca y, en especial, de la zona de sabana centro, donde Sopó y Tocancipá juegan un papel jalonador muy importante para la región.

En el caso de Gachancipá y su Plan de Desarrollo "Progreso Para Todos" 2012-2015, aprobado mediante el Acuerdo No. 011 del 31 de mayo de 2012, el análisis del procesos se estructura, a partir de la información obtenida por 
medio del estudio del Acuerdo 011/12, la lectura de los documentos facilitados por la alcaldía y lo compartido por las dos personas entrevistadas.

La percepción tenida por las investigadoras, es que este es un plan de desarrollo ambicioso, que busca, con la gestión del Alcalde y su equipo, generar, en los cuatro años, un proceso de desarrollo humano integral y del territorio de manera tal que el pueblo gachancipeño en el 2028 pueda tener una alta calidad de vida y un desarrollo político que se concretice en la alta participación democrática y su capacidad de ser actores del crecimiento económico y del manejo ordenado, responsable y sostenible del municipio. (Municipio de Gachancipá, 2012).

Para el análisis del procesos de construcción del PDM, también se tuvo en cuenta que Gachancipá es un municipio con 13.312 habitantes, según la proyección del DANE para el 2012, en el cual el $66.52 \%$ de la población es menor de 18 años (Municipio de Gachancipá, 2012), población que es contemplada como grupo objetivo en el PDM, para el cual se han diseñado programas y estrategias orientadas a su educación básica y superior, así como para el disfrute integral de sus derechos a la salud y a una vida digna, elementos que junto con los que están orientados a través de los ejes social, económico, ambiental, cultural, deportivo, se busca fortalecer la calidad de vida de los niños, niñas y jóvenes en especial y, en general, para toda la población que reside en este territorio.

El afianzamiento de Ganchancipá como municipio dinámico, comprometido con el desarrollo integral humano y del territorio, se visualiza en el Plan de Desarrollo Municipal 2012-2015 "Progreso Para Todos", específicamente en la Misión y Visión del Plan de Desarrollo:

Misión.

Mejorar la calidad de vida de sus habitantes, abriendo espacios de concertación política y social, en el marco de la democracia participativa, logrando que en los diferentes sectores se permitan gestionar nuevas y mejores alternativas de desarrollo socioeconómico 
y cultural para el progreso de la comunidad gachancipeña, dentro de la estructura constitucional del estado social y de derecho definido por la Constitución Política de Colombia. (Municipio de Gachancipá, 2012, p. 12).

Visión.

En 16 años el municipio de Gachancipá brindará calidad de vida a sus habitantes desde los principios constitucionales de la dignidad humana y el respeto al medio ambiente como garantía de progreso, a través de un crecimiento económico y territorial ordenado, responsable y sostenible. En ese mismo periodo, el ciudadano gachancipeño, basado en un proceso educativo fortalecido, afrontará las necesidades y políticas públicas con alto grado de participación democrática. (Municipio de Gachancipá, 2012, p. 12).

Para la formulación de la Misión y Visión y programas y subprogramas del plan de Desarrollo, el equipo responsable de su elaboración tuvo en cuenta las fortalezas que tiene Gachancipá como municipio ubicado en la región Sabana Centro, distante en $35 \mathrm{Km}$ al norte de Bogotá y las potencialidades económicas, sociales, culturales y ambientales, que se han venido construyendo, al cambiar su vocación agrícola hacia una "economía que se soporta básicamente sobre la actividad industrial, el transporte, el comercio, la agroindustria, el sector servicios y la exploración minera". (Municipio de Gachancipá, 2012, p. 18). Por estar ubicada en el corredor vial Bogotá -Tunja-Sogamoso, Gachancipá tiene gran importancia para la región y numerosas posibilidades de desarrollo económico y social, teniendo en cuenta que hace parte de la agenda de competitividad regional y de la estrategia Bogotá- Región, estrategia que potencia a los municipios aledaños a la capital del Departamento de Cundinamarca, y del país, como polos de desarrollo territorial.

Los aspectos que fundamentan los principales ejes del desarrollo humano, social y económico, cultural y ambiental del municipio, se construyeron a través 
de la participación de la comunidad en las 22 mesas de concertación (9 sectoriales, 13 territoriales), convocadas por el alcalde, a las que asistieron 1.023 personas. La metodología utilizada fue liderada por los Secretarios de Despacho, en el primer semestre de 2012.

La información obtenida, sistematizada y analizada, le permitió al equipo de Gobierno elaborar un Plan de Desarrollo de calidad, muy completo y coherente. En la evaluación realizada por medio de Matriz del DNP 2012, diligenciada por las investigadoras, este Plan obtuvo un puntaje de 94,54 puntos sobre 100, ya que su estructura, coherencia y contenidos son pertinentes.

En la entrevista realizada con una funcionaria de la oficina de planeación del municipio, se diligenció la ficha técnica elaborada con el fin de caracterizar geográfica y administrativamente el municipio e identificar los recursos de infraestructura, humanos (personal del despacho) y económicos con que cuenta Gachancipá para implementar lo propuesto en el PDM. Para su evaluación cuantitativa se establecieron criterios de calificación en un rango de 0 a 1 , donde 0 significa que no existe y 1 que sí existe; los rangos intermedios denotan que si bien existe, el porcentaje de cobertura es variable con respecto a las necesidades. No se evaluó la calidad ni la pertinencia de estos servicios.

\section{CUADRO 7}


CARACTERÍSTICAS Y RECURSOS (5)

\begin{tabular}{|c|c|c|c|c|}
\hline ÍTEM & MUNICIPIO & & GACHANCIPÁ & \\
\hline 1 & Categoría & & & 6 \\
\hline 2 & Tamaño en Km2 & & & 42.96 \\
\hline 3 & Número de & Zona & Urbana & 5887 \\
\hline & habitantes & & Rural & 4915 \\
\hline 4 & $\begin{array}{l}\text { Presupuesto anual en } \\
\text { millones de pesos }\end{array}$ & & & 12624 \\
\hline & Cobertura & \multirow{3}{*}{ Servicios públicos } & & \\
\hline \multirow[t]{24}{*}{5} & \multirow{21}{*}{ Infraestructura } & & Domiciliarios & 1 \\
\hline & & & Veredales & 0,5 \\
\hline & & \multirow[t]{3}{*}{ Servicios de salud } & Hospitales & 0 \\
\hline & & & Clínicas & 0 \\
\hline & & & Puestos salud & 1 \\
\hline & & \multirow{3}{*}{$\begin{array}{c}\text { Servicios } \\
\text { educativos }\end{array}$} & Colegios & 1 \\
\hline & & & Escuelas & 1 \\
\hline & & & Universidades (sedes) & 0 \\
\hline & & $\begin{array}{c}\text { Servicios } \\
\text { Transporte }\end{array}$ & Intra Municipal & 0,5 \\
\hline & & & Intermunicipal & 1 \\
\hline & & Servicios bancarios & & 1 \\
\hline & & \multirow{5}{*}{$\begin{array}{c}\text { Espacios culturales } \\
\text { y recreativos }\end{array}$} & Casa cultura & 1 \\
\hline & & & Teatros & 0 \\
\hline & & & Parques & 1 \\
\hline & & & Cines & 0 \\
\hline & & & Polideportivos & 1 \\
\hline & & \multirow[t]{5}{*}{ Entidades varias } & Bomberos & 0 \\
\hline & & & Estación policía & 1 \\
\hline & & & Registraduría & 1 \\
\hline & & & Hoteles & 1 \\
\hline & & & Iglesias & 1 \\
\hline & \multirow[t]{3}{*}{ Recursos } & Humanos & Personal del despacho & 0.5 \\
\hline & & Tecnológicos & $\begin{array}{l}\text { Software y hardware, } \\
\text { internet, conectividad }\end{array}$ & 0.5 \\
\hline & & & & $15 \quad 65.2 \%$ \\
\hline
\end{tabular}

El \% se obtiene sobre la base de 23 aspectos calificados del ítem 5

La situación de Gachancipá, en cuanto a los recursos que dispone para la implementación del Plan de Desarrollo, en concordancia con las características básicas del municipio, se percibe como debilidad, debido a que, 
según las funcionarias entrevistadas, el municipio no cuenta con suficiente talento humano calificado para la implementación de los programas y subprogramas de cada uno de los ejes, ni los recursos económicos y tecnológicos requeridos; sin embargo, el de Plan de Desarrollo ha venido ejecutándose según lo planeado, gracias a la gestión del alcalde y los recursos que ha podido recaudar para su implementación.

Luego de haber transcurrido con éxito la etapa de planeación y terminación de obras inconclusas y siendo consecuentes con los parámetros del buen gobierno, se procedió a realizar la tarea silenciosa pero determinante de poder obtener los recursos para tan ambicioso plan de desarrollo. Es allí donde ha radicado el éxito para que hoy al tercer año de labores y no habiendo un precedente inmediato en el municipio estemos entregando obras concluidas, cosechando triunfos deportivos y culturales, trayendo desarrollo comunal”. (Alcaldía Municipal de Gachancipá, 2014).

Teniendo como base los lineamientos que ofrece la Guía 4 para la Gestión Pública Territorial, elaborada por el DNP (2011) y los aspectos básicos que orientan el proceso de elaboración de los Planes de Desarrollo de los entes territoriales, se realizó el análisis del proceso adelantado para tal fin en Gachancipá, entre el 2 de enero del 2012 y el 31 de mayo del mismo año, cuando fue expedido el Acuerdo 011 de 2012, por parte del Concejo Municipal.

En el municipio de Gachancipá se adelantó el proceso de la siguiente manera: 1) Alistamiento institucional: en esta etapa se realizó la identificación de los recursos humanos y económicos disponibles para desarrollar todas las actividades requeridas para la elaboración del Plan de Desarrollo, se diseñó el programa de trabajo para los cinco (5) meses disponibles para su elaboración y aprobación, se definió la "metodología participativa que siguió las rutas diseñadas por el Departamento de Planeación Nacional, Planeación Departamental y la consulta de planes de desarrollo exitosos que se sustentaron en la estrategia participativa, consolidando el concepto de 
democratización de las decisiones públicas en el municipio. (Municipio de Gachancipá, 2012, p. 10).

Se asignó responsabilidades a los Secretarios del despacho y se elaboró el material requerido para recoger y sistematizar la información; en un segundo momento de realizó la convocatoria ciudadana, la cual se hizo por medio de radio, prensa, sitio web de la Alcaldía, voceadores, afiches, plegables y se adelantó una campaña de sensibilización frente al papel de la ciudadanía en la formulación del Plan de Desarrollo Municipal.

2) Elaboración preliminar del Plan: en esta etapa se hizo la consulta a la comunidad, que se sustentó desde la perspectiva de la participación ciudadana contemplada en la Constitución Política de 1991.

Los elementos constitucionales de participación ciudadana nos invitaron a convocar a la comunidad para la recolección de las opiniones y proyección de su información dentro de la construcción de los programas e ideales del Plan de Desarrollo, es decir, dando lugar a la consolidación de la democracia participativa y no simplemente representativa.

La comunidad de distintos sectores sociales y de todas las localidades sumaron sus inquietudes en las mesas de concertación durante la construcción de la carta de navegación que regirá el destino del municipio durante el próximo cuatrienio. Una iniciativa que convocó a diversos sectores de la comunidad gachancipeña con el fin de escuchar sus voces y tomar nota atenta de las inquietudes presentadas. (Municipio de Gachancipá, 2012).

Una vez realizada la consulta a la comunidad, estudiado las líneas base y analizados los diagnósticos previos, y teniendo como base al Plan de Gobierno, se elaboró el Plan de Desarrollo preliminar, que se presentó ante el Consejo de Gobierno para su ajuste, y se pasó a la elaboración de la versión definitiva del Plan; luego se hizo la presentación ante la Corporación Autónoma Regional (CAR), quien emitió su concepto aprobatorio. En la etapa subsiguiente, se entregó el proyecto de Plan de desarrollo al Consejo Territorial de Planeación 
(CTP), constituido según ordena la Ley, el cual planteo valiosas recomendaciones que enriquecieron el documento, según se expresa en el Acuerdo 011/12 (Municipio de Gachancipá, 2012, p. 8). Posteriormente, se socializó el Proyecto de PDM ante la comunidad; esta actividad se realizó a través de encuentros territoriales, medios masivos de comunicación.

Finalmente se realizó la presentación y aprobación del Plan de Desarrollo "Progreso Para Todos 20012-2015", ante el Honorable Concejo Municipal de Gachancipá, Cundinamarca, para un primer debate en la Comisión de Segunda o de Presupuesto, el día 25 de Mayo de 2012, y en un segundo debate en la plenaria celebrada el día 26 de Mayo para su aprobación definitiva, tal como consta el Acuerdo 011 del 31 de mayo de 2012 (Municipio de Gachancipá, 2012).

El documento del PDM de este municipio es muy completo en su estructura, la cual consta de cinco partes: Marco General, Diagnóstico, Componente Estratégico, Componente Financiero y Anexos; es coherente, explícito y de fácil comprensión para cualquier lector, fortaleza que le ha permitido ser accesible para la comunidad.

El proceso, como se pudo apreciar en lo expuesto anteriormente, se siguió de acuerdo con los lineamientos dados por el DNP y se tramitó en el tiempo reglamentario. Se identificó como aspecto significativo de este PDM, la intencionalidad explicita allí consignada por el Alcalde de consolidar en la comunidad gachancipeña la democracia participativa e incentivar la participación como motor del desarrollo integral de los habitantes del municipio y su territorio.

Como conclusión de lo encontrado en el procesos de construcción del PDM de Gachancipá, se destaca la apuesta prospectiva de la visión, el enfoque humanista y político de la Misión y la coherencia de los ejes estratégicos, 
programas y metas para lograr el desarrollo propuesto y la intencionalidad de un equipo de gobierno, con gran sentido de pertenencia, de hacer una gestión efectiva, eficiente, transparente que, a la fecha, ha cumplido con las metas y objetivos propuestos, tal como consta en el informe de rendición de cuentas del periodo 2012 - 2014 (Alcaldía de Gachancipá, 2014).

\subsubsection{Subachoque}

Es un municipio categoría sexta con una población de 15.174 personas (proyección Dane para el año 2012). Con vocación eminentemente agrícola, ganadera y un intencionado viraje hacia el fomento del turismo ecológico, la preservación del medio ambiente y el fortalecimiento del sector micro empresarial, tal como se expresa en el Plan de desarrollo Subachoque. (Municipio de Subachoque, 2012, p. 9).

El Programa de Gobierno del municipio de Subachoque tiene como lema "Unidos Logramos el Cambio" y constituye la base para la realización del ejercicio de planificación del Plan de Desarrollo, que se enriquece con los aportes de los diferentes actores de la dinámica local y la articulación con las políticas nacionales, departamentales y regionales.

Por el acuerdo Municipal No. 05 de Junio 5 de 2012, se adoptó el plan de desarrollo "Unidos logramos el Cambio". Como visión en el Plan de Desarrollo 2012 se propone "la calidad de vida, el sentido de pertenencia, la defensa del patrimonio natural y la productividad de sus recursos, permitirán el reconocimiento nacional y promoverán la inversión, direccionada por una Administración eficiente, transparente y comprometida con el desarrollo." (Municipio de Subachoque, 2012, p. 9).

El secretario de Planeación del municipio (2014) comentó que:

el Alcalde le apuesta a un desarrollo sostenible a través de la cual se transformen las prácticas productivas y de ocupación del territorio, a la vez que se interioricen y apliquen criterios y actuaciones cotidianas 
de responsabilidad ambiental que transforman la amenaza en oportunidad para garantizar una vida más sana y una producción ecológica y de calidad que abra nuevos mercados y mejore la rentabilidad sin atentar contra las fuentes de agua, la composición de los suelos y las fronteras de estricta reserva y protección donde no puede permitirse la primacía de intereses económicos privados como la explotación minera en zonas de páramo con áreas de nacimiento y recarga hídrica. (Municipio de Subachoque, 2012, p. 5).

La visión muestra la importancia que tienen los recursos naturales y su conservación, por lo cual se denomina Municipio "Verde y Ecológico", lo cual se reafirma en la entrevista con el jefe de planeación el objetivo del Alcalde es conservar la vocación "esa es la intensión que sea netamente agrícola y turística". (Entrevista, enero 2014).

El plan de desarrollo es coherente con la vocación del municipio, en continuar siendo agrícola, conservar los recursos naturales, por lo que, a pesar de ser parte de los municipios de occidente, donde se han desplazado gran parte de las empresas ubicadas en Bogotá, el municipio de Subachoque no plantea programas en su plan de desarrollo que evidencien el articularse con la zona empresarial.

En cuanto a la estructura, el plan de desarrollo municipal cumple con lo planteado en el artículo $5^{\circ}$ y $6^{\circ}$ de la ley 152 de 1994, en el cual se definen objetivos, metas, estrategias y políticas y el presupuesto plurianual.

El proceso de elaboración del plan de desarrollo se realizó de acuerdo con lo establecido en la ley 152 de 1994; fue dirigido por el señor Alcalde, con el apoyo del Secretario de Planeación y los secretarios del despacho; contó, además, con la asesoría de un funcionario de la Alcaldía que había sido jefe de planeación del municipio.

El Plan se estructura según los ejes que propone la ley 152 de 1994, en materia económica, social y ambiental; una vez establecidos los ejes, se determinaron los sectores correspondientes a cada uno y a partir de estos se estructuró la consulta sectorial a la comunidad. El proceso se identificó a partir 
de lo expresado en la entrevista realizada al jefe de planeación de Subachoque.

"Lo primero que se hizo fue, digamos, obtener una línea base, para cada una de las meta, con la información de la ejecución de los Planes de Desarrollo anteriores, sobre el cumplimiento de esos planes, sobre el impacto de esos planes se hizo una propuesta. Entonces lo que se hizo es construir a partir del Plan de Gobierno, incluir las metas que estaban por fuera de ese Plan de Gobierno y realizar un diagnóstico previo para establecer una línea base. Sobre esa línea base se hizo la consulta a las comunidades, entonces se hizo por sectores, los agricultores, a los educadores, del tema veredal.

Luego se hizo visita a cada de las asociaciones de... a cada una de las juntas de acción comunal, las juntas de acción de los barrios, señalando esos inconvenientes 0 esas necesidades y pues escuchando cual eran los requerimientos de la comunidad. Una vez hecho ese análisis, ese registro, se condensaron cuáles fueron los más recurrentes, se priorizó y se construyó un plan que nuevamente se presentó al Consejo Territorial, pues para un estudio antes de su concepto y pues eso nos llevó bastante tiempo... eso fue un trabajo arduo". (Entrevista, enero 2014).

Según lo expuesto por el Secretario de Planeación, la metodología fue totalmente participativa, donde se consultaron los diferentes sectores y grupos poblacionales

La formulación del presente Plan de Desarrollo Municipal responde plenamente a su premisa fundamental de "Unidos Logramos el Cambio"; la identificación de más de cincuenta actores sociales y la realización de múltiples mesas de trabajo con instrumentos y metodologías acordes a los perfiles y contextos en los que se programaron cada una de ellas garantizaron la representación de los diferentes puntos de vista, intereses y propuestas de la comunidad La metodología que se utilizo es la propuesta por Planeación Nacional ajustada a la realidad del municipio, generando la participación de la población en tres grandes componentes el social, el territorial económico y el institucional, participación que es coherente con los ejes formulados en el Plan de Desarrollo. (Municipio de Subachoque, 2012, p. 6).

Para la realización del diagnóstico y lograr la participación de la comunidad en las mesas, se utilizaron varias metodologías: 
Con los niños, participaron los papás, donde se les preguntó qué es lo que quisieran ellos para sus hijos. Con los niños más grandecitos se hizo una actividad, pues ellos dibujaban como querían ver al municipio y de esa idea que ellos querían ver al municipio, cuando ellos fueran grandes, se empezó pues, digamos se sustrajo que era lo que querían en la primera infancia. Con los adolescentes por ejemplo, se les reunió en los colegios y se les preguntó que esperaban para sí mismos, y luego que esperaban para el municipio... Fue muy consecuente el tema de oportunidades, que muchos no querían irse, pero que no encontraban formas, entonces eso empezó a orientarse a encadenarse, bueno hagamos una industria turística, hagamos un tema de industria o mejores prácticas agropecuarias que requieran niveles técnicos y profesionales... entonces empezar a construir eso. Por eso se empezó a traer el tema, a construir el tema de educación". (Entrevista, enero 2013).

Igualmente, se utilizaron diferentes preguntas como ¿qué quieren de su municipio que no se pierda? consulta realizada con la población en situación de discapacidad y su familia, adulto mayor, mujeres, los gremios y las organizaciones sociales.

Realizado el diagnóstico, se procedió a la elaboración del plan de desarrollo, para el cual se capacitó al equipo de la Alcaldía, quien elaboró el primer esquema fue en asesor externo; a partir del esquema, se trabajaron los ejes, sectores y programas, teniendo como insumos la línea base y el plan de gobierno, cruzando los programas con el presupuesto.

Dentro del proceso, se tuvo en cuenta la elaboración del cronograma y programación de las actividades a seguir para su aprobación final. Se dio el tiempo estipulado de un (1) mes para la recepción de comentarios y aportes que complementarán el trabajo técnico, requerido para la elaboración del documento completo y riguroso que a 30 de marzo de 2012 sería sometido a consideración del Consejo Territorial de Planeación y una vez surtido el trámite en esta instancia se programó entregar el 30 de abril de 2012, el Proyecto de Acuerdo que se sometió a aprobación del Concejo Municipal. (Municipio de Subachoque., 2012, p. 16). 
Una vez aprobado, se inicia la programación para la ejecución del plan, como lo plantea en la entrevista el Secretario de Planeación:

En ese punto ya se crean proyectos concretos donde se incluyen ya las actividades que se pueden determinar en el presupuesto. Contratos, convenios, asociaciones, eso ya se articula de esa manera, entonces se crea un proyecto que incluya las metas que se quieren lograr y sobre ese proyecto se hace un plan de acción, se determinan unas acciones a cumplir, pues que generalmente nosotros no nos complicamos la vida diciendo y haciendo románticos. El plan de acción es contratar un profesional que soporte las actividades de desarrollo... de desarrollo social en estas actividades: Contratar unas personas que se encarguen de las cosas... cuantas personas, tantas y eso se articula y eso se ejecuta. (Entrevista, 2014).

En la revisión de documentos y en la entrevista se evidenció la utilización de metodologías innovadoras de acuerdo a los grupos poblacionales consultados lo que generó una mayor participación y se reflejó en la elaboración del Plan de Desarrollo.

El seguimiento del Plan de desarrollo lo elabora el Secretario de Planeación, a parir de la revisión global junto con el Consejo de Gobierno, sobre cómo van en la implementación de los ejes, los avances por sectores y programas. El seguimiento a las metas las hace cada secretario de despacho, "ellos ya responden por la meta como tal. Dicho seguimiento se hace sobre una tabla elaborada en Excel". (Entrevista, 2014).

Con el fin de corroborar lo percibido a través de las entrevista y lo extraído de los documento pertinentes al PDM, las investigadoras realizaron la evaluación del plan de desarrollo a través del instrumento "Una Aproximación a su estructura y contenidos del Plan de Desarrollo", evaluación en la que la estructura de este PDM obtuvo una calificación satisfactoria del $90 \%$ en cuanto a lo contenido en los aspectos evaluados. La estructura del documento es coherente, ordenado y cumple con los parámetros establecidos por la ley 152 de 1994. 
En lo referente al plan plurianual de inversión se especifica claramente a cada eje y sector la destinación de los recursos propios libres, los del sistema general de regalías y otros que no se especifican.

Se destacan como aspectos significativos del proceso de construcción e implementación del PDM de Subachoque las metodologías utilizadas para la elaboración del diagnóstico, el compromiso de equipo de trabajo, la elaboración de una política pública integral donde se benefician todos los grupos poblacionales y que fue elaborada con la participación de la comunidad.

Como debilidades del documento del PDM, se considera que el no haberlo contextualizado con la información obtenida en el diagnóstico participativo que se realizó con la comunidad, le resta sustento argumentativo a las acciones plantadas para responder a las necesidades identificadas.

En lo referente a objetivos, solo formula el objetivo general del plan sin que se desagregue en objetivos específicos que recoja lo que se pretende alcanzar con el Plan de desarrollo.

No se evidencia la articulación con el plan de desarrollo departamental, ni con otros sectores que muestren un desarrollo integral.

La formulación del Plan contempla lo básico que plantea la ley; en el documento no se muestran las estrategias de evaluación y seguimiento del plan, aun cuando en la entrevista lo manifiesta el Secretario de Planeación.

En cuanto a los recursos e infraestructura, se observa que, siendo un municipio con un presupuesto anual reducido e insuficiente para sus necesidades sociales y de desarrollo integral, ha avanzado en cobertura de infraestructura y se mantiene bajo la convicción de no industrializar su territorio, sino fomentar la industria liviana (como procesadoras de los productos 
agrícolas) para generar desarrollo económico y a su vez proteger el medio ambiente. A continuación, en el cuadro 7 , se visualizan los recursos con que cuenta el municipio.

CUADRO 8.

CARACTERIZACIÓN Y RECURSOS (6)

\begin{tabular}{|c|c|c|c|c|}
\hline ÍTEM & MUNICIPIOS & & & SUBACHOQUE \\
\hline 1 & Categoría & & & 6 \\
\hline 2 & Tamaño en Km2 & & & 21,153 \\
\hline 3 & Número de habitantes & Zona & Urbana & 5.722 \\
\hline & & & Rural & 9.452 \\
\hline 4 & $\begin{array}{l}\text { Presupuesto anual en } \\
\text { millones de pesos }\end{array}$ & & & 6.500 \\
\hline \multirow{18}{*}{5} & \multirow{18}{*}{ Infraestructura } & Servicios públicos & Domiciliarios & 1 \\
\hline & & & Veredales & 0,8 \\
\hline & & Servicios de salud & Hospitales & 0 \\
\hline & & & Clínicas & 0 \\
\hline & & & Puestos salud & 1 \\
\hline & & Servicios educativos & Colegios & 1 \\
\hline & & & Escuelas & 1 \\
\hline & & & Universidades (sedes) & 1 \\
\hline & & Servicios Transporte & Municipal & 0,6 \\
\hline & & & Intermunicipal & 1 \\
\hline & & Servicios bancarios & & 1 \\
\hline & & $\begin{array}{l}\text { Espacios culturales y } \\
\text { recreativos }\end{array}$ & Casa cultura & 1 \\
\hline & & & Teatros & 0 \\
\hline & & & Parques públicos & 1 \\
\hline & & & Cines & 0 \\
\hline & & & Polideportivos & 1 \\
\hline & & Entidades varias & Bombero & 0 \\
\hline & & & Estación policía & 1 \\
\hline
\end{tabular}




\begin{tabular}{|c|c|c|c|}
\hline & & Registraduría & 1 \\
\hline & & Hoteles & 0 \\
\hline & & Iglesias & 1 \\
\hline & & Humanos & 0,5 \\
\hline & Recursos & tecnológicos & 0,5 \\
\hline $\begin{array}{l}\text { TOTALES POR } \\
\text { MUNICIPIO: }\end{array}$ & & & $15,4 \quad 67 \%$ \\
\hline
\end{tabular}

Las restricciones presupuestales no le permiten al municipio contratar más personal calificado que apoye la implementación de los ejes y programas, por lo tanto se apoya en convenios con instituciones universitarias y la colaboración de la ciudadanía y del sector privado para sacar adelante su PDM y ofrecer servicios sociales a la población.

A continuación se presenta el cuadro resumen de la evaluación realizada a cada uno de los municipios seleccionados para la investigación, a través de la Matriz: Planes de desarrollo: una aproximación a su estructura y contenidos de Departamento Nacional de Planeación. Rosero, (2013)

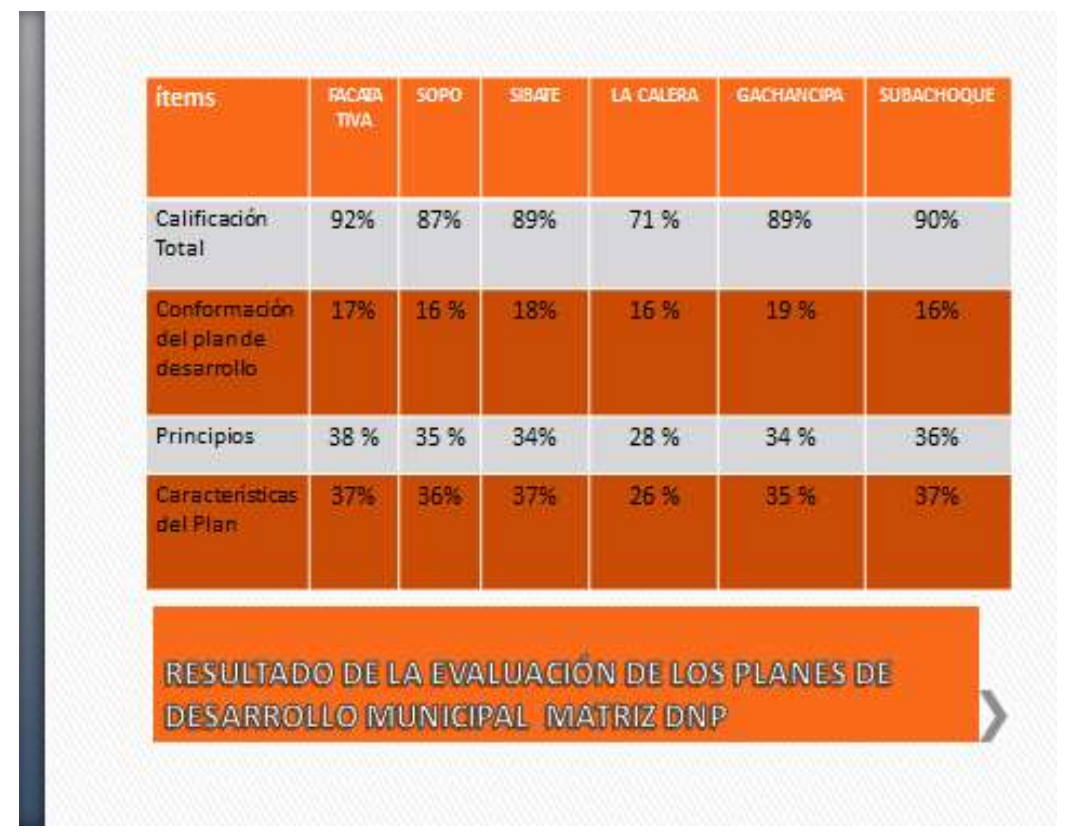

Fuente: Elaboración propia 


\subsection{Análisis comparativo}

En esta aparte se hace un análisis comparativo de los procesos realizados en los seis municipios estudiados, identificando similitudes y aspectos diferenciadores, así como la relación que puede existir entre la categoría y las fortalezas y debilidades observadas en los entes territoriales estudiados.

Igualmente, la Constitución de 1991 avanzó en el sentido de abrir paso a la participación de los ciudadanos en la planeación de sus regiones y municipios; en su artículo 340 se conformó el Sistema Nacional de Planeación compuesto por el Consejo Nacional y los Consejos Territoriales de Planeación; luego, la Ley 152 o Ley Orgánica Nacional de Planeación reglamentó lo estipulado en la Constitución.

Como resultado de la evaluación del diseño y estructuración de los PDM de Facatativá, Sopó, Sibaté, La Calera, Subachoque y Gachancipá, se identificó que todos contemplan la estructura mínima y unificadora y los lineamientos básicos establecidos en la ley 152/94 (Capítulo VIII, Artículo 31) en la que se explicita, que los "planes de desarrollo de las entidades territoriales estarán conformados por una parte estratégica y un plan de inversiones a mediano y corto plazo en los términos y condiciones que de manera general reglamenten las Asambleas Departamentales y los Concejos Distritales y Municipales o las autoridades administrativas que hicieren sus veces, siguiendo los criterios de formulación establecidos en la presente Ley".

Si bien cada municipio tiene autonomía para planear y diseñar el desarrollo que pretende alcanzar en los 4 años (2012-2015) y determinar la especificidad de los programas, proyectos, recursos, actividades y metas, entre otros asuntos, estos deben tener en cuenta para su elaboración las políticas y estrategias del Plan Nacional de Desarrollo y garantizar la coherencia entre estos. (Ley 152/94, Artículo 32). 
Para el análisis de los resultados, se tuvo en cuenta lo contenido en el mencionado artículo 32, observándose que los seis planes estudiados están estructurados en las dos partes ordenadas. En los contenidos de la parte uno (1) se vislumbra las diferencias en cuanto a contenidos, diseño y estructuración de los documentos, así como en la formulación técnica de metas e indicadores.

En algunos casos, como el de Facatativá y Gachancipá, se contemplan marcos conceptuales, enfoques, normatividad, mientras que en otros se limitan a los incluir los ejes estratégicos y programas que determinan la especificidad de las acciones a implementar en el periodo 2012-2015 (o 2016, según sea el caso), información que se analizará una vez se exponga lo observado en cada uno de los municipios estudiados.

En los seis municipios, el proceso de elaboración de los Planes de Desarrollo Municipal se cumplió a cabalidad, siguiendo lo establecido en la normatividad, concluyendo los procesos con la validación y aprobación de sus contenidos por medio de la expedición de los Acuerdos de los Concejos Municipales de los respectivos municipios en el tiempo reglamentario (Primer semestre de 2012).

Como aspectos comunes identificados con este estudio, los municipios estudiados se rigieron fielmente por las indicaciones dadas a través de la Ley Orgánica del Plan de Desarrollo (Ley 152/1994), siguiendo los procedimientos y mecanismos establecidos para la elaboración, aprobación, ejecución, seguimiento, evaluación y control de los planes de desarrollo nacional y de los entes territoriales y la regulación de los aspectos contemplados en el artículo 342 del capítulo $2^{\circ}$ del título XII de la Constitución Política y demás normas referidas al plan de desarrollo y la planificación municipal..

Los aspectos más relevantes y diferenciadores, identificados en los procesos de elaboración e implementación de los PDM de los seis municipios, 
se observan básicamente en los planes estratégicos, por la forma en que se expresan las misiones, visiones y orientaciones conceptuales que sustentan los planes y en el énfasis programático expresado en la titulación de los ejes de cada uno de los planes estudiados, lo que muestra que siguen los parámetros ordenados en la Ley 152/94 para la estructuración de los planes.

En el contenido de los ejes y programas, cada municipio busca expresar su identidad territorial; el derrotero y énfasis que le dan a los programas, permite inferir el enfoque de desarrollo que subyace en el PDM y la orientación a la gestión que el alcalde electo y su equipo de gobierno pretenden darla al municipio, en el corto y mediano plazo, según la proyección expresada en la visión.

En los seis municipios se contextualizan los programas del PDM, con base en las necesidades, problemas y proyecciones identificadas por medio de líneas base, consultas a la comunidad y documentos de las alcaldías y los lineamientos contenidos en el programa de gobierno y se sustentan las acciones por medio de la normatividad y la estructuración del documento con base en los contenidos mínimos que se exigen a través de la ley 152/94; en los PDM de Facatativá, Gachancipá y Sibaté se hace alusión a la armonización con los planes de desarrollo regional y nacional, y a la implementación de algunas políticas públicas como son las de infancia y adolescencia y educación, sin embargo en la operacionalización de los contenidos de los PDM no se hace explicito como es la estrategia de articulación y de las sinergias que se requieren desarrollar para la armonización de los planes.

Básicamente, los aspectos significativos y diferenciadores entre los municipios estudiados se encontraron en la formulación de las misiones, visiones y orientaciones conceptuales (de las que las tienen) que sustentan el sentido del plan. El énfasis programático se diferencia en los programas y 
subprogramas, ya que los ejes son similares en todos siguiendo los lineamientos

Teniendo como base la categoría planeación y las subcategorías participación, gestión y recursos se realizó el análisis e interpretación de la incidencia de estas en los procesos, diseño y gestión de los PDM de los seis municipios estudiados.

\subsection{Fortalezas y debilidades, similitudes y diferencias}

En los procesos de elaboración de los PDM de Facatativá, Sopó, Sibaté, La Calera, Gachancipá y Subachoque se aprecia el avance en la institucionalidad que ha adquirido el proceso de planeación territorial en Cundinamarca. Estos municipio son representativos, cada uno en su categoría; por lo tanto, es posible suponer que la implementación de la Ley 152 de 1994 ha ido surtiendo un efecto positivo sobre las estructuras administrativas de las alcaldías y ha ido perfeccionando la manera de planear el desarrollo integral de los territorios, para beneficio de sus habitantes y del departamento en general.

El aspecto más significativo a desatacar en el proceso de elaboración de los PDM fue el componente participativo, al cual se le dio la real importancia que esta tiene en un Estado Social de Derecho como es el caso de Colombia, en el que su eje central es la democracia participativa.

Las consultas participativas son un instrumento valioso para el Alcalde y su equipo de Gobierno, ya que les permite conocer de viva voz la realidad del municipio, quien, por su parte, tiene un panorama aproximado de qué pasa en el territorio y hacia dónde debe ir el desarrollo del mismo, lo cual está plasmado en el plan de gobierno. 
La Participación como subcategoría se contempló en esta investigación como un factor fundamental para la construcción del plan de desarrollo, no solo porque es de obligatorio cumplimiento según la Ley 152/94, sino porque lo requieren los candidatos a alcaldes para la construcción del plan de gobierno y luego de la elección, para la elaboración del Plan de Desarrollo Municipal.

Según González (1995), participación

Es una forma de intervención social que le permite a los individuos reconocerse como actores, que al compartir una situación determinada tiene la oportunidad de identificarse a partir de intereses, expectativas comunes y que están en capacidad de traducirlas en formas de actuación colectiva con cierta autonomía frente a otros actores sociales y políticos". (González, 1995, p. 17).

En los municipios estudiados, el proceso de participación se concretó en las consultas a las comunidades, los sectores sociales, los diferentes segmentos poblacionales, en la recolección de información y priorización de acciones basadas en la determinación de intereses, posibilidades y necesidades locales, lo que le permitió al alcalde buscar respuestas pertinentes a las expectativas de sus electores y, además, garantizar gobernabilidad y posibilidades de una gestión exitosa.

Para el análisis de lo acontecido en cada municipio, se tuvo en cuenta lo expresado por el entrevistado y lo contenido en cada uno de los Planes de Desarrollo Municipales, en los que se explicita, con más o menos detalles según sea el caso, el proceso de consulta y construcción, los criterios, los medios, estrategias, los niveles y las formas de participación de los diferentes actores consultados.

De los seis municipios estudiados, Facatativá (categoría 3) es el que presentó las mejores condiciones en el proceso de elaboración e implementación del PDM en todos los aspectos; la participación para la 
realización del diagnóstico y definición de los contenidos pertinentes para su PDM fue amplia, suficiente, plural; para la gestión cuenta con recursos económicos propios, mayor autonomía administrativa (municipio certificado) para la realización de los programas y proyectos que no requieren ser financiados con recursos de la nación o el departamento y que le permiten responder a sus necesidades locales, no con la cobertura y efectividad requerida de acuerdo con las demandas del entorno social, pero sí con la autonomía que le da su categoría, situación muy diferente a Sopó, que igualmente es categoría 3 , sin embargo, en cuanto a dinámica institucional y el desarrollo del municipio se aprecia una gran diferencia; Facatativá tiene un entorno territorial semejante al de una ciudad en vía de crecimiento, mientras que Sopó se visualiza como un territorio rural, planificado para el desarrollo de la industria láctea y de la construcción, que no ha impactado negativamente la cultura campesina y aún se respira en el casco urbano el ambiente de un hábitat rural, lo que hace suponer que las diferencias en cuanto a recursos y posibilidades no necesariamente tienen impacto negativo sobre un municipio, sino que los procesos se ajustan a sus recursos y se optimizan al máximo para cumplir con lo ordenado por la Ley.

Además de lo dicho sobre Facatativá en lo referido a la participación, este estudio permitió constatar que también en Sopó (categoría 3), Sibaté (categoría 4), La Calera (Categoría 5) y Gachancipá y Subachoque (categoría 6) la participación de la comunidad fue una gran fortaleza; se usaron técnicas innovadoras, se logró consultar sectores y grupos poblacionales y adelantar procesos democráticos en la priorización de necesidades y definición de las problemáticas a privilegiar en el Plan de Desarrollo Municipal; la variedad de estrategias metodológicas utilizadas permitieron la libre expresión o el direccionamiento de las discusiones con base en temáticas y factibilidad previamente establecidas, como fue el caso de La Calera.

Es importante tener en cuenta que los niveles de participación de la comunidad en los procesos de elaboración e implementación del plan de 
desarrollo municipal, dependen de muchos aspectos exógenos como son: el interés de la comunidad sobre los temas a tratar, la credibilidad y liderazgo que tengan quienes convocan, la facilidad de acceso al lugar de la reunión, las expectativas que se tengan frente a beneficios que puedan obtener, la metodología y la confianza que se tengan sobre sí mismos las personas convocadas, entre otros aspectos.

El asesor de planeación de uno de los Municipio estudiados, quien ha tenido la oportunidad de participar y conocer varios procesos de construcción de planes de desarrollo de Municipios de Cundinamarca comento:

Normalmente la comunidad, lo que hace son listas de mercado y excúseme el término que voy a decir, listas de mercado simples, cada quien tiene un interés puntual. Entonces, quieren que pique acá, quieren el pedazo de manguera acá, quieren el pedazo de tubo aquí, o quiere el viaje de recebo allí. Requerimientos que no obedecen obviamente a un programa... a la política de un sector y a la aplicación de un programa o de un subprograma que realmente venga enmarcado de lo macro a lo micro... La inclusión de estas demandadas en los planes de desarrollo, con el ánimo de cumplirle a la comunidad lo prometido en las campañas, termina desbordando los recursos, pulverizando el presupuesto en actividades de bajo impacto, por satisfacer a la comunidad, pero no solucionando los problemas de fondo. (Entrevista, 2014).

Cuando se realiza la convocatoria de la población, los equipos de gobierno y metodólogos que la ejecutan, tienen como punto de partida los ejes de discusión, basados en el Plan de Gobierno, y la factibilidad de atender demandas que requieren grandes inversiones y el apoyo del departamento y/o la nación.

Como se aprecia en el Cuadro 8, en los seis municipios estudiados los aspectos contemplados para desarrollar la consulta participativa e involucrar a la comunidad en la elaboración de los PDM, fue muy similar; la diferencia estuvo básicamente en las estrategias metodológicas utilizadas para recopilar el sentir de los diferentes grupos poblacionales y sectores, aspecto no asociado a 
la categoría del municipio sino a la capacidad innovadora en las técnicas aplicadas, que facilitaron la realización del diagnóstico y priorización de necesidades.

\section{CUADRO 9}

\section{PARTICIPACIÓN}

\begin{tabular}{|c|c|c|c|c|c|c|c|}
\hline Proceso & Ítem & Subachoque & Facatativá & Sibaté & Gachancipá & $\begin{array}{c}\text { La } \\
\text { Calera }\end{array}$ & Sopó \\
\hline $\begin{array}{l}\text { Actividades } \\
\text { preliminar }\end{array}$ & $\begin{array}{c}\text { Línea base } \\
\text { Pilares/ejes del } \\
\text { Plan de gobierno }\end{array}$ & 1 & 1 & 1 & 1 & 1 & 1 \\
\hline \multirow{4}{*}{$\begin{array}{c}\text { Consulta } \\
\text { participativa }\end{array}$} & $\begin{array}{c}\text { Criterios de } \\
\text { participación Por } \\
\text { segmentos } \\
\text { poblacionales }\end{array}$ & 1 & 1 & 1 & 1 & 1 & 1 \\
\hline & $\begin{array}{l}\text { Sectoriales, } \\
\text { organizaciones } \\
\text { gremiales y } \\
\text { sociales. }\end{array}$ & 1 & 1 & 1 & 1 & 1 & 1 \\
\hline & $\begin{array}{c}\text { Consulta verbal, } \\
\text { escrita, } \\
\text { cartografía }\end{array}$ & 1 & 1 & 1 & 1 & 1 & 1 \\
\hline & $\begin{array}{l}\text { Lúdica según } \\
\text { grupo } \\
\text { poblacional. }\end{array}$ & 1 & 1 & 0 & 0 & 0 & 1 \\
\hline
\end{tabular}




\begin{tabular}{|c|c|c|c|c|c|c|c|}
\hline & $\begin{array}{c}\text { Mesas de } \\
\text { concertación por } \\
\text { sectores (barrios, } \\
\text { veredas) }\end{array}$ & 1 & 1 & 1 & 1 & 1 & 1 \\
\hline & $\begin{array}{c}\text { Mesas } \\
\text { especializadas }\end{array}$ & 1 & 1 & 1 & 1 & 1 & 1 \\
\hline & $\begin{array}{c}\text { grupos } \\
\text { poblacionales }\end{array}$ & 1 & 1 & 1 & 1 & 1 & 1 \\
\hline & Territoriales & 1 & 1 & 1 & 1 & 1 & 1 \\
\hline & $\begin{array}{l}\text { Consejo de } \\
\text { gobierno }\end{array}$ & 1 & 1 & 1 & 1 & 1 & 1 \\
\hline & Diagnostico & 1 & 1 & 1 & 1 & 1 & 1 \\
\hline & $\begin{array}{l}\text { Priorización por } \\
\text { ejes según plan } \\
\text { de gobierno y } \\
\text { sectores }\end{array}$ & 1 & 1 & 1 & 1 & 0 & 1 \\
\hline $\begin{array}{l}\text { Elaboración } \\
\text { del PDM }\end{array}$ & $\begin{array}{l}\text { Toma de } \\
\text { decisiones }\end{array}$ & 1 & 1 & 1 & 1 & 1 & 1 \\
\hline Total & & 13 & 13 & 12 & 12 & 11 & 13 \\
\hline
\end{tabular}

Fuente: Elaboración propia

Para realizar estas consultas, los alcaldes y su equipo de gobierno, en algunos casos a través de los asesores externos, definen diferentes criterios para la participación, como son: por grupos poblacionales, por problemáticas, por grupos según el ciclo vital, niños y niñas, jóvenes, adultos y adultos mayores, por organizaciones sociales como las juntas de acción comunal y gremiales, así como por sectores como salud, educación, industrial, agrícola, entre otras; estrategias que se reflejan en la amplia participación que se logra cuando de definir las problemáticas y necesidades de cada uno de los sectores y que realmente se puedan ver incluidas en el plan de desarrollo municipal.

Los mecanismos generalmente utilizados para poder escuchar a cada uno de los grupos, sectores y poblaciones interesadas, son las mesas de trabajo donde se definen los de acuerdo con los ejes establecidos en el plan de gobierno. Las estrategias las establecen cada municipio, según se constata a través del siguiente testimonio. 
...Se estableció otro mecanismo que era, identificar un problema, y a ese problema plantearle un determinado número de soluciones, ¿cierto? Y había dentro de la misma mesa, por ejemplo mesas que eran ciudadanas, se establecían varios temas, por ejemplo, quienes quieren hablar sobre el eje de movilidad, quienes quieren hablar sobre el eje de seguridad, quienes quieren sobre salud, etc.

- $\quad$ Se iban como subdividiendo esas mesas.

Sí, digamos que el Plan de Desarrollo como tal tiene cinco ejes. Digamos que los cinco ejes fundamentales del Plan son, uno que es el eje social, otro que es el que tiene que ver con desarrollo económico, que es el de movimiento, un tercer eje que es el de infraestructura, un cuarto eje que es con el tema de seguridad y gobierno y un quinto eje con tecnología e innovación, esos eran como los cinco ejes. Entonces las mesas lo hacían de acuerdo a eso. Entonces, quienes quieren opinar sobre el tema de tecnología, quienes quieren opinar sobre el tema de seguridad, sobre el tema de infraestructura, sobre movilidad y se hacía un planteamiento, no para que la gente fuera a pedir cosas puntuales, sino que la gente pudiera llegar a determinar cuál era la problemática del sector, por ejemplo si era de movilidad, cuál era la problemática... que no había vías suficientes, o que el transporte no cumple horarios o que hay mala calidad del servicio, entonces se establecía como la problemática y se planteaban soluciones. (Entrevistado 1, 2014).

Otro elemento importante es los tipos de convocatorias, las cuales se hacen a través de medios tradicionales como son el perifoneo, la cartelera, radio comunitaria y la televisión comunitaria como en el caso del municipio de Sibaté, lo esencial para lograr un alto grado de participación es convocarlos en el caso de las comunidades en los barrios o veredas directamente, como lo expresa uno de los entrevistados.

"Se hizo convocatoria igual, pero se hace es, en donde ellos están en el sitio en donde ellos están para asegurarse... no que la gente venga acá sino en los salones comunales, en los espacios, en las escuelas... El tema es de convocatoria si se hizo directamente en sectores". (Entrevistado 3, 2014).

Otro aspecto que incidió en la consulta en los municipios es la directiva contenida en la ley 154 de 1994, que contempla en su artículo $3^{\circ}$, literal g, que "Durante el proceso de discusión de los planes de desarrollo, las autoridades de 
planeación velarán porque se hagan efectivos los procedimientos de participación ciudadana". Esta obligatoriedad implica que el alcalde realice consultas a la población sobre las necesidades y problemas globales, que deben ser atendidas a través del plan de desarrollo Municipal, a partir de los ejes contemplados en los planes de gobierno.

En algunas ocasiones, los resultados de los procesos participativos no fueron los esperados por los alcaldes y sus equipos de gobierno, ni por las comunidades, ya que los aspectos consultados requerían estar enmarcados en las líneas establecidas en el plan de gobierno y a los mandatos del Plan de Desarrollo Nacional, que no siempre concuerdan ni son pertinentes con las necesidades del municipio y sus pobladores.

Si bien el número de participantes en los seis municipios fue suficiente para los procesos, es importante resaltar la necesidad que existe de "crear una cultura democrática de la participación, que implica valores como la solidaridad, el respeto por la diferencia, la tolerancia y la participación" (González et al., 1995, p. 20), aspectos fundamentales para fortalecer la participación ciudadana y el compromiso con el desarrollo integral del territorio.

Como una fortaleza, se identificó la creatividad de los alcaldes y sus equipos de gobierno o, en su defecto, el asesor externo, en la utilización de la lúdica y otras estrategias para conocer las necesidades y problemáticas de los grupos; por medio de estas técnicas, se realizó el diagnóstico y la prospectiva del municipio, técnicas especialmente utilizadas con niños, jóvenes y adultos mayores.

Una debilidad, observada en los procesos de planeación municipal, es que, a pesar de que hay metodologías y cartillas elaboradas por el DNP para la formulación del plan de desarrollo, en los de los municipios participes de este estudio, con excepción de La Calera, no utilizan dicha metodología; algunos de 
los entrevistados manifestaron que estos instrumentos no aportan todos los elementos requeridos a nivel particular para elaborar el plan de desarrollo, ni para articular los programas con el del Plan Nacional de Desarrollo, especialmente en aspectos relacionados con primera infancia, población desplazada y población vulnerable, entre otros.

También se observó que, en todos los municipios, la participación ciudadana disminuye sustancialmente en el momento de la ejecución y evaluación del plan, debido a que las personas, organizaciones y grupos poblacionales no participan de la misma manera; algunos comités de veedurías, Juntas de Acción Comunal y personas a nivel individual están pendientes de los cumplimientos de las metas que se han establecido en el plan de desarrollo y de fiscalizar las acciones del gobierno municipal.

Como se aprecia en el análisis de los resultados de esta subcategoría, y los testimonios de los entrevistados, la participación de la comunidad es un eje estratégico para la elaboración del plan de desarrollo municipal, el interrogante que surge es ¿qué tan preparada esta política y culturalmente las comunidades para que su participación aporte realmente los elementos, componentes y reflexiones que incidan y determinen los derroteros que debe seguir el gobierno municipal para alcanzar el desarrollo integral y efectivo del municipio y sus pobladores?

\subsection{Gestión para el direccionamiento de la planeación}

Para poder analizar la gestión del proceso de elaboración de los PDM, se desagregó la esta subcategoría en indicadores, sobre los cuales se determinaron las acciones que permitieron identificarlos aspectos tenidos en cuenta para la construcción del Plan de Desarrollo Municipal (PDM), como es si los alcaldes y su equipo contaron con: a) asesores externos, b) autonomía del alcalde electo y el equipo de trabajo para definir la estrategia y la elaboración del PDM, c) capacitación metodológica de equipo responsable interna y/o 
externa, d) acompañamiento del DNP/metodología o departamental, e) articulación explícita con plan de desarrollo departamental y plan nacional, e) estructura del PDM por ejes, metas, programas, poblaciones, y f) si el PDM cuenta con Indicadores cuantitativos y cualitativos.

Entre las principales fortalezas encontradas en esta subcategoría se destaca la capacidad profesional y recursos humanos con que cuentan los municipios, la cual es más alta en la medida en que el municipio está mejor categorizado; otra es la disponibilidad de recursos propios y transferencias de la nación, ventajas competitivas que permiten inferir que estos son aspectos determinantes para que el municipio logre mayor nivel de desempeño integral, ser más eficiente y efectivo, tal como se constata en el documento "Evaluación del desempeño integral de los municipios y distritos", realizada por el DNP (2013) para el periodo 2013.

Según el documento del DNP (2013), entre los 20 municipios del país que lograron mejor desempaño integral están: Facatativá, puesto 4; Sibaté, puesto 9; Sopó, puesto 15; y La Calera, puesto 17 (DPN, 2013, p. 28), resultados importantes para el departamento de Cundinamarca y que se pudieron constatar desde una perspectiva académica en las visitas realizadas a los territorios y con las entrevistas realizadas a los funcionarios de las alcaldías municipales.

CUADRO 10

Resultados Municipales

\begin{tabular}{|l|l|l|l|}
\hline $\begin{array}{l}\text { Municipios con } \\
\text { mejor desempeño } \\
\text { Integral 2013 } \\
\text { Código DANE }\end{array}$ & Entidad Territorial & $\begin{array}{l}\text { Indicador } \\
\text { Desempeño } \\
\text { Integral } \\
\mathbf{2 0 1 3}\end{array}$ \\
\hline 05001 & 1 & Medellín-Antioquia & 92,4 \\
\hline 25430 & 2 & Madrid-Cundinamarca & 91,6 \\
\hline 76520 & 3 & Palmira-Valle Del Cauca & 91,5 \\
\hline 25269 & $\mathbf{4}$ & Facatativá-Cundinamarca & $\mathbf{9 1 , 2}$ \\
\hline 76563 & 5 & Pradera-Valle Del Cauca & 89,7 \\
\hline 25175 & 6 & Chía-Cundinamarca & 89,7 \\
\hline 05088 & 7 & Bello-Antioquia & 89,5 \\
\hline
\end{tabular}




\begin{tabular}{|l|l|l|l|}
\hline 25899 & 8 & Zipaquirá-Cundinamarca & 89,3 \\
\hline 25740 & $\mathbf{9}$ & Sibaté-Cundinamarca & $\mathbf{8 9}$ \\
\hline 85010 & 10 & Aguazul-Casanare & 89 \\
\hline 54498 & 11 & Ocaña-Norte De Santander & 88,9 \\
\hline 25123 & 12 & Cachipay-Cundinamarca & 88,9 \\
\hline 08001 & 13 & Barranquilla-Atlántico & 88,8 \\
\hline 25290 & 14 & Fusagasugá-Cundinamarca & 88,5 \\
\hline 25758 & 15 & Sopo-Cundinamarca & $\mathbf{8 8 , 4}$ \\
\hline 68211 & 16 & Contratación-Santander & 88,3 \\
\hline 25377 & $\mathbf{1 7}$ & La Calera-Cundinamarca & $\mathbf{8 8 , 2}$ \\
\hline 25183 & 18 & Chocontá-Cundinamarca & 88,1 \\
\hline 25898 & 19 & Zipacón-Cundinamarca & 87,5 \\
\hline 25807 & 20 & Tibirita-Cundinamarca & 87,4 \\
\hline
\end{tabular}

Fuente: DNP. Evaluación del desempeño integral de los municipios y distritos,

Vigencia 2013.

En cuanto al desempeño Integral por regiones, en el documento DNP "Evaluación del desempeño integral de los municipios y distritos, Vigencia 2013", se presenta la consolidación de los resultados del Desempeño Integral con una óptica regional, de manera que se puedan realizar comparaciones para territorios vecinos que compartan características geográficas y culturales. Los resultados en la región Centro Oriente se destaca que 105 municipios tuvieron una medición "Sobresaliente" (29\% de las entidades). En este grupo se destacan 10 municipios de Cundinamarca (Madrid, Facatativá, Chía, Zipaquirá, Sibaté, Cachipay, Fusagasugá, Sopó, La Calera y Chocontá), junto con los municipios de Ocaña, Norte de Santander, y Contratación, Santander.

Subachoque y Gachancipá, municipios categoría 6, si bien no se encuentran entre los seleccionados por su desempeño integral, por lo que se pudo observar, avanzan en sus procesos organizativos, con una clara visión de desarrollo e identidad local, que seguramente sí continuará en el camino trazado, en un mediano plazo será también reconocido por su desempaño integral. En el caso de Gachancipá, no se obtuvo la información que permita hacer una mirada prospectiva de 
su desarrollo, aunque por lo que se observa en el espacio físico, se está desarrollando una vocación industrial que posiblemente jalonará el empleo y el fortalecimiento de las arcas municipales y fue reconocido en la evaluación del DNP (2014) por su desempeño fiscal.

El direccionamiento de la gestión para la estructuración del Plan de Desarrollo de los municipios es un aspecto netamente administrativo, en el que juegan factores a favor y en contra relacionados con las competencias y capacidades profesionales del equipo de gobierno y asesores que lo orientan. La posibilidad y disponibilidad de acceder a asesorías externas, acompañamiento del departamento de Cundinamarca y de contar con funcionarios altamente calificados en el tema de la planeación, se convierte en fortalezas que se reflejan en los logros alcanzados en los procesos de desarrollo municipal, y que se constata en las evaluaciones anuales que hace el Departamento Nacional de Planeación; la tabla 15 del documento del 2013, que se presenta a continuación muestra el honroso lugar que ocupan cuatro de los seis municipios seleccionados para este estudio.

A continuación se presenta un cuadro resumen que permite visualizar los factores comunes y diferenciales que se presentan en las estructuras de los PDM de los seis municipios estudiados, identificados a través de la lectura de los Decretos de aprobación expedidos por los Concejos Municipales de cada uno de ellos en el 2012.

\section{CUADRO 11}

COMPARATIVO DE LAS ESTRUCTURAS Y PARTICULARIDADES DE LOS PDM DE LOS SEIS MUNICIPIOS ESTUDIADOS

\begin{tabular}{|l|l|c|c|c|c|c|}
\hline Ítem & Facatativá & Sopó & Sibaté & La Calera & Subachoque & Gachancipá \\
\hline Categoría & $\mathbf{3}$ & $\mathbf{3}$ & $\mathbf{4}$ & $\mathbf{5}$ & $\mathbf{6}$ & $\mathbf{6}$ \\
\hline $\begin{array}{l}\text { Articulación } \\
\text { explicita con el PD } \\
\begin{array}{l}\text { Nacional y / o } \\
\text { departamental }\end{array}\end{array}$ & $\begin{array}{l}\text { Se enuncia y } \\
\text { diagrama en el } \\
\text { PDM }\end{array}$ & Sí & $\begin{array}{c}\text { Enunciado, } \\
\text { no } \\
\text { explicitado }\end{array}$ & $\begin{array}{c}\text { Enunciado, } \\
\text { explicitado } \\
\text { la } \\
\text { articulación } \\
\text { con }\end{array}$ & Sí & Sí \\
\hline
\end{tabular}




\begin{tabular}{|l|c|c|c|c|c|c|} 
& & & & $\begin{array}{c}\text { proyectos } \\
\text { del } \\
\text { departament } \\
\text { o de } \\
\text { Cundinamar } \\
\text { ca }\end{array}$ & & \\
\hline $\begin{array}{l}\text { Articulación con el } \\
\text { Plan } \\
\text { Departamental }\end{array}$ & $\begin{array}{l}\text { Se enuncia } \\
\text { en el plan }\end{array}$ & Sí & No & $\begin{array}{l}\text { Sí a través } \\
\text { proyectos } \\
\text { conjuntos }\end{array}$ & Sí & Sí \\
\hline $\begin{array}{l}\text { Coherencia de la } \\
\text { misión con el PDM }\end{array}$ & Sí & Sí & Sí & Sí & Sí & Sí \\
\hline $\begin{array}{l}\text { Prospectiva visión } \\
\text { a mediano y largo } \\
\text { plazo }\end{array}$ & 2025 & 2016 & 2023 & No, & 2023 & Sí, al 2028 \\
\hline $\begin{array}{l}\text { Coherencia } \\
\text { objetivos } \\
\text { estratégicos con } \\
\text { visión }\end{array}$ & Sí & Sí & Sí & Parcialment \\
\hline
\end{tabular}

\begin{tabular}{|c|c|c|c|c|c|c|}
\hline Ítem & Facatativá & Sopó & Sibaté & La Calera & Subachoque & Gachancipá \\
\hline $\begin{array}{l}\text { Pertinencia y } \\
\text { actualidad del } \\
\text { diagnóstico, línea } \\
\text { base }\end{array}$ & Sí & $\begin{array}{l}\text { No hay } \\
\text { suficiente } \\
\text { informaci } \\
\text { ón }\end{array}$ & $\begin{array}{l}\text { Sí, cada eje } \\
\text { se sustenta } \\
\text { en el } \\
\text { diagnostico }\end{array}$ & $\begin{array}{|lr|}\text { No hay } \\
\text { información } \\
\text { en el } \\
\text { documento } \\
\text { de las } \\
\text { fuentes } \\
\text { consultadas, } \\
\text { diferente a } \\
\text { la } \\
\text { comunidad } \\
\end{array}$ & $\begin{array}{l}\text { En cada eje y } \\
\text { sector se } \\
\text { plantea el } \\
\text { diagnóstico }\end{array}$ & $\begin{array}{c}\mathrm{Si}, \\
\text { detallado, } \\
\text { comparativo } \\
\text {, } \\
\text { contextualiz } \\
\text { ado }\end{array}$ \\
\hline ¿Se definen ejes? & Sí & Sí & $\begin{array}{c}\mathrm{Si}, \\
\text { estructurale } \\
\text { s y de } \\
\text { programas }\end{array}$ & $\mathrm{Si}$ & Sí & $\begin{array}{c}\text { Sí, y se } \\
\text { contextualiz } \\
\text { an en } \\
\text { sectores }\end{array}$ \\
\hline
\end{tabular}




\begin{tabular}{|c|c|c|c|c|c|c|}
\hline $\begin{array}{l}\text { ¿Se enuncia } \\
\text { programas por } \\
\text { ejes? }\end{array}$ & $\begin{array}{l}\text { Sí, Sector, } \\
\text { Programas, } \\
\text { propósitos, } \\
\text { objetivos y metas }\end{array}$ & $\begin{array}{l}\text { Sí, } \\
\text { objetivos } \\
\text { y } \\
\text { program } \\
\text { as, } \\
\text { Metas e } \\
\text { indicador } \\
\text { es }\end{array}$ & $\begin{array}{l}\text { Sí, objetivos } \\
\text { meta de } \\
\text { impacto, de } \\
\text { resultado, } \\
\text { responsable } \\
\text { s }\end{array}$ & Sí & $\begin{array}{l}\text { SI, eje sector } \\
\text { u objetivos } \\
\text { estrategias, } \\
\text { metas e } \\
\text { indicadores }\end{array}$ & $\begin{array}{c}\text { Sí, y se } \\
\text { contextualiz } \\
\text { an en } \\
\text { sectores }\end{array}$ \\
\hline $\begin{array}{l}\text { ¿Se definen o } \\
\text { enuncia } \\
\text { subprogramas? }\end{array}$ & $\mathrm{Si}$ & Sí & $\begin{array}{c}\text { Sí, } \\
\text { objetivos, } \\
\text { meta de } \\
\text { producto, } \\
\text { diagnóstico }\end{array}$ & Si & No & $\begin{array}{c}\text { Sí, y se } \\
\text { contextualiz } \\
\text { an en } \\
\text { sectores }\end{array}$ \\
\hline $\begin{array}{l}\text { ¿Están planteadas } \\
\text { adecuadamente } \\
\text { las metas? }\end{array}$ & $\begin{array}{l}\text { En unas sí y en } \\
\text { otras se plantean } \\
\text { como objetivos }\end{array}$ & $\begin{array}{l}\text { En unas } \\
\text { sí y en } \\
\text { otras se } \\
\text { plantean } \\
\text { como } \\
\text { objetivos }\end{array}$ & $\begin{array}{l}\text { Se plantean } \\
\text { como } \\
\text { objetivos. }\end{array}$ & $\begin{array}{l}\text { Se plantean } \\
\text { como } \\
\text { objetivos }\end{array}$ & $\begin{array}{l}\text { En unas sí y } \\
\text { en otras se } \\
\text { plantean } \\
\text { como } \\
\text { objetivos }\end{array}$ & \begin{tabular}{|c|} 
Se plantean \\
como \\
objetivos, \\
pero se \\
explicita \\
muy bien los \\
alcances \\
cuantitativos
\end{tabular} \\
\hline $\begin{array}{l}\text { ¿Están planteados } \\
\text { los indicadores? }\end{array}$ & Sí & Sí & $\begin{array}{l}\text { Sí, para } \\
\text { algunos } \\
\text { programas }\end{array}$ & No & Sí & Sí \\
\hline $\begin{array}{l}\text { Contiene el PDM } \\
\text { un marco } \\
\text { normativo }\end{array}$ & Sí & Sí & Sí & No & Sí & Sí \\
\hline Ítem & Facatativá & Sopó & Sibaté & La Calera & Subachoque & Gachancipá \\
\hline Categoría & 3 & 3 & 4 & 5 & 6 & 6 \\
\hline $\begin{array}{l}\text { Se explicita el } \\
\text { enfoque de } \\
\text { desarrollo }\end{array}$ & No & Sí & No & 0 & Sí & Sí \\
\hline $\begin{array}{l}\text { Se definen los } \\
\text { recursos. Cuáles }\end{array}$ & $\begin{array}{l}\text { Proyección de } \\
\text { ingresos, Matriz } \\
\text { Financiera }\end{array}$ & $\begin{array}{l}\text { Proyecci } \\
\text { ón de } \\
\text { recursos, } \\
\text { Plan } \\
\text { Plurianu } \\
\text { al de } \\
\text { inversión }\end{array}$ & $\begin{array}{c}\text { plan } \\
\text { financiero, } \\
\text { y plurianual } \\
\text { de } \\
\text { inversiones }\end{array}$ & no & $\begin{array}{l}\text { Plan } \\
\text { plurianual de } \\
\text { inversiones, } \\
\text { análisis y } \\
\text { proyección de } \\
\text { recursos }\end{array}$ & $\begin{array}{c}\text { Exhaustivo } \\
\text { diagnóstico } \\
y \\
\text { caracterizaci } \\
\text { ón del } \\
\text { municipio, } \\
\text { contextualiz } \\
\text { ación y }\end{array}$ \\
\hline
\end{tabular}




\begin{tabular}{|c|c|c|c|c|c|c|}
\hline & & & & & & $\begin{array}{c}\text { armonizació } \\
\text { n de sus } \\
\text { necesidades } \\
\text { con recursos } \\
\text { y visión y el } \\
\text { PND y el } \\
\text { departamen } \\
\text { tal }\end{array}$ \\
\hline $\begin{array}{l}\text { Aspectos } \\
\text { específicos. }\end{array}$ & $\begin{array}{l}\text { Diagnóstico y la } \\
\text { contextualización } \\
\text { del municipio }\end{array}$ & $\begin{array}{l}\text { Estrategi } \\
\text { as para } \\
\text { el } \\
\text { seguimie } \\
\text { nto del } \\
\text { plan, } \\
\text { perspecti } \\
\text { var de } \\
\text { desarroll } \\
\text { orr }\end{array}$ & $\begin{array}{c}\text { Fortalecer la } \\
\text { participació } \\
n \\
\text { ciudadana, } \\
\text { programa } \\
\text { para } \\
\text { fortalecer la } \\
\text { gestión de } \\
\text { calidad, } \\
\text { modernizaci } \\
\text { ón de la } \\
\text { estructura } \\
\text { orgánica } \\
\text { municipal }\end{array}$ & $\begin{array}{c}\text { Estrategia } \\
\text { comunicativ } \\
\text { a. Canales } \\
\text { de } \\
\text { información } \\
\text { entre la } \\
\text { Administraci } \\
\text { ón } \\
\text { Municipal y } \\
\text { la } \\
\text { Comunidad }\end{array}$ & $\begin{array}{|ll|}\text { Articulación } \\
\text { con los } \\
\text { objetivos del } \\
\text { milenio, } \\
\text { Metodología } \\
\text { de } \\
\text { participación }\end{array}$ & $\begin{array}{c}\text { Exhaustivo } \\
\text { diagnóstico } \\
\text { y } \\
\text { caracterizaci } \\
\text { ón del } \\
\text { municipio, } \\
\text { armonizació } \\
\text { n de sus } \\
\text { necesidades } \\
\text { con recursos } \\
\text { y visión y el } \\
\text { PND y el } \\
\text { departamen } \\
\text { tal }\end{array}$ \\
\hline
\end{tabular}

Fuente: elaboración propia (2015)

El nivel cada día más técnico y de consolidación de los Planes de Desarrollo Municipales (PDM) como herramientas para direccionar el desarrollo territorial en el Departamento de Cundinamarca, indica el avance de los municipios categoría 3 a 5 en los procesos de planeación y en la cualificación técnica de los funcionarios responsables de liderar la elaboración de los PDM; los resultados positivos obtenidos por cuatro de los seis municipios estudiados que se reflejan en la figuración en la lista de los 20 mejores procesos de desarrollo integral a nivel municipal en el nivel (DNP, 2014) en la que los municipios de Subachoque y Gachancipá no quedan incluidos, a pesar de los avances en la búsqueda de un desarrollo integral para el periodo 2012-2015, aunque hayan progresado en la tecnificación y calidad de los procesos de gestión e implementación de sus PDM. A Gachancipá se le reconoce la calidad en la gestión financiera.

Según nuestra percepción, sustentada en la aplicación de la Guía básica para la revisión y comprensión de los planes de desarrollo de las entidades 
territoriales elaborada por el DNP, la estructuración de los PDM de estos dos municipios denotan rigurosidad, sistematicidad y coherencia, lo cual permite suponer que cuentan con una orientación clara para conducir el desarrollo en sus territorios. Gachancipá obtiene una calificación sobresaliente de $94.5 \%$ en la calidad de la estructura y formulación del PDM, y Subachoque 90.22 puntos sobre 100.

Es importante tener en cuenta que la estructura de los Planes de Desarrollo Municipales, establecida por el Departamento Nacional de Planeación, es una guía en la que se contemplan los mínimos a los que debe responder el proceso de planeación y el contenido del documento. Este instrumento, al ser seguido con rigurosidad por los municipios, permite hacer miradas comparativas por la similitud en los contenidos, pero si solo se rigen en el los municipios es posible que se pierda se la mirada singular y diferenciadora que, en los casos estudiados, se puede apreciar en la formulación de los Planes de Desarrollo, lo cual se hace evidente, no la categoría del municipio, sino por el tipo de asesorías que reciben de asesores privados y de las entidades públicas pertinentes cuando lo solicitan.

En las entrevista estructuradas realizados con funcionarios vinculados a la oficina de planeación de cada municipio, se pudo percibir que su nivel de conocimientos sobre los procesos adelantado en sus entes territoriales fueron muy disímiles; algunos de ellos, como en los casos de Facatativá, Sopó y Subachoque, los entrevistados participaron desde la formulación del plan de gobierno del alcalde electo y actualmente son los jefes o directores de las oficinas de planeación de sus municipios. En el caso de La Calera y Sibaté, son asesores externos con gran experiencia en el campo de la planeación y seguimiento a la implementación de los planes de desarrollo, han acompañado en periodos anteriores procesos en estos y otros municipios; por lo tanto, tienen una visión objetiva y académica de las fortalezas y debilidades que tiene los procesos de planeación en los municipios de Cundinamarca en general; en el caso de Gachancipá, la persona que suministró la información tenía muy 
poco conocimiento del proceso, información parcial de la implementación y se apreció poca sistematicidad y articulación al seguimiento global del plan por parte de esta oficina.

Con referencia a la estructura misma de los planes de desarrollo, uno de los aspecto comunes identificados es el énfasis que se le da al eje o estrategia social, en la que se incluye el mayor número de programas para cubrir todos los grupos poblacionales tradicionales y el desarrollo de políticas públicas de infancia, adolescencia, jóvenes, mujer, adulto mayor y población vulnerable, básicamente sólo Facatativá incluye explícitamente políticas y programas para población LGBTI. Un aspecto diferenciador que se aprecia en los PDM de Facatativá es el eje de tecnología e innovación, tema que no contempla ninguno de los otros cinco PDM.

En general ,como se puede deducir de las entrevistas y la evaluación de los PDM y de la gestión integral realizada por el DNP 2014, todos los municipios presentan una adecuada gestión del proceso de elaboración de sus planes de desarrollo, destacándose Facatativá, del cual se puede concluir que su clasificación en categoría 3, y la disponibilidad de mayores recursos propios y capacidad de gestión de recursos de la nación y del departamento de Cundinamarca y la experiencia administrativa adquirida en las últimas 4 administraciones, le ha permitido cualificar los procesos de gestión, potenciar su desarrollo y liderar el desarrollo regional de la Provincia Sabana Occidente.

También se destaca el caso de La Calera, municipio categoría 5, que se ha visto favorecido por la presencia, dentro de los equipos de gobierno, de asesores y personas con experiencia en el área de la planeación, que han jalonado los procesos de gestión y han sido partícipes activos en la implementación del PDM; una debilidad observada en este municipio es la inestabilidad del equipo de trabajo y dificultades en la gobernabilidad, generada por los grupos de oposición en el Concejo Municipal. 
Se destaca el proceso de Subachoque, que siendo un municipio categoría 6, desarrolló un proceso para la construcción de su plan de desarrollo muy técnico, con metodologías participativas innovadoras y la articulación de la implementación a partir de una política social única, que cobija todos los sectores poblacionales y direcciona las acciones y ejes del campo social.

Es equitativo reconocer que en estas seis alcaldías se observa un esfuerzo importante en la cualificación de su gestión, lo que se refleja en todos los planes de desarrollo que contemplan un eje específico, cuya finalidad es el desarrollo institucional, la incorporación de metodologías de evaluación y control, la erradicación de la prácticas corruptas y el aseguramiento de la calidad, así como la articulación al interior de los despachos y oficinas responsables de la implementación del plan y de brindar los soportes correspondientes en cada proceso administrativo.

\subsection{Recursos del municipio}

La inclusión de esta subcategoría se hizo con el fin de poder identificar con qué recursos cuenta el municipio tanto de talento humano, como económicos, técnicos y de infraestructura, para la implementación del PDM y su seguimiento.

A través del diligenciamiento de un formato, se recopiló la información sobre los recursos más relevantes de los cuales dispone cada uno de los municipios, información que fue tratada de manera individual en el aparte 5.1; por lo tanto, aquí solo se retoma la mirada sobre sí la disponibilidad de recursos afecta o no el procesos de construcción de los PDM y su incidencia en la gestión del mismo.

En este aspecto es en el que realmente se ve la diferencia entre un municipio de categoría 3 y uno de 6 , ya que la proporción en cuanto a área 
geográfica total, número de habitantes, así como la distribución poblacional entre el casco urbano y la zona rural y la disponibilidad de recursos económicos, de infraestructura y de personal para desarrollar el plan, varían sustancialmente, así como los procesos políticos de favorecen o frenan el desarrollo.

Con el fin de contar con parámetros de comparación, se indagó sobre la disponibilidad de recursos humanos, tecnológicos y de infraestructura, para el seguimiento del plan, en cada uno de los municipios. En el caso de recursos humanos, Facatativá cuenta con profesionales calificados, formados en áreas administrativas y financieras, quienes coordinan y participaron activamente en la elaboración del PDM, con el apoyo de expertos en sistemas, ingenieros y arquitectos para las líneas del plan relacionadas con vivienda, infraestructura y servicios públicos, a diferencia de los otros cinco municipios que, básicamente, cuentan con profesionales de las áreas de arquitectura e ingeniería, adscritos a las oficinas de planeación, que focalizan su mirada planificadora hacia la infraestructura física, no integrando el seguimiento a la ejecución del PDM desde una perspectiva sistémica, que denote la intencionalidad del desarrollo integral del territorio y el mejoramiento en la calidad de vida de los habitantes, más allá del impacto de las obras de infraestructura física, que si bien en todos los municipios es una debilidad sentida, no se puede considerar que a través de sus mejoramiento se logre el desarrollo integral.

Las propuestas teóricas confirman que para que se dé un auténtico desarrollo territorial, este debe ser emprendido y apropiado por los actores que lo habitan; dichos actores, como artífices de su desarrollo, deben diseñar e implementar estrategias claras, consistentes y compartidas, soportadas en un juicioso análisis territorial que identifique los potenciales y las restricciones en cada una de las dimensiones del desarrollo, con el fin de constituir entornos territoriales que contribuyan al mejoramiento de la calidad de vida de la población. (D.N.P, s.f.)- 
El caso de Sopó (categoría 3) es un ejemplo de los dicho anteriormente,

El tema de espacio público en el municipio está muy quedado... la gran dificultad que tienen los municipios para formular sus planes de desarrollo es la información con la que se cuenta y más cuando nosotros no veníamos de la misma línea del Alcalde que salía, entonces toda la información se pierde... en el Municipio estábamos muy, muy lejos de la meta. De Sopó hablan que el indicador debe ser de 2,5 mts2 por habitante... nosotros tenemos que llegar a $2.3 \mathrm{mts} 2$ por habitante. Es la meta a la cual queremos llegar, para eso tenemos una meta que es adquirir, diseñar y ejecutar al menos nueve mil ochocientos catorce metros cuadrados de espacio público. Una meta súper ambiciosa. (Entrevista, 2014)

En este municipio se destaca el compromiso social con el sector rural y el interés por jalonar el desarrollo de los jóvenes y del territorio, con el fin de beneficiar a todos con programas y servicios que garanticen sus derechos y calidad de vida.

En todos los municipios se identifica como debilidades, que afectan el proceso de planeación, la falta de recursos para contratar apoyo técnico para la elaboración de indicadores y contratar más personal que les permita implementar lo propuesto y hacerle seguimiento técnico al PDM.

Los municipios ubicados en categorías 5 y 6 (La Calera, Gachancipá y Subachoque) tienen importantes similitudes en recursos y procesos; los diferencian las fortalezas y debilidades que tienen según la mirada prospectiva y de desarrollo, que les han imprimido las tendencias políticas de sus representantes, la influencia de los municipios vecinos, su cercanía y acceso a Bogotá y el desarrollo industrial de la zona

Facatativá, municipio de categoría 3, que tiene 124.300 habitantes y cuenta con un presupuesto anual de $\$ 76.000$ millones de pesos, es el municipio, de los seis estudiados, que tiene las mejores condiciones en términos de recursos e infraestructura para implementar su PDM; sin embargo, también debe 
enfrentar mayores y más difíciles problemas sociales, asociados a la migración del campo a la zona urbana, asentamientos de población en situación de desplazamiento forzado, bandas delincuenciales, demanda de vivienda, servicios públicos, educación y salud de una población flotante, que usa el municipio como dormitorio y que no aporta a los ingresos y desarrollo integral local.

En cuanto a disponibilidad de recursos humanos, tecnológicos y de infraestructura, no hay variaciones cuantitativas sustanciales en los municipios de categoría 4, 5 y 6; la variabilidad es cualitativa, en cuanto a cualificación profesional, experiencia y disponibilidad. Un aspecto común y significativo identificado es la prevalencia que se le da a los profesionales nacidos y criados en el municipio para que sean parte de la administración municipal, aspecto que, en el caso de Sopó y Gachancipá, se destacan como fortalezas, según lo expresado por los entrevistados y lo consignado en los informes de rendición de cuentas del 2012. Como debilidad, observada en los seis municipios, está la falta de profesionales para acompañar la implementación, evaluación y seguimiento a los PDM, así como la falta de disponibilidad de tecnología apropiada y la inexistencia de un sistema de información que acopie información y permita mirar el desarrollo integral de los procesos en los municipios.

También es evidente la falta de espacio y funcionalidad de las plantas físicas de las alcaldías y la deficiente infraestructura requerida para la implementación de los programas y responder a las necesidades de bienestar de la totalidad de la población y, en especial, en las zonas rurales de los seis municipios.

La ausencia de capacidad de manejo que tienen estos municipios sobre variables exógenas tan vitales como la descentralización y la transferencia de recursos económicos de la nación y de regalías, que están bajo el total control del gobierno nacional, se hicieron evidentes en las entrevistas, ya que la falta 
de autonomía y homogenización de todos los procesos de planeación, sin que se tenga en cuenta la especificidad y disponibilidad de recursos apropiados, se convierte en una amenaza para los municipios categoría 6 , que puede afectar el derrotero de desarrollo que debería establecerse según su contexto y dinámica social, económica, ambiental y cultural.

Según lo encontrado a través de las consultas con fuentes primarias y secundarias de los seis municipios, se concluye que en cada uno de ellos hay fortalezas y debilidades que viabilizan la elaboración e implementación de los planes de desarrollo municipal; fortalezas y debilidades que, asociadas a cada una de las subcategorías, podrían ser potenciados y/ o mejoradas, de acuerdo con la capacidad política y el empoderamiento que tiene cada territorio y la importancia que adquiere la participación, la capacidad de gestión y la disponibilidad de recursos de infraestructura, humanos y tecnológicos dentro de la estructura de los planes de desarrollo de las entidades territoriales y en el Plan Departamental, aspectos que deben ir ligados a la normatividad y lineamiento expedidos por el DNP y la nación, si se quiere un desarrollo armónico e integral de los territorios, indistintamente de la categoría la que pertenecen, haciendo énfasis en el apoyo y acompañamiento que requieren en especial los municipios que hayan sido mal calificados en las evaluaciones realizadas por el DNP.

El modelo establecido por el Departamento Nacional de Planeación (DPN) para la elaboración de los planes de desarrollo municipal, no establece estructuras diferenciadas según la categoría de los municipios, lo que implica para ellos responder a contenidos, procesos y procedimientos, sin tener en cuenta su especificidad, características geográficas y los factores externos que los afectan positiva o negativamente, como son las condiciones del territorio, la situación social, el acceso a medios de comunicación, la posibilidad de contar con asesorías, recursos económicos y expertos, el nivel educativo de sus dirigentes y pobladores, el papel de los políticos, de los actores armados y la visión de territorio y país, que se puede tener desde lo local, factores que 
definirían la posibilidad de elaborar un Plan de Desarrollo pertinente, estratégico y con identidad, que responda a las necesidades reales de los municipios y a una visión de desarrollo, con alcances de mediano y largo plazo.

\section{CAPÍTULO VI. CONCLUSIONES}

Adentrarse en el conocimiento de los municipio de Facatativá, Sopó, Sibaté, La Calera, Gachancipá y Subachoque por medio de los instrumentos propios de esta investigación, permitió al equipo investigador acercarse a los entes territoriales, de manera desprevenidas y sin hipótesis preestablecidas.

1. Las variables contempladas para la categorización de los municipios no son suficientes; no se aborda la valoración de aspectos de orden social, cultural, político, educativo y regional que determinan la unicidad y especificidad de cada uno de ellos, parámetros que podrían aportar información significativa sobre las características comunes y diferenciadoras que pueden incidir en su desarrollo integral y en la forma 
en que se clasifiquen y sean acompañados y evaluados por el DNP y las entidades del el gobierno nacional pertinentes.

2. La falta de coherencia entre el planear y el actuar, enmarcada en el direcionamiento centralista de la planeción nacional, es una debilidad evidenciada en los procesos de implementacion de los planes de desarrollo de los municipios estudiados, ya que, si bien en todos ellos se percibe la necesidad de reconocer su identidad y sus derechos politicos, económicos, sociales, culturales y ambientales, aún la armonización con el Plan Nacional de Desarrollo marca el derrotero y, en ocasiones, direcciona la transformación de la vocación e intereses particulares de los municipios y sus gentes, hacia componetes basicamante económicos del desarrollo (Locomotora minera, tratados de libre comercio, planes de ordenamiento territorial, entre otros) que pueden ser perjudiciales para los territrorios, grupos etnicos, campesinos y la región en general.

3. La mirada caso por caso de cada uno de los municipios de los estudiados, permite concluir que, si bien el país cuenta con una entidad como el Departamento Nacional de Planeación (DNP), y el Departamento de Cundinamarca con la Secretaría de Planeación, en cuyas funciones se contempla la orientación, el acompañamiento y el seguimiento a los planes de desarrollo municipal y los municipios utilizan los instrumentos por ellos emitidos, en la mayoría de los casos (66.6 \%) no buscaron apoyo y la orientación de expertos, ni tuvieron disponibilidad de recursos y capacidades técnicas suministradas por el Estado o el Departamento de Cundinamarca para adelantar con sistematicidad el proceso metodológico requerido para la elaboración de los PDM, apoyándose en diagnósticos locales y datos oficiales no actualizados para definir aspectos prioritarios a incluir en el PDM.

4. En el diseño y estructuración de los Planes de Desarrollo Municipal PDM de Facatativá, Sopó, Sibaté, La Calera, Subachoque y Gachancipá, todos cumplen con la estructura mínima y los lineamientos 
básicos establecidos en la ley 152/94 (Capítulo VIII, Artículo 31), en cuanto a la parte estratégica y la formulación de un plan plurianual de inversiones para los cuatro años de gobierno.

5. En cada Municipio se evidencia autonomía en la planeación y coherencia con la visión propuesta para el municipio en cuanto al tipo de desarrollo que se pretende alcanzar en los 4 años (2012-2015), lo que les permite determinar la especificidad de los programas, proyectos, recursos, actividades y metas, entre otros.

6. En los seis municipios, el proceso de elaboración de los Planes de Desarrollo Municipal se cumplió a cabalidad, siguiendo lo establecido en la normatividad, concluyendo los procesos con la validación y aprobación de sus contenidos de los entes territoriales establecidos por la Ley, como son el Consejo territorial de Planeación y el Consejo Municipal, el cual se hizo por medio de la expedición de los Acuerdos de los Concejos Municipales de los respectivos municipios, en el tiempo reglamentario. (Primer semestre del 2012).

7. Los aspectos más relevantes y diferenciadores, identificados en los procesos de elaboración e implementación de los PDM de los seis municipios se observan básicamente en los planes estratégicos, por la forma como se expresan las misiones, visiones y orientaciones conceptuales que sustentan los planes y en el énfasis programático expresado en la titulación de los ejes de cada uno de los planes estudiados.

8. La implementación de la ley 152 de 1994 ha ido surtiendo un efecto positivo sobre las estructuras administrativas de las alcaldías y ha ido perfeccionando la manera de planear el desarrollo integral de los territorios, para beneficio de sus habitantes y del Departamento en general.

9. El aspecto más significativo a desatacar en el proceso de elaboración de los PDM es el componente participativo, al cual se le dio la real importancia que esta tiene en un Estado Social de Derecho, como es el 
caso de Colombia, en el que su eje central es la democracia participativa.

10. En el proceso de lograr la participación de la comunidad, llevó a los equipos de gobierno a la utilización de técnicas innovadoras, que permitieron consultar sectores y grupos poblacionales y adelantar procesos democráticos en la priorización de necesidades y definición de las problemáticas a privilegiar en el Plan de Desarrollo Municipal.

11. En el proceso de lograr la participación comunitaria se evidencia como fortaleza la creatividad de los alcaldes y sus equipos de gobierno o en su defecto el asesor externo, en la utilización de la lúdica y del para conocer las necesidades y problemáticas de los grupos; por medio de estas técnicas, se realizó el diagnóstico y la prospectiva del municipio, técnicas especialmente utilizadas con niños, jóvenes y adultos mayores.

12. En la elaboración y diseño del PDM, se destaca la capacidad profesional y de recursos humanos con que cuentan los municipios, la cual es más alta en la medida en que el municipio está mejor categorizado; otra es la disponibilidad de recursos propios $y$ transferencias de la nación, ventajas competitivas que permiten inferir que estos son aspectos determinantes para que el municipio logre mayor nivel de desempeño integral, ser más eficiente y efectivo, tal como se constata en el documento "Evaluación del desempeño integral de los municipios y distritos", realizada por el DNP (2013) para el periodo 2013.

13. Es equitativo reconocer que en estas seis alcaldías se observa un esfuerzo importante en la cualificación de su gestión, lo que se refleja en todos los planes de desarrollo, que contemplan un eje específico, cuya finalidad es el desarrollo institucional, la incorporación de metodologías de evaluación y control, la erradicación de la prácticas corruptas y el aseguramiento de la calidad, así como la articulación al interior de los despachos y oficinas responsables de la implementación del plan y de brindar los soportes correspondientes en cada proceso administrativo. 
14. En todos los municipios se identifica como debilidades, que afectan el proceso de planeación, la falta de recursos para contratar apoyo técnico para la elaboración de indicadores y contratar más personal que les permita implementar lo propuesto y hacerle seguimiento técnico al PDM.

15. Los municipios ubicados en categorías 5 y 6 (La Calera, Gachancipá y Subachoque), tienen importantes similitudes en recursos y procesos; los diferencian las fortalezas y debilidades que tienen, según la mirada prospectiva y de desarrollo que les han imprimido las tendencias políticas de sus representantes, la influencia de los municipios vecinos, su cercanía y acceso a Bogotá y el desarrollo industrial de la zona.

16. La descentralización y la transferencia de recursos económicos de la nación y de regalías que están bajo el total control del gobierno nacional, incide en la falta de autonomía y homogenización de todos los procesos de planeación, sin que se tenga en cuenta la especificidad y disponibilidad de recursos apropiados, se convierte en una amenaza para los municipios categoría 6 , que puede afectar el derrotero de desarrollo que debería establecerse según su contexto y dinámica social, económica, ambiental y cultural.

17. El modelo establecido por el Departamento Nacional de Planeación (DPN) para la elaboración de los planes de desarrollo municipal, no establece estructuras diferenciadas según la categoría de los municipios, lo que implica para ellos responder a contenidos, procesos y procedimientos, sin tener en cuenta su especificidad, características geográficas y los factores externos que los afectan positiva 0 negativamente, como son las condiciones del territorio, la situación social, el acceso a medios de comunicación, la posibilidad de contar con asesorías, recursos económicos y expertos, el nivel educativo de sus dirigentes y pobladores, el papel de los políticos, de los actores armados y la visión de territorio y país que se puede tener desde lo local, factores que definirían la posibilidad de elaborar un Plan de Desarrollo pertinente, estratégico y con identidad, que responda a las 
necesidades reales de los municipios y a una visión de desarrollo con alcances de mediano y largo plazo.

Al finalizar la investigación, surgen algunas preguntas como:

1. ¿Qué tan preparadas están política y culturalmente las comunidades para que su participación aporte realmente los elementos, componentes y reflexiones que incidan y determinen los derroteros que debe seguir el gobierno municipal para alcanzar el desarrollo integral y efectivo del municipio y sus pobladores?

2. ¿Es necesario revisar los aspectos que se contemplan para la clasificación de los municipios?

\section{REFERENCIAS}

Alcaldia de Bogotá. (s.f.). Información Genrel. Disponible en: www.alcaldiabogota.gov.co

Alcaldía Municipal de Gachancipá. (2014). Primer Informe de gestión. Progreso para todos 2012-2014. Disponible en: http://www.gachancipacundinamarca.gov.co/

Arizaldo Carvajal, B. R. (1999). Guía para la Elaboración de Proyectos de Investigación Social (Vol. 2). (I. p. implementación?, Ed.) Cali: Universidad del Valle. 
Baena, M. E. (2012). El Énfasis en Familia en el Programa de Trabajo Social.Revista Hoyjas y Hablas \# 11. Bogotá: Fundación Universitaria Monserrate.

Bonilla, E. R. (1995). Más Allá del Dilma de los Métodos. Bogotá: Norma.

Cideu. (s.f.). Información general. Disponible en: http://www.cideu.org/

Cinep. (s.f.) Información general. Disponible en: www.cinep.org.co

Departamento de Cundinamarca. (2001). Ordenanza 007. Disponible en:

http://www.cundinamarca.gov.co/wps/portal/Home/Inicio.homegc

Corporación para el Desarrollo Regional. (2003). Información general.

Disponible en: www.corporacionparaeldesarrolloregional.org

DNP. (2013).Versión ejecutiva de la matriz del DNP para evaluar el cumplimiento de los requisitos, principios y características que según la Ley 152 de 1994 deben tener los planes de desarrollo de las entidades territoriales. Disponible en www.dnp.gov.co

Federación Dominicana de Municipios. (2009). Introducción a la Planificación

Estratégica del Desarrollo Local. Disponible en:

Http://fedomu.org.do/Publicaciones/Manuales/Cartilla-Planificacion-

Estrategica.pdf

Gialdino de Vasilachis, I. (2006). Estrategias de Investiagción Cualitativa.

Madrid: Gedisa.

González R, E. (1995). Manual sobre Participación y Organización para la

Gestión Local. Cali: Foro Nacional por Colombia.

Gutiérrez Aldana, C. (s.f.). impacto psico social y Nutricional de los hogares. s.e.

Hernández S, R. F. (2008). Mwetodología de la Investigación. México: Mac

Graw Hill .

Hawkins, F.G. (s.f.). Desarrollo Regional en Colombia. Disponible en:

http://www.cybertesis.cl/tesis/uchile/2008/amador_f/sources/amador_f.pdf 
Municipio de Facatativá. (2012). Plan de Desarrollo Municipal 2012 - 2015.

Disponible en: http://www.facatativa-cundinamarca.gov.co/index.shtml

Municipio de Gachancipá. (2012). Acuerdo 011. Plan de Desarrollo Municipal

2012 - 2015. Disponible en: http://www.gachancipa-

cundinamarca.gov.co/index.shtml

Municipio de La Calera. (2012). Plan de Desarrollo Municipal 2012 - 2015.

Disponible en: http://lacalera-cundinamarca.gov.co/

Municipio de Sibaté. (s.f.). Información general del municipio. Disponible en:

http://www.sibate-cundinamarca.gov.co/index.shtml\#6

Municipio de Sopó. (2012). Plan de Desarrollo Municipal 2012 - 2015.

Disponible en: http://sopo-cundinamarca.gov.co/index.shtml

Municipio de Subachoque. (2012). Plan de Desarrollo Municipal 2012 - 2015.

Disponible en: http://www.subachoque-

cundinamarca.gov.co/informacion general.shtml

Nohlen, D. (s.f.). Método comparativo. Disponible en: http://www.rzuser.uniheidelberg.de/ k95/es/doc/diccionario metodo-comparativo.pdfRepública de Colombia. (1991). Constitución Política de Colombia. Disponible en: http://wsp.presidencia.gov.co/Normativa/Documents/Constitucion-

Politica-Colombia.pdf

Tamayo y tamayo, M. (2002). El proceso de la Investigación Científica. México: Limusa.

Vallejo Zamudio, F. L. (2006). Apuntes y docuemntos. Disponible en: www.uptc.edu.co/Publicaciones/Apuntescenes/Documentos/Vol 41-5. pdf

Van Dalen, B. y Meyer, W. (2006). Estrategia de la investigación descriptiva. En: Manual de técnica de la investigación educacional. Disponible en: http://noemagico.blogia.com/2006/091301-

Velasquez F. G. (2003). Planes de Desarrollo. Disponible en:

www.fundacioncorona.org.co/bajarDocDos.php 
Work. (2004). La democracia en América. Revista Eure (Vol. XXX, No. 90), pp.27-40. Santiago de Chile.

ANEXOS

\section{ANEXO N ${ }^{\circ} 1$}

MATRIZ DE EVALUACIÓN PLANES DE DESARROLLO: UNA APROXIMACIÓN A SU ESTRUCTURA Y CONTENIDOS MUNICIPIOS DE FACATATIVÁ, SOPÓ, SIBATÉ, LA CALERA, GACHANCIPÁ Y SUBACHOQUE 
GUÍA BÁSICA PARA LA REVISIÓN Y COMPRENSIÓN DE LOS PLANES DE DESARROLLO DE LAS

ENTIDADES TERRITORIALES

Nombre del Plan de Desarrollo: Todos Somos

Facatativá 2012-2015

Entidad territorial:

Componente I: Conformación del Plan de Desarrollo

Criterio: 1. Contenido del Plan de

Desarrollo

74,54545455

Verifique si el contenido del plan de desarrollo desarrolla los ítems 1.1 al 1.11

\begin{tabular}{|c|c|c|}
\hline Ítem & $\begin{array}{l}\text { Puntaje } \\
\text { De } 0 \text { a } \\
100\end{array}$ & Apreciación cualitativa del puntaje \\
\hline - Diagnóstico & 100 & $\begin{array}{l}\text { El plan de desarrollo presenta el diagnóstico en cada uno } \\
\text { de los ejes }\end{array}$ \\
\hline Parte general o estratégica & 100 & $\begin{array}{l}\text { Compuesta por Visión, objetivos, principios, valores, } \\
\text { estrategias, principios ejes estratégicos y programas, } \\
\text { metas e indicadores }\end{array}$ \\
\hline - Plan de inversiones & 90 & $\begin{array}{l}\text { Realizado básicamente sobre los recursos propios, el SGP y } \\
\text { otras fuentes, para los cuatro años de gobierno }\end{array}$ \\
\hline - Visión & 100 & Proyecta al municipio a largo plazo para el 2025 \\
\hline - Objetivos Estratégicos & 70 & $\begin{array}{l}\text { Se definen unos objetivos generales y específicos y en } \\
\text { cada eje y sector y programa se formula los objetivos } \\
\text { estratégicos }\end{array}$ \\
\hline ¿NOMBRE? & 80 & Se plantean unas estrategias para cada eje \\
\hline ¿NOMBRE? & 100 & $\begin{array}{l}\text { Se plantea la articulación con el plan departamental y el } \\
\text { plan nacional en las líneas estratégicas }\end{array}$ \\
\hline - Proyección de recursos financieros & 80 & $\begin{array}{l}\text { Se realiza la proyección para los cuatro años de gobierno, } \\
\text { desde los recursos y los gastos }\end{array}$ \\
\hline - Programas & 100 & se evidencian los programas para cada eje y sector \\
\hline - Subprogramas & 0 & No plantea subprogramas \\
\hline - Proyectos & 0 & No se plantean proyectos \\
\hline
\end{tabular}


Verifique si el contenido del plan de desarrollo desarrolla los ítems 2.1 al 2.3

\begin{tabular}{|l|l|l|}
\hline Ítem & $\begin{array}{l}\text { Puntaje } \\
\text { De } 0 \text { a } \\
100\end{array}$ & Apreciación cualitativa del puntaje \\
\hline a. Es organizado & 100 & $\begin{array}{l}\text { El plan presenta los elementos esenciales de la planeación } \\
\text { estratégica, el diagnóstico, primero se plantean los } \\
\text { programas y los subprogramas para cada línea estratégica y } \\
\text { después en otro capítulo se definen las metas, indicadores } \\
\text { y línea base la proyección y el plan plurianual }\end{array}$ \\
\hline b. plantea una secuencia lógica & 90 & Falta mejor distribución en cada línea estratégica \\
\hline c. Es comprensible & 100 & Maneja un vocabulario comprensivo para el lector \\
\hline
\end{tabular}

Criterio: 3. Claridad Conceptual del Plan de Desarrollo

Verifique si el contenido del plan de desarrollo guarda relación con las dimensiones del desarrollo

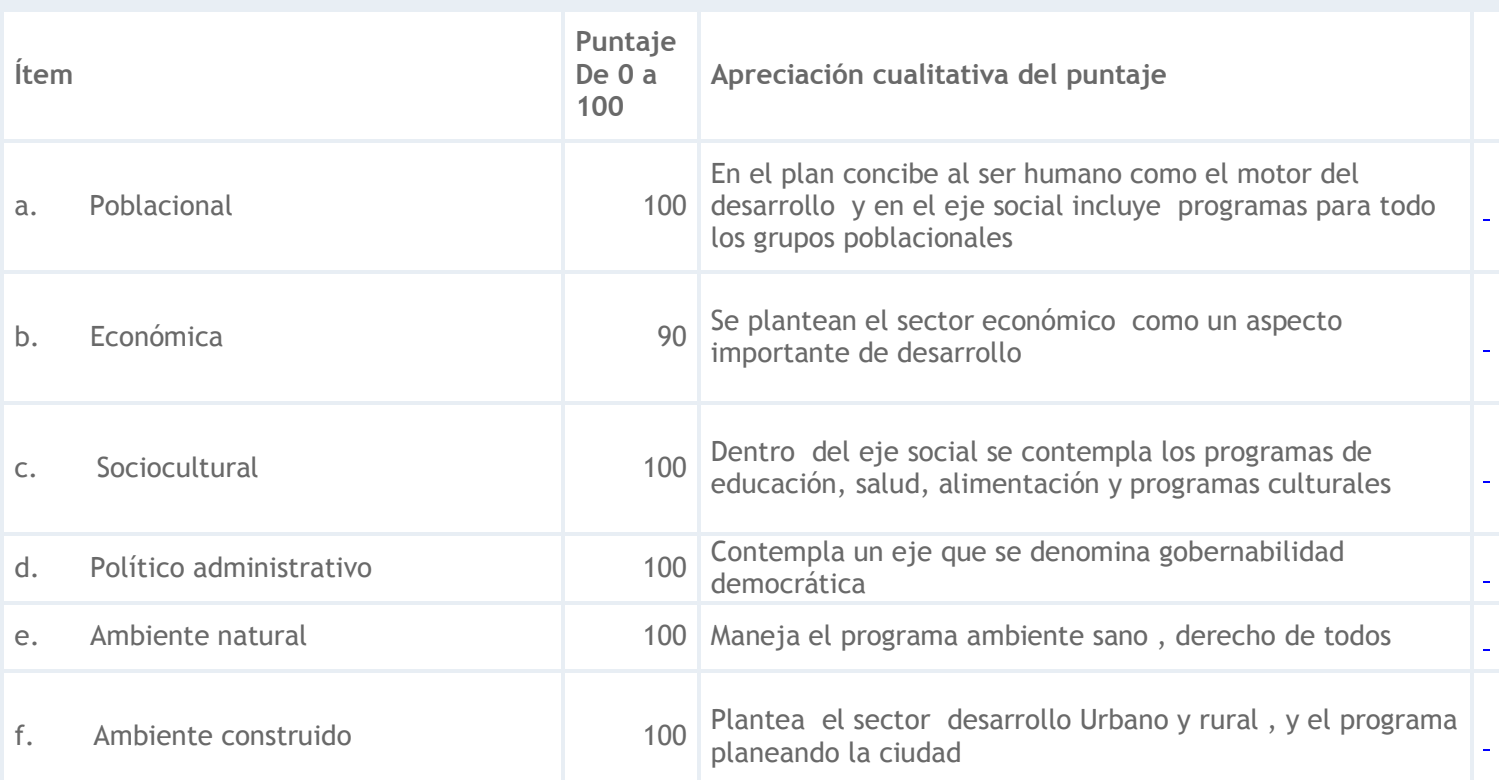

Verifique si el contenido del plan de desarrollo guarda relación los diferentes grupos poblacionales

\begin{tabular}{|l|l|l}
\hline Ítem & $\begin{array}{l}\text { Puntaje } \\
\text { De } 0 \mathrm{a}\end{array}$ & \\
100 & Apreciación cualitativa del puntaje
\end{tabular}

a. Niños y niñas

b. Mujeres
En el eje de desarrollo social plantea programas para niños 100 y niñas un futuro mejor, abarca salud, educación , deporte, recreación, cultura

100
Se plantean programas desde la equidad de género y el enfoque de derechos 


\begin{tabular}{|c|c|c|c|}
\hline c. Jóvenes & 100 & $\begin{array}{l}\text { Se plantean el sector juventud y programas para los } \\
\text { jóvenes }\end{array}$ & \\
\hline d. Adultos mayores & 100 & $\begin{array}{l}\text { Se plantean desde el eje social, programas a desarrollar } \\
\text { para el adulto mayor }\end{array}$ & - \\
\hline e. Personas con discapacidad & 100 & $\begin{array}{l}\text { Se plantean programas para esta población desde el eje } \\
\text { social }\end{array}$ & - \\
\hline f. Desplazados & 100 & $\begin{array}{l}\text { Se plantean programas para esta población incluida en el } \\
\text { programa de víctimas del conflicto armado }\end{array}$ & - \\
\hline g. Víctimas & 100 & Incluida en el programa de víctimas del conflicto & - \\
\hline h. Población en extrema pobreza & 70 & $\begin{array}{l}\text { Está incluida en el eje social, pero no un programa } \\
\text { específico }\end{array}$ & - \\
\hline i. Población LGTBI & 100 & $\begin{array}{l}\text { En el eje social se contempla programas para dicha } \\
\text { población }\end{array}$ & - \\
\hline j. Población indígena & 0 & No se contempla esta población & - \\
\hline k. Población afrodescendiente & 0 & No se contempla esta población & - \\
\hline l. Población raizal & 0 & No se contempla esta población & - \\
\hline m. Población rom o gitana & 0 & No se contempla esta población & - \\
\hline \multicolumn{4}{|l|}{ Visión de desarrollo } \\
\hline Ítem & $\begin{array}{l}\text { Puntaje } \\
\text { De } 0 \text { a } \\
100\end{array}$ & Apreciación cualitativa del puntaje & \\
\hline $\begin{array}{l}\text { a. Está armonizada con la visión del nivel } \\
\text { superior de gobierno (Visión } \\
\text { departamental para el caso de los } \\
\text { municipios o Visión } 2019 \text { para el caso de } \\
\text { los departamentos) }\end{array}$ & 40 & $\begin{array}{l}\text { Solo se encuentra coincidencia en la parte ambiental y en } \\
\text { brindar seguridad a sus habitantes }\end{array}$ & - \\
\hline $\begin{array}{l}\text { b. Tiene un horizonte mayor o igual a } 10 \\
\text { años }\end{array}$ & 100 & La visión está proyectada para el 2025 & - \\
\hline $\begin{array}{l}\text { c. Fue construida con la participación } \\
\text { actores de la comunidad, de la sociedad } \\
\text { civil y del sector público }\end{array}$ & 100 & $\begin{array}{l}\text { Se dio una amplia participación de } 25 \text { mesas de los } \\
\text { diferentes sectores y grupos poblacionales }\end{array}$ & \\
\hline $\begin{array}{l}\text { d. Resalta por lo menos una propiedad } \\
\text { cultural y/o valores sociales para } \\
\text { distinguir al territorio y darle arraigo }\end{array}$ & 100 & Plantea un alto significado histórico y cultural & - \\
\hline e. Plantea retos posibles de llevar a cabo & 100 & Plantea estrategias de desarrollo & - \\
\hline \multicolumn{4}{|l|}{ Parte estratégica } \\
\hline Ítem & $\begin{array}{l}\text { Puntaje } \\
\text { De } 0 \text { a } \\
100\end{array}$ & Apreciación cualitativa del puntaje & \\
\hline $\begin{array}{l}\text { a. Responden al diagnóstico de la entidad } \\
\text { territorial }\end{array}$ & 100 & $\begin{array}{l}\text { Incluye un diagnóstico completo del municipio y muestra la } \\
\text { realidad }\end{array}$ & \\
\hline $\begin{array}{l}\text { b. Contribuyen al logro de los objetivos } \\
\text { planteados }\end{array}$ & 100 & $\begin{array}{l}\text { Los ejes, el sector y los programas permiten el } \\
\text { cumplimiento de los objetivos }\end{array}$ & \\
\hline
\end{tabular}


c. Expresan efectos o cambios que se esperan generar con la implementación de la estrategia (programas, subprogramas, proyectos)

\section{d. Cuantifican los objetivos}

e. Define metas para los objetivos

f. Tienen un indicador asociado consistente

g. Tienen líneas de base
A través de los indicadores y metas se muestran los

100 cambios que se esperan lograr y la población que se va a beneficiar

90 A través de indicadores y población beneficiada

100 Para los objetivos se definen las metas

90 Está relacionada con la línea base y las metas

100 Para cada sector define unos programas y en el plan de acción muestra la línea base

Verifique si en el diagnóstico financiero y el plan plurianual de inversiones se contemplan los siguientes ítems

\begin{tabular}{|c|c|c|}
\hline Ítem & $\begin{array}{l}\text { Puntaje } \\
\text { De } 0 \text { a } \\
100\end{array}$ & Apreciación cualitativa del puntaje \\
\hline a. La definición de ingresos y gastos & 100 & En el plan financiero define los ingresos y gastos \\
\hline $\begin{array}{l}\text { b. La forma como se elabora una } \\
\text { proyección de recursos financieros }\end{array}$ & 100 & Es clara la proyección de los recursos por cada año del plan \\
\hline c. Los gasto de inversión & 100 & Están planteados para cada año del proyecto \\
\hline d. Los recursos propios & 100 & $\begin{array}{l}\text { Se define en la proyección de ingresos para cada año del } \\
\text { plan }\end{array}$ \\
\hline $\begin{array}{l}\text { e. La definición de estrategias para } \\
\text { mejorar el esfuerzo fiscal }\end{array}$ & 100 & Se contemplan algunas fuentes de financiación \\
\hline $\begin{array}{l}\text { f. Los recursos del Sistema General de } \\
\text { Regalías }\end{array}$ & 100 & $\begin{array}{l}\text { Están definidos dentro de los ingresos para la ejecución } \\
\text { del plan para cada año }\end{array}$ \\
\hline
\end{tabular}

Verifique si el plan plurianual de inversiones contiene los siguientes ítems

\begin{tabular}{|l|l|l|}
\hline Ítem & $\begin{array}{l}\text { Puntaje } \\
\text { De } 0 \text { a } \\
100\end{array}$ & Apreciación cualitativa del puntaje \\
\hline a. Programas y subprogramas & 60 & Se contempla el sector y el programa \\
\hline $\begin{array}{l}\text { b. Objetivos y metas de inversión } \\
\begin{array}{l}\text { c. Inversión para los cuatro años de } \\
\text { gobierno }\end{array}\end{array} \quad$ No se plantea \\
\hline $\begin{array}{l}\text { d. Inversión de los programas y } \\
\text { subprogramas por fuente de } \\
\text { financiamiento para cada vigencia }\end{array}$ & 100 & Se establece el plan por los cuatro años \\
\hline
\end{tabular}

Componente II: Principios Generales del plan 


\begin{tabular}{|l|l|l|}
\hline Ítem & $\begin{array}{l}\text { Puntaje } \\
\text { De } 0 \text { a } \\
100\end{array}$ & Apreciación cualitativa del puntaje \\
\hline $\begin{array}{l}\text { a. Realiza un diagnóstico de los recursos } \\
\text { propios de la entidad territorial }\end{array}$ & 100 & $\begin{array}{l}\text { Se incluye el análisis de acuerdo con la proyección, sobre } \\
\text { los recursos propios }\end{array}$ \\
\hline $\begin{array}{l}\text { b. Incluye estrategias viables, para } \\
\text { aumentar los recursos propios }\end{array}$ & 100 & Plantea algún mecanismos de financiación \\
\hline
\end{tabular}

Criterio: 2. Prioridad del gasto público social

69,23076923

En el plan se da prioridad del gasto público para:

\begin{tabular}{|l|r|l|l|}
\hline Ítem & $\begin{array}{l}\text { Puntaje } \\
\text { De } 0 \text { a } \\
100\end{array}$ & Apreciación cualitativa del puntaje \\
\hline a. Niños y niñas & 100 & En el eje de desarrollo social se incluye la población \\
\hline b. Mujeres & 100 & En el eje de desarrollo social se incluye la población \\
\hline c. Jóvenes & 100 & $\begin{array}{l}\text { En el eje de desarrollo social se incluye la población y en } \\
\text { cultura y jurentud }\end{array}$ \\
\hline d. Adultos mayores & 100 & En el eje de desarrollo social se incluye la población \\
\hline e. Personas en situación de discapacidad & 100 & En el eje de desarrollo social se incluye la población \\
\hline f. Desplazados & 100 & En el eje de desarrollo social se incluye la población \\
\hline g. Víctimas & 100 & En el eje de desarrollo social se incluye la población \\
\hline h. Población en extrema pobreza & 100 & En el eje de desarrollo social se incluye la población \\
\hline i. Población LGTBl & 100 & En el eje de desarrollo social se incluye la población \\
\hline j. Población indígena & 0 & No se contempla en el plan \\
\hline k. Población afro descendiente & 0 & No se contempla en el plan \\
\hline l. Población raizal & - & - \\
\hline m. Población Rom o gitana contempla en el plan \\
\hline
\end{tabular}

Criterio: 3. Participación (diagnóstico,

objetivo, programa, recursos)

Ítem

Puntaje

De 0 a Apreciación cualitativa del puntaje 
a. Se evidencia que el plan fue elaborado con la participación de la comunidad
Se muestra al comienzo del plan la eficiente participación 100 pública en veinticinco (25) mesas de diálogo y concertación para la elaboración del diagnóstico

Contempla el programa de participación democrática

b. Tiene estrategias (programas, subprogramas y/o proyectos) orientadas a fortalecer la participación
Criterio: 4. Sustentabilidad ambiental

Verifique si el contenido del pan incluye

Ítem

Puntaje

De 0 a

100

a. Estrategias (programas, subprogramas y/o proyectos) orientadas a garantizar la preservación y conservación de la base ambiental, y hacer uso sostenible de los recursos naturales

b. Metas orientadas a garantizar la preservación y conservación de la base ambiental, y hacer uso sostenible de los recursos naturales

Dentro de los programas se contemplan metas e indicadores
Apreciación cualitativa del puntaje

90

Plantea el eje territorio sostenible y el sector medio ambiente y el programa Ambiente sano derechos

Criterio: 5. Coherencia

\begin{tabular}{|l|l|l|}
\hline Ítem & $\begin{array}{l}\text { Puntaje } \\
\text { De } 0 \mathrm{a} \\
100\end{array}$ & Apreciación cualitativa del puntaje \\
\hline
\end{tabular}

a. Los objetivos y la visión son coherentes

100

b. Los objetivos y el diagnóstico son coherentes

c. Los objetivos y las estrategias (Programas/Subprogramas/Proyectos) son coherentes

d. Los objetivos y las metas son coherentes

e. Las metas y los indicadores son coherentes

f. El Plan Plurianual de inversiones y la parte programática son coherentes
100

100

100

100

100
Se evidencia una articulación entre la visión y el objetivo general y los específicos del plan

Plantea la situación actual y sobre esta información se definieron los objetivos

A través de los programas, se dará cumplimiento a I objetivo general del plan

Existe coherencia entre las metas y los objetivos a través de las metas se dará cumplimiento a los objetivos

Hay coherencia entre los indicadores y las metas y permite que se cumplan los objetivos

El plan plurianual está elaborado para dar respuesta a los ejes, los sectores y los programas, así como a las diferentes secretarias del despacho 


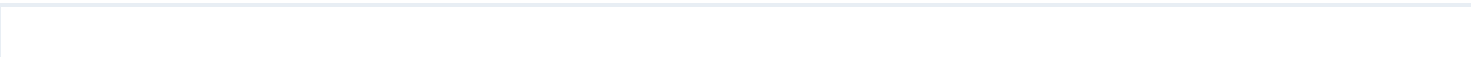

Componente III: Características del plan

Criterio: 1. Correspondencia con el programa de gobierno

Ítem

Verifique si el Plan de Desarrollo guarda correspondencia con el programa de gobierno

\section{Puntaje}

De 0 a

100

100 plan de gobierno, no se encontró el plan de gobierno
Se evidencia la coherencia entre el plan de desarrollo y el

Apreciación cualitativa del puntaje

Criterio: 2. Integralidad

Ítem

a. Considera en el diagnóstico todas las dimensiones del desarrollo (poblacional, económica, ambiente construido, ambiente natural, política administrativa, sociocultural)

b. Refleja un análisis sistémico de la entidad territorial
Ítem

a. Verifique si la visión incluida en el Plan de Desarrollo delinea una imagen de la Entidad Territorial que se quiere

b. Algún eje/ programa/ subprograma/ proyecto que plantee formular o participar en la construcción de una visión del Territorio

c. Define recursos en el plan de inversiones para construir o participar en la construcción de una visión de territorio

\section{Puntaje}

De 0 a

100

100

Se evidencia el diagnóstico en el plan de desarrollen en cada eje y sector

90

\section{Apreciación cualitativa del puntaje}


Ítem

a. ¿Se incluye un componente de seguimiento y evaluación del plan?

b. Se incluye una estrategia para promover la transparencia y el buen gobierno, a través de instrumentos como: la rendición de cuentas, los canales de comunicación de quejas y reclamos por parte de la ciudadanía, atención al ciudadano, etc.
Puntaje

De 0 a

100

100

Se incluye un punto en el plan de desarrollo sobre evaluación y monitoreo

A través de los diferentes

80 medios de comunicación y con jornadas informativas sectoriales

\begin{tabular}{|c|c|c|}
\hline \multicolumn{2}{|c|}{ Puntaje obtenido de la evaluación del Plan } & \multirow[b]{2}{*}{ Apreciación cualitativa del puntaje } \\
\hline Componentes & $\begin{array}{l}\text { Calificaci } \\
\text { ón }\end{array}$ & \\
\hline 1. Conformación del Plan de Desarrollo (20\%) & $\begin{array}{l}16,94259 \\
67\end{array}$ & $\begin{array}{l}\text { El plan está conformado por ejes, sectores, objetivos y programa } \\
\text { se plantea de forma clara }\end{array}$ \\
\hline 2. Principios del Plan de Desarrollo (40\%) & $\begin{array}{l}37,13846 \\
154\end{array}$ & $\begin{array}{l}\text { Los principios del plan amplían lo que se quiere proyectar con la } \\
\text { visión }\end{array}$ \\
\hline 3. Características del Plan de Desarrollo (40\%) & 37,5 & Existe coherencia entre el plan de gobierno y el plan de desarrollo \\
\hline CALIFICACIÓN TOTAL & $\begin{array}{l}91,58105 \\
824\end{array}$ & $\begin{array}{l}\text { El plan presenta una buena estructura, pero faltan dividir el } \\
\text { programa en subprogramas }\end{array}$ \\
\hline
\end{tabular}

\section{PLAN DE DESARROLLO SOPO}

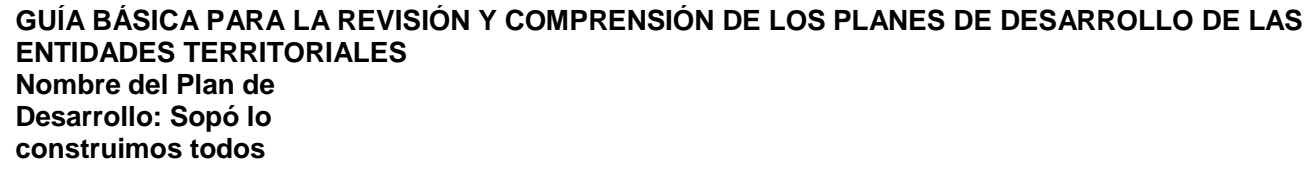

Entidad territorial: SOPÓ

Componente I: Conformación del Plan de Desarrollo

Criterio: 1. Contenido del

Plan de Desarrollo

Verifique si el contenido del plan de desarrollo desarrolla los ítems 1.1 al 1.11

\begin{tabular}{|l|l|l|}
\hline Ítem & $\begin{array}{l}\text { Punta } \\
\text { je } \\
\text { De } 0 \\
\text { a } 100\end{array}$ & Apreciación cualitativa del puntaje \\
\hline - Diagnóstico & 20 & $\begin{array}{l}\text { El plan de desarrollo solo presenta en algunos ejes la línea base, pero no se } \\
\text { evidencia el diagnóstico, }\end{array}$ \\
\hline
\end{tabular}




\begin{tabular}{|c|c|c|}
\hline Parte general o estratégica & 100 & $\begin{array}{l}\text { Compuesta por Visión, objetivos, principios perspectiva de desarrollo, ejes } \\
\text { estratégicos y programas y subprogramas }\end{array}$ \\
\hline - Plan de inversiones & 70 & $\begin{array}{l}\text { Realizado básicamente sobre los recursos propios, el SGP y otras fuentes, } \\
\text { fue modificado en Noviembre de } 2012 \text { mediante decreto por la evaluación del } \\
\text { DNP }\end{array}$ \\
\hline - Visión & 100 & Proyecta al municipio a largo plazo de acuerdo con el EOT \\
\hline - Objetivos Estratégicos & 70 & $\begin{array}{l}\text { Se definen unos objetivos generales y en cada eje se formula los objetivos } \\
\text { estratégicos, esto se contempla después de que se han formulado los } \\
\text { programas y subprogramas para cada eje }\end{array}$ \\
\hline - Estrategias y políticas & 80 & $\begin{array}{l}\text { Dentro de los programas estratégicos se incluyen programas relacionados } \\
\text { con las políticas públicas }\end{array}$ \\
\hline $\begin{array}{l}\text { - Formas, medios e } \\
\text { instrumentos de vinculación } \\
\text { y armonización de la } \\
\text { planeación territorial con la } \\
\text { planeación sectorial y de } \\
\text { otros niveles de gobierno }\end{array}$ & 100 & $\begin{array}{l}\text { Se plantea la articulación con el plan departamental y el plan nacional en las } \\
\text { líneas estratégicas }\end{array}$ \\
\hline $\begin{array}{l}\text { - Proyección de recursos } \\
\text { financieros }\end{array}$ & 80 & $\begin{array}{l}\text { Se realiza la proyección para los cuatro años de gobierno, desde los } \\
\text { recursos. }\end{array}$ \\
\hline - Programas & 100 & se evidencian los programas para cada línea estratégica \\
\hline - Subprogramas & 100 & se plantean subprogramas para cada proyecto \\
\hline - Proyectos & 0 & No se plantean proyectos \\
\hline $\begin{array}{l}\text { Criterio: } 2 \text {. Estructura del } \\
\text { Plan de Desarrollo }\end{array}$ & & 86,66666667 \\
\hline
\end{tabular}

Verifique si el contenido del plan de desarrollo desarrolla los ítems 2.1 al 2.3

\begin{tabular}{|c|c|c|}
\hline Ítem & $\begin{array}{l}\text { Punta } \\
\text { je } \\
\text { De } 0 \\
\text { a } 100\end{array}$ & Apreciación cualitativa del puntaje \\
\hline a. Es organizado & 80 & $\begin{array}{l}\text { El plan presenta los elementos esenciales de la planeación estratégica, pero } \\
\text { no contempla el diagnóstico, , primero se plantean los programas y los } \\
\text { subprogramas para cada línea estratégica y después en otro capítulo se } \\
\text { definen las metas, indicadores y línea base la proyección y el plan plurianual }\end{array}$ \\
\hline $\begin{array}{l}\text { b. Tiene una secuencia } \\
\text { lógica }\end{array}$ & 80 & Falta mejor distribución en cada línea estratégica \\
\hline c. Es comprensible & 100 & Maneja un vocabulario comprensivo para el lector \\
\hline
\end{tabular}

Criterio: 3. Claridad

Conceptual del Plan de

Desarrollo

78,29268293 


\begin{tabular}{|c|c|c|}
\hline Ítem & $\begin{array}{l}\text { Punta } \\
\text { je } \\
\text { De } 0 \\
\text { a } 100\end{array}$ & Apreciación cualitativa del puntaje \\
\hline a. Poblacional & 80 & $\begin{array}{l}\text { En las líneas estratégicas se nombra alguna población como niños, } \\
\text { adolescentes y mujeres }\end{array}$ \\
\hline b. Económica & 80 & Se plantean programas encaminados a la parte económica \\
\hline Sociocultural & 100 & $\begin{array}{l}\text { Dentro de los programas estratégicos contempla subprogramas en lo } \\
\text { cultural y patrimonial }\end{array}$ \\
\hline d. Político administrativo & 100 & $\begin{array}{l}\text { Hace referencia a subprogramas dirigidos a las buenas prácticas del buen } \\
\text { gobierno }\end{array}$ \\
\hline e. Ambiente natural & 100 & $\begin{array}{l}\text { Maneja la línea estratégica sobre el hábitat, que implica la protección del } \\
\text { medio ambiente }\end{array}$ \\
\hline Ambiente construido & 100 & plantea temas de vivienda para sectores de la población menos favorecidos \\
\hline \multicolumn{3}{|c|}{ Verifique si el contenido del plan de desarrollo guarda relación los diferentes grupos poblacionales } \\
\hline Ítem & $\begin{array}{l}\text { Punta } \\
\text { je } \\
\text { De } 0 \\
\text { a } 100\end{array}$ & Apreciación cualitativa del puntaje \\
\hline a. Niños y niñas & 100 & $\begin{array}{l}\text { Se plantean programas desde los ejes sociales, de educación, salud y } \\
\text { bienestar para los niños y niñas }\end{array}$ \\
\hline b. Mujeres & 100 & Se plantean programas desde la política municipal de mujer y género \\
\hline c. Jóvenes & 100 & $\begin{array}{l}\text { Se plantean programas desde los ejes sociales de educación, salud y } \\
\text { bienestar para los niños y niñas }\end{array}$ \\
\hline d. Adultos mayores & 100 & $\begin{array}{l}\text { Se plantean programas para esta población desde el programa estratégico } \\
\text { grupos vulnerables }\end{array}$ \\
\hline $\begin{array}{l}\text { e. Personas con } \\
\text { discapacidad }\end{array}$ & 100 & $\begin{array}{l}\text { Se plantean programas para esta población desde el programa estratégico } \\
\text { grupos vulnerables }\end{array}$ \\
\hline f. Desplazados & 100 & $\begin{array}{l}\text { Se plantean programas para esta población desde el programa estratégico } \\
\text { grupos vulnerables }\end{array}$ \\
\hline g. Víctimas & 100 & $\begin{array}{l}\text { Se plantean programas para esta población desde el programa estratégico } \\
\text { grupos vulnerables }\end{array}$ \\
\hline $\begin{array}{l}\text { h. Población en extrema } \\
\text { pobreza }\end{array}$ & 100 & $\begin{array}{l}\text { Se plantean programas para esta población desde el programa estratégico } \\
\text { grupos vulnerables }\end{array}$ \\
\hline i. Población LGTBI & 0 & No se contempla esta población \\
\hline j. Población indígena & 0 & No se contempla esta población \\
\hline $\begin{array}{l}\text { k. Población } \\
\text { afrodescendiente }\end{array}$ & 0 & No se contempla esta población \\
\hline
\end{tabular}




\begin{tabular}{|c|c|c|}
\hline I. Población raizal & 0 & No se contempla esta población \\
\hline m. Población rom o gitana & 0 & No se contempla esta población \\
\hline \multicolumn{3}{|l|}{ Visión de desarrollo } \\
\hline Ítem & $\begin{array}{l}\text { Punta } \\
\text { je } \\
\text { De } 0 \\
\text { a } 100\end{array}$ & Apreciación cualitativa del puntaje \\
\hline $\begin{array}{l}\text { a. Está armonizada con la } \\
\text { visión del nivel superior de } \\
\text { gobierno (Visión } \\
\text { departamental para el caso } \\
\text { de los municipios o Visión } \\
2019 \text { para el caso de los } \\
\text { departamentos) }\end{array}$ & 40 & $\begin{array}{l}\text { Solo se encuentra coincidencia en el mejoramiento de la calidad de vida de } \\
\text { las personas y el cuidado del medio ambiente desarrollo integral }\end{array}$ \\
\hline $\begin{array}{l}\text { b. Tiene un horizonte mayor } \\
\text { o igual a } 10 \text { años }\end{array}$ & 100 & La visión está proyectada para el 2016 \\
\hline $\begin{array}{l}\text { c. Fue construida con la } \\
\text { participación actores de la } \\
\text { comunidad, de la sociedad } \\
\text { civil y del sector público }\end{array}$ & 100 & $\begin{array}{l}\text { Se dio una amplia participación de los diferentes sectores y grupos } \\
\text { poblacionales }\end{array}$ \\
\hline $\begin{array}{l}\text { d. Resalta por lo menos una } \\
\text { propiedad cultural y/o } \\
\text { valores sociales para } \\
\text { distinguir al territorio y darle } \\
\text { arraigo }\end{array}$ & 100 & $\begin{array}{l}\text { Plantea un programa de reconstrucción de la memoria histórica y del cuidado } \\
\text { del territorio }\end{array}$ \\
\hline $\begin{array}{l}\text { e. Plantea retos posibles de } \\
\text { llevar a cabo }\end{array}$ & 100 & Plantea las metas de producto y de resultado posibles de cumplir \\
\hline \multicolumn{3}{|l|}{ Parte estratégica } \\
\hline Ítem & $\begin{array}{l}\text { Punta } \\
\text { je } \\
\text { De } 0 \\
\text { a } 100\end{array}$ & Apreciación cualitativa del puntaje \\
\hline $\begin{array}{l}\text { a. Responden al diagnóstico } \\
\text { de la entidad territorial }\end{array}$ & 30 & $\begin{array}{l}\text { No se evidencia el diagnóstico en el plan de desarrollo, solo en algunos } \\
\text { programas estratégicos a través de la línea base }\end{array}$ \\
\hline $\begin{array}{l}\text { b. Contribuyen al logro de } \\
\text { los objetivos planteados }\end{array}$ & 90 & Los programas y subprogramas permiten el cumplimiento de los objetivos \\
\hline $\begin{array}{l}\text { c. Expresan efectos o } \\
\text { cambios que se esperan } \\
\text { generar con la } \\
\text { implementación de la } \\
\text { estrategia (programas, } \\
\text { subprogramas, proyectos) }\end{array}$ & 90 & $\begin{array}{l}\text { A través de los indicadores y metas se muestran los cambios que se esperan } \\
\text { lograr }\end{array}$ \\
\hline d. Cuantifican los objetivos & 90 & Definen metas e indicadores \\
\hline $\begin{array}{l}\text { e. Define metas para los } \\
\text { objetivos }\end{array}$ & 100 & Para los objetivos se definen las metas \\
\hline $\begin{array}{l}\text { f. Tienen un indicador } \\
\text { asociado consistente }\end{array}$ & 90 & Están relacionados con la meta y el programa \\
\hline g. Tienen líneas de base & 90 & En cada programa estratégico se plantea la línea base \\
\hline
\end{tabular}

Verifique si en el diagnóstico financiero y el plan plurianual de inversiones se contemplan los siguientes ítems

\begin{tabular}{|l|r|r|}
\hline Ítem & $\begin{array}{l}\text { Punta } \\
\text { je } \\
\text { De } 0 \\
\text { a } 100\end{array}$ & Apreciación cualitativa del puntaje \\
\hline $\begin{array}{l}\text { a. La definición de ingresos } \\
\text { y gastos }\end{array}$ & 100 & Plantea claramente los recaudos, las proyecciones y el plan plurianual \\
\hline
\end{tabular}


b. La forma como se elabora una proyección de recursos financieros

c. Los gasto de inversión

d. Los recursos propios

e. La definición de estrategias para mejorar el esfuerzo fiscal

f. Los recursos del Sistema

General de Regalías
100 Están realizados por cada año y sobre las líneas de desarrollo

100 Se definen para cada línea de desarrollo y los programas

80 Se contemplan algunas fuentes de financiación

100 Están definidos para algunas líneas por cada año de ejecución del plan

Verifique si el plan plurianual de inversiones contiene los siguientes ítems

\begin{tabular}{|l|r|l|}
\hline Ítem & $\begin{array}{l}\text { Punta } \\
\text { je } \\
\text { De 0 } \\
\text { a } 100\end{array}$ & Apreciación cualitativa del puntaje \\
\hline \begin{tabular}{l|l|l|} 
a. Programas y \\
subprogramas
\end{tabular} & 50 & Se contempla para las líneas estratégicas y los programas \\
\hline $\begin{array}{l}\text { b. Objetivos y metas de } \\
\text { inversión }\end{array}$ & 0 & No se plantea \\
\hline $\begin{array}{l}\text { c. Inversión para los cuatro } \\
\text { años de gobierno }\end{array}$ & 100 & Se establece el plan por los cuatro años \\
\hline $\begin{array}{l}\text { d. Inversión de los } \\
\text { programas y subprogramas } \\
\text { por fuente de financiamiento } \\
\text { para cada vigencia }\end{array}$ & 100 & $\begin{array}{l}\text { Se elabora por cada fuente de financiamiento se hace por línea o eje } \\
\text { estratégico y programa }\end{array}$ \\
\hline
\end{tabular}

Componente II: Principios Generales del plan

Criterio: 1. Autonomía

Item

Punta

je Apreciación cualitativa del puntaje

a 100

a. Realiza un diagnóstico de los recursos propios de la entidad territoria

b. Incluye estrategias viables, para aumentar los recursos propios

100 Se incluye el análisis de acuerdo con la proyección, sobre los recursos propios

100 Plantea algún mecanismos de financiación

Criterio: 2. Prioridad del gasto público social

En el plan se da prioridad del gasto público para:

Ítem

Punta

je

De 0

a 100

Apreciación cualitativa del puntaje 


\begin{tabular}{|c|c|c|}
\hline a. Niños y niñas & 100 & $\begin{array}{l}\text { en la línea estratégica Progreso social y ejercicio de derechos se incluye un } \\
\text { porcentaje del presupuesto }\end{array}$ \\
\hline b. Mujeres & 100 & $\begin{array}{l}\text { en la línea estratégica Progreso social y ejercicio de derechos se incluye un } \\
\text { porcentaje del presupuesto }\end{array}$ \\
\hline c. Jóvenes & 100 & $\begin{array}{l}\text { en la línea estratégica Progreso social y ejercicio de derechos se incluye un } \\
\text { porcentaje del presupuesto }\end{array}$ \\
\hline d. Adultos mayores & 100 & $\begin{array}{l}\text { en la línea estratégica Progreso social y ejercicio de derechos se incluye un } \\
\text { porcentaje del presupuesto }\end{array}$ \\
\hline $\begin{array}{l}\text { e. Personas en situación de } \\
\text { discapacidad }\end{array}$ & 100 & $\begin{array}{l}\text { en la línea estratégica Progreso social y ejercicio de derechos se incluye un } \\
\text { porcentaje del presupuesto }\end{array}$ \\
\hline f. Desplazados & 0 & $\begin{array}{l}\text { en la línea estratégica Progreso social y ejercicio de derechos se incluye un } \\
\text { porcentaje del presupuesto }\end{array}$ \\
\hline g. Víctimas & 100 & $\begin{array}{l}\text { en la línea estrategia Progreso social y ejercicio de derechos se incluye un } \\
\text { porcentaje del presupuesto }\end{array}$ \\
\hline $\begin{array}{l}\text { h. Población en extrema } \\
\text { pobreza }\end{array}$ & 100 & $\begin{array}{l}\text { en la línea estrategia Progreso social y ejercicio de derechos se incluye un } \\
\text { porcentaje del presupuesto }\end{array}$ \\
\hline i. Población LGTBI & 0 & No se contempla en el plan \\
\hline j. Población indígena & 0 & No se contempla en el plan \\
\hline $\begin{array}{l}\text { k. Población afro } \\
\text { descendiente }\end{array}$ & 0 & No se contempla en el plan \\
\hline I. Población raizal & 0 & No se contempla en el plan \\
\hline m. Población ROM o gitana & 0 & No se contempla en el plan \\
\hline
\end{tabular}

Criterio: 3. Participación

(diagnóstico, objetivo, programa, recursos)

\begin{tabular}{|c|c|c|}
\hline Ítem & $\begin{array}{l}\text { Punta } \\
\text { je } \\
\text { De } 0 \\
\text { a } 100\end{array}$ & Apreciación cualitativa del puntaje \\
\hline $\begin{array}{l}\text { a. Se evidencia que el plan } \\
\text { fue elaborado con la } \\
\text { participación de la } \\
\text { comunidad }\end{array}$ & 90 & $\begin{array}{l}\text { Se muestra al comienzo del plan la participación de los diferentes grupos } \\
\text { poblacionales en la elaboración del diagnóstico }\end{array}$ \\
\hline $\begin{array}{l}\text { b. Tiene estrategias } \\
\text { (programas, subprogramas } \\
\text { y/o proyectos) orientadas a } \\
\text { fortalecer la participación }\end{array}$ & 100 & $\begin{array}{l}\text { En la línea de convivencia, y seguridad se contempla un subprograma de } \\
\text { participación }\end{array}$ \\
\hline $\begin{array}{l}\text { Criterio: 4. Sustentabilidad } \\
\text { ambiental }\end{array}$ & & \\
\hline
\end{tabular}


Verifique si el contenido del pan incluye

Ítem

Punta

je

De 0 Apreciación cualitativa del puntaje

a. Estrategias (programas, subprogramas $\mathrm{y} / \mathrm{o}$ proyectos) orientadas a garantizar la preservación y conservación de la base ambiental, y hacer uso sostenible de los recursos naturales

b. Metas orientadas a garantizar la preservación y conservación de la base ambiental, y hacer uso sostenible de los recursos naturales

a 100

90 conservación del medio ambiente

100 Dentro de los programas estratégicos se contemplan metas e indicadores
Ítem

a. Los objetivos y la visión son coherentes

b. Los objetivos y el diagnóstico son coherentes

c. Los objetivos y las estrategias

(Programas/Subprogramas/

Proyectos) son coherentes

d. Los objetivos y las metas son coherentes

e. Las metas y los indicadores son coherentes

f. El Plan Plurianual de inversiones y la parte programática son coherentes

\section{Punta}

je

De 0

a 100

100

Aun cuando no se evidencia el diagnóstico, o los objetivos programáticos responden a las necesidades y problemáticas del municipio

100

A través de los programas y subprogramas se dará cumplimiento al objetivo general del plan

100

Existe coherencia entre las metas y los objetivos a través de las metas se dará cumplimiento a los objetivos

100

Hay coherencia entre los indicadores y las metas y permite que se cumplan los objetivos

100

El plan plurianual está elaborado para dar respuesta a las líneas estratégicas y los programas

Componente III: Características del plan

Criterio: 1. 


\begin{tabular}{|c|c|c|}
\hline Ítem & $\begin{array}{l}\text { Punta } \\
\text { je } \\
\text { De } 0 \\
\text { a } 100\end{array}$ & Apreciación cualitativa del puntaje \\
\hline $\begin{array}{l}\text { Verifique si el Plan de } \\
\text { Desarrollo guarda } \\
\text { correspondencia con el } \\
\text { programa de gobierno }\end{array}$ & 100 & $\begin{array}{l}\text { Se evidencia la coherencia entre el plan de desarrollo y el plan de gobierno } \\
\text { en cuanto a las líneas programáticas como son social, económico, } \\
\text { convivencia, hábitat que se amplía más en el plan de desarrollo }\end{array}$ \\
\hline \multicolumn{2}{|l|}{ Criterio: 2. Integralidad } & 80 \\
\hline Ítem & $\begin{array}{l}\text { Punta } \\
\text { je } \\
\text { De } 0 \\
\text { a } 100\end{array}$ & Apreciación cualitativa del puntaje \\
\hline $\begin{array}{l}\text { a. Considera en el } \\
\text { diagnóstico todas las } \\
\text { dimensiones del desarrollo } \\
\text { (poblacional, económica, } \\
\text { ambiente construido, } \\
\text { ambiente natural, política } \\
\text { administrativa, sociocultural) }\end{array}$ & 70 & $\begin{array}{l}\text { No se evidencia el diagnóstico en el plan de desarrollo, solo en algunos } \\
\text { programas estratégicos a través de la línea base }\end{array}$ \\
\hline $\begin{array}{l}\text { b. Refleja un análisis } \\
\text { sistémico de la entidad } \\
\text { territorial }\end{array}$ & 90 & Muestra componente cualitativo y cuantitativo del municipio \\
\hline Criterio: 3. Es prospectivo & & 90 \\
\hline Ítem & $\begin{array}{l}\text { Punta } \\
\text { je } \\
\text { De } 0 \\
\text { a } 100\end{array}$ & Apreciación cualitativa del puntaje \\
\hline $\begin{array}{l}\text { a. Verifique si la visión } \\
\text { incluida en el Plan de } \\
\text { Desarrollo delinea una } \\
\text { imagen de la Entidad } \\
\text { Territorial que se quiere }\end{array}$ & 100 & $\begin{array}{l}\text { La visión plantea lo que se quiere para el municipio el cual está centrado en } \\
\text { lo social y en un territorio sostenible }\end{array}$ \\
\hline $\begin{array}{l}\text { b. Algún eje/ programa/ } \\
\text { subprograma/ proyecto que } \\
\text { plantee formular o participar } \\
\text { en la construcción de una } \\
\text { visión del Territorio }\end{array}$ & 70 & $\begin{array}{l}\text { En el programa estratégico Ordenando nuestro entorno, se evidencia todo el } \\
\text { desarrollo del territorio, que incluye el desarrollo social y sostenible }\end{array}$ \\
\hline $\begin{array}{l}\text { c. Define recursos en el plan } \\
\text { de inversiones para construir } \\
\text { o participar en la } \\
\text { construcción de una visión } \\
\text { de territorio }\end{array}$ & 100 & $\begin{array}{l}\text { En el plan de inversiones se plantea el presupuesto para programa } \\
\text { estratégico Ordenando nuestro entorno }\end{array}$ \\
\hline Criterio: 4. Es evaluable & & 85 \\
\hline Ítem & $\begin{array}{l}\text { Punta } \\
\text { je } \\
\text { De } 0 \\
\text { a } 100\end{array}$ & Apreciación cualitativa del puntaje \\
\hline
\end{tabular}


a. ¿Se incluye un componente de seguimiento

y evaluación del plan?

b. Se incluye una estrategia para promover la transparencia y el buen gobierno, a través de instrumentos como: la rendición de cuentas, los canales de comunicación de quejas y reclamos por parte de la ciudadanía, atención al ciudadano, etc.
Se plantea una estrategia denominada tableros de control para el seguimiento y evaluación del plan

En el eje de mejoramiento institucional y el programa de Buen Gobierno plantea los mecanismos para promover la transparencia.

\begin{tabular}{|c|c|c|}
\hline \multicolumn{2}{|c|}{ Puntaje obtenido de la evaluación del Plan } & \multirow[b]{2}{*}{ Apreciación cualitativa del puntaje } \\
\hline Componentes & Calificación & \\
\hline $\begin{array}{l}\text { 1. Conformación del Plan de } \\
\text { Desarrollo (20\%) }\end{array}$ & 15,96698694 & $\begin{array}{l}\text { El plan está conformado por ejes, sectores, objetivos y programa, } \\
\text { se plantea de forma clara }\end{array}$ \\
\hline $\begin{array}{l}\text { 2. Principios del Plan de } \\
\text { Desarrollo }(40 \%)\end{array}$ & 35,50769231 & $\begin{array}{l}\text { Los principios del plan amplían lo que se quiere proyectar con la } \\
\text { visión }\end{array}$ \\
\hline $\begin{array}{l}\text { 3. Características del Plan } \\
\text { de Desarrollo }(40 \%)\end{array}$ & 35,5 & Existe coherencia entre el plan de gobierno y el plan de desarrollo \\
\hline CALIFICACIÓN TOTAL & 86,97467925 & $\begin{array}{l}\text { El plan presenta una buena estructura , pero faltan dividir el } \\
\text { programa en subprogramas y desarrollar más el diagnóstico y las } \\
\text { poblaciones que van a cubrir }\end{array}$ \\
\hline
\end{tabular}

GUÍA BÁSICA PARA LA REVISIÓN Y COMPRENSIÓN DE LOS PLANES DE DESARROLLO DE LAS ENTIDADES TERRITORIALES

Nombre del Plan de Desarrollo:

TODOS DE LA MANO TRANSFORMAMOS SIBATE

Entidad territorial:

MUNICIPIO DE SIBATE

Componente I: Conformación del Plan de Desarrollo

Criterio: 1. Contenido del Plan de

Desarrollo

Verifique si el contenido del plan de desarrollo desarrolla los ítems 1.1 al 1.11

\begin{tabular}{|l|r|l|}
\hline Ítem & $\begin{array}{l}\text { Puntaje } \\
\text { De 0 a 100 }\end{array}$ & Apreciación cualitativa del puntaje \\
\hline - Diagnóstico & 100 & Se incluye en cada eje y programa \\
\hline Parte general o estratégica & 100 & está estructurado de acuerdo a la ley 17/94 \\
\hline - Plan de inversiones & 100 & se presenta por ejes \\
\hline - Visión & 100 & enunciada a \\
\hline - Objetivos Estratégicos & 100 & $\begin{array}{l}\text { No están enunciados como tal. Se definen como } \\
\text { ejes estratégicos }\end{array}$ \\
\hline - Estrategias y políticas & 60 & \begin{tabular}{l} 
se mencionan pero no se articulan \\
\hline
\end{tabular}
\end{tabular}




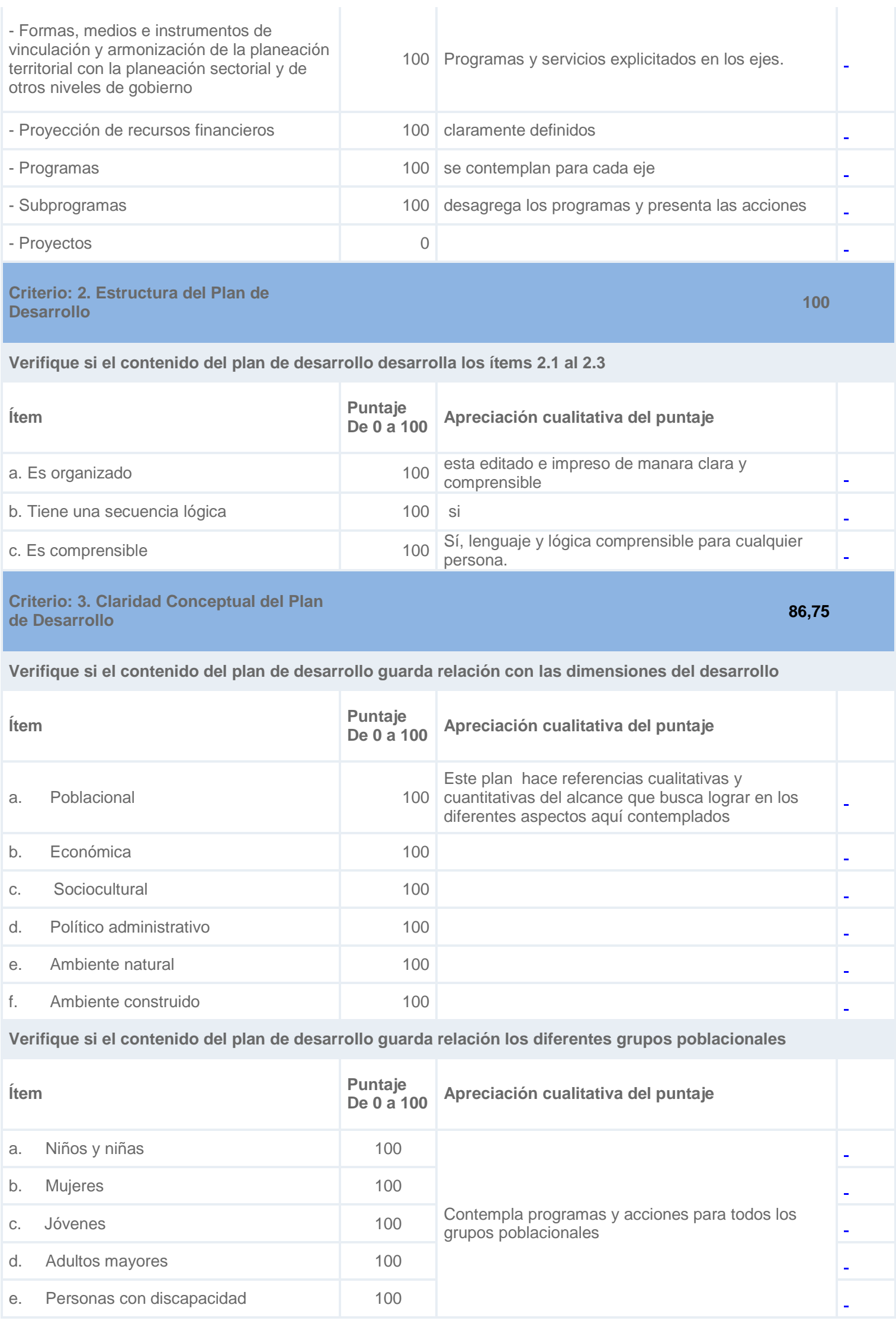




\begin{tabular}{|c|c|c|c|}
\hline f. Desplazados & 100 & & - \\
\hline g. Víctimas & 100 & & - \\
\hline h. Población en extrema pobreza & 100 & eje transversal en los programas & - \\
\hline i. Población LGTBI & 0 & no se evidencian acciones particulares & - \\
\hline j. $\quad$ Población indígena & 0 & no se evidencian acciones particulares & - \\
\hline k. Población afrodescendiente & 0 & no se evidencian acciones particulares & . \\
\hline I. Población raizal & 0 & no se evidencian acciones particulares & - \\
\hline m. Población rom o gitana & 0 & no se evidencian acciones particulares & - \\
\hline Ítem & $\begin{array}{l}\text { Puntaje } \\
\text { De } 0 \text { a } 100\end{array}$ & Apreciación cualitativa del puntaje & \\
\hline $\begin{array}{l}\text { a. Está armonizada con la visión del nivel } \\
\text { superior de gobierno (Visión departamental } \\
\text { para el caso de los municipios o Visión } \\
2019 \text { para el caso de los departamentos) }\end{array}$ & & no se explicita & - \\
\hline $\begin{array}{l}\text { b. Tiene un horizonte mayor o igual a } 10 \\
\text { años }\end{array}$ & 100 & si , está planteada al 2023 & - \\
\hline $\begin{array}{l}\text { c. Fue construida con la participación } \\
\text { actores de la comunidad, de la sociedad } \\
\text { civil y del sector público }\end{array}$ & 100 & si & - \\
\hline $\begin{array}{l}\text { d. Resalta por lo menos una propiedad } \\
\text { cultural y/o valores sociales para distinguir } \\
\text { al territorio y darle arraigo }\end{array}$ & 100 & su carácter rural, su historia & - \\
\hline e. Plantea retos posibles de llevar a cabo & 100 & $\begin{array}{l}\text { Sí, especialmente en lo que se referir a la gestión } \\
\text { administrativa del municipio }\end{array}$ & - \\
\hline \multicolumn{4}{|l|}{ Parte estratégica } \\
\hline Ítem & $\begin{array}{l}\text { Puntaje } \\
\text { De } 0 \text { a } 100\end{array}$ & Apreciación cualitativa del puntaje & \\
\hline $\begin{array}{l}\text { a. Responden al diagnóstico de la entidad } \\
\text { territorial }\end{array}$ & 90 & $\begin{array}{l}\text { Si bien en el documento no aparece el diagnostico } \\
\text { detallado, por lo consignado en el PDM, se infiere } \\
\text { que hay un buen conocimiento importante de los } \\
\text { aspectos que aborda el PDM }\end{array}$ & - \\
\hline $\begin{array}{l}\text { b. Contribuyen al logro de los objetivos } \\
\text { planteados }\end{array}$ & 80 & si, falta explicitación & - \\
\hline $\begin{array}{l}\text { c. Expresan efectos o cambios que se } \\
\text { esperan generar con la implementación de } \\
\text { la estrategia (programas, subprogramas, } \\
\text { proyectos) }\end{array}$ & 100 & si & - \\
\hline d. Cuantifican los objetivos & 100 & en metas & - \\
\hline e. Define metas para los objetivos & 100 & si & . \\
\hline f. Tienen un indicador asociado consistente & 100 & si & - \\
\hline g. Tienen líneas de base & 100 & si & . \\
\hline
\end{tabular}

Verifique si en el diagnóstico financiero y el plan plurianual de inversiones se contemplan los siguientes ítems 


\begin{tabular}{|c|c|c|c|}
\hline Ítem & $\begin{array}{l}\text { Puntaje } \\
\text { De } 0 \text { a } 100\end{array}$ & Apreciación cualitativa del puntaje & \\
\hline a. La definición de ingresos y gastos & 100 & \multirow{6}{*}{ este ítem es muy completo y explicito } & _ \\
\hline $\begin{array}{l}\text { b. La forma como se elabora una } \\
\text { proyección de recursos financieros }\end{array}$ & 100 & & - \\
\hline c. Los gasto de inversión & 100 & & - \\
\hline d. Los recursos propios & 100 & & - \\
\hline $\begin{array}{l}\text { e. La definición de estrategias para mejorar } \\
\text { el esfuerzo fiscal }\end{array}$ & 100 & & - \\
\hline $\begin{array}{l}\text { f. Los recursos del Sistema General de } \\
\text { Regalías }\end{array}$ & 100 & & - \\
\hline \multicolumn{4}{|c|}{ Verifique si el plan plurianual de inversiones contiene los siguientes ítems } \\
\hline Ítem & $\begin{array}{l}\text { Puntaje } \\
\text { De } 0 \text { a } 100\end{array}$ & Apreciación cualitativa del puntaje & \\
\hline a. Programas y subprogramas & 100 & es detallado & - \\
\hline b. Objetivos y metas de inversión & 100 & $\begin{array}{l}\text { se articula con lo propuesto en ejes, programas y } \\
\text { proyectos }\end{array}$ & - \\
\hline $\begin{array}{l}\text { c. Inversión para los cuatro años de } \\
\text { gobierno }\end{array}$ & 100 & 1 & - \\
\hline $\begin{array}{l}\text { d. Inversión de los programas y } \\
\text { subprogramas por fuente de financiamiento } \\
\text { para cada vigencia }\end{array}$ & 100 & si, va incluida la información en el PDM & - \\
\hline
\end{tabular}

\section{Componente II: Principios Generales del plan}

Criterio: 1. Autonomía

\begin{tabular}{|c|c|c|c|}
\hline Ítem & $\begin{array}{l}\text { Puntaje } \\
\text { De } 0 \text { a } 100\end{array}$ & Apreciación cualitativa del puntaje & \\
\hline $\begin{array}{l}\text { a. Realiza un diagnóstico de los recursos } \\
\text { propios de la entidad territorial }\end{array}$ & 60 & & - \\
\hline $\begin{array}{l}\text { b. Incluye estrategias viables, para } \\
\text { aumentar los recursos propios }\end{array}$ & 60 & & - \\
\hline
\end{tabular}

Criterio: 2. Prioridad del gasto público social

61,53846154

En el plan se da prioridad del gasto público para:

\begin{tabular}{|l|r|l|l|}
\hline Ítem & $\begin{array}{l}\text { Puntaje } \\
\text { De } 0 \text { a } 100\end{array}$ & Apreciación cualitativa del puntaje \\
\hline a. Niños y niñas & 100 & El plan de inversión es por programas no por & - \\
\hline
\end{tabular}




\begin{tabular}{|c|c|c|}
\hline b. Mujeres & 100 & $\begin{array}{l}\text { poblaciones, por lo tanto en este ítem no se puede } \\
\text { determinar la inversión por población sino por }\end{array}$ \\
\hline c. Jóvenes & 100 & acciones. \\
\hline d. Adultos mayores & 100 & \\
\hline e. Personas en situación de discapacidad & 100 & \\
\hline f. Desplazados & 100 & \\
\hline g. Víctimas & 100 & \\
\hline h. Población en extrema pobreza & 100 & \\
\hline i. Población LGTBI & 0 & \\
\hline j. Población indígena & 0 & \\
\hline k. Población afro descendiente & 0 & \\
\hline I. Población raizal & 0 & \\
\hline m. Población ROM o gitana & 0 & \\
\hline
\end{tabular}

Criterio: 3. Participación (diagnóstico, objetivo, programa, recursos)

100

a. Se evidencia que el plan fue elaborado con la participación de la comunidad

b. Tiene estrategias (programas, subprogramas y/o proyectos) orientadas a fortalecer la participación

\section{Puntaje \\ De 0 a 100 \\ Apreciación cualitativa del puntaje}

Se desarrollaron 54 mesas temáticas y sectoriales, 40 en el sector rural y $144 \mathrm{n}$ el sector urbano, abordándose temas concernientes a la población (niñez, juventud, adulto mayor y aspectos como turismos, agricultura, deportes organización comunitaria entre otros.

En el eje de desarrollo institucional, está el

100 programa Comprometidos con la comunidad por medio del cual se busca fortalecer la participación.

Criterio: 4. Sustentabilidad ambiental

Verifique si el contenido del pan incluye

Ítem

a. Estrategias (programas, subprogramas y/o proyectos) orientadas a garantizar la preservación y conservación de la base ambiental, y hacer uso sostenible de los recursos naturales

b. Metas orientadas a garantizar la preservación y conservación de la base ambiental, y hacer uso sostenible de los recursos naturales

\section{Puntaje \\ De 0 a 100 \\ Apreciación cualitativa del puntaje}

100

Hay programas y subprefectos explícitos
100 
Ítem

a. Los objetivos y la visión son coherentes

b. Los objetivos y el diagnóstico son coherentes

c. Los objetivos y las estrategias

(Programas/Subprogramas/Proyectos) son coherentes

d. Los objetivos y las metas son coherentes

e. Las metas y los indicadores son

coherentes

f. El Plan Plurianual de inversiones y la parte programática son coherentes

\begin{tabular}{|r|l|l|}
\hline $\begin{array}{l}\text { Puntaje } \\
\text { De 0 a } 100\end{array}$ & Apreciación cualitativa del puntaje & \\
\hline 100 & & - \\
\hline 100 & & - \\
\hline 100 & & - \\
\hline 100 & Todo está debidamente articulado & - \\
\hline 100 & & - \\
\hline 100 & & - \\
\hline
\end{tabular}

Componente III: Características del plan

Criterio: 1. Correspondencia con el programa de gobierno

\begin{tabular}{|l|l|l|l|}
\hline Ítem & $\begin{array}{l}\text { Puntaje } \\
\text { De 0 a } 100\end{array}$ & Apreciación cualitativa del puntaje \\
\hline $\begin{array}{l}\text { Verifique si el Plan de Desarrollo guarda } \\
\text { correspondencia con el programa de } \\
\text { gobierno }\end{array}$ & 100 & Sí. & - \\
\hline
\end{tabular}

Criterio: 2. Integralidad

Ítem

a. Considera en el diagnóstico todas las dimensiones del desarrollo (poblacional, económica, ambiente construido, ambiente natural, política administrativa, sociocultural)

b. Refleja un análisis sistémico de la entidad territorial

\begin{tabular}{|r|l|}
$\begin{array}{l}\text { Puntaje } \\
\text { De 0 a 100 }\end{array}$ & Apreciación cualitativa del puntaje \\
\hline 100 & Sí, y sustenta cada eje. \\
\hline 70 & $\begin{array}{l}\text { hay una mirada sistémica en la diagra } \\
\text { plan, sin embargo no es muy evidente } \\
\text { armonización cuando se desagrega en }\end{array}$ \\
\hline $\begin{array}{l}\text { Puntaje } \\
\text { De 0 a 100 }\end{array}$ & Apreciación cualitativa del puntaje \\
\hline
\end{tabular}


a. Verifique si la visión incluida en el Plan de Desarrollo delinea una imagen de la

Entidad Territorial que se quiere

b. Algún eje/ programa/ subprograma/ proyecto que plantee formular o participar en la construcción de una visión del

Territorio

c. Define recursos en el plan de inversiones para construir o participar en la construcción de una visión de territorio
60

Parcialmente se enuncia pero no hace una

referencia específica a este a la entidad como tal.

se enuncia en los objetivos específicos, y se

especifica en el programa Sibaté territorio ordenado

\section{Esta se incluye en un eje.}

\begin{tabular}{|c|c|c|c|}
\hline Ítem & $\begin{array}{l}\text { Puntaje } \\
\text { De } 0 \text { a } 100\end{array}$ & Apreciación cualitativa del puntaje & \\
\hline $\begin{array}{l}\text { a. ¿Se incluye un componente de } \\
\text { seguimiento y evaluación del plan? }\end{array}$ & 100 & $\begin{array}{l}\text { si, teniendo en cuenta el progreso de las políticas } \\
\text { públicas, la provisión de bienes para la ejecución de } \\
\text { los programas, la oferta institucional y la percepción } \\
\text { de la ciudadanía }\end{array}$ & - \\
\hline $\begin{array}{l}\text { b. Se incluye una estrategia para promover } \\
\text { la transparencia y el buen gobierno, a } \\
\text { través de instrumentos como: la rendición } \\
\text { de cuentas, los canales de comunicación de } \\
\text { quejas y reclamos por parte de la } \\
\text { ciudadanía, atención al ciudadano, etc. }\end{array}$ & 100 & si & - \\
\hline
\end{tabular}

\begin{tabular}{|c|c|c|}
\hline \multicolumn{2}{|c|}{ Puntaje obtenido de la evaluación del Plan } & \multirow[b]{2}{*}{ Apreciación cualitativa del puntaje } \\
\hline Componentes & $\begin{array}{c}\text { Calificació } \\
n\end{array}$ & \\
\hline $\begin{array}{l}\text { 1. Conformación del Plan de Desarrollo } \\
(20 \%)\end{array}$ & $\begin{array}{l}18,268181 \\
82\end{array}$ & \\
\hline 2. Principios del Plan de Desarrollo (40\%) & $\begin{array}{l}33,723076 \\
92\end{array}$ & \\
\hline $\begin{array}{l}\text { 3. Características del Plan de Desarrollo } \\
(40 \%)\end{array}$ & $\begin{array}{l}37,166666 \\
67\end{array}$ & \\
\hline CALIFICACIÓN TOTAL & $\begin{array}{l}89,157925 \\
41\end{array}$ & \\
\hline
\end{tabular}

\section{GUÍA BÁSICA PARA LA REVISIÓN Y COMPRENSIÓN DE LOS PLANES DE DESARROLLO DE LAS ENTIDADES TERRITORIALES}


Alcalde

ÁLVARO VENEGAS VENEGAS

Componente I: Conformación del Plan de

Desarrollo

Criterio: 1. Contenido del Plan de Desarrollo

Verifique si el contenido del plan de desarrollo desarrolla los ítems 1.1 al 1.11

\begin{tabular}{|c|c|c|}
\hline Ítem & $\begin{array}{l}\text { Puntaje } \\
\text { De } 0 \text { a } \\
100\end{array}$ & Apreciación cualitativa del puntaje \\
\hline - Diagnóstico & 80 & $\begin{array}{l}\text { Cuenta con diagnostico condensado en } \\
\text { líneas base cuantitativas, puntuales sobre } \\
\text { las que se sustenta y contextualiza las } \\
\text { estrategias, metas de resultado }\end{array}$ \\
\hline - Parte general o estratégica & 100 & Contempla todos sus componentes \\
\hline - Plan de inversiones & 90 & $\begin{array}{l}\text { Enuncia en el decreto su existencia, mas } \\
\text { no está incluido en este y no se } \\
\text { encuentra para consulta pública en } \\
\text { internet. }\end{array}$ \\
\hline - Visión & 80 & $\begin{array}{l}\text { No explicita el periodo de tiempo, ni } \\
\text { indica la prospectiva ni modelo de } \\
\text { desarrollo a mediano o largo plazo, }\end{array}$ \\
\hline - Objetivos Estratégicos & 65 & $\begin{array}{l}\text { No se enuncian como tales, se redactan } \\
\text { como objetivos sectoriales, solo el aparte } \\
\text { que se refiere a medio ambiente consigna } \\
\text { un objetivo estratégico }\end{array}$ \\
\hline - Estrategias y políticas & 90 & $\begin{array}{l}\text { Se enuncia la articulación de este PDM } \\
\text { con los Planes de desarrollo nacional y } \\
\text { departamental y su articulación con las } \\
\text { Políticas nacionales }\end{array}$ \\
\hline $\begin{array}{l}\text { - Formas, medios e instrumentos de vinculación y } \\
\text { armonización de la planeación territorial con la } \\
\text { planeación sectorial y de otros niveles de gobierno }\end{array}$ & 35 & $\begin{array}{l}\text { Si bien explicita de manera conceptual la } \\
\text { armonización, en la estructura no se } \\
\text { parecía como se desdobla, algunos } \\
\text { objetivos hacen referencia a la política a } \\
\text { que están respondiendo, pero no es la } \\
\text { constante }\end{array}$ \\
\hline - Proyección de recursos financieros & 80 & $\begin{array}{l}\text { No hay accesos a los documentos, y } \\
\text { estos no aparecen como anexos según } \\
\text { se explica en el decreto. }\end{array}$ \\
\hline - Programas & 100 & Presenta programas. EI PDM he hace \\
\hline - Subprogramas & 100 & $\begin{array}{l}\text { programas, subprogramas y estrategias, } \\
\text { metas e indicadores cada uno de los } \\
\text { ejes. }\end{array}$ \\
\hline
\end{tabular}


Verifique si el contenido del plan de desarrollo desarrolla los ítems 2.1 al 2.3

\begin{tabular}{|c|c|c|}
\hline Ítem & $\begin{array}{l}\text { Puntaje } \\
\text { De } 0 \text { a } \\
100\end{array}$ & Apreciación cualitativa del puntaje \\
\hline a. Es organizado & 80 & $\begin{array}{l}\text { Cumple con los fundamentos de } \\
\text { organización. Incorpora en el despliegue } \\
\text { de los objetivos, Estrategias, Línea base, } \\
\text { Metas de Resultado, Metas de producto, } \\
\text { no incluye los indicadores de gestión }\end{array}$ \\
\hline b. Tiene una secuencia lógica & 85 & $\begin{array}{l}\text { Presenta una división por capítulos } \\
\text { coherente, desdoblando procesos. Le } \\
\text { falta marco conceptual, diseño } \\
\text { metodológico y la sustentación narrativa } \\
\text { del modelo de gestión }\end{array}$ \\
\hline c. Es comprensible & 80 & $\begin{array}{l}\text {, La lectura del plan no es complicada, la } \\
\text { redacción es clara. La construcción } \\
\text { conceptual es mínima y simple de fácil } \\
\text { comprensión, al alcance de la comunidad }\end{array}$ \\
\hline
\end{tabular}

Criterio: 3. Claridad Conceptual del Plan de Desarrollo

Verifique si el contenido del plan de desarrollo guarda relación con las dimensiones del desarrollo

\begin{tabular}{|c|c|}
\hline Ítem & Puntaje \\
De $0 \mathrm{a}$ \\
100
\end{tabular}

Apreciación cualitativa del puntaje

Vincula la población con el desarrollo.

Tiene en cuanta las diferentes poblaciones y la vulnerabilidad para

a. Poblacional formular los subprogramas y las metas de resultado. Hay transversalidad de acciones para los distintos grupos etarios, no contempla algunos grupos poblacionales (minoría)

Destaca las actividades económicas y su

b. Económica impacto. Destina recursos económicos para cada uno de los ejes y acciones correspondientes

c. Sociocultural

90

d. Político administrativo

90

e. Ambiente natural
Es evidente la preocupación y buscan insertarla desde la educación.

Se busca fortalecer la participación y hacer un gobierno eficiente

Hay una declaración explicita sobre el 100 tema, programas y subproyecto para su desarrollo. 


\section{f. Ambiente construido}

Verifique si el contenido del plan de desarrollo guarda relación los diferentes grupos poblacionales

\begin{tabular}{|c|c|c|}
\hline & & $\begin{array}{c}\text { Puntaje } \\
\text { De } 0 \text { a } \\
100\end{array}$ \\
\hline a. & Niños y niñas & 100 \\
\hline b. & Mujeres & 100 \\
\hline c. & Jóvenes & 100 \\
\hline d. & Adultos mayores & 100 \\
\hline e. & Personas con discapacidad & 100 \\
\hline f. & Desplazados & 100 \\
\hline g. & Víctimas & 100 \\
\hline h. & Población en extrema pobreza & 100 \\
\hline i. & Población LGTBI & 0 \\
\hline j. & Población indígena & 0 \\
\hline $\mathrm{k}$. & Población afrodescendiente & 0 \\
\hline I. & Población raizal & 0 \\
\hline & Población rom o gitana & 0 \\
\hline
\end{tabular}

Visión de desarrollo

Ítem

Puntaje

De 0 a 100

a. Está armonizada con la visión del nivel superior de gobierno (Visión departamental para el caso de los municipios o Visión 2019 para el caso de los departamentos)

45

No contempla. No son explicitas las acciones dirigidas a esta población
Declaración explicita y programas y subprogramas dirigidos a su bienestar e integración sociocultural

\section{0}

00
Hay preocupación por el tema en el eje III se propone " Fortalecer la sostenibilidad y el equilibrio del ambiente natural y el ambiente construido, con la implementación de acciones que reduzcan los impactos ambientales que en la actualidad se generan en las áreas pobladas".

\section{III

as

(1)


arraigo

e. Plantea retos posibles de llevar a cabo

Parte estratégica

Ítem

Puntaje

De 0 a

a. Responden al diagnóstico de la entidad territorial

b. Contribuyen al logro de los objetivos planteados

c. Expresan efectos o cambios que se esperan generar con la implementación de la estrategia (programas, subprogramas, proyectos)

d. Cuantifican los objetivos

e. Define metas para los objetivos

f. Tienen un indicador asociado consistente

g. Tienen líneas de base

Verifique si en el diagnóstico financiero y el plan plurianual de inversiones se contemplan los siguientes ítems

Ítem

Puntaje

De 0 a

a. La definición de ingresos y gastos

b. La forma como se elabora una proyección de recursos financieros

c. Los gasto de inversión

d. Los recursos propios

e. La definición de estrategias para mejorar el esfuerzo fiscal

f. Los recursos del Sistema General de Regalías

Verifique si el plan plurianual de inversiones contiene los siguientes ítems

Ítem

Puntaje

De 0 a

a. Programas y subprogramas
100

90

90

80 100

70

100

100

Vincular al gobierno con la Comunidad y promover criterios de transparencia y eficiencia

Apreciación cualitativa del puntaje

El modelo del PDM no está estructurado técnicamente con base en planeación estratégica por lo tanto tratando de inferir que los ejes son los objetivos estratégicos, se podría decir que si responden al diagnóstico, Requiere precisar algunos puntos como de cultura, capital social. (GC)

100 Si, por cuanto fija indicadores y metas.

90

Establece metas de producto y de resultado

Si, aunque están mal formuladas, ya que están redactadas como objetivos, algunas no especifican plazos, cobertura etc.

Los indicadores tienen relación. Algunos mal redactados y todos de tipo cuantitativo por lo tanto, no se define calidad e impacto.

Se aprecia en muchos casos que dispone de líneas de base

Apreciación cualitativa del puntaje

No es clara la definición, da como hecho su definición.

90 Determina la proyección según las normas

100

los gastos de inversión se incluyen

100

Se tienen en cuenta

60

Hace referencia a modernizar la secretaria.

100

Estos recursos se incluyen y revisten de significación.

Apreciación cualitativa del puntaje

tiene en cuenta programas y subprogramas

Carece de estos medios 
c. Inversión para los cuatro años de gobierno

d. Inversión de los programas y subprogramas por fuente de financiamiento para cada vigencia
100

70
Incluye el cuatrenio

Destaca la inversión y deja por fuera las fuentes de financiamiento. Las fuentes están enunciadas en el presupuesto general

Componente II: Principios Generales del plan

Criterio: 1. Autonomía

Ítem

a. Realiza un diagnóstico de los recursos propios de la entidad territorial

b. Incluye estrategias viables, para aumentar los recursos propios
Puntaje

De 0 a 100

100 Presenta un diagnóstico de los recursos

$0 \quad$ No presenta estrategias.

Criterio: 2. Prioridad del gasto público social

En el plan se da prioridad del gasto público para:

$$
\text { Ítem }
$$

a. Niños y niñas

b. Mujeres

c. Jóvenes

d. Adultos mayores

e. Personas en situación de discapacidad

f. Desplazados

g. Víctimas

h. Población en extrema pobreza

i. Población LGTBI

j. Población indígena

k. Población afro descendiente

I. Población raizal

m. Población ROM o gitana
Puntaje

De 0 a 100

100

100

100

100

100

100

100

100

0

0

0

10

0

0
Apreciación cualitativa del puntaje

Cumple con las disposiciones nacionales y está en correspondencia con el plan

En el plan se considera fundamental apoyar a la mujer

Es un punto que tiene apropiado el gasto

Destinación de recursos para programas y subprogramas

Destinación de recursos para programas y subprogramas

Destinación de recursos para programas y subprogramas

Destinación de recursos para programas y subprogramas

Destinación de recursos para programas y subprogramas

No contempla

Facilita la inclusión

No contempla

No contempla

No contempla 


\begin{tabular}{|l|c|l|}
\hline Ítem & $\begin{array}{c}\text { Puntaje } \\
\text { De 0 a } \\
100\end{array}$ & Apreciación cualitativa del puntaje \\
\hline $\begin{array}{l}\text { a. Se evidencia que el plan fue elaborado con la } \\
\text { participación de la comunidad }\end{array}$ & 60 & $\begin{array}{l}\text { Es contundente la Participación del } \\
\text { Consejo Territorial de Planeación Existe } \\
\text { la brecha de la participación más amplia. }\end{array}$ \\
\hline $\begin{array}{l}\text { b. Tiene estrategias (programas, subprogramas } \\
\text { y/o proyectos) orientadas a fortalecer la } \\
\text { participación }\end{array}$ & 90 & $\begin{array}{l}\text { Esto, está planteado y representa un reto } \\
\text { para el municipio. }\end{array}$ \\
\hline
\end{tabular}

Criterio: 4. Sustentabilidad ambiental

Verifique si el contenido del pan incluye

Ítem

a. Estrategias (programas, subprogramas y/o proyectos) orientadas a garantizar la preservación y conservación de la base ambiental, y hacer uso sostenible de los recursos naturales

b. Metas orientadas a garantizar la preservación y conservación de la base ambiental, y hacer uso sostenible de los recursos naturales
Puntaje

De 0 a 100

100

80
Apreciación cualitativa del puntaje

Es clara la posición en este sentido que se incluye en el plan

Existe este punto dentro del plan, se requiere dar continuidad-

2

Criterio: 5. Coherencia

\begin{tabular}{|c|c|c|}
\hline Ítem & $\begin{array}{l}\text { Puntaje } \\
\text { De } 0 \text { a } \\
100\end{array}$ & Apreciación cualitativa del puntaje \\
\hline a. Los objetivos y la visión son coherentes & 80 & $\begin{array}{l}\text { Es tangencial la formación de capital } \\
\text { social e identidad cultural entre otros }\end{array}$ \\
\hline b. Los objetivos y el diagnóstico son coherentes & 90 & Es visible la coherencia. \\
\hline $\begin{array}{l}\text { c. Los objetivos y las estrategias } \\
\text { (Programas/Subprogramas/Proyectos) son } \\
\text { coherentes }\end{array}$ & 60 & Las estrategias no están explícitas. \\
\hline d. Los objetivos y las metas son coherentes & 90 & Se ve un avance \\
\hline e. Las metas y los indicadores son coherentes & 90 & ídem \\
\hline $\begin{array}{l}\text { f. El Plan Plurianual de inversiones y la parte } \\
\text { programática son coherentes }\end{array}$ & 90 & Ídem. \\
\hline
\end{tabular}

\section{Componente III: Características del plan}

Ítem
Puntaje

De 0 a Apreciación cualitativa del puntaje 
Verifique si el Plan de Desarrollo guarda correspondencia con el programa de gobierno
Ítem

a. Considera en el diagnóstico todas las dimensiones del desarrollo (poblacional, económica, ambiente construido, ambiente natural, política administrativa, sociocultural) b. Refleja un análisis sistémico de la entidad territorial
Puntaje

De 0 a Apreciación cualitativa del puntaje 100

Es tangencial lo relacionado con el

75 ambiente natural y la dimensión cultural respecto a la identidad regional

0 No.

Criterio: 3. Es prospectivo

Ítem

Puntaje

De 0 a Apreciación cualitativa del puntaje 100

a. Verifique si la visión incluida en el Plan de Desarrollo delinea una imagen de la Entidad Territorial que se quiere

b. Algún eje/ programa/ subprograma/ proyecto que plantee formular o participar en la construcción de una visión del Territorio

Esta insertado en el plan ese alcance c. Define recursos en el plan de inversiones para construir o participar en la construcción de una visión de territorio

Criterio: 4. Es evaluable

Ítem

a. ¿Se incluye un componente de seguimiento y evaluación del plan?

Puntaje

De 0 a

100

60

b. Se incluye una estrategia para promover la transparencia y el buen gobierno, a través de instrumentos como: la rendición de cuentas, los canales de comunicación de quejas y reclamos por parte de la ciudadanía, atención al ciudadano, etc. 


\begin{tabular}{|c|c|c|}
\hline \multicolumn{2}{|c|}{ Puntaje obtenido de la evaluación del Plan } & \multirow[b]{2}{*}{ Apreciación cualitativa del puntaje } \\
\hline Componentes & Calificació & \\
\hline 1. Conformación del Plan de Desarrollo (20\%) & 16,11 & $\begin{array}{l}\text { La conformación del plan es buena } \\
\text { desdén su organización y su contenido } \\
\text { sin embargo le falta rigor técnico en su } \\
\text { estructura }\end{array}$ \\
\hline 2. Principios del Plan de Desarrollo (40\%) & 28,85 & $\begin{array}{l}\text { Los principios están integrados lo cual es } \\
\text { positivo, sin embargo le falta integración } \\
\text { vertical, y la articulación con el Plar } \\
\text { Nacional de desarrollo y el Plar } \\
\text { Departamental, solo es explicita la la } \\
\text { articulación entre el Programa de } \\
\text { Gobierno y los objetivos del milenio }\end{array}$ \\
\hline 3. Características del Plan de Desarrollo (40\%) & 26,58 & $\begin{array}{l}\text { Es sencillo, puntual, focalizado y viable, le } \\
\text { falta proyección desde la perspectiva } \\
\text { estratégica, fundamentación conceptual }\end{array}$ \\
\hline CALIFICACIÓN TOTAL & 71,54 & $\begin{array}{l}\text { El plan representa una ruta fácil de } \\
\text { evaluar, coherente y viable para los } \\
\text { recursos con que cuenta, enfocado en e } \\
\text { desarrollo humano integral }\end{array}$ \\
\hline
\end{tabular}

\section{GUÍA BÁSICA PARA LA REVISIÓN Y COMPRENSIÓN DE LOS PLANES DE DESARROLLO DE LAS ENTIDADES TERRITORIALES}

Nombre del Plan de Desarrollo:

PROGRESO PARA TODOS

\section{Entidad territorial:}

GACHANCIPA

\section{Componente I: Conformación del Plan de Desarrollo}

Verifique si el contenido del plan de desarrollo desarrolla los ítems 1.1 al 1.11

\begin{tabular}{|l|r|l|}
\hline Ítem & $\begin{array}{l}\text { Puntaje } \\
\text { De } \mathbf{0} \text { a } \\
100\end{array}$ & Apreciación cualitativa del puntaje \\
\hline - Diagnóstico & 100 & detallado poblacional y sectorial \\
\hline Parte general o estratégica & 100 & especifica \\
\hline - Plan de inversiones & 100 & Justificado y discriminado \\
\hline - Visión & 100 & A mediano plazo \\
\hline - Objetivos Estratégicos & 100 & por ejes \\
\hline - Estrategias y políticas & 100 & enunciadas en el decreto \\
\hline
\end{tabular}


- Formas, medios e instrumentos de vinculación y armonización de la planeación territorial con la planeación sectorial y de otros niveles de gobierno

- Proyección de recursos financieros

- Programas

- Subprogramas

- Proyectos

Criterio: 2. Estructura del Plan de Desarrollo leyes, decretos, políticas

100

Clara y definida la estrategia

100 de acuerdo a los ejes

100

de acuerdo a los programas

Verifique si el contenido del plan de desarrollo desarrolla los ítems 2.1 al 2.3

\begin{tabular}{|l|r|l|}
\hline Ítem & $\begin{array}{l}\text { Puntaje } \\
\text { De } 0 \text { a } \\
100\end{array}$ & Apreciación cualitativa del puntaje \\
\hline a. Es organizado & 100 & $\begin{array}{l}\text { organizado, con información suficiente } \\
\text { y pertinente }\end{array}$ \\
\hline b. Tiene una secuencia lógica & 100 & si \\
\hline c. Es comprensible & 100 & si \\
\hline
\end{tabular}

Criterio: 3. Claridad Conceptual del Plan de

Desarrollo

Verifique si el contenido del plan de desarrollo guarda relación con las dimensiones del desarrollo Ítem

Puntaje

Item $\quad$ De 0 a

100

\begin{tabular}{|c|c|c|}
\hline & Poblacional & 100 \\
\hline b. & Económica & 100 \\
\hline c. & Sociocultural & 100 \\
\hline d. & Político administrativo & 100 \\
\hline e. & Ambiente natural & 100 \\
\hline f. & Ambiente construido & 100 \\
\hline
\end{tabular}

Verifique si el contenido del plan de desarrollo guarda relación los diferentes grupos poblacionales

Ítem

\section{a. Niños y niñas}

b. Mujeres

c. Jóvenes

\section{Puntaje}

De 0 a 100 100

100

100
Apreciación cualitativa del puntaje

si

si

si

si

si

si

Apreciación cualitativa del puntaje

Desarrollo e implementación de

políticas y programas dirigidos a estas poblaciones 


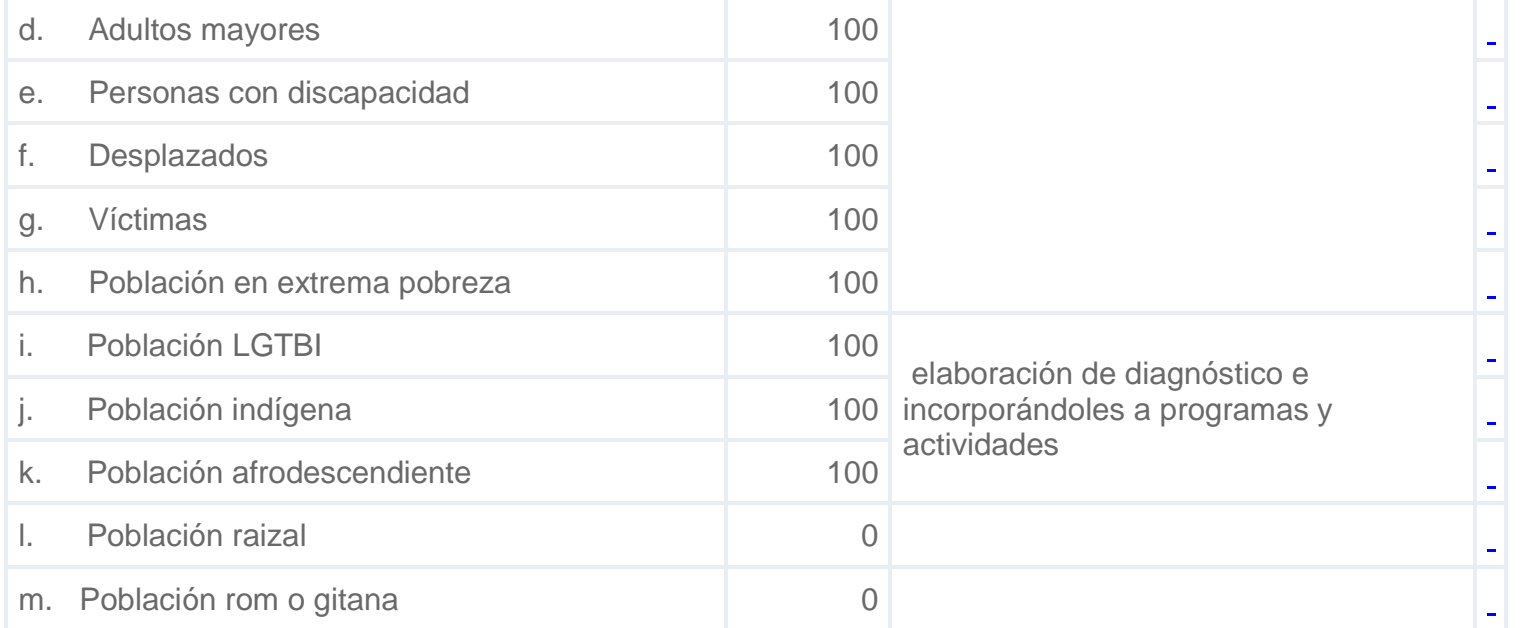

\begin{tabular}{|l|l|}
\hline Visión de desarrollo & \\
\hline & Puntaje \\
Ítem & De O a \\
& 100
\end{tabular}

a. Está armonizada con la visión del nivel superior de gobierno (Visión departamental para el caso de los municipios o Visión 2019 para el caso de los departamentos)

b. Tiene un horizonte mayor o igual a 10 años

c. Fue construida con la participación actores de la comunidad, de la sociedad civil y del sector público

d. Resalta por lo menos una propiedad cultural y/o valores sociales para distinguir al territorio y darle arraigo

e. Plantea retos posibles de llevar a cabo

\section{Parte estratégica}

Ítem

a. Responden al diagnóstico de la entidad territorial

b. Contribuyen al logro de los objetivos planteados

c. Expresan efectos o cambios que se esperan generar con la implementación de la estrategia (programas, subprogramas, proyectos)

d. Cuantifican los objetivos

e. Define metas para los objetivos

f. Tienen un indicador asociado consistente
De 0 a

100

\section{Apreciación cualitativa del puntaje}

incluye un eje de desarrollo regional y

100 se articula con las políticas públicas del nivel nacional

100 si, a 16 años

100

si de manera amplia e incluyente, por poblaciones, y sectores

Explicita la intención de recuperar valores culturales, la difusión de la formación artística; sentido de

100 pertenencia, promoción de las costumbres locales, patrimonios comunes y tengan reconocimiento por los derechos y deberes ciudadanos.

90 Sí, asociados a objetivos estratégicos 
g. Tienen líneas de base

60 en algunos ítems

Verifique si en el diagnóstico financiero y el plan plurianual de inversiones se contemplan los siguientes ítems

\begin{tabular}{|c|c|c|}
\hline Ítem & $\begin{array}{l}\text { Puntaje } \\
\text { De } 0 \text { a } \\
100\end{array}$ & Apreciación cualitativa del puntaje \\
\hline a. La definición de ingresos y gastos & 100 & si, define estrategias y políticas \\
\hline $\begin{array}{l}\text { b. La forma como se elabora una proyección de } \\
\text { recursos financieros }\end{array}$ & 100 & $\begin{array}{l}\text { esquema de racionalización y } \\
\text { optimización del gasto de } \\
\text { funcionamiento, y una adecuada } \\
\text { combinación de solvencia y } \\
\text { sostenibilidad para el uso responsable } \\
\text { del crédito y el pago oportuno del } \\
\text { servicio de la deuda, }\end{array}$ \\
\hline c. Los gasto de inversión & 100 & \multirow{3}{*}{$\begin{array}{l}\text { La estrategia propuesta busca } \\
\text { incrementar las fuentes tradicionales de } \\
\text { recursos propios, mejorando el recaudo } \\
\text { oportuno, respecto del año } 2011 \text {, } \\
\text { recuperando la confianza y credibilidad } \\
\text { que permitan fortalecer la cultura } \\
\text { tributaria del ciudadano, y haciendo un } \\
\text { esfuerzo adicional para la recuperación } \\
\text { de cartera vencida, tanto del impuesto } \\
\text { Predial y complementarios, e industria y } \\
\text { comercio, }\end{array}$} \\
\hline d. Los recursos propios & 100 & \\
\hline $\begin{array}{l}\text { e. La definición de estrategias para mejorar el } \\
\text { esfuerzo fiscal }\end{array}$ & 100 & \\
\hline f. Los recursos del Sistema General de Regalías & 0 & No se explica \\
\hline
\end{tabular}

Verifique si el plan plurianual de inversiones contiene los siguientes ítems

\begin{tabular}{|l|r|r|}
\hline Ítem & $\begin{array}{l}\text { Puntaje } \\
\text { De } 0 \text { a } \\
100\end{array}$ & Apreciación cualitativa del puntaje \\
\hline a. Programas y subprogramas & 100 & \\
\hline b. Objetivos y metas de inversión & 100 & claramente definidos para cada eje \\
\hline c. Inversión para los cuatro años de gobierno & 100 & - \\
\hline \begin{tabular}{l|l|l|}
\hline d. Inversión de los programas y subprogramas \\
por fuente de financiamiento para cada vigencia
\end{tabular} & 100 & \\
\hline
\end{tabular}

\section{Componente II: Principios Generales del plan}

Criterio: 1. Autonomía

100

Ítem

Puntaje

De 0 a

100

a. Realiza un diagnóstico de los recursos propios de la entidad territorial

b. Incluye estrategias viables, para aumentar los recursos propios

\section{Apreciación cualitativa del puntaje}

100

si, detallado

100 si, de manera explicita 


\section{En el plan se da prioridad del gasto público para:}

\begin{tabular}{|c|c|c|}
\hline Ítem & $\begin{array}{l}\text { Puntaje } \\
\text { De } 0 \text { a } \\
100\end{array}$ & Apreciación cualitativa del puntaje \\
\hline a. Niños y niñas & 100 & \multirow{11}{*}{$\begin{array}{l}\text { Sí, este municipio desde las anteriores } \\
\text { administraciones ha privilegiado el } \\
\text { gasto público social y lo continuará } \\
\text { haciendo sin descuidar otros frentes de } \\
\text { trabajo. }\end{array}$} \\
\hline b. Mujeres & 100 & \\
\hline c. Jóvenes & 100 & \\
\hline d. Adultos mayores & 100 & \\
\hline e. Personas en situación de discapacidad & 100 & \\
\hline f. Desplazados & 100 & \\
\hline g. Víctimas & 100 & \\
\hline h. Población en extrema pobreza & 100 & \\
\hline i. Población LGTBI & 100 & \\
\hline j. Población indígena & 100 & \\
\hline k. Población afro descendiente & 100 & \\
\hline I. Población raizal & 0 & \\
\hline m. Población ROM o gitana & 0 & \\
\hline
\end{tabular}

Criterio: 3. Participación (diagnóstico, objetivo, programa, recursos)

Ítem

a. Se evidencia que el plan fue elaborado con la participación de la comunidad

b. Tiene estrategias (programas, subprogramas y/o proyectos) orientadas a fortalecer la participación

\section{Puntaje}

De 0 a 100

\section{Apreciación cualitativa del puntaje}

100

Sí, de manera amplia y suficiente

Sí, como eje transversal se incluye el 100 componente participación y control ciudadano. 


\begin{tabular}{|c|c|c|c|}
\hline Ítem & $\begin{array}{l}\text { Puntaje } \\
\text { De } 0 \text { a } \\
100\end{array}$ & Apreciación cualitativa del puntaje & \\
\hline $\begin{array}{l}\text { a. Estrategias (programas, subprogramas y/o } \\
\text { proyectos) orientadas a garantizar la preservación } \\
\text { y conservación de la base ambiental, y hacer uso } \\
\text { sostenible de los recursos naturales }\end{array}$ & 100 & $\begin{array}{l}\text { Elaboración de la política pública de } \\
\text { medios ambiente y el desarrollo de } \\
\text { actividades para su protección de }\end{array}$ & - \\
\hline $\begin{array}{l}\text { b. Metas orientadas a garantizar la preservación y } \\
\text { conservación de la base ambiental, y hacer uso } \\
\text { sostenible de los recursos naturales }\end{array}$ & 0 & no se explicitan & - \\
\hline & & & 2 \\
\hline Criterio: 5. Coherencia & & 96,66666667 & \\
\hline Ítem & $\begin{array}{l}\text { Puntaje } \\
\text { De } 0 \text { a } \\
100\end{array}$ & Apreciación cualitativa del puntaje & \\
\hline a. Los objetivos y la visión son coherentes & 100 & \multirow{6}{*}{ si } & - \\
\hline b. Los objetivos y el diagnóstico son coherentes & 80 & & - \\
\hline $\begin{array}{l}\text { c. Los objetivos y las estrategias } \\
\text { (Programas/Subprogramas/Proyectos) son } \\
\text { coherentes }\end{array}$ & 100 & & - \\
\hline d. Los objetivos y las metas son coherentes & 100 & & - \\
\hline e. Las metas y los indicadores son coherentes & 100 & & - \\
\hline $\begin{array}{l}\text { f. El Plan Plurianual de inversiones y la parte } \\
\text { programática son coherentes }\end{array}$ & 100 & & - \\
\hline
\end{tabular}

Componente III: Características del plan

Criterio: 1. Correspondencia con el programa de gobierno

\begin{tabular}{|c|c|c|}
\hline Ítem & $\begin{array}{l}\text { Puntaje } \\
\text { De } 0 \text { a } \\
100\end{array}$ & Apreciación cualitativa del puntaje \\
\hline $\begin{array}{l}\text { Verifique si el Plan de Desarrollo guarda } \\
\text { correspondencia con el programa de gobierno }\end{array}$ & 100 & total \\
\hline \multicolumn{3}{|l|}{ Criterio: 2. Integralidad } \\
\hline Ítem & $\begin{array}{l}\text { Puntaje } \\
\text { De } 0 \text { a } \\
100\end{array}$ & Apreciación cualitativa del puntaje \\
\hline
\end{tabular}


a. Considera en el diagnóstico todas las dimensiones del desarrollo (poblacional, económica, ambiente construido, ambiente natural, política administrativa, sociocultural)

b. Refleja un análisis sistémico de la entidad territorial estrategias

\section{Puntaje}

De $\mathrm{O}$ a Apreciación cualitativa del puntaje 100

a. Verifique si la visión incluida en el Plan de Desarrollo delinea una imagen de la Entidad Territorial que se quiere

b. Algún eje/ programa/ subprograma/ proyecto que plantee formular o participar en la construcción de una visión del Territorio

c. Define recursos en el plan de inversiones para construir o participar en la construcción de una visión de territorio
Sí hay un eje transversal que incluye 100 el desarrollo regional, y otro en el que se incluye el ordenamiento y protección del territorio

0 no se explicita puntualmente

Criterio: 4. Es evaluable

Ítem

a. ¿Se incluye un componente de seguimiento y evaluación del plan?

b. Se incluye una estrategia para promover la transparencia y el buen gobierno, a través de instrumentos como: la rendición de cuentas, los canales de comunicación de quejas y reclamos por parte de la ciudadanía, atención al ciudadano, etc.

\section{Puntaje}

De 0 a Apreciación cualitativa del puntaje 100
80 no especifica cómo

100 Sí, con acciones claramente definidas

\begin{tabular}{|l|l|l|}
\hline \multicolumn{2}{|c|}{ Puntaje obtenido de la evaluación del Plan } & \\
Componentes & $\begin{array}{c}\text { Calificaci } \\
\text { ón }\end{array}$ & \multicolumn{1}{|c|}{ Apreciación cualitativa del puntaje } \\
\hline 1. Conformación del Plan de Desarrollo (20\%) & 19,41666 \\
\hline 2. Principios del Plan de Desarrollo (40\%) & 667 & \\
\hline
\end{tabular}




\begin{tabular}{|c|c|}
\hline 3. Características del Plan de Desarrollo (40\%) & $\begin{array}{l}35,16666 \\
667\end{array}$ \\
\hline CALIFICACIÓN TOTAL & $\begin{array}{l}89,08589 \\
744\end{array}$ \\
\hline
\end{tabular}

\section{PLAN DE \\ DESARROLLO DE \\ SUBACHOQUE}

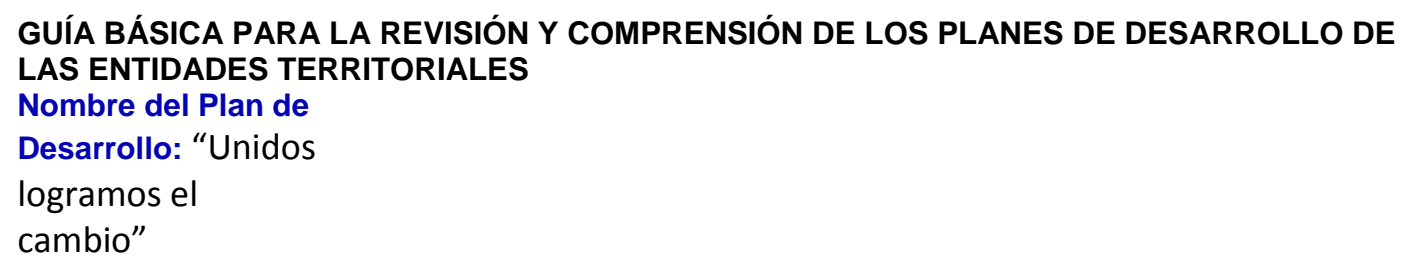

cambio"

Entidad territorial:

Componente I: Conformación del Plan de Desarrollo

\begin{tabular}{|c|c|c|}
\hline $\begin{array}{l}\text { Criterio: } 1 . \\
\text { Contenido del Plan } \\
\text { de Desarrollo }\end{array}$ & & 73,63636364 \\
\hline Verifique si el conter & ido del & plan de desarrollo desarrolla los ítems 1.1 al 1.11 \\
\hline Ítem & $\begin{array}{l}\text { Punt } \\
\text { aje } \\
\text { De } 0 \\
\text { a } 100\end{array}$ & Apreciación cualitativa del puntaje \\
\hline - Diagnóstico & 80 & Contempla ejes social, Económico, Institucional y financiera \\
\hline $\begin{array}{l}\text { Parte general o } \\
\text { estratégica }\end{array}$ & 100 & Compuesta por Visión, objetivos, principios y proyectos estratégicos \\
\hline - Plan de inversiones & 80 & Realizado básicamente sobre los recursos propios y corrientes \\
\hline - Visión & 100 & Proyecta al municipio a largo plazo de acuerdo con el EOT \\
\hline $\begin{array}{l}\text { - Objetivos } \\
\text { Estratégicos }\end{array}$ & 80 & $\begin{array}{l}\text { Se definen unos objetivos generales y en cada eje se formula los } \\
\text { objetivos y las estrategias }\end{array}$ \\
\hline $\begin{array}{l}\text { - Estrategias y } \\
\text { políticas }\end{array}$ & 90 & $\begin{array}{l}\text { Se muestra la articulación del Plan con las políticas Nacionales, pero no } \\
\text { se definen las estrategias }\end{array}$ \\
\hline $\begin{array}{l}\text { - Formas, medios e } \\
\text { instrumentos de } \\
\text { vinculación y } \\
\text { armonización de la } \\
\text { planeación territorial } \\
\text { con la planeación } \\
\text { sectorial y de otros }\end{array}$ & 80 & $\begin{array}{l}\text { Se plantea la articulación con el nivel departamental, pero no se } \\
\text { evidencia la armonización con otros sectores }\end{array}$ \\
\hline
\end{tabular}




\begin{tabular}{|c|c|c|}
\hline niveles de gobierno & & \\
\hline $\begin{array}{l}\text { - Proyección de } \\
\text { recursos financieros }\end{array}$ & 100 & $\begin{array}{l}\text { Se realiza la proyección con los recursos propios recursos propios, } \\
\text { Sistema General de Participaciones de libre destinación y de forzosa } \\
\text { inversión y otros recursos en los cuales se incluyen partidas con } \\
\text { destinación específica de diferentes fuentes. }\end{array}$ \\
\hline - Programas & 100 & se evidencian 63 programas discriminado en cada eje \\
\hline - Subprogramas & 0 & No se plantean los subproyecto, sino las metas \\
\hline - Proyectos & 0 & No se plantean proyectos \\
\hline $\begin{array}{l}\text { Criterio: } 2 . \\
\text { Estructura del Plan } \\
\text { de Desarrollo }\end{array}$ & & 96,66666667 \\
\hline Verifique si el conte & ido del & plan de desarrollo desarrolla los ítems 2.1 al 2.3 \\
\hline Ítem & $\begin{array}{l}\text { Punt } \\
\text { aje } \\
\text { De } 0 \\
\text { a } 100\end{array}$ & Apreciación cualitativa del puntaje \\
\hline a. Es organizado & 90 & $\begin{array}{l}\text { El plan tiene un orden que permite conocer el contexto general , para } \\
\text { luego determinar por sectores el diagnóstico, los programas y las metas, } \\
\text { así como los indicadores y línea base y el presupuesto y el plan } \\
\text { plurianual }\end{array}$ \\
\hline $\begin{array}{l}\text { b. Tiene una } \\
\text { secuencia lógica }\end{array}$ & 100 & Se plantea desde e contexto los sectores y el presupuesto \\
\hline c. Es comprensible & 100 & Maneja un vocabulario comprensivo para el lector \\
\hline $\begin{array}{l}\text { Criterio: } 3 . \text { Claridad } \\
\text { Conceptual del Plan } \\
\text { de Desarrollo }\end{array}$ & & 83,41463415 \\
\hline Verifique si el conte & ido del & plan de desarrollo guarda relación con las dimensiones del desarrollo \\
\hline Ítem & $\begin{array}{l}\text { Punt } \\
\text { aje } \\
\text { De } 0 \\
\text { a } 100\end{array}$ & Apreciación cualitativa del puntaje \\
\hline a. Poblacional & 100 & En cada sector se cubren los diferentes grupos poblacionales \\
\hline b. Económica & 100 & En el presupuesto se contempla cada sector \\
\hline c. Sociocultural & 100 & Incluye los aspecto culturales y patrimoniales \\
\hline $\begin{array}{l}\text { d. Político } \\
\text { administrativo }\end{array}$ & 100 & Hace referencia a la buena administración del municipio \\
\hline
\end{tabular}




\begin{tabular}{|c|c|c|}
\hline $\begin{array}{l}\text { e. Ambiente } \\
\text { natural }\end{array}$ & 100 & $\begin{array}{l}\text { Maneja el sector del medio ambiente, además de que es el eje central } \\
\text { del plan }\end{array}$ \\
\hline $\begin{array}{l}\text { f. Ambiente } \\
\text { construido }\end{array}$ & 100 & plantea temas de infraestructura como vivienda \\
\hline \multicolumn{3}{|c|}{$\begin{array}{l}\text { Verifique si el contenido del plan de desarrollo guarda relación los diferentes grupos } \\
\text { poblacionales }\end{array}$} \\
\hline Ítem & $\begin{array}{l}\text { Punt } \\
\text { aje } \\
\text { De } 0 \\
\text { a } 100\end{array}$ & Apreciación cualitativa del puntaje \\
\hline a. Niños y niñas & 100 & $\begin{array}{l}\text { En cada uno de los ejes y sectores se contemplan los programas para } \\
\text { esta población }\end{array}$ \\
\hline b. Mujeres & 100 & $\begin{array}{l}\text { En cada uno de los ejes y sectores se contemplan los programas para } \\
\text { esta población }\end{array}$ \\
\hline c. Jóvenes & 100 & $\begin{array}{l}\text { En cada uno de los ejes y sectores se contemplan los programas para } \\
\text { esta población }\end{array}$ \\
\hline d. Adultos mayores & 100 & $\begin{array}{l}\text { En cada uno de los ejes y sectores se contemplan los programas para } \\
\text { esta población }\end{array}$ \\
\hline $\begin{array}{l}\text { e. Personas con } \\
\text { discapacidad }\end{array}$ & 100 & $\begin{array}{l}\text { En cada uno de los ejes y sectores se contemplan los programas para } \\
\text { esta población }\end{array}$ \\
\hline f. Desplazados & 100 & $\begin{array}{l}\text { En cada uno de los ejes y sectores se contemplan los programas para } \\
\text { esta población }\end{array}$ \\
\hline g. Víctimas & 100 & $\begin{array}{l}\text { En cada uno de los ejes y sectores se contemplan los programas para } \\
\text { esta población }\end{array}$ \\
\hline $\begin{array}{l}\text { h. Población en } \\
\text { extrema pobreza }\end{array}$ & 100 & $\begin{array}{l}\text { En cada uno de los ejes y sectores se contemplan los programas para } \\
\text { esta población }\end{array}$ \\
\hline i. Población LGTBI & 0 & No se contempla esta población \\
\hline $\begin{array}{l}\text { j. Población } \\
\text { indígena }\end{array}$ & 0 & No se contempla esta población \\
\hline $\begin{array}{l}\text { k. Población } \\
\text { afrodescendiente }\end{array}$ & 0 & No se contempla esta población \\
\hline I. Población raizal & 0 & No se contempla esta población \\
\hline $\begin{array}{l}\text { m. Población rom o } \\
\text { gitana }\end{array}$ & 0 & No se contempla esta población \\
\hline \multicolumn{3}{|l|}{ Visión de desarrollo } \\
\hline Ítem & $\begin{array}{l}\text { Punt } \\
\text { aje } \\
\text { De } 0 \\
\text { a } 100\end{array}$ & Apreciación cualitativa del puntaje \\
\hline $\begin{array}{l}\text { a. Está armonizada } \\
\text { con la visión del nivel } \\
\text { superior de gobierno } \\
\text { (Visión departamental } \\
\text { para el caso de los }\end{array}$ & 40 & Solo se encuentra coincidencia en el desarrollo integral \\
\hline
\end{tabular}




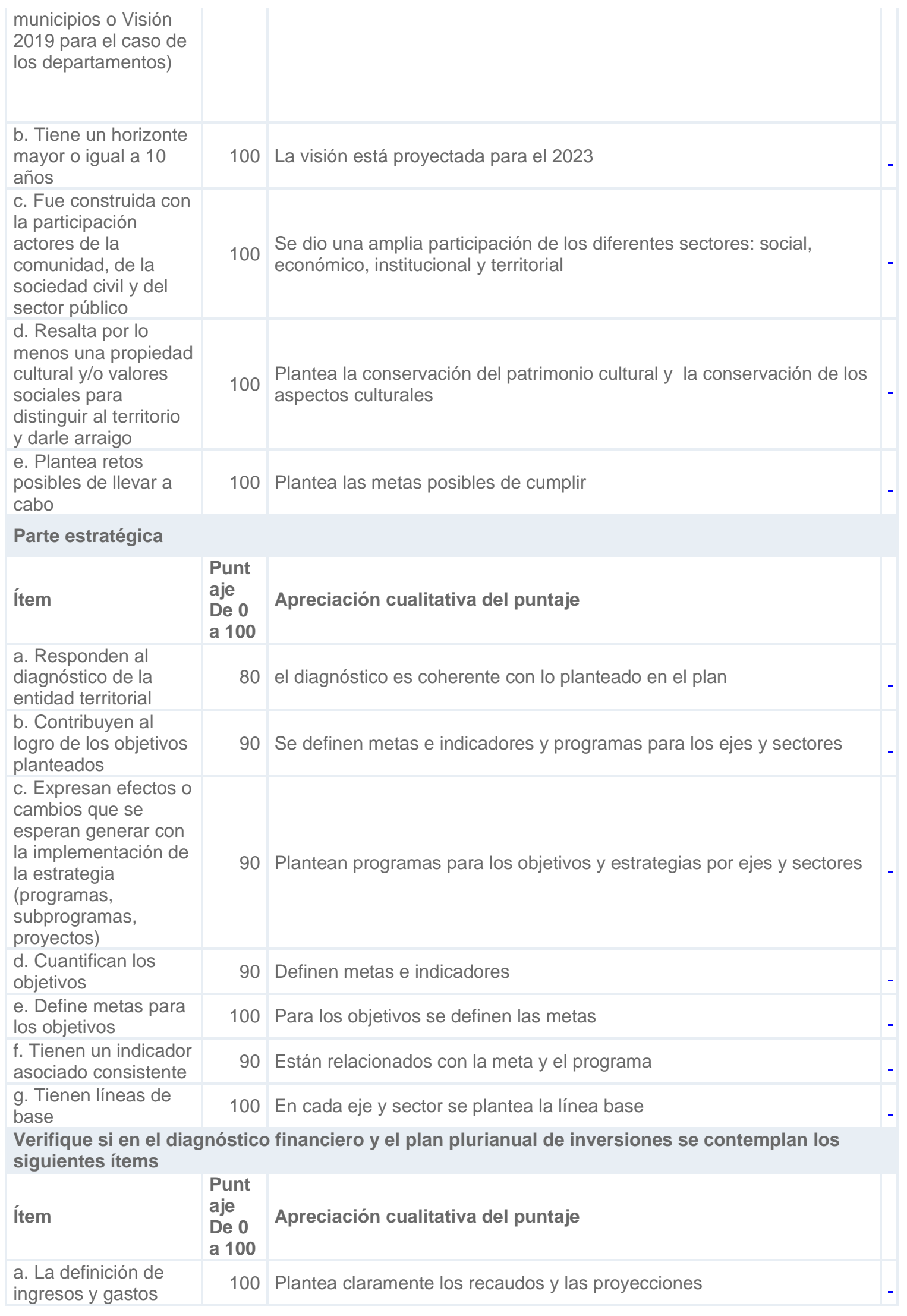


b. La forma como se elabora una proyección de recursos financieros

c. Los gasto de inversión

d. Los recursos propios

e. La definición de estrategias para mejorar el esfuerzo fiscal

f. Los recursos del Sistema General de Regalías

Verifique si el plan plurianual de inversiones contiene los siguientes ítems

\begin{tabular}{|l|l|l|} 
& Punt & \\
Ítem & aje & Apreciación cualitativa del puntaje \\
De 0 & a 100 & \\
\hline
\end{tabular}

a. Programas y subprogramas

b. Objetivos y metas de inversión

c. Inversión para los cuatro años de gobierno d. Inversión de los programas y subprogramas por

fuente de financiamiento para cada vigencia
100 Es clara la proyección de los recursos por cada año del plan

100 Están realizados por cada año y sobre los ejes

100 Se definen para cada eje

100 Se define que el municipio no tiene deudas actualmente

100 Están definidos para los ejes por cada año de ejecución del plan

Son 62 Programas los cuales se contemplan por cada eje estratégico, pero no contempla subprogramas sino metas de resultado y de producto

90 En cada eje se plantean los objetivos y metas de producto, en el plan de inversión se establece por eje, sector y programa

100 Se establece el plan por los cuatro años y el total es de 27.244

Se elabora por cada fuente de financiamiento se hace por eje, sector y programa, ya que el plan no establece subprogramas

\section{Componente II: Principios Generales del plan}

Criterio: 1 . Autonomía

\section{Autonomia}

Ítem

a. Realiza un diagnóstico de los recursos propios de la entidad territorial b. Incluye estrategias viables, para aumentar los recursos propios

100 
Criterio: 2. Prioridad del gasto público social

En el plan se da prioridad del gasto público para:

\begin{tabular}{|l|l|l|}
\hline Ítem & $\begin{array}{l}\text { Punt } \\
\text { aje } \\
\text { De 0 } \\
\text { a 100 }\end{array}$ & Apreciación cualitativa del puntaje \\
\hline
\end{tabular}

a. Niños y niñas

100 presupuesto

b. Mujeres

100

en el Sector de Bienestar social área social se incluye un porcentaje del presupuesto

c. Jóvenes

100

en el Sector de Bienestar social área social se incluye un porcentaje del presupuesto

d. Adultos mayores

100

en el Sector de Bienestar social área social se incluye un porcentaje del presupuesto

e. Personas en situación de discapacidad

100 en el Sector de Bienestar social área social se incluye un porcentaje del presupuesto

f. Desplazados

g. Víctimas

0 No se contempla en el plan

h. Población en extrema pobreza

i. Población LGTBI

en el Sector de Bienestar social área social se incluye un porcentaje del presupuesto

j. Población indígena

k. Población afro descendiente

I. Población raizal

m. Población ROM o gitana

en el Sector de Bienestar social área social se incluye un porcentaje del presupuesto

\section{Criterio: 3.}

Participación

(diagnóstico,

objetivo, programa,

recursos)

0 No se contempla en el plan

0 No se contempla en el plan

0 No se contempla en el plan

0 No se contempla en el plan

0 No se contempla en el plan

\begin{tabular}{|l|l|l|}
\hline Ítem & $\begin{array}{l}\text { Punt } \\
\text { aje } \\
\text { De 0 } \\
\text { a 100 }\end{array}$ & Apreciación cualitativa del puntaje \\
\hline
\end{tabular}


a. Se evidencia que el plan fue elaborado con la participación de la comunidad b. Tiene estrategias (programas, subprogramas y/o proyectos) orientadas a fortalecer la participación
100 Se muestra al comienzo del plan en número de personas que participaron y los sectores de población

100 Existe un eje de participación comunitaria

\section{Criterio: 4.}

Sustentabilidad ambiental

Verifique si el contenido del pan incluye

\begin{tabular}{|l|l|l} 
& Punt & \\
Ítem & aje & Apreciación cualitativa del puntaje \\
& De 0 & a 100
\end{tabular}

\section{a. Estrategias} (programas, subprogramas $\mathrm{y} / \mathrm{o}$ proyectos) orientadas a garantizar la preservación y conservación de la base ambiental, y hacer uso sostenible de los recursos naturales b. Metas orientadas a garantizar la preservación y conservación de la base ambiental, y hacer uso sostenible de los recursos naturales
Plantea el eje territorial, sonde se contempla el programa de medio

100 ambiente y cuidado de los recursos naturales, un tema central del plan de desarrollo es ser ecológico y agropecuario
100

En el sector del medio ambiente plantea metas para la conservación de los recursos, naturales, protección de áreas para la reforestación de zonas del municipio con el fin de proteger los recursos hídricos del municipio

\begin{tabular}{|l|l|l|}
\hline Punt & \\
Ítem & aje & Apreciación cualitativa del puntaje \\
De 0 & Ap 100 & \\
a 100 & \\
\hline
\end{tabular}

a. Los objetivos y la visión son coherentes

b. Los objetivos y el diagnóstico son coherentes
Se evidencia una articulación entre la visión y los objetivos, estos últimos permiten cumplir con la visión del municipio. Cada eje plantea su propia visión que se desarrolla a partir de los sectores y los programas

Los objetivos comprenden los ejes centrales del plan de desarrollo respondiendo al diagnóstico del municipio 
c. Los objetivos y las estrategias

(Programas/Subprogr amas/Proyectos) son coherentes

d. Los objetivos y las metas son

coherentes

e. Las metas y los indicadores son coherentes

f. El Plan Plurianual de inversiones y la parte programática son coherentes
A través de las estrategias se dará cumplimiento a los objetivos de cada uno de los ejes y sectores

Existe coherencia entre las metas y los objetivos a través de las metas se dará cumplimiento a los objetivos

Hay coherencia entre los indicadores y las metas y permite que se cumplan los objetivos

100

El plan plurianual está elaborado para dar respuesta a los ejes y los sectores

\section{Componente III: Características del plan}

\section{Criterio: 1. \\ Correspondencia \\ con el programa de \\ gobierno}

\section{Ítem}

Verifique si el Plan de Desarrollo guarda correspondencia con el programa de gobierno

\section{Apreciación cualitativa del puntaje}

Se evidencia la coherencia entre el plan de desarrollo y el plan de 100 gobierno en cuanto a los ejes sociales, económicos, ambientales, territorial y de buen gobierno, se amplía más en el plan de desarrollo

Criterio: 2.

Integralidad

a. Considera en el diagnóstico todas las dimensiones del desarrollo (poblacional, económica, ambiente construido, ambiente natural, política administrativa, sociocultural) b. Refleja un análisis sistémico de la entidad territorial

\section{Punt \\ aje \\ De 0}

a 100

El diagnóstico se evidencia en cada uno de los sectores pero faltan algunos datos para precisar las situaciones que vive el municipio

90 Muestra componente cualitativo y cuantitativo del municipio 


\begin{tabular}{|c|c|c|}
\hline Ítem & $\begin{array}{l}\text { Punt } \\
\text { aje } \\
\text { De } 0 \\
\text { a } 100\end{array}$ & Apreciación cualitativa del puntaje \\
\hline $\begin{array}{l}\text { a. Verifique si la } \\
\text { visión incluida en el } \\
\text { Plan de Desarrollo } \\
\text { delinea una imagen } \\
\text { de la Entidad } \\
\text { Territorial que se } \\
\text { quiere }\end{array}$ & 100 & $\begin{array}{l}\text { La visión plantea lo que se quiere para el municipio el cual está } \\
\text { centrado en lo social y lo ecológico, mostrando el mejoramiento del } \\
\text { territorio }\end{array}$ \\
\hline $\begin{array}{l}\text { b. Algún eje/ } \\
\text { programa/ } \\
\text { subprograma/ } \\
\text { proyecto que plantee } \\
\text { formular o participar } \\
\text { en la construcción de } \\
\text { una visión del } \\
\text { Territorio }\end{array}$ & 100 & $\begin{array}{l}\text { En el eje territorial de muestra todo el desarrollo del territorio, que } \\
\text { incluye lo ambiental, vivienda, espacio público y servicios públicos }\end{array}$ \\
\hline $\begin{array}{l}\text { c. Define recursos en } \\
\text { el plan de inversiones } \\
\text { para construir o } \\
\text { participar en la } \\
\text { construcción de una } \\
\text { visión de territorio }\end{array}$ & 100 & $\begin{array}{l}\text { En el plan de inversiones se plantea el presupuesto para el eje de } \\
\text { territorio y los sectores }\end{array}$ \\
\hline
\end{tabular}

Criterio: 4. Es evaluable

\begin{tabular}{|c|c|c|}
\hline Ítem & $\begin{array}{l}\text { Punt } \\
\text { aje } \\
\text { De } 0 \\
\text { a } 100\end{array}$ & Apreciación cualitativa del puntaje \\
\hline $\begin{array}{l}\text { a. ¿Se incluye un } \\
\text { componente de } \\
\text { seguimiento y } \\
\text { evaluación del plan? }\end{array}$ & 70 & $\begin{array}{l}\text { En el sector del buen gobierno plantea programas, metas e indicadores } \\
\text { para el seguimiento y evaluación del plan falta mayor ampliación de } \\
\text { este factor }\end{array}$ \\
\hline $\begin{array}{l}\text { b. Se incluye una } \\
\text { estrategia para } \\
\text { promover la } \\
\text { transparencia y el } \\
\text { buen gobierno, a } \\
\text { través de } \\
\text { instrumentos como: } \\
\text { la rendición de } \\
\text { cuentas, los canales } \\
\text { de comunicación de } \\
\text { quejas y reclamos } \\
\text { por parte de la } \\
\text { ciudadanía, atención } \\
\text { al ciudadano, etc. }\end{array}$ & 100 & $\begin{array}{l}\text { En el sector del buen gobierno plantea los mecanismos para promover } \\
\text { la transparencia. }\end{array}$ \\
\hline
\end{tabular}




\begin{tabular}{|c|c|c|}
\hline \multicolumn{2}{|c|}{$\begin{array}{l}\text { Puntaje obtenido de la } \\
\text { evaluación del Plan }\end{array}$} & \multirow[b]{2}{*}{ Apreciación cualitativa del puntaje } \\
\hline Componentes & $\begin{array}{c}\text { Califi } \\
\text { cació } \\
n\end{array}$ & \\
\hline $\begin{array}{l}\text { 1. Conformación del } \\
\text { Plan de Desarrollo } \\
(20 \%)\end{array}$ & $\begin{array}{l}16,91 \\
4510 \\
96\end{array}$ & $\begin{array}{l}\text { El plan está conformado por ejes, sectores, objetivos y programa, se } \\
\text { plantea de forma clara }\end{array}$ \\
\hline $\begin{array}{l}\text { 2. Principios del Plan } \\
\text { de Desarrollo }(40 \%)\end{array}$ & $\begin{array}{l}36,30 \\
7692 \\
31\end{array}$ & Los principios del plan amplían lo que se quiere proyectar con la visión \\
\hline $\begin{array}{l}\text { 3. Características del } \\
\text { Plan de Desarrollo } \\
(40 \%)\end{array}$ & 37 & Existe coherencia entre el plan de gobierno y el plan de desarrollo \\
\hline $\begin{array}{l}\text { CALIFICACIÓN } \\
\text { TOTAL }\end{array}$ & $\begin{array}{l}90,22 \\
2203 \\
27\end{array}$ & $\begin{array}{l}\text { El plan presenta una buena estructura , pero faltan dividir el programa } \\
\text { en subprogramas y desarrollar más el diagnóstico y las poblaciones que } \\
\text { van a cubrir }\end{array}$ \\
\hline
\end{tabular}

\section{ANEXO No2}

\section{MECANISMOS DE PARTICIPACIÓN}

A continuación se presentará un resumen de cada mecanismo de participación, establecidos en

- Iniciativa popular: Es el derecho político de un grupo de ciudadanos para presentar proyectos de Acto legislativo y de Ley ante el Congreso de la República, de Ordenanza ante las asambleas departamentales, de Acuerdo ante los concejos municipales y de Resolución ante las juntas administradoras locales bajo los parámetros de la ley.

- Referendo: Es la convocatoria que se hace al pueblo para que apruebe o rechace un proyecto de norma jurídica, o derogue o no una norma vigente; se toman decisiones obligatorias cuando sea aprobado por la mitad más uno del censo electoral. 
- Plebiscito: Es el pronunciamiento del pueblo convocado por el presidente de la república mediante el cual apoya o rechaza una decisión del ejecutivo.

- Consulta popular: Una pregunta general sobre un asunto de trascendencia nacional, departamental o municipal, es sometida por el presidente, el gobernador o el alcalde a consideración del pueblo para que este se pronuncie al respecto. La decisión del pueblo es obligatoria.

- Cabildo abierto: Es la reunión pública de los concejos distritales, municipales o de las juntas administradoras locales, en la cuáles los habitantes pueden participar directamente con el fin de discutir asuntos de interés para la comunidad; un número no menor de cinco mil personas podrá presentar propuesta de cabildo.

- Veedurías ciudadanas: Las organizaciones civiles podrán constituir veedurías o juntas de vigilancia a nivel nacional y en todos los niveles territoriales, con el fin de vigilar la gestión pública.

- Revocatoria del mandato: Es un derecho político por medio del cual los ciudadanos dan por terminado el mandato que le ha conferido a un gobernador o a un alcalde. Esta revocatoria se hace ante la Registraduría del Estado Civil, por un número de ciudadanos no menor al $40 \%$ del censo electoral. La elección del sucesor se hará durante los siguientes treinta días.

- Acción de tutela: Es la garantía constitucional del derecho que tiene toda persona a la protección judicial de sus derechos fundamentales cuando estos resulten vulnerados o amenazados por la acción o la omisión de cualquier autoridad pública

- Voto programático: Todo gobernante debe cumplir con lo propuesto en su plan de gobierno al ser elegido debido a que su programa se convierte en mandato del pueblo.

\section{ANEXO $\mathbf{N}^{\circ} 3$}

\section{MARCO LEGAL}

Dentro del marco legal a nivel de los entes territoriales, surgen la ley 136 de 1994 y la ley 1551 de 2012, esta información es valiosa para la investigación ya que aporta la información sobre la conformación de los municipios, las funciones que cumplen y todo lo referente al marco legal.

\section{LEY 136 DE 1994}

Con esta ley se dictan normas tendientes a modernizar la organización y el funcionamiento de los municipios. 
Artículo 1. Definición. El municipio es la entidad territorial fundamental de la división político administrativa del Estado, con autonomía política, fiscal y administrativa, dentro de los límites que le señalen la Constitución y la ley y cuya finalidad es el bienestar general y el mejoramiento de la calidad de vida de la población en su respectivo territorio

Artículo 3. Funciones. Corresponde al municipio:

1. Administrar los asuntos municipales y prestar los servicios públicos que determine la ley.

2. Ordenar el desarrollo de su territorio y construir las obras que demande el progreso municipal.

3. Promover la participación comunitaria y el mejoramiento social y cultural de sus habitantes.

4. Planificar el desarrollo económico, social y ambiental de su territorio, de conformidad con la ley y en coordinación con otras entidades.

Artículo 6. Categorización.

Los municipios de Colombia se clasificarán, atendiendo su población y sus recursos fiscales como indicadores de sus condiciones socioeconómicas así:

Categoría Especial. Todos aquellos con población superior a los quinientos mil (500.000) habitantes y cuyos ingresos anuales superen Los cuatrocientos mil (400.000) salarios mínimos legales mensuales.

- Primera Categoría. Todos aquellos municipios con población comprendida entre cien mil uno (100.001) y quinientos mil (500.000) habitantes y cuyos ingresos anuales oscilen entre cien mil (100.000) y cuatrocientos mil (400.000) salarios mínimos legales mensuales. Segunda Categoría. Todos aquellos municipios con población comprendida entre cincuenta mil uno (50.001) y cien mil (100.000) habitantes y cuyos ingresos anuales oscilen entre cincuenta mil (50.000) y cien mil (100.000) salarios mínimos legales mensuales.
5. Solucionar las necesidades insatisfechas de salud, educación, saneamiento ambiental, agua potable, servicios públicos domiciliarios, vivienda, recreación y deporte con especial énfasis en la niñez, la mujer, la tercera edad y los sectores discapacitados, directamente y en concurrencia, complementariedad y coordinación con las demás entidades territoriales y la Nación, en los términos que defina la ley.

6. Velar por el adecuado manejo de los recursos naturales y del medio ambiente, de conformidad con la ley.

7. Promover el mejoramiento económico y social de los habitantes del respectivo municipio.

8. Hacer cuanto pueda adelantar por sí mismo, en subsidio de otras entidades territoriales, mientras éstas proveen lo necesario.

9. Las demás que le señale la Constitución y la ley.

- Tercera Categoría. Todos aquellos municipios con población comprendida entre treinta mil uno (30.001) y cincuenta mil (50.000) habitantes y cuyos ingresos anuales oscilen entre treinta mil (30.000) y cincuenta mil (50.000) salarios mínimos legales mensuales

- Cuarta Categoría. Todos aquellos municipios con población comprendida entre quince mil uno (15.001) y treinta mil (30.000) habitantes y cuyos ingresos anuales oscilen entre quince mil (15.000) treinta mil (30.000) salarios mínimos legales mensuales.

- Quinta Categoría. Todos aquellos municipios con población comprendida entre siete mil uno (7.001) y quince mil (15.000) habitantes y cuyos ingresos anuales oscilen entre cinco mil (5.000) y quince mil (15.000) salarios mínimos legales mensuales.

- Sexta Categoría. Todos aquellos municipios con población inferior a siete mil (7.000) habitantes y con ingresos no superiores a cinco mil 
(5.000) salarios mínimos legales

mensuales. (Personeria, s.f.)

\section{LEY 152 DE 1994}

Artículo 1․- Propósitos. La presente Ley tiene como propósito establecer los procedimientos y mecanismos para la elaboración, aprobación, ejecución, seguimiento, evaluación y control de los planes de desarrollo.

Artículo 2ํ-. Ámbito de aplicación. La Ley Orgánica del Plan de Desarrollo se aplicará a la Nación, las entidades territoriales y los organismos públicos de todo orden.

. Artículo 33․-- Autoridades e instancias de planeación en las entidades territoriales. Son autoridades de planeación en las entidades territoriales:

1. El Alcalde o gobernador, que será el máximo orientador de la planeación en la respectiva entidad territorial.

2. El Consejo de Gobierno Municipal, Departamental o Distrital, 0 aquellas dependencias equivalentes dentro de la estructura administrativa de las entidades territoriales.

3. La Secretaría, Departamento Administrativo u Oficina de Planeación, que desarrollará las orientaciones de planeación impartidas por el Alcalde o Gobernador, dirigirá y coordinará técnicamente el trabajo de formulación del Plan con las Secretarías y Departamentos Administrativos, y las entidades descentralizadas departamentales o nacionales que operen en la jurisdicción.

4. Las demás Secretarías, Departamentos Administrativos $u$ Oficinas especializadas en su respectivo ámbito funcional, de acuerdo con las orientaciones de las autoridades precedentes.

Son instancias de planeación en las entidades territoriales:

1. Las Asambleas Departamentales, los Concejos Municipales, Distritales y de las Entidades Territoriales Indígenas, respectivamente.

2. Los Consejos Territoriales de Planeación Municipal, Departamental, Distrital, 0 de las Entidades Territoriales Indígenas, y aquellas dependencias equivalentes dentro de la estructura administrativa de las entidades territoriales
Artículo 38․- Los planes de las entidades territoriales. Se adoptarán con el fin de garantizar el uso eficiente de los recursos y el desempeño adecuado de sus funciones. La concertación de que trata el artículo 339 de la Constitución procederá cuando se trate de programas y proyectos de responsabilidad compartida entre la Nación y las entidades territoriales, o que deban ser objeto de cofinanciación.

Los programas y proyectos de cofinanciación de las entidades territoriales tendrán como prioridad el gasto público social y en su distribución territorial se deberán tener en cuenta el tamaño poblacional, el número de personas con necesidades básicas insatisfechas y la eficiencia fiscal y administrativa.

Artículo 39․- Elaboración. Para efecto de la elaboración del proyecto del plan, se observarán en cuanto sean compatibles las normas previstas para el Plan Nacional, sin embargo deberá tenerse especialmente en cuenta lo siguiente:

1. El Alcalde 0 Gobernador elegido impartirá las orientaciones para la elaboración de los planes de desarrollo conforme al programa de gobierno presentado al inscribirse como candidato.

2. Una vez elegido el Alcalde o Gobernador respectivo, todas las dependencias de la administración territorial y, en particular, las autoridades y organismos de planeación, le prestarán a los candidatos electos y a las personas que éstos designen para el efecto, todo el apoyo administrativo, técnico y de información que sea necesario para la elaboración del plan.

Los programas y proyectos de cofinanciación de las entidades territoriales tendrán como prioridad el gasto público social y en su distribución territorial se deberá tener en cuenta el tamaño poblacional, el número de personas con necesidades básicas insatisfechas y la eficiencia fiscal y administrativa.

3. El Alcalde o Gobernador, presentará por conducto del secretario de planeación o jefe de la oficina que haga sus veces en la respectiva entidad territorial, a 
que llegaren a surgir en aplicación de las normas constitucionales que autorizan su creación.

Parágrafo.- Si surgieren nuevas entidades territoriales, las dependencias que dentro de sus estructuras se creen y sean equivalentes a las citadas en el presente artículo, tendrán el mismo carácter funcional respecto de aquéllas.

Artículo 34․․-Consejos Territoriales de Planeación. Los Consejos Territoriales de Planeación del orden departamental, distrital - municipal, estarán integrados por las personas que designe el Gobernador o el Alcalde de las ternas que presenten las correspondientes autoridades y organizaciones, de acuerdo con la composición que definan las Asambleas o Concejos, según sea el caso.

Dichos Consejos, como mínimo, deberán estar integrados por representantes de su jurisdicción territorial de los sectores económicos, sociales, ecológicos, educativos, culturales y comunitarios.

El Consejo Consultivo de Planificación de los territorios indígenas, estará integrado por las autoridades indígenas tradicionales y por representantes de todos los sectores de las comunidades, designados éstos por el Consejo Indígena Territorial, de ternas que presenten cada uno de los sectores de las comunidades o sus organizaciones.

Con el fin de articular la planeación departamental con la municipal, en el Consejo Departamental de planeación participarán representantes de los municipios

CAPÍTULO VIII

Los Planes de Desarrollo de las entidades territoriales.

Artículo 31‥- Contenido de los planes de desarrollo de las entidades territoriales. Los planes de desarrollo de las entidades territoriales estarán conformados por una parte estratégica y un plan de inversiones a mediano y corto plazo, en los términos y condiciones que de manera general reglamenten las Asambleas Departamentales y los Concejos Distritales y Municipales 0 las autoridades administrativas que hicieren sus veces, siguiendo los criterios de formulación, establecidos en la presente Ley.

Las autoridades de las entidades territoriales indígenas definirán en los alcances y los procedimientos para la elaboración, consideración del Consejo de Gobierno o el cuerpo que haga sus veces, el proyecto del plan en forma integral o por elementos 0 componentes del mismo.

Dicho Consejo de Gobierno consolidará el documento que contenga la totalidad de las partes del plan, dentro de los dos (2) meses siguientes a la posesión del respectivo Alcalde o Gobernador conforme a la Constitución Política y a las disposiciones de la presente Ley.

4. Simultáneamente a la presentación del proyecto de plan a consideración del Consejo de Gobierno o el cuerpo que haga sus veces, la respectiva administración territorial convocará a constituirse al Consejo Territorial de Planeación.

5. El proyecto de plan como documento consolidado, será presentado por el Alcalde - Gobernador a consideración de los Consejos Territoriales de Planeación, a más tardar dentro de los dos (2) meses siguientes a la fecha de su posesión, para análisis y discusión del mismo y con el propósito de que rinda su concepto y formule las recomendaciones que considere convenientes.

En la misma oportunidad, la máxima autoridad administrativa deberá enviar copia de esta información a la respectiva corporación de elección popular.

6. El respectivo Consejo Territorial de Planeación deberá realizar su labor antes de transcurrido un (1) mes contado desde la fecha en que haya presentado ante dicho Consejo el documento consolidado del respectivo plan.

$\mathrm{Si}$ transcurriere dicho mes sin que el respectivo Consejo Territorial se hubiere reunido o pronunciado sobre la totalidad o parte del proyecto del plan, considerará surtido el requisito en esa fecha. Tanto los Consejos Territoriales de Planeación, como los Concejos y Asambleas, verificarán la correspondencia de los planes con los programas de gobierno que hayan sido registrados al momento de la inscripción como candidato por el Alcalde 0 Gobernador electo.

Parágrafo.- Las disposiciones de este artículo se aplicarán respecto de la máxima autoridad administrativa y corporación de elección popular de las demás entidades territoriales.

Artículo 40․․- Aprobación. Los planes serán sometidos a la consideración de la 
aprobación, ejecución, evaluación y seguimiento de los planes, de acuerdo con sus usos y costumbres, atendiendo los principios generales de esta Ley y haciendo compatibles los tiempos de presentación y la articulación con los procesos presupuestales, de tal manera que se logre la coordinación y concertación de la planeación con las autoridades de las demás entidades territoriales y con la Nación.

Artículo 32‥-Alcance de la planeación en las entidades territoriales. Las entidades territoriales tienen autonomía en materia de planeación del desarrollo económico, social y de la gestión ambiental, en el marco de las competencias, recursos y responsabilidades que les han atribuido la Constitución y la Ley.

Los planes de desarrollo de las entidades territoriales, sin prejuicio de su autonomía, deberán tener en cuenta para su elaboración las políticas y estrategias del Plan Nacional de desarrollo para garantizar la coherencia.

Artículo 34\%-Consejos Territoriales de Planeación. Los Consejos Territoriales de Planeación del orden departamental, distrital - municipal, estarán integrados por las personas que designe el Gobernador o el Alcalde de las ternas que presenten las correspondientes autoridades y organizaciones, de acuerdo con la composición que definan las Asambleas o Concejos, según sea el caso.

Artículo 35․- Funciones de los Consejos Territoriales de Planeación. Son funciones de los Consejos Territoriales de Planeación las mismas definidas para el Consejo Nacional, en cuanto sea compatible.

Parágrafo.- La dependencia de planeación de la correspondiente entidad territorial prestará al respectivo Consejo, el apoyo administrativo y logístico que sea indispensable para su funcionamiento.

CAPÍTULO $X$

Procedimientos para los planes territoriales de desarrollo.

Artículo 36‥- En materia de elaboración, aprobación, ejecución seguimiento y evaluación de los planes de desarrollo de las entidades territoriales, se aplicarán, en cuanto sean compatibles, las mismas reglas previstas en esta Ley para el Plan Nacional de Desarrollo.

Artículo 37‥-Para los efectos del procedimiento correspondiente, se entiende que:
Asamblea o Concejo dentro de los primeros cuatro (4) meses del respectivo período del Gobernador o Alcalde para su aprobación La Asamblea o Concejo deberá decidir sobre los Planes dentro del mes siguiente a su presentación y si transcurre ese lapso sin adoptar decisión alguna, el Gobernador - alcalde podrá adoptarlos mediante decreto. Para estos efectos y si a ello hubiere lugar, el respectivo Gobernador o Alcalde convocará a sesiones extraordinarias a la correspondiente Asamblea o Concejo.

Artículo 41‥-Planes de acción en las entidades territoriales. Con base en los planes generales departamentales 0 municipales aprobados por el correspondiente Concejo o Asamblea, cada secretaría y departamento administrativo preparará, con la coordinación de la oficina de planeación, su correspondiente plan de acción y lo someterá a la aprobación del respectivo Consejo de Gobierno departamental, distrital o municipal. En el caso de los sectores financiados con transferencias nacionales, especialmente educación y salud, estos planes deberán ajustarse a las normas legales establecidas para dichas transferencias.

Para el caso de los municipios, además de los planes de desarrollo regulados por la presente Ley, contarán con un plan de ordenamiento que se regirá por las disposiciones especiales sobre la materia. El Gobierno Nacional y los departamentos brindarán las orientaciones y apoyo técnico para la elaboración de los planes de ordenamiento territorial.

Artículo $42^{\circ}$.- Evaluación. Corresponde a los organismos departamentales de planeación efectuar la evaluación de gestión y resultados de los planes y programas de desarrollo e inversión tanto del respectivo departamento, como de los municipios de su jurisdicción.

Artículo 43‥- Informe del Gobernador o Alcalde. El Gobernador o Alcalde presentará informe anual de la ejecución de los planes a la respectiva Asamblea o Concejo o la autoridad administrativa que hiciere sus veces en los otros tipos de entidades territoriales que llegaren a crearse.

Artículo 44‥- Armonización con los presupuestos. En los presupuestos anuales se debe reflejar el plan plurianual de 


\begin{tabular}{|c|c|}
\hline $\begin{array}{l}\text { a) En lugar del Departamento Nacional de } \\
\text { Planeación actuará la Secretaría, } \\
\text { Departamento Administrativo u oficina de } \\
\text { Planeación de la entidad territorial o la } \\
\text { dependencia que haga sus veces; } \\
\text { b) En lugar del Conpes, actuará el Consejo } \\
\text { de Gobierno, o la autoridad de planeación } \\
\text { que le sea equivalente en las otras } \\
\text { entidades territoriales. En lugar del Consejo } \\
\text { Nacional de Planeación lo hará el respectivo } \\
\text { Consejo Territorial de Planeación que se } \\
\text { organice en desarrollo de lo dispuesto por la } \\
\text { presente Ley; } \\
\text { c) En lugar del Congreso, la Asamblea, } \\
\text { Consejo o la instancia de planeación que le } \\
\text { sea equivalente en las otras entidades } \\
\text { territoriales }\end{array}$ & $\begin{array}{l}\text { inversión. Las Asambleas y Concejos } \\
\text { definirán los procedimientos a través de los } \\
\text { cuales los Planes territoriales serán } \\
\text { armonizados con los respectivos } \\
\text { presupuestos. }\end{array}$ \\
\hline
\end{tabular}

Tomado de http://www.alcaldiabogota.gov.co/sisjur/normas/Norma1.jsp?i=327

\section{LEY 1551 DE 2012}

\begin{abstract}
Artículo $1^{\circ}$. Objeto de la ley. La presente ley tiene por objeto modernizar la normativa relacionada con el régimen municipal, dentro de la autonomía que reconoce a los municipios la Constitución y la ley, como instrumento de gestión para cumplir sus competencias y funciones.
\end{abstract}

Artículo $2^{\circ}$. Derechos de los municipios. Los municipios gozan de autonomía para la gestión de sus intereses, dentro de los límites de la Constitución y la ley tendrán los siguientes derechos:

1. Elegir a sus autoridades mediante procedimientos democráticos y participativos de acuerdo con la Constitución y la ley.

2. Ejercer las competencias que les correspondan conforme con la Constitución y a la ley.

3. Administrar los recursos y establecer los tributos necesarios para el cumplimiento de sus funciones.

4. Participar en las rentas nacionales, de acuerdo a las normas especiales que se dicten en dicha materia.

5. Adoptar la estructura administrativa que puedan financiar $y$ que se determine conveniente para dar cumplimiento a las competencias que les son asignadas por la Constitución y la ley. (Bogotà, s.f.).

II Segundo grupo (municipios intermedios)

- Segunda categoría

Población: Con población comprendida entre
Artículo $6^{\circ}$. Categorización de los Distritos y municipios. Los distritos y municipios se clasificarán atendiendo su población, ingresos corrientes de libre destinación, importancia económica y situación geográfica. Para efectos de lo previsto en la ley y las demás normas que expresamente lo dispongan, las categorías serán las siguientes:

I. Primer grupo (grandes municipios):

- Categoría especial: Población: Superior o igual a los quinientos mil uno (500.001) habitantes.

Ingresos corrientes de libre destinación anuales: que superen cuatrocientos mil (400.000) salarios mínimos legales mensuales vigentes.

Importancia económica: Grado uno.

Primera categoría

Población: Comprendida entre cien mil uno (100.001) y quinientos mil (500.000) habitantes.

Ingresos corrientes de libre destinación anuales: Superiores a cien mil (100.000) y hasta de cuatrocientos mil (400.000) salarios mínimos legales mensuales vigentes.

Importancia económica: Grado dos.

III. Tercer grupo (municipios básicos)

- Quinta categoría

Población: población comprendida entre 


\begin{tabular}{|c|c|}
\hline $\begin{array}{l}\text { cincuenta mil uno (50.001) y cien mil } \\
\text { (100.000) habitantes. } \\
\text { Ingresos corrientes de libre destinación } \\
\text { anuales: Superiores a cincuenta mil (50.000) } \\
\text { y hasta de cien mil (100.000) salarios } \\
\text { mínimos legales mensuales vigentes. } \\
\text { Importancia económica: Grado tres. } \\
\text { - Tercera categoría } \\
\text { Población: Con población comprendida entre } \\
\text { treinta mil uno ( } 30.001) \text { y cincuenta mii } \\
\text { (50.000) habitantes. } \\
\text { Ingresos corrientes de libre destinación } \\
\text { anuales: Superiores a treinta mil (30.000) y } \\
\text { hasta de cincuenta mil (50.000) salarios } \\
\text { mínimos legales mensuales. } \\
\text { Importancia económica: Grado cuatro. } \\
\text { - Cuarta categoría } \\
\text { Población: Con población comprendida entre } \\
\text { veinte mil uno (20.001) y treinta mil (30.000) } \\
\text { habitantes. } \\
\text { Ingresos corrientes de libre destinación } \\
\text { anuales: Superiores a veinticinco mii (25.000) } \\
\text { y de hasta de treinta mil (30.000) salarios } \\
\text { mínimos legales mensuales. } \\
\text { Importancia económica: Grado cinco. }\end{array}$ & $\begin{array}{l}\text { diez mil uno (10.001) y veinte mil (20.000) } \\
\text { habitantes } \\
\text { Ingresos corrientes de libre destinación } \\
\text { anuales: Superiores a quince mil (15.000) } \\
\text { y hasta veinticinco mil (25.000) salarios } \\
\text { mínimos legales mensuales. } \\
\text { Importancia económica: Grado seis. } \\
\text { • Sexta categoría } \\
\text { Población: Población igual o inferior a diez } \\
\text { mil (10.000). } \\
\text { Ingresos corrientes de libre destinación } \\
\text { anuales: No superiores a quince mil } \\
\text { (15.000) salarios mínimos legales } \\
\text { mensuales. } \\
\text { Importancia económica: Grado siete. } \\
\text { (Bogotà, s.f.) } \\
\text { La clasificación de los municipios se } \\
\text { incluye en el anexo } 1 .\end{array}$ \\
\hline
\end{tabular}




\section{ANEXO N4}

Municipios seleccionados según categorización 2013- 2014

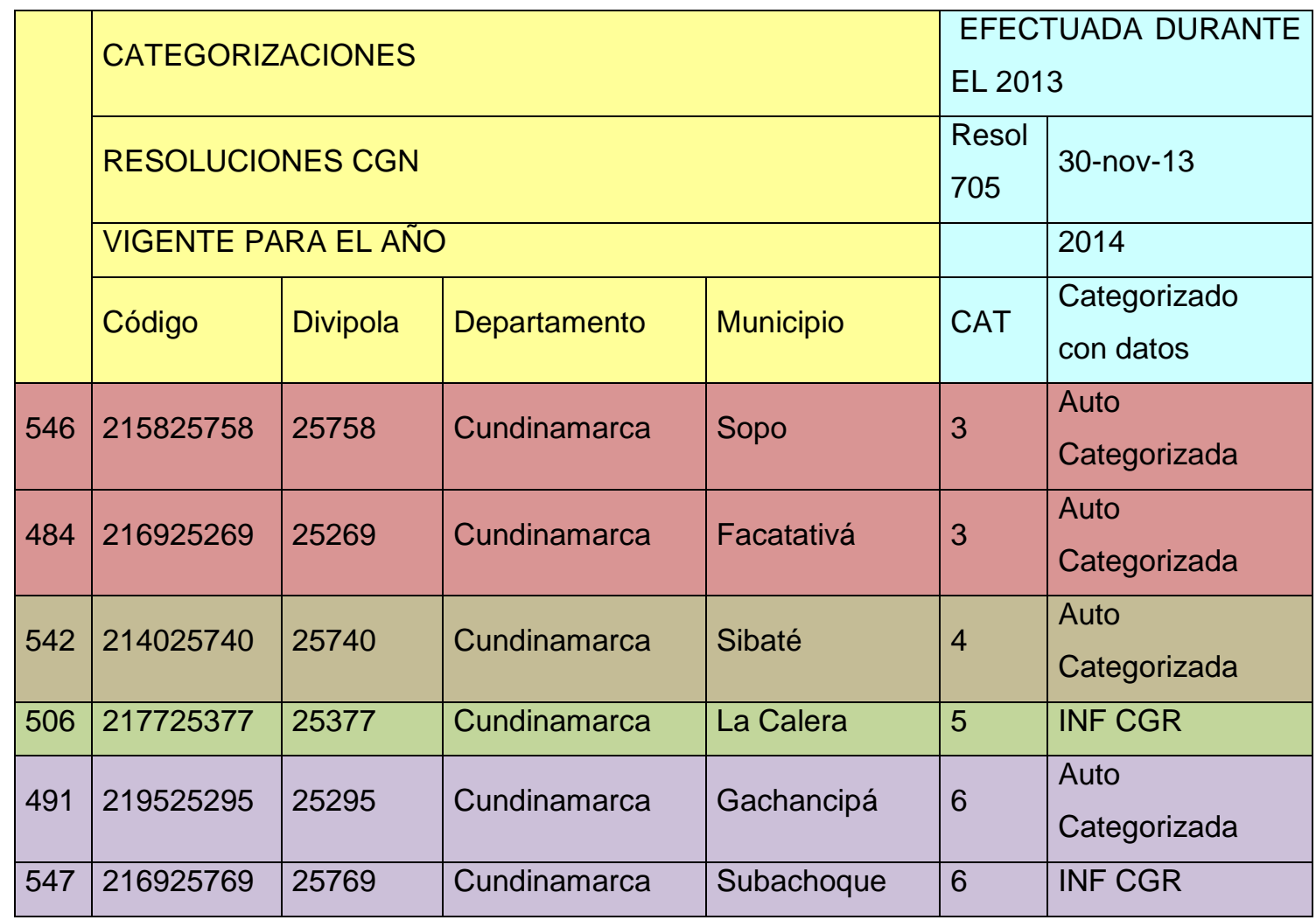

Fuente. Contaduría general de la Nación 2014 


\section{ANEXO 5 \\ FORMATO DE ENTREVISTA \\ UNIVERSIDAD SANTO TOMÁS \\ Facultad de Sociología \\ Maestría en Planeación para el Desarrollo \\ Proyecto de Investigación}

\section{ENTREVISTA}

\section{DIRECTOR OFICINA DE PLANEACIÓN}

\section{Objetivo General}

Analizar los procesos de planeación que desarrollan los Municipios de Sopó, Facatativá, Sibaté, La Calera, Gachancipá y Subachoque del Departamento Cundinamarca - Colombia con el fin de identificar aspectos significativos que se tuvieron en cuenta para orientar el desarrollo local.

Tipo de entrevista

INFORMACIÓN GENERAL DEL ENTRVISTADO

Nombre Apellidos

Cargo ___ Tiempo de vinculación

Cel Correo electrónico

Municipio _ Departamento

Nivel de escolaridad:

Universitaria_ Titulo

Postgrado: Especialización Doctorado

Títulos:

Tiempo de la entrevista:

Fecha

a) Metodología.

1. ¿Cuál fue el proceso de planeación que manejó el municipio para el diseño del Plan de desarrollo 2012-2015? 
2. ¿Qué metodologías se utilizaron para la elaboración del diagnóstico y la priorización de necesidades (Dofa, meta plan, Árbol de problemas, otro) para determinar los aspectos a incluir en el Plan de Desarrollo Municipal (PDM)?

3. ¿Qué metodologías se utilizaron para el diseño del PDM?

4. ¿Realizaron capacitaciones técnicas y metodológicas a los funcionarios de la alcaldía para el diseño del plan de desarrollo? Sí _ ¿Quién la dirigió?

5. ¿Qué instrumentos de planeación participativa conoce usted? ¿Y Cuáles utiliza?

6. ¿Cómo fue el proceso adelantado para la implementación del Plan de Desarrollo del cuatrienio?

7. ¿Qué estrategias se utilizan en la implementación del PDM?

b) Actores

8. ¿Cómo se vinculó y participó la comunidad en este proceso?

9. ¿El municipio utilizó el acompañamiento (asesoría) de alguna empresa o experto para el diseño y elaboración del plan de desarrollo, o lo hizo directamente la oficina de Planeación?

10. ¿.Con qué equipo humano contó el municipio para el diseño del plan de desarrollo?

11. ¿Con qué equipo humano cuenta el municipio para la implementación del plan de desarrollo?

12. ¿Cuáles son los niveles de participación de los diferentes grupos, organizaciones comunitarias, gremiales, consejos territoriales?

13. ¿Cuáles organizaciones Sociales, gremiales, políticas, participan en este proceso y quienes la integran

\section{c) Recursos}

14. ¿Con qué recursos cuenta el municipio para el diseño e implementación del plan?

- Económicos.

- Materiales

15. ¿Con qué recursos tecnológicos contó el municipio para el diseño PDM?

16. ¿Cuáles son los recursos tecnológicos que utiliza el municipio para la implementación y seguimiento del plan?

_Observaciones. 


\section{ANEXO 6 \\ UNIVERSIDAD SANTO TOMÁS \\ Facultad de Sociología \\ Maestría en Planeación para el Desarrollo}

\section{FICHA TÉCNICA}

\section{UNIDAD DE ANÁLISIS MUNICIPIO}

Denominación

Localización

Cercanía a Capitales o municipios de categorías -1 y 2

Área geográfica $\mathrm{Km} 2$

Población

Vocación

Organización- estructura administrativa Organigrama

Servicios públicos/privados:

Agua Alcantarillados Energía Teléfono Celular Internet

Hospital/Clínicas Puesto de Salud nivel Centro de Salud

Bomberos Estación de policía

Parque públicos Colegios/escuelas CERES

Universidades/IES Iglesias Registraduría Sector

Bancario , Hoteles Transporte publico Casa de cultura

Teatros____ Cines Polideportivos Vías: pavimentadas , sin pavimentar , accesos terrestres aéreos , fluviales

Categoría del Municipio

Presupuesto anual 
